\title{
DESIGN AND LAYOUT CONCEPTS FOR COMPACT, FACTORY-PRODUCED, TRANSPORTABLE, GENERATION IV REACTOR SYSTEMS
}

\author{
Fred R. Mynatt \\ Lead Principal Investigator \\ University of Tennessee
}

November 12, 2003

\author{
University of Tennessee \\ Nuclear Engineering Department \\ And \\ Massachusetts Institute of Technology \\ Nuclear Engineering Department \\ In collaboration with \\ Northrop Grumman Newport News \\ Westinghouse Electric Company \\ And \\ Oak Ridge National Laboratory
}


NUCLEAR ENERGY RESEARCH INITIATIVE (NERI) PROGRAM

GRANT NUMBER DE-FG07-00SF22168

FINAL REPORT

Professor Fred R. Mynatt

Lead Principal Investigator

Nuclear Engineering Department

University of Tennessee

Light-Water Cooled Reactor Concept and Layout

Professor Larry Townsend

Martin Williamson

Wesley Williams

Nuclear Engineering Department

University of Tennessee

Lead-Bismuth Cooled Reactor Concept and Layout

Professor L.F. Miller

M. Khurram Khan

Martin Williamson

Joe McConn

Nuclear Engineering Department

University of Tennessee

Modular Pebble Bed Reactor Concept and Layout

Professor Andrew C. Kadak

Marc V. Berte

Nuclear Engineering Department

Massachusetts Institute of Technology

Heat Exchanger Manufacturing Simulations

Professor Rapinder Sawhney

Jacob Fife

Industrial Engineering Department

University of Tennessee

In collaboration with

Todd Sedler

Northrop Grumman Newport News

Larry Conway

Westinghouse Electric Company

Dave Felde

Oak Ridge National Laboratory 


\section{NUCLEAR ENERGY RESEARCH INITIATIVE (NERI) PROGRAM \\ GRANT NUMBER DE-FG07-00SF22168 \\ FINAL REPORT}

\section{Acknowledgment}

This material is based on work supported by the U.S. Department of Energy under the NERI program Award Number DE-FG07-00SF22168 and NERI Project Number 2000047

\section{Disclaimer}

Any opinions, findings, and conclusions or recommendations expressed in this material are those of the author(s) and do not necessarily reflect the views of the Department of Energy 


\section{NUCLEAR ENERGY RESEARCH INITIATIVE (NERI) PROGRAM \\ GRANT NUMBER DE-FG07-00SF22168 \\ FINAL REPORT \\ Executive Summary}

\section{RESEARCH OBJECTIVES}

The purpose of this research project is to develop compact (100 to $400 \mathrm{MWe}$ ) Generation IV nuclear power plant design and layout concepts that maximize the benefits of factorybased fabrication and optimal packaging, transportation and siting. The potentially small footprint of compact Generation IV systems offers the opportunity for maximum factory fabrication and optimal packaging for transportation and siting. Barge mounting is an option to be considered and will offer flexibility for siting including floating installation, on-shore fixed siting, and transportation to nearby inland sites. Railroad and truck transportation of system modules is also considered in this work. The project utilizes the work of others including both previous work and concurrent Generation IV work. This includes a previously funded NERI project to develop standards and guidelines for cost effective layout and modularization of nuclear power plants. The reactor concepts selected were compact designs under development in the 2000 to 2001 period.

This interdisciplinary project was comprised of three university-led nuclear engineering teams identified by reactor coolant type (water, gas, and liquid metal). The University of Tennessee (UT) led the teams for two types (water and liquid metal) and the Massachusetts of Technology (MIT) led the team for the gas cooled type. The industry and laboratory participants were Westinghouse Science and Technology for the LWR team and Oak Ridge National Laboratory for the HTGR team. Northrop Grumman Newport News (formerly Newport News Shipbuilding) provided comments on the effectiveness of modular manufacturing. A fourth UT-led industrial engineering team studied computer simulation and optimization of the factory fabrication processes. Each team consisted of a Professor (ten percent time) and a graduate student (half time) who performed most of the effort with review and consultation by industry and laboratory partners. This interdisciplinary arrangement enhanced the opportunity to satisfy DOE objectives for advancing state-of-the-art nuclear technology while at the same time strengthening nuclear science and engineering infrastructure in the U.S

\section{RESEARCH RESULTS}

This project was funded as a grant to the University of Tennessee and a subgrant to the Massachusetts Institute of Technology. The first tasks were acquisition and reviews of available designs and requirements for each reactor type. Based on that work the project team selected three reactor types. These included a Modular Pebble Bed helium-cooled concept being developed at MIT, the IRIS water-cooled concept being developed by a team led by Westinghouse Electric Company, and a Lead-Bismuth-cooled concept to be developed by UT.

Development of plant layout and modularization concepts requires an understanding of both primary and secondary systems. At the beginning of this study the MPBR development at MIT included initial concepts for both systems. The IRIS project did not 


\section{NUCLEAR ENERGY RESEARCH INITIATIVE (NERI) PROGRAM \\ GRANT NUMBER DE-FG07-00SF22168 \\ FINAL REPORT}

have a secondary system conceptual design and neither appropriate primary nor secondary system concepts were available for a lead-bismuth cooled reactor. The second phase of this project focused efforts to further develop the MPBR concept, to develop a secondary system and integrated plant concept for IRIS and development of a leadbismuth-cooled integrated plant concept. The second phase also included increased interaction with the IRIS development team for the LWR concept, with Oak Ridge National Laboratory for the MPBR concept and with several individuals also working on lead-bismuth-cooled reactor concepts. The primary effort in the third phase of this project was simulation and analysis of modular reactor fabrication and manufacturing. An Industrial Engineering student and professor at UT performed this task with assistance and input by the professors who led the reactor concept developments. The focus was on evaluation of economies of factory fabrication versus economies of scale of site-constructed large plants. A related effort was to evaluate whether the modular approach really works in that it is feasible and cost effective to build modules in the factory and assemble at the site. This task was performed by Northrop Grumman Newport News and was based on their experience with modular construction of ships and submarines.

\section{LWR Concept}

A conceptual design and balance of plant (BOP) for a Generation IV nuclear power plant using the Westinghouse International Reactor, Innovative \& Secure (IRIS) has been developed. The preliminary BOP design formed the basis of a thesis presented for the degree of Master of Science in Nuclear Engineering by Wesley Williams (degree awarded by the University of Tennessee (UT) in May 2002). In a following effort, modifications were made to the preliminary design to include an increased and more conservative cold side inlet temperature for the condenser, a corrected condenser duty, more accurate condenser models, and changes to the sizes for the feedwater heaters. The feedwater heaters were also reoriented to a vertical configuration in order to achieve better maintenance and repair conditions. The system output is $1000 \mathrm{MW}$ thermal and approximately $345 \mathrm{MW}$ electric. It has six feed water heaters and dual reheat with one high pressure and one low-pressure tandem compound turbo-generator unit. Sizes and weights of the components and associated piping are estimated. The final layout of the plant has a footprint that is 100 meters long by 40 meters wide, and weighs approximately 7047 tons. Figures containing visualizations of plant components layout and solid modeling have been developed. In order to develop an example of barge mounting and transportation the footprint was constrained by modularity requirements that the plant be transportable by barge from the mouth of the Mississippi River to any desired sites along the Tennessee River or its tributaries. This requires that the components fit on a barge no larger than 400 feet long by 110 feet wide with a draft less than 9 feet. Navigation charts for the Mississippi River from its mouth to the mouth of the Ohio River, and for the Tennessee River from it mouth to Knoxville, Tennessee, have been searched and detailed listings of all potential obstructions (bridges, overhanging cables, locks and dams) and their relevant clearance parameters (height, width, etc.), and channel depth limitations have been tabulated. The final plant design meets these criteria. 


\section{NUCLEAR ENERGY RESEARCH INITIATIVE (NERI) PROGRAM \\ GRANT NUMBER DE-FG07-00SF22168 \\ FINAL REPORT}

\section{MPBR Concept}

The modular pebble bed reactor concept project was developed closely with another NERI project at MIT that was designing the major components including the intermediate heat exchange, turbines, compressors, recuperators, precoolers and intercoolers. The teams worked together to establish layout options given the actual conceptual designs being developed. The MPBR design power level is approximately $100 \mathrm{MWe}$.

The modularity and packaging studies performed for the MPBR project BOP can be broken down into several tasks. 1. System layout and design (physical layout and packaging of the plant components). 2. System concept design for increased modularity and decreased cost. 3. Advanced component design concepts for future implementation. The first task involves defining the physical layout of the power plant itself, and the breakdown of any transportation issues involved in its construction. The second task involves making high level trade studies of the actual system, such as the number of intercoolers, limiting temperatures, and other system parameters. The third task involves searching for advanced component concepts that may aid in the other two tasks by making individual components simpler, cheaper, or more fault tolerant.

The proposed modular BOP system uses components and component carriers sized to fit within the limitations of truck transport. These component carriers are steel space-frames that encapsulate each component. Using this method, all the BOP components can be built in factories, and easily assembled on site without the need for significant cranes, assembly jigs, alignment, etc. Using the integral matrix structure of steel space-frames, all the necessary access hardware (catwalks, valves, flanges, etc) can be built in the factory further minimizing on site assembly.

\section{Lead-Bismuth Concept}

Liquid metal breeder reactors hold particular promise for future energy supply since they offer sustainability of energy production through effective utilization of fertile and fissile materials. They also can be used to recycle nearly all of the actinide radioactive waste produced by current nuclear reactors, and consequently use the waste for energy production. Many breeder reactors have been designed and a few have been built and operated. However, most designs have an inherent problem with positive coolant voiding reactivity coefficients; thus, they may present more risk than many would prefer to accept. Results from our calculations indicate that proper choices of thorium, plutonium, and uranium fuels, along with some changes in geometry, permit a $\mathrm{PbBi}$ cooled reactor to operate with a negative $\mathrm{PbBi}$ voiding reactivity coefficient, so that a reactor with considerably more inherent safety than previous designs can be designed and operated.

One significant advantage of $\mathrm{PbBi}$ as a coolant is that the reactor spectrum is relatively hard, and this permits significant quantities of actinides to be used as fuel, which eliminates the need to dispose of them as waste. The nuclear characteristics of this design also permit operation for at least five years without refueling, or reshuffling, since the conversion ratio can be maintained very near unity. The time between refueling is 


\section{NUCLEAR ENERGY RESEARCH INITIATIVE (NERI) PROGRAM \\ GRANT NUMBER DE-FG07-00SF22168 \\ FINAL REPORT}

limited by performance of fuel materials rather than by the ability to sustain the chain reaction. Proliferation resistance is improved relative to the reactors in current commercial use since the Pu-239 inventory can be held constant or be diminished, depending on fuel management choices.

In order to accomplish the size limitation for reactor components, the proposed design is constrained by a reactor vessel size that will be transportable on a standard rail car. This limits the height and width to about twelve feet, the length to about eighty feet, and the weight to about eighty tons. This should be adequate for producing 300 to $400 \mathrm{MW}$ electrical, depending on optimization of primary and secondary system performance, while satisfying all licensing requirements.

It is determined that a $\mathrm{PbBi}$ cooled fast reactor that produces $310 \mathrm{MWe}$ can be designed with primary system components that are all rail transportable. It is further determined that a cylindrical $\mathrm{PbBi}$ cooled reactor that uses only $\mathrm{Pu}$ as fuel and that has a negative voiding coefficient, probably cannot be designed without the use of leakage-enhanced fuel assemblies. However, results to date indicate that a relatively high leakage slab core that uses a combination of $\mathrm{Pu}, \mathrm{U}$, and $\mathrm{Th}$ for fuel does have a negative coolant voiding coefficient. The reference system design uses steam generators coupled to the secondary system BOP designed for IRIS as part of this NERI project and has an overall efficiency of about 35 percent. The efficiency could probably be increased to about 40 percent with additional design effort. A $\mathrm{PbBi}$ cooled fast reactor provides a long term option for sustainable nuclear power, and it can be operated to produce very little transuranic waste.

\section{Simulation and Optimization of Manufacturing}

The purpose of the third phase of our project was to use recently developed industrial engineering methods to simulate the factory fabrication of our reactor concepts and perform analyses to reduce cost. Simulation of factory fabrication requires detailed data on materials, labor and fabrication processes and simulation of an entire reactor fabrication is far beyond the scope of this project. In order to address the key issues we performed a detailed simulation of the fabrication of a heat exchanger, a ubiquitous component that represents much of a reactor BOP. This work was joined with a much broader study in which the experience in the modular construction of nuclear submarines was used to evaluate the potential cost savings by modular design of the Modular Pebble Bed Reactor concept.

In the factory fabrication study a simulation model was developed that mimics the current and desired production processes for shell-and-tube heat exchanger manufacturing. A costing model was also developed so that the product cost for variations in manufacturing simulations can be determined. When the fabrication and costing models were complete a variations-of-parameters study analysis was performed for a $2 \times 4$ matrix. The bur factors chosen for the study were: annual demand, equipment reliability, learning curve and quality. Two levels were considered for each factor thereby making the $2 \times 4$ matrix. The study showed that demand and learning curve are the dominant influences to cost. In 


\section{NUCLEAR ENERGY RESEARCH INITIATIVE (NERI) PROGRAM \\ GRANT NUMBER DE-FG07-00SF22168 \\ FINAL REPORT}

order for learning curve to take effect the factory must use a flow-process rather than the usual job-shop process manufacturing. This in turn depends on demand quantity and certainty. Significant cost savings, $\sim 20 \%$, can be obtained by these improvements. This saving is large when you consider that these components have rather high material costs which were held constant.

In the second part of this phase experts in modular submarine construction at Northrop Grumman Newport News reviewed the design of the MPBR concept and evaluated the potential cost savings from modular design and fabrication. Experience in modular submarine construction has shown that reductions in labor costs for fabrication and installation are as much as an order of magnitude. However, the same experience shows that overall labor costs are reduced about a factor of two because of increased engineering costs, planning time and investment in fabrication and assembly equipment.

If additional steps are taken to make the modules and components more amenable to automated fabrication and by using manufacturing processes that result in near nominal production dimensions, then further cost reductions are possible. Devising a connecting scheme for the modules that allows for adjustment in all six degrees of freedom during connection and developing construction processes that result in the module connection points always being at nominal dimensions are the two most important aspects of successful modular construction. This report includes several recommendations on how to achieve these two important criteria. 


\section{NUCLEAR ENERGY RESEARCH INITIATIVE (NERI) PROGRAM \\ GRANT NUMBER DE-FG07-00SF22168 \\ FINAL REPORT}

\section{Table of Contents}

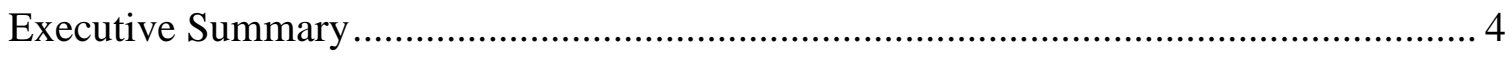

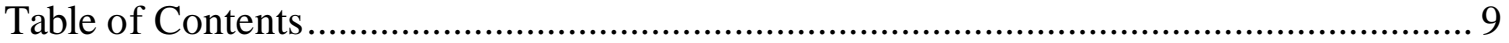

Light-Water Cooled Reactor Concept and Layout .................................................... 10

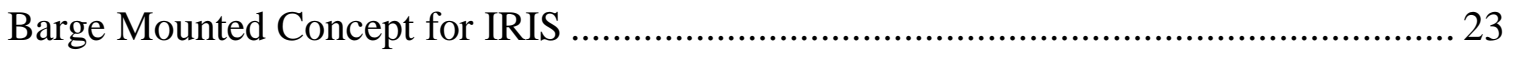

Lead-Bismuth Cooled Reactor Concept and Layout .................................................. 40

Modular Pebble Bed Reactor Concept and Layout ..................................................... 66

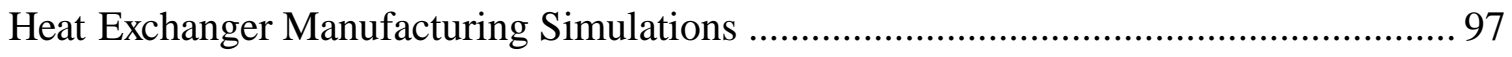

Construction and Cost Impacts of Proposed Modular Designs ..................................... 117

Appendix A - Review of Relevant Reactor Systems ................................................. 133

Appendix B - Neutronics Calculations ................................................................... 143

Appendix C - Description of a Loop-Type Cylindrical Reactor System Design with no

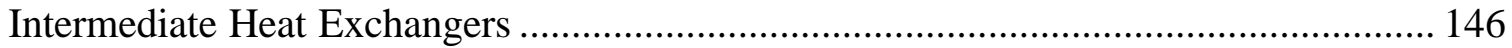

Appendix D - Manufacturing Process of a Heat Exchanger ....................................... 157

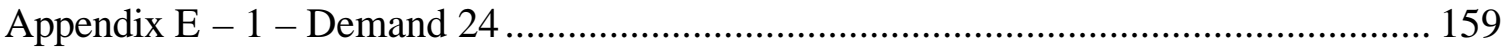

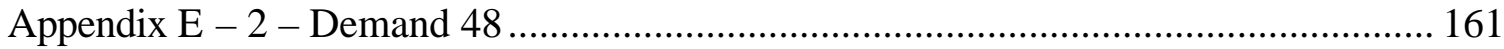

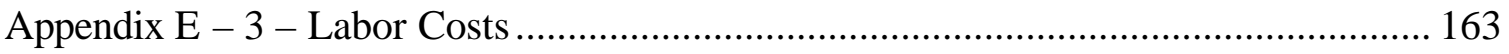

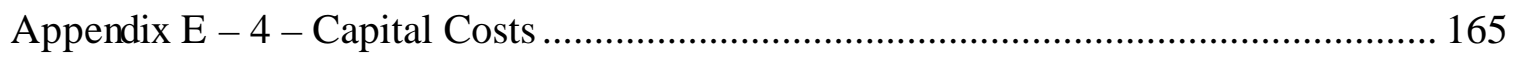

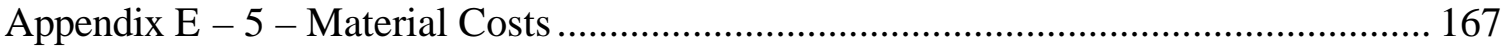

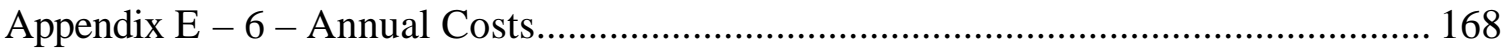

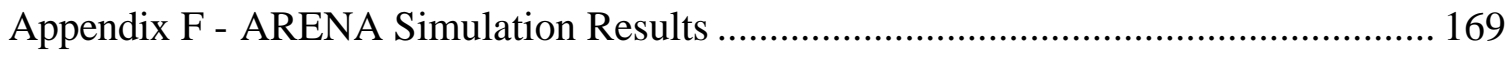

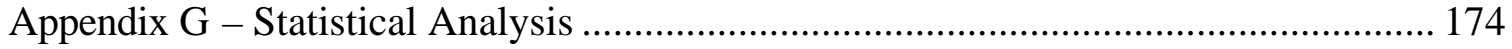




\title{
NUCLEAR ENERGY RESEARCH INITIATIVE (NERI) PROGRAM \\ GRANT NUMBER DE-FG07-00SF22168 \\ FINAL REPORT
}

\section{Light-Water Cooled Reactor Concept and Layout}

\author{
Professor Larry Townsend \\ Wesley Williams \\ Martin Williamson
}

\section{INTRODUCTION}

A conceptual design and balance of plant for a Generation IV nuclear power plant has been developed using the Westinghouse International Reactor, Innovative \& Secure (IRIS) as the primary system. The preliminary plant design formed the basis of a thesis presented for the degree of Master of Science in Nuclear Engineering by Wesley Williams (degree awarded by the University of Tennessee (UT) in May 2002). Modifications were made to the preliminary design to include an increased and more conservative cold side inlet temperature for the condenser, a corrected condenser duty, more accurate condenser models, and changes to the sizes for the feedwater heaters. The feedwater heaters were also reoriented to a vertical configuration in order to achieve better maintenance and repair conditions. The system output is 1000MW thermal and approximately $345 \mathrm{MW}$ electric. It has six feed water heaters and dual reheat with one high pressure and one low-pressure tandem compound turbo-generator unit. Sizes and weights of the components and associated piping are estimated. The final layout of the plant has a footprint that is 100 meters long by 40 meters wide, and weighs approximately 7047 tons. Figures containing visualizations of plant components layout and solid modeling have been developed. The footprint is constrained by modularity requirements that the plant be transportable by barge from the mouth of the Mississippi River to any desired TVA sites along the Tennessee River or its tributaries, which require that the components fit on a barge no larger than 400 feet long by 110 feet wide with a draft less than 9 feet. Navigation charts for the Mississippi River from its mouth to the mouth of the Ohio River, and for the Tennessee River from it mouth to Knoxville, Tennessee, have been searched and detailed listings of all potential obstructions (bridges, overhanging cables, locks and dams) and their relevant clearance parameters (height, width, etc.), and channel depth limitations have been tabulated. The final plant design meets these criteria.

\section{WESTINGHOUSE IRIS}

The Westinghouse IRIS is used as the primary plant for this study. The selection of the IRIS plant by the UT team is "due to its innovative design and its compliance with Generation IV reactor goals" (Williams, 2002). The key difference between IRIS and other pooltype PWRs is its integral design. The integral design encloses the steam generators (SGs) as well as the primary pumps inside the primary pressure vessel. This eliminates the possibility of large break loss of coolant accidents (LOCA) in primary looping a major design concern in PWR technology. In 1999, the IRIS was originally proposed as a modular $300 \mathrm{MW}$ thermal power unit to be deployed by 2010. Since then it 


\section{NUCLEAR ENERGY RESEARCH INITIATIVE (NERI) PROGRAM \\ GRANT NUMBER DE-FG07-00SF22168 \\ FINAL REPORT}

has been modified to $1000 \mathrm{MW}$ of thermal power output. The IRIS has undergone various other design modifications mainly involving the steam generators. At present, the reference design incorporates a system of 8 helical tube SGs with parameters as shown in Table 1. These values differ slightly from the ones used in our original balance of plant studies. In particular, the feedwater temperature was increased slightly from 413.6 ?F to 435.02?F, the exit steam pressure was decreased from $7.0 \mathrm{MPa}(1015.28 \mathrm{psia})$ to $5.8 \mathrm{MPa}$ (841.2 psia), and the steam mass flow rate was decreased slightly $(0.06 \%)$. The values in Table 1 are used as a steady state condition for all of the heat balance calculations. Figure 1 is a simplified 3D rendering of the IRIS reactor.

Table 1. IRIS Steam Generator Parameters

\begin{tabular}{|c|c|}
\hline Total Thermal Power & $1000 \mathrm{MW}\left(3.415 \times 10^{9} \mathrm{Btu} / \mathrm{hr}\right)$ \\
\hline Thermal Power Per Module & $125 \mathrm{MW}\left(4.269 \times 10^{8} \mathrm{Btu} / \mathrm{hr}\right)$ \\
\hline Feedwater Temperature & $223.9^{\circ} \mathrm{C}\left(435.02^{\circ} \mathrm{F}\right)$ \\
\hline Exit Steam Pressure & $5.8 \mathrm{MPa}(841 \mathrm{psia})$ \\
\hline Exit Steam Temperature & $317^{\circ} \mathrm{C}\left(602.6^{\circ} \mathrm{F}\right)$ \\
\hline Total Steam Mass Flow Rate & $502.8 \mathrm{~kg} / \mathrm{s}\left(3.99 \times 10^{6} \mathrm{lb} / \mathrm{hr}\right)$ \\
\hline
\end{tabular}

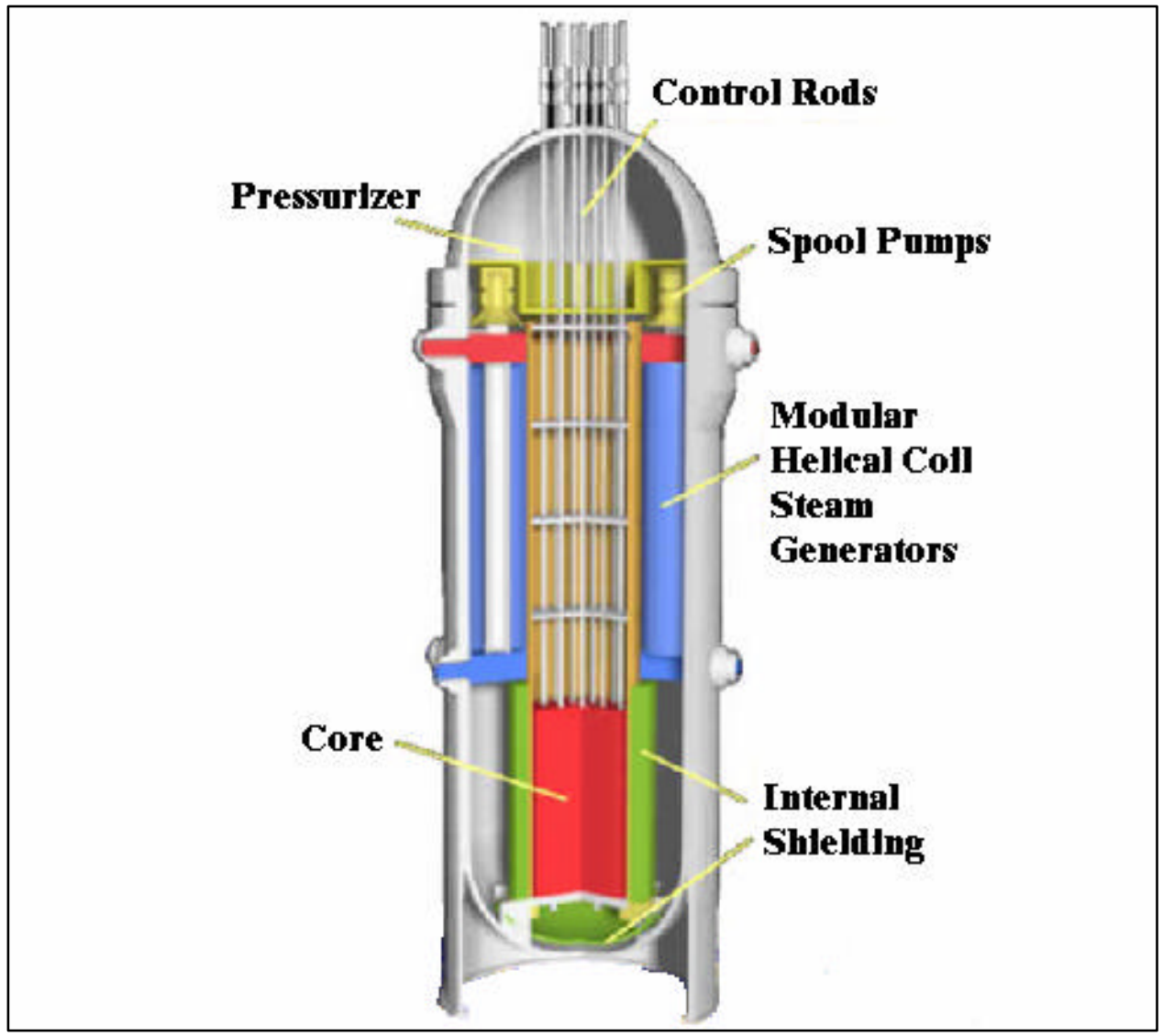

Figure 1: Simplified 3D cutaway model of IRIS 


\section{NUCLEAR ENERGY RESEARCH INITIATIVE (NERI) PROGRAM \\ GRANT NUMBER DE-FG07-00SF22168 \\ FINAL REPORT}

\section{BALANCE OF PLANT DESIGN}

\section{Introduction}

The Westinghouse IRIS (International Reactor, Innovative and Secure) design is used as the primary system. The parameters of the IRIS primary system are for $1000 \mathrm{MW}$ thermal power. The parameters of most importance for this study are the steam generator entrance and exit conditions. The parameters used are taken at steady state operating conditions; therefore, the secondary plant calculations are also steady state. Using typical values for PWR type plants, a general BOP design, and IRIS steam generator output values, an ORCENT2 heat balance is carried out for the secondary side of the plant. Using the ORCENT2 output, standard heat transfer methods are then used to calculate system performance and component sizes.

\section{Mathematical Modeling}

Mathematical modeling of the BOP was accomplished by using CyclePad v2 for 32-bit Windows Copyright (C) 1995 Kenneth D. Forbus \& Peter B. Whalley to perform a thermodynamic analysis of a simplified IRIS using an assumed Rankine cycle. The simplified model assumes a single turbine with an efficiency of $90 \%$, thereby yielding a Carnot efficiency for the plant of $48.19 \%$ and a thermal efficiency (ignoring reheat or feed water heat) of $38.14 \%$. These results provide a general idea of plant performance and provide a starting point for more detailed analysis using the ORCENT2 code, which provides advanced generalized heat balance analyses.

ORCENT2, an advanced generalized heat balance program, is used to calculate the complete heat and mass balances. It was developed at the Oak Ridge National Laboratory and released in 1979. This program is designed for general-purpose studies of power plants using steam cycles with outputs larger than $100 \mathrm{MWe}$. The general features of the secondary system analyzed herein are as follows: one double flow high pressure (HP) turbine unit with a single extraction in tandem compound with one double flow low pressure (LP) turbine unit with five extraction points, dual reheat with moisture separations between HP and LP units, and six non- mixing feed water heaters. The reheat is produced by main steam extracted prior to the HP unit. 


\section{NUCLEAR ENERGY RESEARCH INITIATIVE (NERI) PROGRAM \\ GRANT NUMBER DE-FG07-00SF22168 \\ FINAL REPORT}

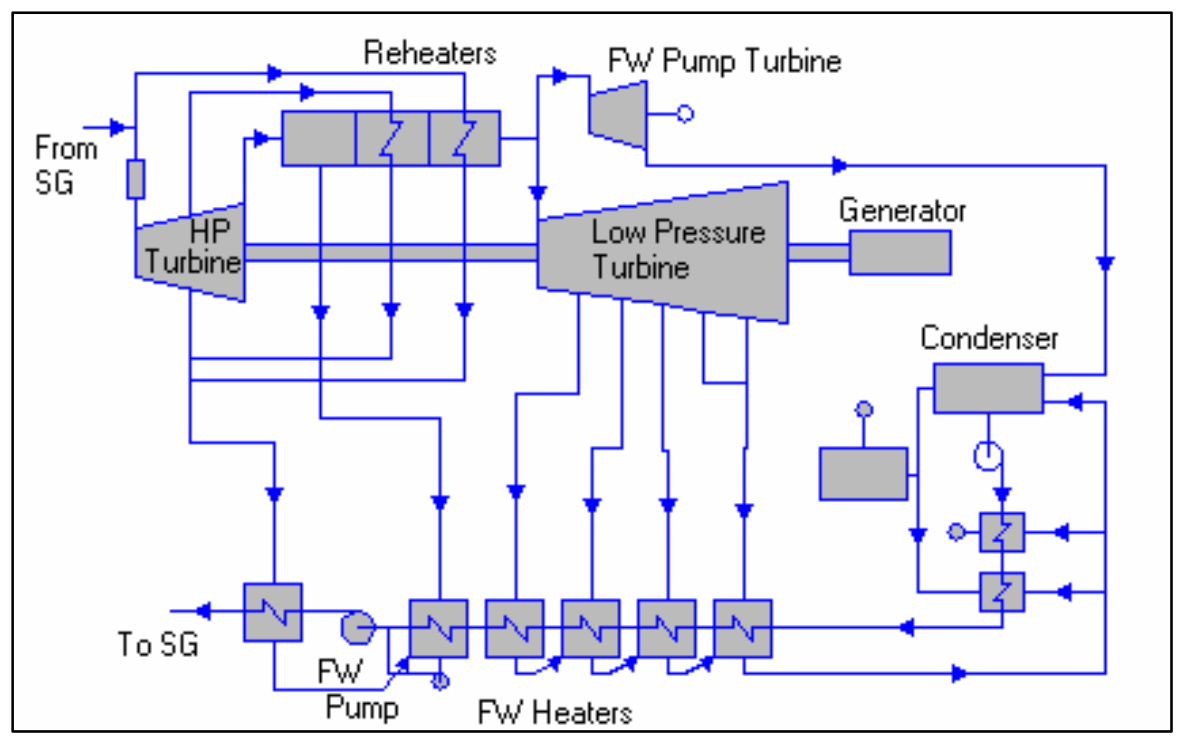

Figure 2: Simplified BOP Features

\section{ORCENT2 Input}

Using typical values for PWR type plants, a general BOP design, and IRIS steam generator values, an ORCENT2 heat bala nce is carried out for the secondary side of the plant. As mentioned, the IRIS steam generator parameters used in the ORCENT2 input were shown in Table 1.

\section{ORCENT2 Output}

ORCENT2 output includes the overall turbine cycle performance including the turbine cycle efficiency and the generator output. The output also contains individual component data including: mass flow rates, enthalpy rise/drop, inlet and outlet temperatures, and pressure rise/drop. The gross turbine cycle efficiency shown in Table 2 includes all of the generator and mechanical losses, but does not include the losses due to reheat and feedwater heating. The net turbine cycle efficiency equals the gross efficiency minus the power required for the turbine driven feedwater pump. Typical output parameters are shown in Tables 2-4.

Table 2 ORCENT2 Turbine Cycle Performance Output

\begin{tabular}{|l|l|}
\hline Net Turbine Cycle Efficiency & $34.59 \%$ \\
\hline Gross Turbine Cycle Efficiency & $34.99 \%$ \\
\hline Generator Output (MWe) & 345.9 \\
\hline Mechanical Losses (MW) & 1.51 \\
\hline Generator Losses (MW) & 4.55 \\
\hline
\end{tabular}




\section{NUCLEAR ENERGY RESEARCH INITIATIVE (NERI) PROGRAM \\ GRANT NUMBER DE-FG07-00SF22168 \\ FINAL REPORT}

Table 3 ORCENT2 Condenser Output

\begin{tabular}{|l|l|}
\hline Pressure (bar) & $9.38 \mathrm{E}-02$ \\
\hline Condensate Flow Rate $(\mathrm{kg} / \mathbf{s})$ & $3.84 \mathrm{E}+02$ \\
\hline Condensate Temperature $\left.\mathbf{~}^{\mathbf{0}} \mathbf{C}\right)$ & $4.46 \mathrm{E}+01$ \\
\hline
\end{tabular}

Table 4 ORCENT2 Feed Water Heaters Output

\begin{tabular}{|l|l|l|l|l|l|l|}
\hline & FWH \#1 & FWH \#2 & FWH \#3 & FWH \#4 & FWH \#5 & FWH \#6 \\
\hline FW Flow (kg/s) & $5.03 \mathrm{E}+02$ & $3.84 \mathrm{E}+02$ & $3.84 \mathrm{E}+02$ & $3.84 \mathrm{E}+02$ & $3.84 \mathrm{E}+02$ & $3.84 \mathrm{E}+02$ \\
\hline FW Temperature Out (?C) & $2.24 \mathrm{E}+02$ & $1.80 \mathrm{E}+02$ & $1.58 \mathrm{E}+02$ & $1.41 \mathrm{E}+02$ & $1.04 \mathrm{E}+02$ & $7.19 \mathrm{E}+01$ \\
\hline FW Temperature In (?C) & $1.82 \mathrm{E}+02$ & $1.58 \mathrm{E}+02$ & $1.41 \mathrm{E}+02$ & $1.04 \mathrm{E}+02$ & $7.19 \mathrm{E}+01$ & $4.53 \mathrm{E}+01$ \\
\hline Extraction Stage Pressure (bar) & $2.86 \mathrm{E}+01$ & $1.13 \mathrm{E}+01$ & $6.89 \mathrm{E}+00$ & $4.41 \mathrm{E}+00$ & $1.38 \mathrm{E}+00$ & $4.14 \mathrm{E}-01$ \\
\hline Extraction Steam Flow (kg/s) & $4.08 \mathrm{E}+01$ & $1.71 \mathrm{E}+01$ & $1.21 \mathrm{E}+01$ & $2.56 \mathrm{E}+01$ & $2.01 \mathrm{E}+01$ & $1.31 \mathrm{E}+01$ \\
\hline Shell Pressure (bar) & $2.63 \mathrm{E}+01$ & $1.07 \mathrm{E}+01$ & $6.34 \mathrm{E}+00$ & $4.06 \mathrm{E}+00$ & $1.27 \mathrm{E}+00$ & $3.79 \mathrm{E}-01$ \\
\hline Shell Temperature (?) & $2.27 \mathrm{E}+02$ & $1.83 \mathrm{E}+02$ & $1.61 \mathrm{E}+02$ & $1.44 \mathrm{E}+02$ & $1.06 \mathrm{E}+02$ & $7.47 \mathrm{E}+01$ \\
\hline Shell Drain Flow (kg/s) & $7.88 \mathrm{E}+01$ & $1.19 \mathrm{E}+02$ & $1.24 \mathrm{E}+01$ & $3.81 \mathrm{E}+01$ & $5.96 \mathrm{E}+01$ & $8.45 \mathrm{E}+01$ \\
\hline Shell Drain Temperature (?C) & $1.87 \mathrm{E}+02$ & $1.83 \mathrm{E}+02$ & $1.47 \mathrm{E}+02$ & $1.09 \mathrm{E}+02$ & $7.75 \mathrm{E}+01$ & $5.09 \mathrm{E}+01$ \\
\hline $\mathbf{q}(\mathbf{C})$ & $9.46 \mathrm{E}+07$ & $3.69 \mathrm{E}+07$ & $2.79 \mathrm{E}+07$ & $6.16 \mathrm{E}+07$ & $5.13 \mathrm{E}+07$ & $4.28 \mathrm{E}+07$ \\
\hline
\end{tabular}

The locations of the extraction points in the current configuration, in which the HP unit has one extraction point and the LP unit has three, can be manipulated to help improve performance through reheating and feed water heating. The output conditions from ORCENT2, taken at each extraction point on the turbine expansion line, are used as initial conditions for the correlations discussed in the following section. This assumes that there are no losses in the piping runs.

\section{Component Sizing}

The Log Mean Temperature Difference (LMTD) method is used to determine the surface area required for heat transfer in each component. The component lengths are then calculated after assuming the number of tubes, tube diameters, and tube types. The tubes in the feedwater heaters are arranged in vertical tube banks, while the condenser and reheaters' tubes are arranged horizontally. Factors used in the calculations include heat exchanger geometry, in conjunction with fluid mass flows from ORCENT2 output, and thermo-physical properties.

The results of the heat exchanger calculations give the sizes and approximate weights of the components. Each unit's weight is approximated as the total weight of the combined tubes in addition to the weight of a pressure vessel to hold them. The pressure vessels are assumed to be one-inch thick steel. The moisture separator reheater (MSR) size is approximated from existing designs in combination with the calculations.

\section{Component Size Results}

The heat transfer correlations are coded using the MATLAB ${ }^{\circledR}$ computational environment. The results of these calculations are shown in Table 5. 


\section{NUCLEAR ENERGY RESEARCH INITIATIVE (NERI) PROGRAM \\ GRANT NUMBER DE-FG07-00SF22168 \\ FINAL REPORT}

Table 5. Balance of Plant Parameters

(UTBOPmod3 - Vertical FWHs, Horizontal RHs and Condenser)

\begin{tabular}{|c|c|c|c|c|c|c|c|c|c|}
\hline & FW\#1 & FW\#2 & FW\#3 & FW\#4 & FW\#5 & FW\#6 & RH\#1 & RH\#2 & Condenser \\
\hline $\mathbf{T}_{\mathrm{HI}}\left({ }^{\circ} \mathbf{C}\right)$ & $2.27 \mathrm{E}+02$ & $1.83 \mathrm{E}+02$ & $1.61 \mathrm{E}+02$ & $1.44 \mathrm{E}+02$ & $1.06 \mathrm{E}+02$ & $7.47 \mathrm{E}+01$ & $3.17 \mathrm{E}+02$ & $3.17 \mathrm{E}+02$ & $4.46 \mathrm{E}+01$ \\
\hline $\mathrm{T}_{\mathrm{HO}}\left({ }^{\circ} \mathrm{C}\right)$ & $1.87 \mathrm{E}+02$ & $1.83 \mathrm{E}+02$ & $1.47 \mathrm{E}+02$ & $1.09 \mathrm{E}+02$ & $7.75 \mathrm{E}+01$ & $5.09 \mathrm{E}+01$ & $2.29 \mathrm{E}+02$ & $2.72 \mathrm{E}+02$ & $4.46 \mathrm{E}+01$ \\
\hline $\mathrm{T}_{\mathrm{CI}}\left({ }^{\circ} \mathrm{C}\right)$ & $1.82 \mathrm{E}+02$ & $1.58 \mathrm{E}+02$ & $1.41 \mathrm{E}+02$ & $1.04 \mathrm{E}+02$ & $7.19 \mathrm{E}+01$ & $4.53 \mathrm{E}+01$ & $1.85 \mathrm{E}+02$ & $2.15 E+02$ & $3.22 \mathrm{E}+01$ \\
\hline $\mathrm{T}_{\mathrm{CO}}\left({ }^{\circ} \mathrm{C}\right)$ & $2.24 \mathrm{E}+02$ & $1.80 \mathrm{E}+02$ & $1.58 \mathrm{E}+02$ & $1.41 \mathrm{E}+02$ & $1.04 \mathrm{E}+02$ & $7.19 \mathrm{E}+01$ & $2.15 \mathrm{E}+02$ & $2.59 \mathrm{E}+02$ & $3.78 \mathrm{E}+01$ \\
\hline$m_{\text {hot }}(\mathrm{kg} / \mathrm{s})$ & $7.88 \mathrm{E}+01$ & $1.19 \mathrm{E}+02$ & $1.24 \mathrm{E}+01$ & $3.81 \mathrm{E}+01$ & $5.96 \mathrm{E}+01$ & $8.45 \mathrm{E}+01$ & $1.58 \mathrm{E}+01$ & $2.22 \mathrm{E}+01$ & $3.84 \mathrm{E}+02$ \\
\hline$m_{\text {cold }}(\mathrm{kg} / \mathrm{s})$ & $5.03 \mathrm{E}+02$ & $3.84 \mathrm{E}+02$ & $3.84 \mathrm{E}+02$ & $3.84 \mathrm{E}+02$ & $3.84 \mathrm{E}+02$ & $3.84 \mathrm{E}+02$ & $3.82 \mathrm{E}+02$ & $3.82 \mathrm{E}+02$ & $2.81 \mathrm{E}+04$ \\
\hline $\mathbf{V}_{\text {hot }}(\mathbf{m} / \mathbf{s})$ & $4.44 \mathrm{E}+00$ & $4.84 \mathrm{E}+01$ & $5.64 \mathrm{E}+00$ & $1.56 \mathrm{E}+01$ & $7.05 \mathrm{E}+01$ & $1.45 \mathrm{E}+02$ & $9.45 \mathrm{E}-01$ & $8.03 \mathrm{E}-01$ & $1.40 \mathrm{E}+02$ \\
\hline $\mathrm{v}_{\text {cold }}(\mathrm{m} / \mathrm{s})$ & $2.13 \mathrm{E}+00$ & $2.13 \mathrm{E}+00$ & $2.13 \mathrm{E}+00$ & $2.13 \mathrm{E}+00$ & $2.13 \mathrm{E}+00$ & $2.13 \mathrm{E}+00$ & $2.37 \mathrm{E}+01$ & $1.42 \mathrm{E}+01$ & $2.13 \mathrm{E}+00$ \\
\hline q (Watts) & $9.46 \mathrm{E}+07$ & $3.69 \mathrm{E}+07$ & $2.79 \mathrm{E}+07$ & $6.16 \mathrm{E}+07$ & $5.13 \mathrm{E}+07$ & $4.28 \mathrm{E}+07$ & $2.90 \mathrm{E}+07$ & $3.90 \mathrm{E}+07$ & $6.54 \mathrm{E}+08$ \\
\hline \# of Tubes & $3.02 \mathrm{E}+03$ & $9.90 \mathrm{E}+02$ & $1.47 \mathrm{E}+03$ & $2.49 \mathrm{E}+03$ & $2.56 \mathrm{E}+03$ & $5.47 \mathrm{E}+03$ & $6.00 \mathrm{E}+02$ & $1.00 \mathrm{E}+03$ & $1.50 \mathrm{E}+04$ \\
\hline Length (m) & $1.00 \mathrm{E}+01$ & $6.00 \mathrm{E}+00$ & $8.00 \mathrm{E}+00$ & $1.00 \mathrm{E}+01$ & $1.00 \mathrm{E}+01$ & $6.00 \mathrm{E}+00$ & $3.13 \mathrm{E}+00$ & $3.33 \mathrm{E}+00$ & $1.08 \mathrm{E}+01$ \\
\hline Diameter of & $2.54 \mathrm{E}-02$ & $2.54 \mathrm{E}-02$ & $2.54 \mathrm{E}-02$ & $2.54 \mathrm{E}-02$ & $2.54 \mathrm{E}-02$ & $2.54 \mathrm{E}-02$ & $2.54 \mathrm{E}-02$ & $2.54 \mathrm{E}-02$ & $2.54 \mathrm{E}-02$ \\
\hline Diameter of component (m) & $2.37 \mathrm{E}+00$ & $1.36 \mathrm{E}+00$ & $1.65 \mathrm{E}+00$ & $2.15 \mathrm{E}+00$ & $2.18 \mathrm{E}+00$ & $3.19 \mathrm{E}+00$ & $1.06 \mathrm{E}+00$ & $1.37 \mathrm{E}+00$ & $8.00 \mathrm{E}+00$ \\
\hline HT Area $\left(\mathrm{m}^{2}\right)$ & $4.82 \mathrm{E}+03$ & $9.48 \mathrm{E}+02$ & $1.88 \mathrm{E}+03$ & $3.98 \mathrm{E}+03$ & $4.09 \mathrm{E}+03$ & $5.24 \mathrm{E}+03$ & $3.00 \mathrm{E}+02$ & $5.32 \mathrm{E}+02$ & $2.58 \mathrm{E}+04$ \\
\hline Weight (tons) & $4.26 \mathrm{E}+01$ & $1.02 \mathrm{E}+01$ & $1.83 \mathrm{E}+01$ & $3.57 \mathrm{E}+01$ & $3.66 \mathrm{E}+01$ & $4.73 \mathrm{E}+01$ & $4.02 \mathrm{E}+00$ & $6.30 \mathrm{E}+00$ & $2.36 \mathrm{E}+02$ \\
\hline
\end{tabular}

\section{BALANCE OF PLANT LAYOUT}

A diagram of the system showing balance of plant component layout is shown in Figure 3. In the BOP, the turbo-generator set is axially aligned with the primary plant. The HP turbine is facing the primary plant in order to facilitate connection of steam lines and to preclude rupture of the primary containment in the event of turbine blade failure. The reheater is offset to one side of the HP unit to facilitate connections of the main steam line. The feed water heaters are aligned in descending order clockwise under the bottom of the turbine to facilitate connection of the extraction steam lines. By convention, the condenser is placed under the LP turbine with the coolant intake facing away from the containment. 


\section{NUCLEAR ENERGY RESEARCH INITIATIVE (NERI) PROGRAM \\ GRANT NUMBER DE-FG07-00SF22168 \\ FINAL REPORT}

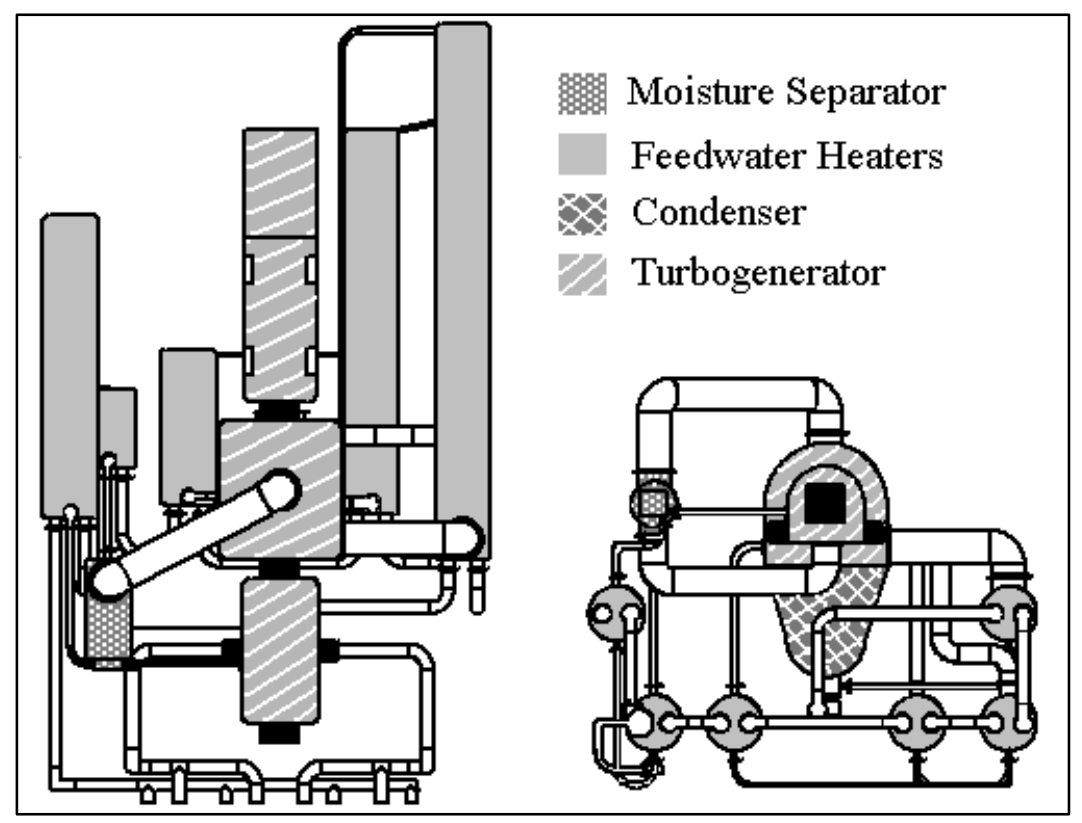

Figure 3: Balance of Plant Layout

Next, piping runs are measured in order to determine their weights and lengths. The total volume of each piping run is determined from solid models and multiplied by the density of stainless steel to determine the weight. Table 6 shows the results of the piping run calculations. 


\section{NUCLEAR ENERGY RESEARCH INITIATIVE (NERI) PROGRAM GRANT NUMBER DE-FG07-00SF22168 \\ FINAL REPORT}

Table 6. Piping Run Calculations

\begin{tabular}{|c|c|c|c|c|c|c|c|c|c|}
\hline \multirow{2}{*}{\multicolumn{2}{|c|}{$\begin{array}{l}\text { Diameter } \\
\text { mm inches }\end{array}$}} & \multicolumn{2}{|c|}{ Volume } & \multicolumn{2}{|c|}{ Weight } & \multicolumn{2}{|c|}{ Length } & \multirow{2}{*}{$\begin{array}{c}\text { Elbow } \\
\quad \#\end{array}$} & \multirow{2}{*}{$\begin{array}{c}\text { Flanges } \\
\#\end{array}$} \\
\hline & & $m^{\wedge} 3$ & $\mathrm{ft}^{\wedge} \mathbf{3}$ & kg & ton & m & ft & & \\
\hline 600 & 24 & 0.89 & 31.43 & 6897.83 & 7.60 & 12.00 & 39.37 & 2 & 2 \\
\hline 600 & 24 & 0.95 & 33.55 & 7362.85 & 8.12 & 6.90 & 22.64 & 2 & 2 \\
\hline 1800 & 72 & 2.29 & 80.87 & 17748.35 & 19.57 & 6.00 & 19.69 & 1 & 2 \\
\hline 1000 & 40 & 2.04 & 72.04 & 15810.76 & 17.43 & 8.12 & 26.64 & 3 & 2 \\
\hline 600 & 24 & 0.82 & 28.96 & 6355.31 & 7.01 & 7.06 & 23.16 & 1 & 2 \\
\hline 600 & 24 & 1.12 & 39.55 & 8680.42 & 9.57 & 8.90 & 29.20 & 2 & 2 \\
\hline 600 & 24 & 0.76 & 26.84 & 5890.28 & 6.49 & 4.80 & 15.75 & 2 & 2 \\
\hline 600 & 24 & 1.89 & 66.74 & 14648.20 & 16.15 & 16.21 & 53.18 & 3 & 2 \\
\hline 600 & 24 & 0.52 & 18.36 & 4030.19 & 4.44 & 3.70 & 12.14 & 0 & 2 \\
\hline 600 & 24 & 0.72 & 25.43 & 5580.27 & 6.15 & 5.90 & 19.36 & 1 & 2 \\
\hline 400 & 16 & 0.53 & 18.72 & 4107.70 & 4.53 & 7.02 & 23.03 & 1 & 2 \\
\hline 350 & 14 & 0.68 & 24.01 & 5270.25 & 5.81 & 11.76 & 38.58 & 1 & 2 \\
\hline 300 & 12 & 0.53 & 18.72 & 4107.70 & 4.53 & 7.59 & 24.90 & 3 & 2 \\
\hline 250 & 10 & 1.12 & 39.55 & 8680.42 & 9.57 & 29.62 & 97.18 & 3 & 2 \\
\hline 250 & 10 & 0.35 & 12.36 & 2712.63 & 2.99 & 6.87 & 22.54 & 2 & 2 \\
\hline 200 & 8 & 0.19 & 6.71 & 1472.57 & 1.62 & 3.63 & 11.91 & 2 & 2 \\
\hline 200 & 8 & 0.55 & 19.42 & 4262.70 & 4.70 & 17.38 & 57.02 & 3 & 2 \\
\hline 350 & 14 & 0.58 & 20.48 & 4495.22 & 4.96 & 7.09 & 23.26 & 3 & 1 \\
\hline 250 & $\overline{10}$ & 0.65 & 22.95 & 5037.74 & 5.55 & 13.16 & 43.18 & 4 & 2 \\
\hline 200 & 8 & 0.17 & 6.00 & 1317.56 & 1.45 & 5.76 & 18.90 & 0 & 2 \\
\hline 1500 & 60 & 3.12 & 110.18 & 24181.16 & 26.66 & 9.75 & 31.99 & 2 & 2 \\
\hline 1800 & 72 & 4.58 & 161.74 & 35496.70 & 39.13 & 12.75 & 41.83 & 2 & 2 \\
\hline 600 & 24 & 2.12 & 74.87 & 16430.79 & 18.11 & 20.95 & 68.73 & 2 & 1 \\
\hline 700 & 28 & 2.62 & 92.52 & 20305.97 & 22.39 & 16.44 & 53.94 & 4 & 1 \\
\hline 700 & 28 & 2.62 & 92.52 & 20305.97 & 22.39 & 16.44 & 53.94 & 4 & 1 \\
\hline 600 & 24 & 3.86 & 136.31 & 29916.44 & 32.98 & 15.00 & 49.21 & 0 & 0 \\
\hline & tals & 36.27 & $\overline{280.86}$ & 81105.99 & 09.8 & 80.80 & 921.26 & $\overline{53}$ & 46 \\
\hline
\end{tabular}

The footprint of the plant is taken from a projection of the solid model layout. The reactor building size, $40 \mathrm{~m}$ ? $56 \mathrm{~m}(132 \mathrm{ft}$ ? $184 \mathrm{ft})$ is predetermined from the Westinghouse design. The final layout of the balance of plant uses the same width, $40 \mathrm{~m}$ $(132 \mathrm{ft})$, and is $44 \mathrm{~m}(144 \mathrm{ft})$ in length. This gives a total footprint of $40 \mathrm{~m}$ ? $100 \mathrm{~m}(132 \mathrm{ft}$ ? $328 \mathrm{ft}$ ). Note that none of the auxiliary buildings are included in this layout. The footprint is depicted in Figure 4. 


\section{NUCLEAR ENERGY RESEARCH INITIATIVE (NERI) PROGRAM \\ GRANT NUMBER DE-FG07-00SF22168 \\ FINAL REPORT}

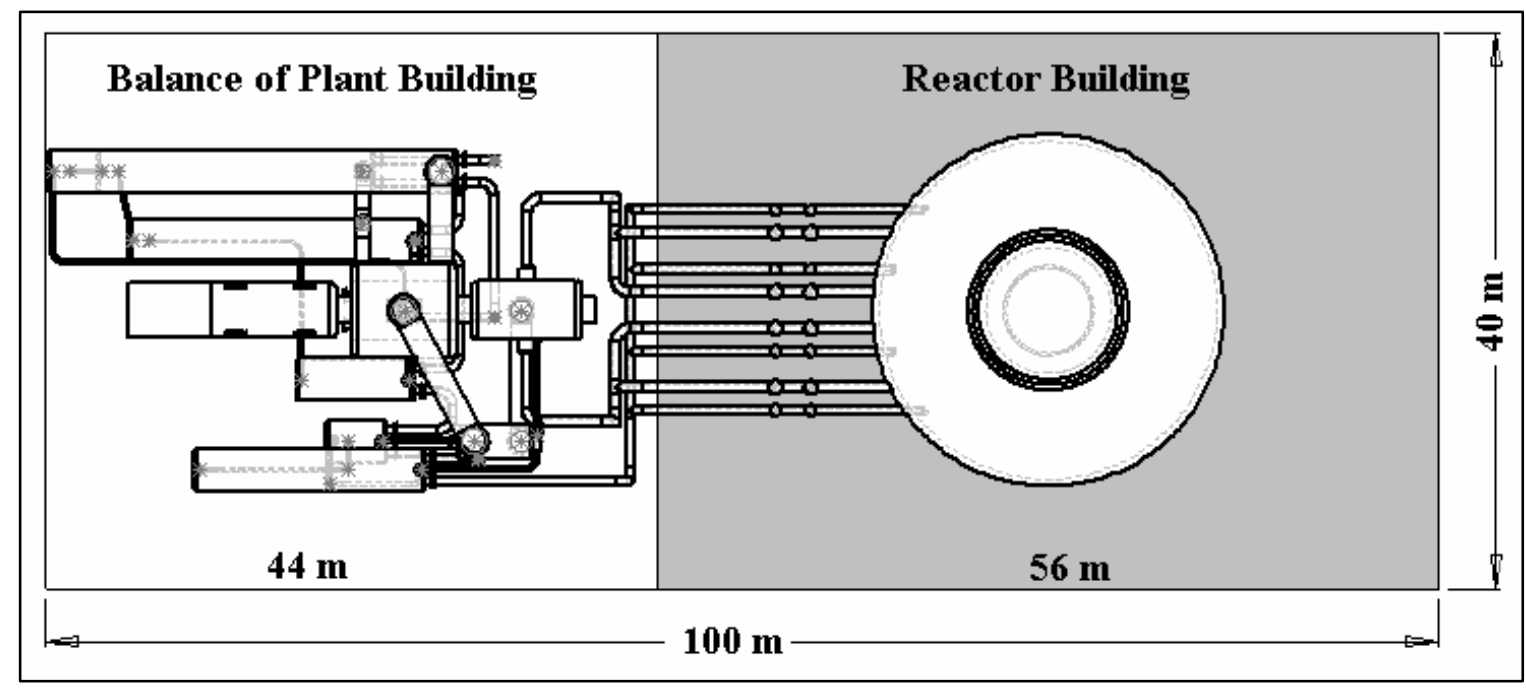

Figure 4: Footprint of IRIS Plant La yout

\section{RESTRICTIONS ON BARGE TRANSPORT}

Size limitations on barges traveling on the Tennessee, Ohio, and Mississippi Rivers are analyzed to determine the feasibility of transporting a modular power plant to a site accessible by these river systems. These river systems were selected based on discussions at the DOE NERI review in July 2001 and is typical of considerations for other river systems. Navigation charts were reviewed for the Tennessee, Ohio, and Mississippi Rivers to determine constraints imposed by channel depths, lock and dam dimensions, and overhead obstructions including cables and bridges. The limiting constraints for each of these river systems are presented.

\section{Tennessee River System}

The Tennessee River main navigable channel begins near Knoxville, TN and ends 652 miles later when it empties into the Ohio River in Paducah, KY. Commercial navigation also extends into three major tributaries: 61 miles up the Clinch River, 29 miles up the Little Tennessee River, and 21 miles up the Hiawassee River. Over the course of the river's length, the elevation drops a total of 156.4 meters (513 feet). Nine main and four auxiliary locks exist on this river system. Three of the locks have limiting clear chamber dimensions of 109.7 meters (360') length by 18.3 meters (60') width, which is considerably less than the dimensions of the other main locks of 182.88 meters (600') length by 33.53 meters (110') width. The first of these smaller locks is the Fort Loudoun Lock and Dam located on mile marker 602.3 in Le noir City, TN, and the last is the Chickamauga Lock and Dam located on mile marker 471.0 in Chattanooga, TN. The Chickamauga Lock, however, is deteriorating and is likely to be replaced by a larger/wider lock within the next several years. The minimum vertical clearance along the river is limited to 15.24 meters (50 feet) minus gage when the water is at pool stage at 


\section{NUCLEAR ENERGY RESEARCH INITIATIVE (NERI) PROGRAM \\ GRANT NUMBER DE-FG07-00SF22168 \\ FINAL REPORT}

mile marker 647.3 by the Southern Railway Bridge in Knoxville, TN. TVA maintains water levels sufficient to provide a minimum navigation channel depth of 2.74 meters (9') (with a two-foot overdraft) throughout this navigable waterway.

\section{Ohio River System}

In Paducah, Kentucky, the Tennessee and the Ohio Rivers merge at mile marker 933. Forty-eight miles later, the Ohio River flows into the Mississippi River at mile marker 981. Two lock systems exits between these points, both with dimensions of 182.88 meters (600') length and 33.53 meters (110') width. The minimum vertical clearance is 27.7 meters (91') minus gage by The Irvin S. Cobb Bridge at mile marker 937.3. The minimum water depth is maintained at 2.74 meters (9')

\section{Mississippi River System}

The Mississippi River travels upstream from the Gulf of Mexico at mile marker 0, and merges with the Ohio River at mile marker 953 in Alexander County, Kentucky. No locks exist between these points. The minimum vertical clearance is 25.6 meters (80') minus gage at mile marker 369.1 by an aerial power crossing in Adams County, MS. The horizontal clearance constraint is 152.4 meters (500') at mile marker 229.3 by the Baton Rouge Highway Bridge in Baton Rouge, LA. A series of dams maintain a minimum water depth of 2.74 meters (9') in the channel of the river during low water conditions.

\section{Determination of Barge Dimensions}

A rough estimate of the weight for a $1000 \mathrm{MWt}$ modular reactor and its secondary system, similar to the Westinghouse IRIS plant, is taken as the summation of all of the major components in the analysis. Many of the smaller subcomponents have been neglected. The containment structure contributes $\sim 2.81 \mathrm{E} 6 \mathrm{~kg}$ (3100 tons). The primary reactor vessel and the turbo-generator contribute $\sim 1.45 \mathrm{E} 6 \mathrm{~kg}$ (1600 tons) each. The heat exchange equipment and piping contribute $\sim 6.78 \mathrm{E} 5 \mathrm{~kg}$ (747 tons). Therefore, the total weight of the major plant components is $\sim 6.39 \mathrm{E} 6 \mathrm{~kg}$ (7047 tons).

Assuming a barge with dimensions 121.92 meters (400 feet) long by 33.53 meters (110 feet) wide, the draft of the barge can be calculated. Assuming a barge mass of 1.81E5 kg (200 tons) gives a total weight for the barge and its load of $\sim 6.57 \mathrm{E} 6 \mathrm{~kg}$ ( $7247 \mathrm{tons}$ ). The draft of the barge is calculated using

Draft $? \frac{\mathrm{m}_{\text {barge }}}{?_{\text {water }} \mathrm{L}_{\text {barge }} \mathrm{W}_{\text {barge }}}$

\section{$\underline{\text { Results }}$}

Using a freshwater density at $80{ }^{\circ} \mathrm{F}$ of $996.48 \mathrm{~kg} / \mathrm{m}^{3}$, the barge draft is calculated to be 1.61 meters (5.29 feet). Since the minimum water level for both of the considered river systems is 2.74 meters, the assumed barge is capable of successfully delivering the modular power plant to its destination. For a narrower lock with a width of 18.3 meters (60 feet) and a length of 109.7meters (360 feet), the draft for a barge and load of 6.57E6 


\section{NUCLEAR ENERGY RESEARCH INITIATIVE (NERI) PROGRAM \\ GRANT NUMBER DE-FG07-00SF22168 \\ FINAL REPORT}

$\mathrm{kg}$ (7247 tons) is 3.29 meters (10.78 feet), which exceeds the minimum channel depth of 2.74 meters, requiring more than one smaller barge to be used to transport plant components.

Note that the $100 \mathrm{~m}$ (328 ft) length of the plant is less than the $400 \mathrm{ft}$ capacity (length) of the locks on the Mississippi/Ohio River system for barge transport. However, the 40m (144 ft) width of the plant exceeds the $110 \mathrm{ft}$ width limitation for barge traffic through the Mississippi/Ohio River locks. The excess width in the plant layout arises from the width of the Westinghouse reactor building specifications. The actual width of the reactor containment and balance of plant is less than this $110 \mathrm{ft}$ width limitation. Therefore, barge transport is still possible if the "buildings" are redesigned or are constructed after barge arrival at the plant site.

\section{REGENERATIVE HEATER OPTIMIZATION STUDIES}

In a study by Williams (ORNL/TM-2002/154), the Salisbury methodology (Salisbury 1974 ) is used to make a comparison of two conceptual steam plant designs for the Westinghouse IRIS. The first design is using the reference design as proposed by Famiani in the document Steam Cycle and BOP Calculations for IRIS (Famiani, 2002). The study by Famiani is to assist in the comparison in trade-off between steam generator size and regeneration rate. The conceptual design in this study is for an 1800-RPM dual flow high-pressure turbine with two dual flow low-pressure turbines. The unit has a steam moisture separator reheater (MSR) and seven regenerative feedwater heaters (six closed and one deaerator). The condenser operates at 0.08465 bar (1.227745 psi) and 42.6 ?C (108.68 ?F). It is important to mention that this cycle mimics the cycle used for the Westinghouse AP600. The AP600 unit is designed for nearly 2000 MW of thermal output. It is also important to note that the design by Famiani utilizes a previous IRIS design value for steam generator exit steam pressure of $7 \mathrm{MPa}(1015.2285 \mathrm{psi})$, in this study it is converted to the new pressure of $5.8 \mathrm{MPa}(841.219 \mathrm{psi})$. The second design is a new design being proposed for this study alone called INRC8. It hopes to encompass the idea of modularity as less complex. This concept consists of one dual flow high-pressure turbine and one dual flow low-pressure turbine. It also proposes single stage MSR and four regenerative heaters. This concept keeps the same condenser parameters as the first design. The two designs can be seen in schematic form in Figure 5. Utilizing the above methods the two designs can be compared. A key point is the maintenance of the steam generator conditions. Each cycle is evaluated as in Table 7.

Table 7. Comparison of Famiani and INRC8 cycles

\begin{tabular}{|c|c|c|c|}
\hline Cycle & Famiani & INRC8 & Difference \\
\hline Heat Rate $(\mathrm{Btu} / \mathrm{kWh})$ & 9870 & 9970 & $1.01 \%$ \\
\hline Output $(\mathrm{kW})$ & 343,635 & 340,219 & $-0.99 \%$ \\
\hline Surface Area $\left(\mathrm{ft}^{2}\right)$ & 147,546 & 164,259 & $11.33 \%$ \\
\hline
\end{tabular}




\section{NUCLEAR ENERGY RESEARCH INITIATIVE (NERI) PROGRAM \\ GRANT NUMBER DE-FG07-00SF22168 \\ FINAL REPORT}

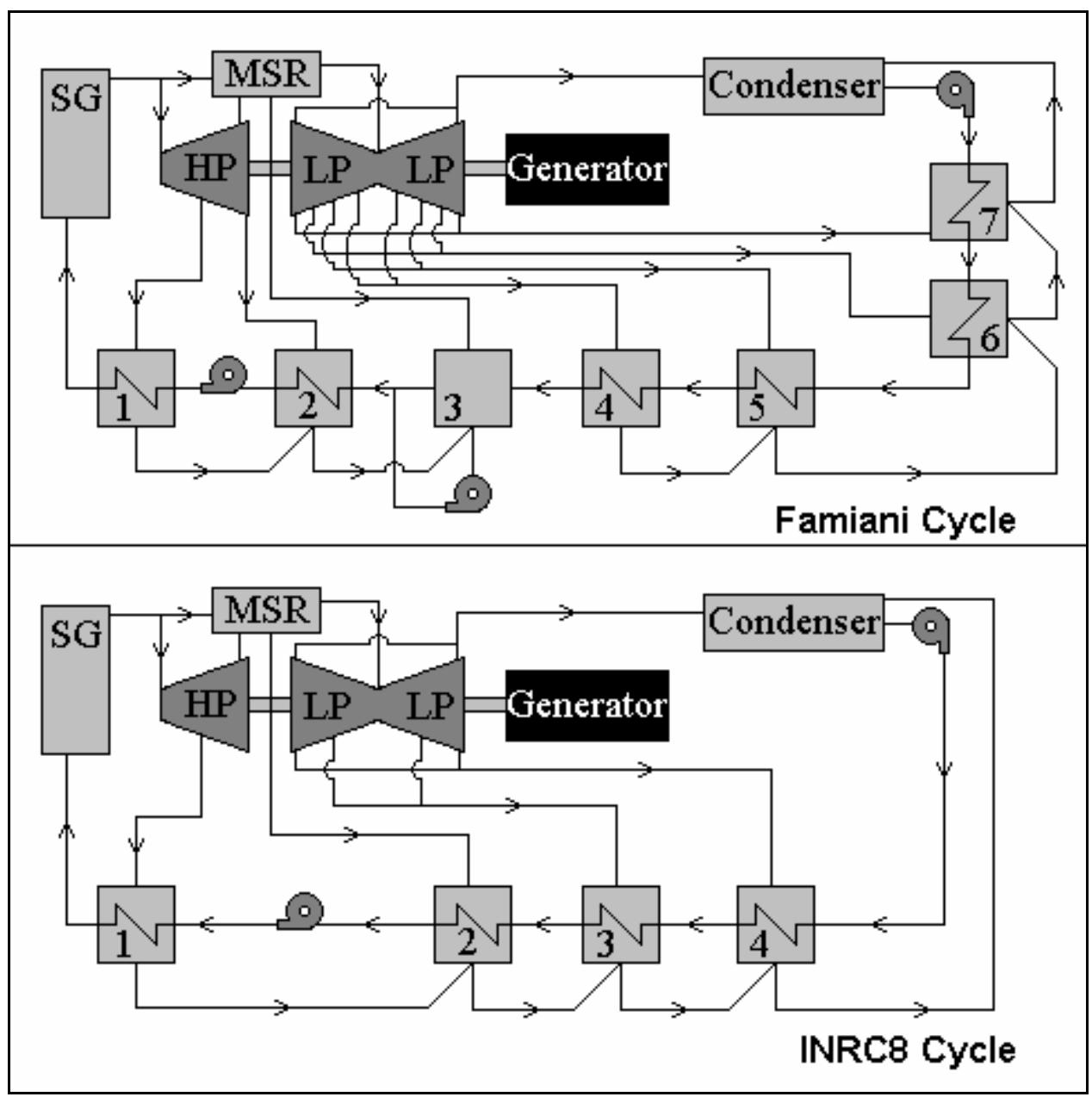

Figure 5. Schematics of Famiani and INRC8 Cycles

The important differences are that the net output is about 1\% less for the INRC8 as compared to the Famiani design. There is an increase of $11 \%$ more surface area in the INRC8 heaters but the reduction in complexity could outweigh these effects. It is important to note that for each feedwater heater there are at least four piping runs that need to be added just for the main steam. This does not include the sensors and auxiliary equipment needed.

This means that there are also only four units instead of seven to be moved. Another important finding is that in order to decrease the surface area of the feedwater heaters; the steam generator conditions must be modified. It might be worthwhile to study the effectiveness of reducing the steam generator inlet temperature and losing some of the efficiency in order to reduce the size of the overall plant. The primary purpose of this small study is to show the possibilities for complexity reduction as an important idea in modularity as well as size reduction. 


\section{NUCLEAR ENERGY RESEARCH INITIATIVE (NERI) PROGRAM \\ GRANT NUMBER DE-FG07-00SF22168 \\ FINAL REPORT}

\section{REFERENCES}

Famiani, F. 2002, Steam Cycle and BOP Calculations for IRIS, IRIS-POLIMI-11, Department of Nuclear Engineering, Polytechnic of Milan, Italy.

Forbus, Kenneth D. and Peter B. Whalley, CyclePad (C) 1995, <http://www.qrg.nwu.edu/software.htm>

Fuller, L. C. 1979. User's Instructions for ORCENT II - A Digital Computer Program for the Analysis of Steam Turbine Cycles Supplied by Light-Water-Cooled Reactors, ORNL/TM-6525, Oak Ridge National Laboratory, Oak Ridge, TN.

Oak Ridge National Laboratory, ORCENT2 - Code System for Analysis of Steam Turbine Cycles Supplied by Light Water Reactors, Radiation Safety Information Computational Center (RSICC), Peripheral Shielding Routine Calculation, PSR-474, April (2000).

Oriani, L. 2002, Steam Cycle Economical Optimization for IRIS, IRIS-POLIMI-12, Department of Nuclear Engineering, Polytechnic of Milan, Italy.

Salisbury, J. K.1974. Steam Turbines and Their Cycles, Robert E. Krieger Publishing Co., Inc., New York.

Williams, W. C. 2002. Conceptual Design and Layout of the Balance of Plant for a Generation IV Nuclear Power Plant Using the Westinghouse International Reactor, Innovative \& Secure (IRIS), Masters Thesis, Nuclear Engineering Department, University of Tennessee, Knoxville.

Williams, W. C. 2002. Regenerative Heater Optimization for Steam Turbo-Generation Cycles of Generation IV Nuclear Power Plants with a Comparison of Two Concepts for the Westinghouse International Reactor Innovative and Secure (IRIS). ORNL/TM2002/154, Oak Ridge National Laboratory, Oak Ridge, TN.

U.S. Army Corps of Engineers, "1998 Flood Control and Navigation Maps: Mississippi River Below Hannibal, Missouri to the Gulf of Mexico", $61^{\text {st }}$ Edition (1998).

U.S. Army Corps of Engineers, "Tennessee River Navigation Charts, Paducah, Kentucky to Knoxville, Tennessee", January (2000).

U.S. Army Corps of Engineers. " Ohio River Navigation Charts, Cairo, Illinois to Foster, Kentucky", January (2003). 


\title{
NUCLEAR ENERGY RESEARCH INITIATIVE (NERI) PROGRAM \\ GRANT NUMBER DE-FG07-00SF22168 \\ FINAL REPORT
}

\author{
Barge Mounted Concept for IRIS \\ Larry E. Conway \\ Westinghouse Electric Company, LLC
}

\section{INTRODUCTION}

Westinghouse has assisted the University of Tennessee in establishing a conceptual design and layout for a compact, factory-produced, transportable, nuclear reactor electrical power system. The Westinghouse effort was focused on creating a barge-mounted version of the IRIS (International Reactor Innovative \& Safe) reactor that could be transported via US inland waterways. For the purpose of the study the reference location for the power plant was the city of Chattanooga, Tennessee. Because of the limitations imposed on the overall barge dimensions (based on the navigation limits imposed by existing locks, bridge clearances, and river depths; and because the IRIS reactor is quite large when compared to most other Generation IV reactor concepts (335MWe versus 50-150 MWe); this effort focused on creating separate barge "modules" for the reactor building and the turbine-generator building. The effort utilized some existing layout studies that were performed as part of the IRIS NERI Program development, which was completed in 2002; the work by the University of Tennessee which developed the steam turbine and feed water heat balance and sized the turbine building major components; and the layout review and comments provided by the Newport News Shipyard.

\section{DESIGN OVERVIEW/SUMMARY}

The Westinghouse barge mounted IRIS reactor modules were limited in size based on input from the University of Tennessee. The barge dimension limitations were established to be 30 meters (98'-5') wide, 100 meters (328'-1") long, with a 2.74 meter (9') draft. These dimensions establish the barge maximum displacement at 8,220 metric tons. In addition, the barge(s) are limited to $\sim 20$ meters (65'-7') in height above the water surface, so that they fit under crossing bridges and can be floated up the Mississippi, Ohio, and Tennessee Rivers as far as the city of Chattanooga, Tennessee. Further movement above Chattanooga is currently limited by the locks at the Chickamauga Reservoir dam.

The above barge displacement limitation will impose severe limits on how much structural support and shield concrete can be placed in the barge modules at the shipyard. For example, the estimated weight of concrete in the IRIS containment and the surrounding cylindrical shield structure alone greatly exceeds the total allowable barge displacement. This however does not mean that bargemounted pressurized water reactors (PWRs) are not feasible. It does mean that barge-mounted PWRs need to employ steel structures that are then used as the forms for the addition of needed concrete after the barge has been floated into its final location and founded. The use of steel structural modules in the construction of PWRs is not a new technology, and has been employed in the construction plan for the latest Westinghouse PWR designs including the AP600 and AP1000 


\section{NUCLEAR ENERGY RESEARCH INITIATIVE (NERI) PROGRAM \\ GRANT NUMBER DE-FG07-00SF22168 \\ FINAL REPORT}

reactors. For these nuclear power plants, the structural steel modules are fabricated on-site, from smaller rail/truck shippable modules, and then lifted into place using a heavy-lift crane. For a shipyard fabrication, the use of steel structural modules, as well as equipment modules, is actually the preferred construction method. The concrete placed at the shipyard is limited to that needed to provide support of major heavy structures, such as the reactor vessel and containment; and to that needed for barge stiffness and stability during shipment.

The IRIS reactor design, used as the basis for this study, is well suited for the barge-mounted concept. IRIS employs an integral reactor coolant system (RCS), whereby all the major reactor components are in a single reactor pressure vessel (RPV). The IRIS integral RPV contains not only the reactor core, the control rods, and the required supporting structures; but also contains the steam generators, the coolant pumps, and the pressurizer. Thus the IRIS RCS has no large pipes which interconnect separate RCS components, as in current loop-type PWRs. Although this integral concept results in a larger RPV than a loop-type PWR, the RCS can be placed in a much smaller containment vessel (CV). In IRIS, this containment vessel is a 25 meter (82') diameter sphere; which is consistent with the maximum allowable barge width of 30 meters. Also; the containment height (without the closure head in place), minus the barge draft is very close to the 20 meter height specified as the clearance from the water surface to bridges crossing the above rivers. In fact, this bridges clearance elevation is sufficient such that most of the IRIS reactor building can be transported by barge. Note however that the top-most portion of the IRIS reactor building is mostly comprised of vaulted tanks for spent fuel storage pit, spent fuel cask pits, and refueling water storage tank. These vaulted tanks as well as the fuel handing area operating floor, walls, roof, and gantry crane will have to be put in place after the reactor building barge has been floated to its destination, due to the transportation height limitation. This additional construction at the destination can also be minimized by the use of structural and equipment modules that are prefabricated at the shipyard and barged to the plant destination. The size of these modules would be dictated by the capacity of the heavy-lift crane(s) used/available at the plant's final destination.

Both the reactor building and turbine-generator building barge layouts have utilized barges that are 30 meters wide $\times 70$ meters long. Therefore the total weight of the barges and their contained structures and equipment are limited to 5,760 metric tons to limit the barge draft to 2.74 meters. As discussed above this weight limitation will greatly limit the amount of structural concrete that can be placed at the fabrication shipyard. Therefore a detailed evaluation of the barge designs that includes all the major component weights, the equipment and structural module weights, the weight of the added concrete, and the barge weight will be required. In addition, analyses will be required to both; 1) assure that the structural steel and concrete used in the as-fabricated barge provides the necessary stiffness needed to prevent buckling of the barge during transportation, and 2) results in a center of gravity sufficiently low such that the barge will not capsize. This detailed evaluation of the barge, component, and structure weights is beyond the scope of this report; however, the estimated weights of some major IRIS components in the reactor building barge are listed in Table 1 for comparison to the barge total displacement. This listing illustrates the fact that the IRIS reactor vessel (with its internal components), the containment vessel, and their estimated support structures will weigh $\sim 5000$ metric tons. This weight can be reduced to $\sim 4500$ metric tons by installing the reactor vessel internal components at the plant site. However, this is still a large fraction of the total allowable 5760 metric ton displacement of the barge. The remaining 1260 


\section{NUCLEAR ENERGY RESEARCH INITIATIVE (NERI) PROGRAM \\ GRANT NUMBER DE-FG07-00SF22168 \\ FINAL REPORT}

metric tons would be mostly devoted to steel structural modules and concrete. The auxiliary equipment, including pumps, heat exchangers, tanks, piping, wires and cables, instrumentation, etc.; would comprise only a fraction of the barge displacement.

It should also be noted that in addition to a barge mounted reactor building and turbine-generator building, other plant buildings/structures can be constructed in the shipyard and floated to the site to complete the power plant. These barges could include a mechanical draft cooling tower and main circulating water pump barge(s), a barge containing supply water treatment equipment and water storage tanks, waste water treatment barge, a support equipment and health physics barge, and a barge containing the plant switchyard and transformers. In this manner an entire plant can be constructed using barged modules and thus maximize the advantages of shipyard construction techniques. These barges are less of a technical challenge but the entire layout and design of all these structures is an area for future work.

Table 1 - IRIS Reactor Building Component Weights

\begin{tabular}{|l|c|}
\hline COMPONENT/STRUCTURE & $\begin{array}{c}\text { ESTIMATED WEIGHT } \\
\text { (metric tons) }\end{array}$ \\
\hline Reactor Vessel (RV) Shell & $\mathbf{9 5 0}$ \\
\hline RV Internal Components & 51 \\
\hline RV Bottom Shield Plates & 14 \\
\hline Lower Core Plate & 50 \\
\hline Radial Reflector & 52 \\
\hline Core Barrel & 33 \\
\hline Upper Internals & 280 \\
\hline Steam Generators (8) & 32 \\
\hline Reactor Coolant Pumps (8) & $\mathbf{5 1 2}$ \\
\hline RV Internals Sub-total & $\mathbf{7 5 0}$ \\
\hline Containment Vessel (w/o head) & $\mathbf{1 0 0 0}$ (estimated minimum) \\
\hline In-side CV Concrete/steel & $\mathbf{1 5 0 0}$ (estimated minimum) \\
\hline CV Pedestal Concrete/steel & $\mathbf{2 8 0}$ \\
\hline Barge & $\mathbf{4 9 9 2}$ \\
\hline & \\
\hline Total Weight & \\
\hline
\end{tabular}

\section{REACTOR BUILDING BARGE}

The reactor building barge contains the reactor inside the containment structure, a shield structure that surrounds the containment, as well as the fuel handling facilities and equipment. It also contains typical reactor (auxiliary) building features such as the main control room, steam and feed water piping and isolation valve room, safe shutdown panel, and all safety related equipment including batteries for electrical power and equipment associated with monitoring reactor 


\section{NUCLEAR ENERGY RESEARCH INITIATIVE (NERI) PROGRAM \\ GRANT NUMBER DE-FG07-00SF22168 \\ FINAL REPORT}

operation and initiating required safety functions. Figure 4 shows that the lowest elevation of the reactor building barge forms a common basemat, which includes the containment, the containment support structure, and the surrounding cylindrical shield structure. This common basemat concept provides the IRIS reactor building barge with a large and stable foundation able to withstand large uplift and overturn forces once the barge is founded at the power plant site. It is anticipated that the barge will be backfilled with soil so that plant grade is established above the lower two levels (See grade level indicated on the right hand of the building). This will place the plant foundation at 13 meters below grade, which is typical of a common plant site, assuring that the soil can support the plant weight while also assuring that the plant remains stable for postulated high water conditions. The left side of the reactor building barge interfaces with the turbine-generator barge, which is sited so that it is just below the plant grade elevation.

The major structures and components of the reactor building barge are discussed below:

\section{REACTOR CONTAINMENT}

The IRIS reactor vessel (RV) is contained in a spherical, steel reactor containment vessel (CV) that is 25 meters (82') in diameter. This containment vessel is normally at nominal atmospheric pressure during all plant operations. The CV is constructed of $13 / 4$ " steel plate and has an internal design pressure of 1.4 MPa ( 190 psig). This containment vessel serves to contain water and/or steam that may be released from the reactor vessel, or from the steam generator steam and feed water piping as a result of postulated piping breaks or other events. By containing released water and/or steam, the containment also prevents the potential release of any significant amounts of radioactive material. An isometric view of the IRIS CV and the major in-containment equipment is shown in Figure 1. Figures 2 and 3 provide an elevation view and a plan view of the IRIS containment and inside structures and equipment. 


\section{NUCLEAR ENERGY RESEARCH INITIATIVE (NERI) PROGRAM}

GRANT NUMBER DE-FG07-00SF22168

FINAL REPORT

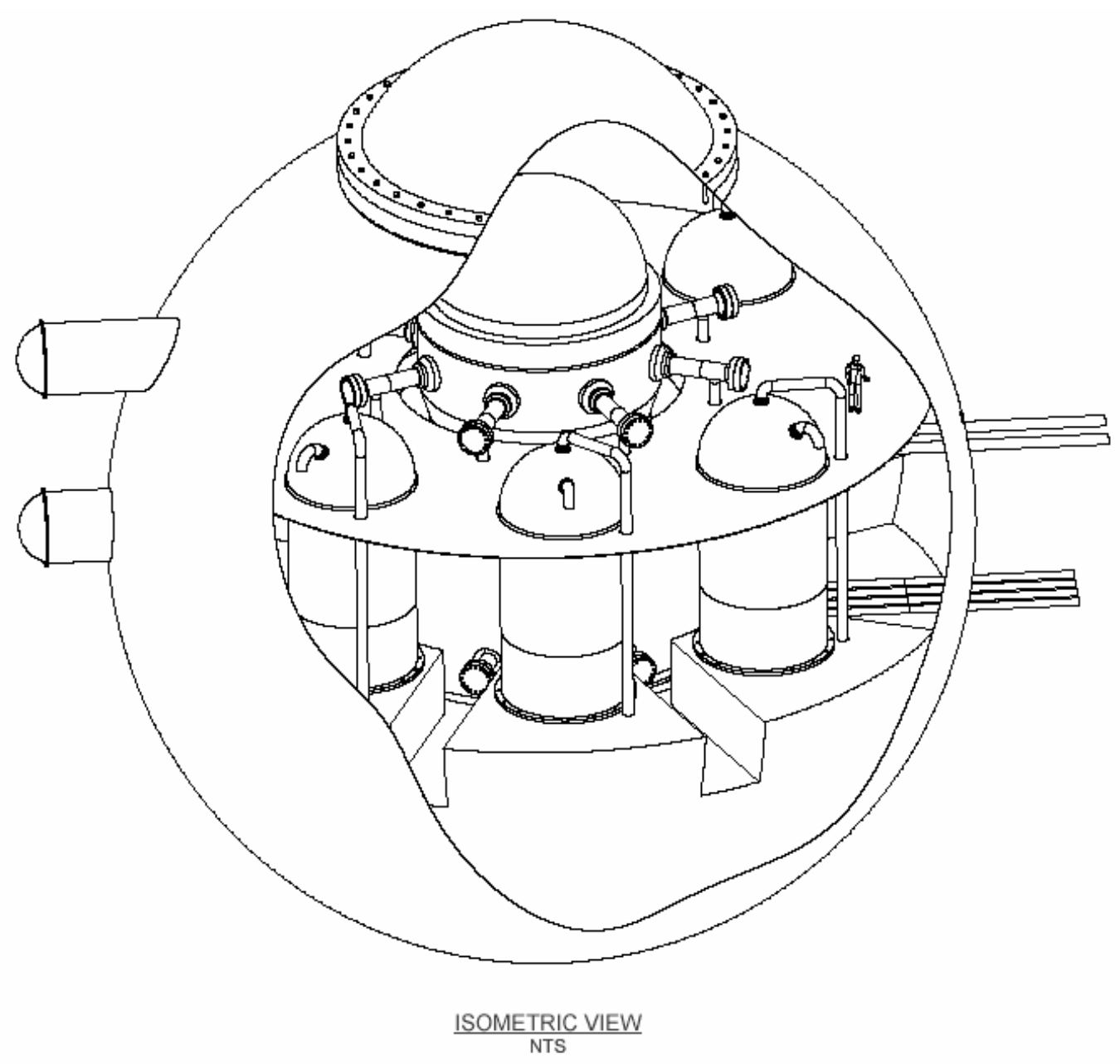

Figure 1 - Isometric View of IRIS Containment, and Major In-containment Equipment 


\section{NUCLEAR ENERGY RESEARCH INITIATIVE (NERI) PROGRAM \\ GRANT NUMBER DE-FG07-00SF22168 \\ FINAL REPORT}

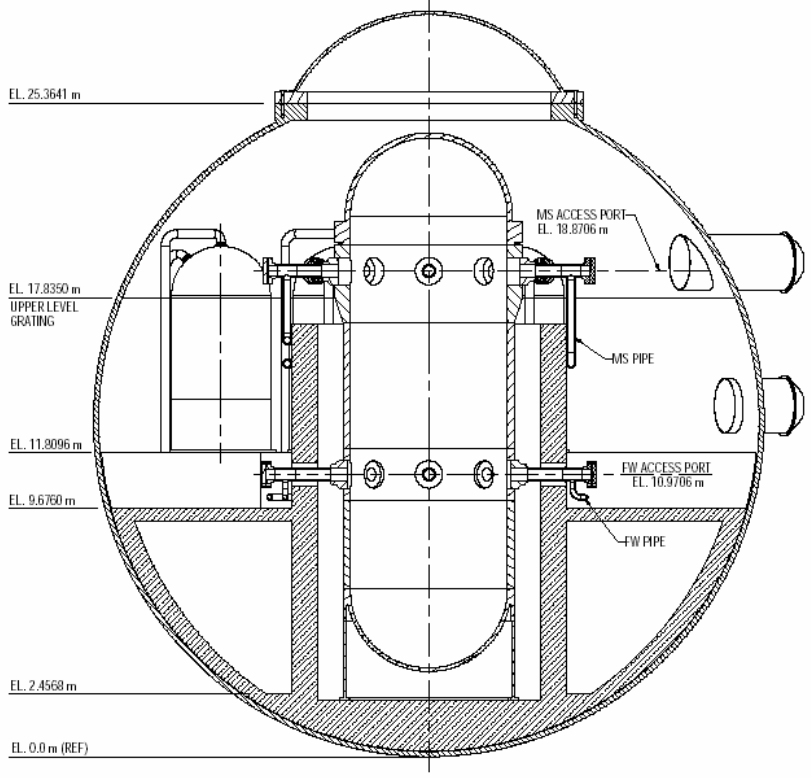

Figure 2 - IRIS Containment, Elevation View

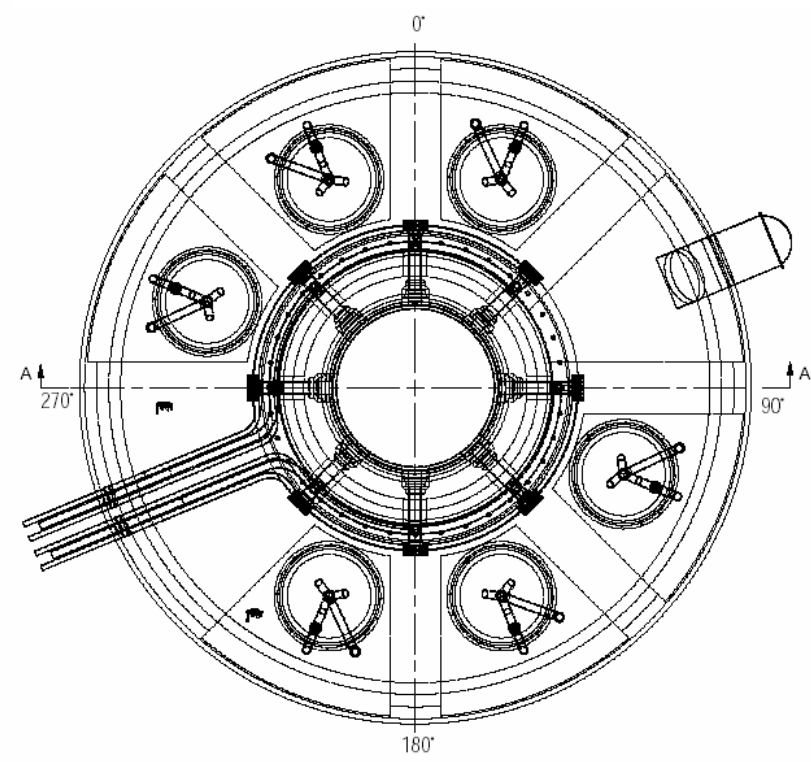

Figure 3 - IRIS Containment, Plan View

Key features include:

? The spherical steel containment vessel (CV) has a bolted and flanged closure head at the top that provides access to the RV upper head flange and bolting. The removal of the CV and RV closure heads provides access for the removal of the RV internals and for refueling operations where fuel assemblies are removed, replaced and/or "shuffled." This is also the access for the inspection, removal, and replacement of any equipment within the RV.

? The integral reactor vessel, which contains the reactor core, control rods, coolant pumps, steam generators, and the pressurizer; is located at the center of the containment. The RV is 6.78 meters in diameter and is 22.2 meters in length. The RV has a hemispherical bottom head, and a removable upper hemispherical head.

? The RV is surrounded by a concrete shield wall that forms a cavity in which the RV is placed. The containment and other features are designed such that this cavity fills with water following any serious event that results in a loss of coolant from the RV and/or significantly pressurizes the containment. This water flood-up height is sufficient to provide long-term gravity makeup, so that the RV water inventory is maintained above the core for an indefinite period of time. It also provides sufficient heat removal from the external RV surface to prevent any vessel failure following beyond design basis scenarios.

? The RV is shown with eight (8) steam generator feed water supply nozzles and eight steam discharge nozzles in its cylindrical section. These nozzle penetrations connect directly to their associated steam generator using a specially designed coupling. At each of these penetrations, a blind flange is provided to access the steam generator tube sheets. The feed water and steam lines are routed to a common containment penetration area.

? The IRIS containment includes a pressure suppression system that limits the containment peak pressure to well below the $\mathrm{CV}$ design pressure. This suppression system is comprised 


\section{NUCLEAR ENERGY RESEARCH INITIATIVE (NERI) PROGRAM \\ GRANT NUMBER DE-FG07-00SF22168 \\ FINAL REPORT}

of six (6) water tanks that are shown at elevation 11.8 meters. These tanks each contain a vent pipe from the containment atmosphere to a submerged sparger. The tanks each have a pipe connection to a large pressure suppression air space located below the water tanks. These tanks also provide an elevated gravity driven source of makeup water to the RV should it be required following postulated small/medium LOCA events, and they also provide the water source for ensuring the RV cavity can be/is flooded.

The IRIS integral RV, containment, and the RV/CV heat removal system (not shown in the figures) comprises a unique, patent pending, configuration which practically eliminates the need for any safety injection following small-to-medium LOCAs (which are historically the accidents yielding the worst consequences). It is based on thermathydraulically coupling the containment and the reactor vessel. The water inventory within the reactor pressure vessel after a LOCA is maintained by reducing and practically zeroing the pressure differential between the vessel and containment, i.e., the driving force across the break, and therefore the coolant loss. This is accomplished through 1) the small, high design pressure, spherical containment which increases the pressure downstream of the break; 2) the multiple steam generators, which are used to remove the heat directly from inside the vessel, thus reducing the pressure upstream of the break; and 3) the Emergency Heat Removal System (EHRS) heat exchangers located outside containment, which transfer the heat to the environment. Calculations have indicated that for the worst combination of LOCA size and axial location the core can remain safely under water for an extended period of time, several days to weeks, without the need for water makeup. However, water makeup is in any case available, as discussed before. Because no water addition is required even after the worst case postulated LOCAs, IRIS does not require the high capacity, safety grade, high pressure injection emergency core cooling system (ECCS) characteristic of loop reactors. This greatly reduces and minimizes the amount of safety-grade equipment that is located outside of the reactor containment and thus minimizes the total required reactor building volume.

\section{REACTOR BUILDING GENERAL COMMENTS}

Figure 4 shows an elevation view of the reactor building barge. This figure clearly illustrates that the portion of the building left of the spherical containment contains non-radioactive (clean) electrical equipment, while the right-hand portion contains radioactive mechanical equipment and access to the containment. This separation between non-radioactive and radioactive equipment is maintained throughout the building elevations.

The left "clean" side of the building is devoted to the batteries and their support equipment that provide the safety-grade electrical power for monitoring the plant parameters, actuating safety related equipment, and powering the main control room. The lowest level of this portion of the building contains two of four battery power divisions, and the next higher elevation contains the remaining two divisions. Fire barrier and separate access paths to the separate divisions would be provided. A normally closed, emergency egress path is provided between the two separated divisions on each level that is only used in the event the normal access/egress is not usable. The next two levels contain battery associated electrical equipment including battery chargers, switchgear, electrical cabinets, containment electrical penetration areas, and the remote shutdown workstation. The upper most levels of the clean side of the reactor building are largely devoted to 


\section{NUCLEAR ENERGY RESEARCH INITIATIVE (NERI) PROGRAM \\ GRANT NUMBER DE-FG07-00SF22168 \\ FINAL REPORT}

the main control room and safety related electrical control and logic cabinets. The reactor trip and reactor coolant pump trip switch gear are also on this elevation.

This left side of the auxiliary building also contains separated valve/penetration rooms for the feedwater piping and isolation valves, and for the steam lines and their isolation valves. Each of these penetration areas is devoted to the feedwater and steam line piping penetrations through the containment. Ventilation shafts extend up through this elevation from the steam and feed water piping penetration areas below. These large vents provide a path for the venting of steam, in the event of a steam line or feed water line break in the steam/feed penetration room. This piping penetrates the concrete shield surrounding the containment and is then contained within guard piping through the space between the shield wall and the steel containment shell. These lines are routed from and to the turbine building barge, which is discussed below.

The right-side of the building houses equipment that normally contains/processes fluids that contain some radioactivity and is therefore called the "dirty" side of the building. The lower two levels on the right side of the building contain normally used mechanical equipment including the normal residual heat removal pumps and heat exchangers, the reactor makeup pumps, gaseous waste treatment, liquid radwaste treatment and storage tanks, and sampling room. Two access/egress paths are provided to this portion of the building.

The next two elevations are largely devoted to providing personnel access and equipment access to the containment and fuel handling area. Two personnel/equipment hatches for access to two levels in the containment are located adjacent to the open areas where equipment used for in-containment inspection and maintenance can be staged. These access hatches are utilized for personnel and equipment during plant shutdowns. Also included here is a large bay at the proposed grade elevation that provides access for a railroad car. Sufficient room will be provided to serve as a staging area for activities within the containment during plant shutdowns and refueling. Equipment can be moved into this containment access area directly from the railcar bay below, using the lifting cranes in the fuel handling area above. This railroad car bay is sufficiently large to accommodate a specialized railcar that is capable of transporting spent fuel casks to a disposal site. A hatch above the railcar location is provide such that the fuel building overhead crane can be used to lift and lower the spent fuel casks from and to the railcar from the fuel storage and handling area of the building. This portion of the reactor building barge also contains the access region to the demineralizers and filters, and provides a route for the removal of used filters to the railcar bay. A portion of the area directly above the railcar bay contains the auxiliary building HVAC equipment and non-safety related electrical switchgear.

As noted above, the portion of the reactor building barge above the containment vessel closure head flange must be constructed after the barge has reached its final destination, since there is limited clearance under bridges to some proposed sites. These levels are discussed in the next section of this report. Also note that on the right side of the building, the grade elevation is shown to be above the bottom two floor elevations of the reactor building barge. 


\section{NUCLEAR ENERGY RESEARCH INITIATIVE (NERI) PROGRAM \\ GRANT NUMBER DE-FG07-00SF22168}

FINAL REPORT

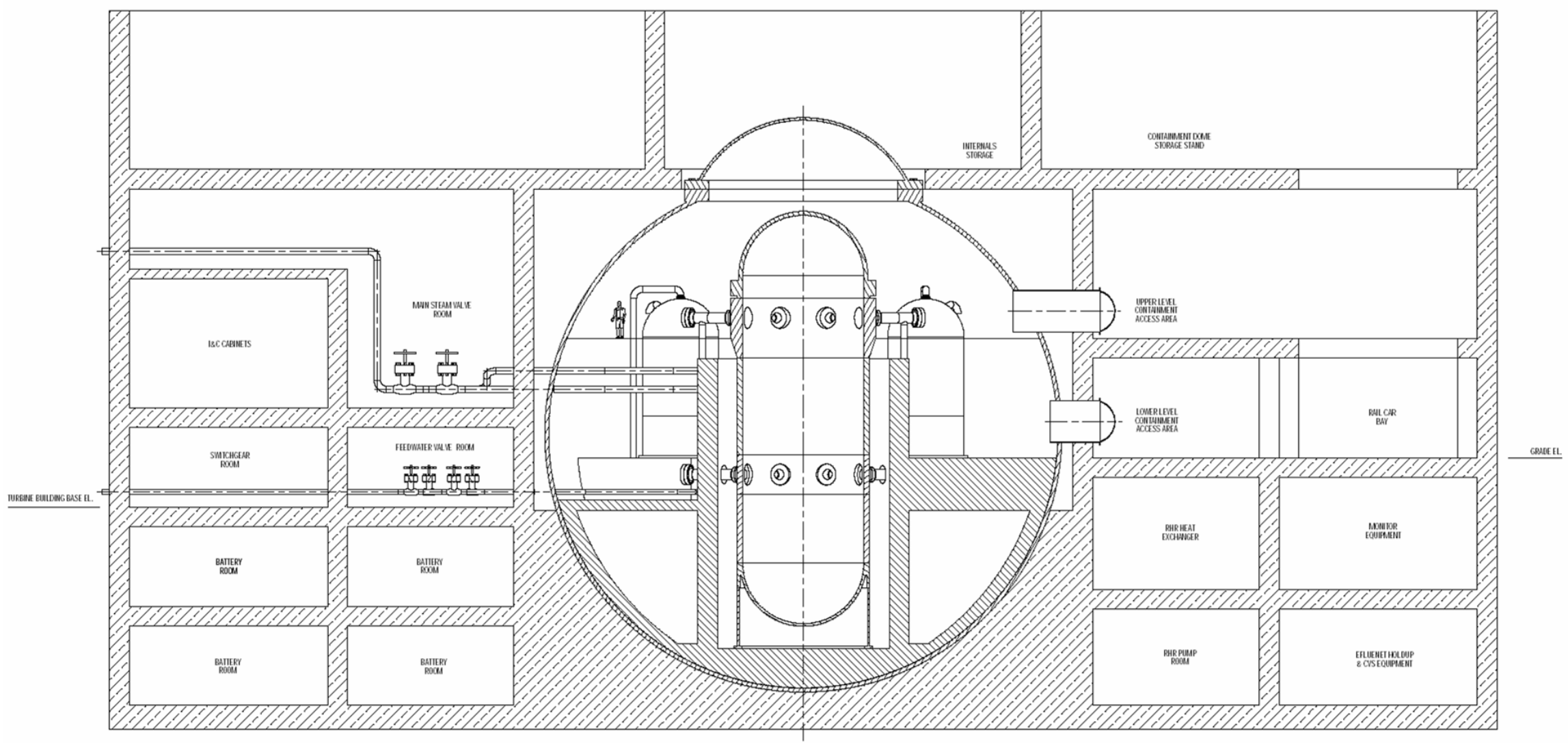

Figure 4 - IRIS Reactor Building Barge, Elevation View 


\section{NUCLEAR ENERGY RESEARCH INITIATIVE (NERI) PROGRAM \\ GRANT NUMBER DE-FG07-00SF22168 \\ FINAL REPORT}

\section{FUEL HANDLING AREA}

The Fuel Handling and Storage Area occupies most of the upper two levels of the reactor building barge, shown in elevation view in Figures 4 and 5 and in plan view in Figure 6 . This Figure 6 plan is the operating floor elevation for all the fuel handling and refueling activities. This portion of the building includes the refueling cavity directly above the containment (and reactor) closure head, as well as the spent fuel pit, cask loading and wash-down pits, refueling machine, new fuel storage area, laydown areas, and rail-car loading bay. Refueling of the reactor is accomplished by (See Figure 4) removing the containment vessel closure head and installing a sealing collar between the $\mathrm{CV}$ and RV, and removing the RV head. The refueling cavity above the containment and RV is then flooded using water stored in a refueling water storage tank (RWST) that is located adjacent to the refueling cavity, outside the containment vessel. This RWST is shown in Figure 6, on the top-most elevation of the reactor building, just above and to the right of the CV closure head. The $\mathrm{RV}$ internals are removed and placed in storage stands in the refueling cavity. Two storage stands are provided for the upper internals and one stand for the lower internals. Fuel assemblies are vertically lifted from the RV directly into the fuel handling and storage area, using a refueling machine located in the fuel handling area which moves directly above the open CV/RV. Thus, no refueling equipment is required inside containment and the single refueling machine is used for all fuel movement activities. A large gantry crane is provided in the fuel handling area for the movement of the containment closure head, the $\mathrm{CV}$ to RV seal collar, and reactor vessel closure head to their laydown areas. This crane is also used to remove the reactor vessel upper internals prior to refueling, removal of the lower internals as needed, and to remove the reactor coolant pumps and steam generator modules if required. This overhead crane would also be employed to lower a shielded maintenance/inspection basket into the top of the reactor vessel for the placement of the reactor vessel flange seal rings, or other normal vessel/component maintenance.

The refueling cavity is $\sim 7.5$ meters deep, which is sufficient to keep the fuel assemblies and reactor internals under water and shielded during the refueling operations. The refueling cavity is connected by a narrow canal to the spent fuel pool, which is then connected to the cask loading pit. The canals are normally closed by redundant gates that have seals that are pressurized with air. The gate seal air pressure as well as the water level between the gates is monitored and alarmed to assure that the gates maintain the water level in the spent fuel pool. Note that the spent fuel is located in the very lowest portion of the spent fuel pool, which cannot drain even in the event of the postulated failure of both redundant sealed gates. A canal is also provided to the spent fuel cask loading pit and this pit is also isolated by redundant gates. Finally, the spent fuel cask washdown pit is shown.

The upper left hand side of the building shown in Figure 6 is where the refueling machine can traverse over the refueling cavity above the containment and reactor vessel closure heads and the spent fuel pit and spent fuel cask loading area. The operating floor provides large laydown areas for storing the containment closure head, and the reactor vessel upper head package. The building area over the containment closure heads and including the laydown areas is traversed by a large 200 ton capacity, over-head crane that is used to lift these large components. Also the handling of heavy loads by the over-head crane is restricted such that these loads cannot travel over the stored 


\section{NUCLEAR ENERGY RESEARCH INITIATIVE (NERI) PROGRAM \\ GRANT NUMBER DE-FG07-00SF22168 \\ FINAL REPORT}

spent fuel, or the new fuel storage area. Hatches are provided in the floor of this elevation to provide access to the rail car bay both for new fuel delivered to the site, and for the removal of loaded spent fuel casks. The rail car bay is at the left end of the fuel handling area at the grade elevation.

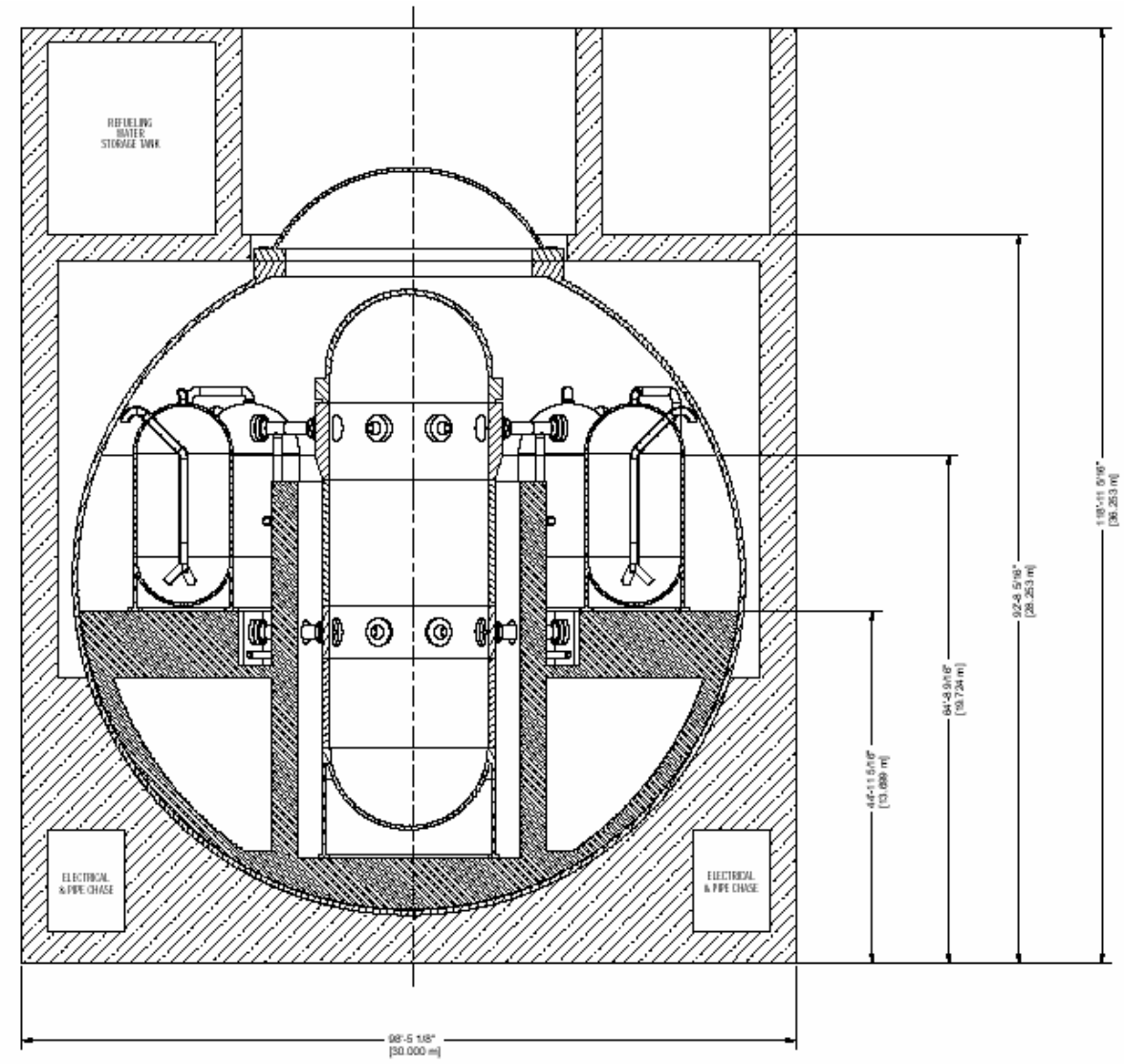

Figure 5 - IRIS Reactor Building Barge, Elevation View

The upper right side of the building houses the refueling water storage tank which contains the water needed to fill the refueling cavity above the reactor after the containment closure head and reactor vessel head have been removed. This tank also contains the passive Emergency Heat Removal System (EHRS) heat exchangers that provide the safety grade means of removing heat from the reactor vessel via the in-vessel steam generators. Thus, this water serves also the function of being the safety grade heat sink and therefore the tank is vented to the atmosphere to allow it to steam to the environment in the event that extended heat removal from the reactor vessel is required. This portion of the building also contains the normal and emergency HVAC equipment for the safety grade electrical areas and main control room located directly below.

Note that the top-most portion of the IRIS reactor building is mostly comprised of vaulted tanks for spent fuel storage pit, spent fuel cask pits, and refueling water storage tank. These vaulted tanks as well as the fuel handing area operating floor, walls, roof, and gantry crane will have to be put in place after the reactor building barge has been floated to its destination, due to the 


\section{NUCLEAR ENERGY RESEARCH INITIATIVE (NERI) PROGRAM \\ GRANT NUMBER DE-FG07-00SF22168 \\ FINAL REPORT}

transportation height limitation. This additional construction at the destination can also be minimized by the use of structural and equipment modules that are prefabricated at the shipyard and barged to the plant destination. The size of these modules would be dictated by the capacity of the heavy-lift crane(s) used/available at the plant's final destination. 
NUCLEAR ENERGY RESEARCH INITIATIVE (NERI) PROGRAM

GRANT NUMBER DE-FG07-00SF22168

FINAL REPORT

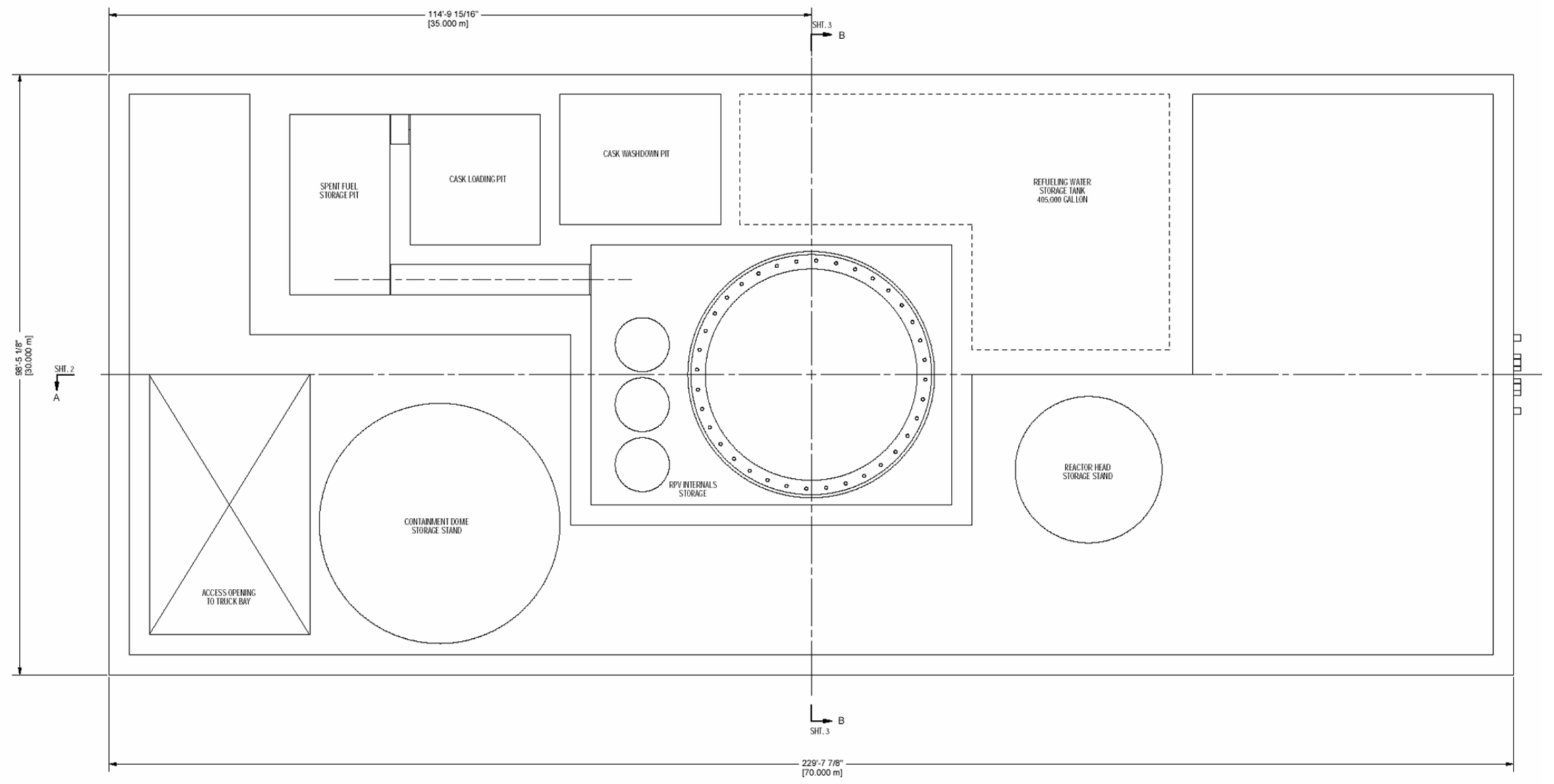

Figure 6 - IRIS Reactor Building Barge,

Plan View of the Fuel Handling and Storage Area 


\section{NUCLEAR ENERGY RESEARCH INITIATIVE (NERI) PROGRAM \\ GRANT NUMBER DE-FG07-00SF22168 \\ FINAL REPORT}

\section{TURBINE GENERATOR BUILDING BARGE}

The turbine building barge is shown in isometric view in Figure 7 and contains the power conversion equipment for the power plant and other auxiliary and support equipment. The main components and structures include the steam turbine, the electrical power generator, the moisture separator and reheater, the turbine condenser, the main feedwater systems and feed water heaters, and the turbine generator pedestal and operating deck. Figure 8 shows the barge in elevation view where it can be seen that the lowest elevation of the turbine building barge forms a common basemat. This common basemat concept provides the IRIS turbine building barge with a large and stable foundation once the barge is founded at the power plant site. It is anticipated that this barge will be founded just below the plant grade elevation defined above by the reactor building. This shallow founding will permit convenient interface with the main feed water and steam line penetration areas of the reactor building, as well as minimize the amount of excavation, backfilling, and overall costs. This turbine building has no safety related functions, although it will contain some support equipment for the reactor building functions; such as the component cooling water system pumps and heat exchangers and the service water cooling system for the CCWS and HVAC systems. The shallow founding also makes the installation of the plant circulating water piping to/from the cooling towers, and access to the condenser for maintenance easier.

Note that just like the reactor barge described above, the allowable barge displacement limitation will impose limits on how much concrete can be placed in the barge modules at the shipyard. For example, the estimated weight of concrete required for the barge basemat and the turbine generator pedestal, exceeds the total allowable barge displacement. Therefore, the turbine-generator barge also needs to employ steel structures that are then used as the forms for the addition of needed concrete after the barge has been floated into its final location and founded. The concrete placed at the shipyard is limited to that needed to provide support of major heavy equipment, such as the turbine-generator-condenser, the feedwater heaters; and to that needed for barge stiffness and stability during shipment.

This barge arrangement has been developed to promote the easy replacement and maintenance of all the major, large pieces of equipment using a single main overhead gantry crane located above the TB barge operating deck. For this reason the feed water heaters have been oriented vertically and placed in-line along side the turbine-generatorcondenser, and positioned so that they are accessed at the turbine generator operating deck. The moisture separator and reheater are also placed at the turbine generator operating deck. Figures 9 and 10 provide elevation end views of the barge. 
NUCLEAR ENERGY RESEARCH INITIATIVE (NERI) PROGRAM

GRANT NUMBER DE-FG07-00SF22168

FINAL REPORT

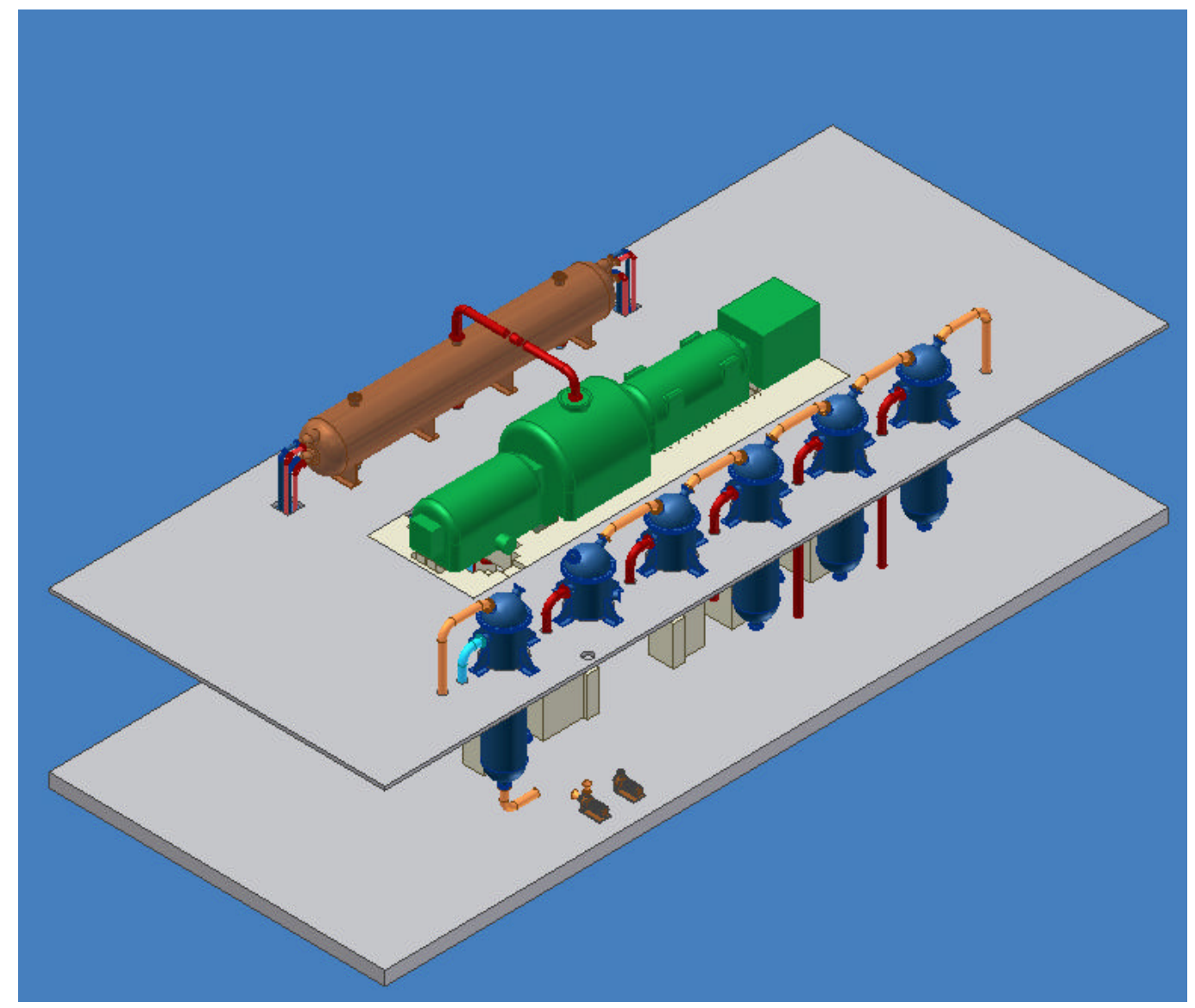

Figure 7 - IRIS Turbine Generator Barge, Isometric View

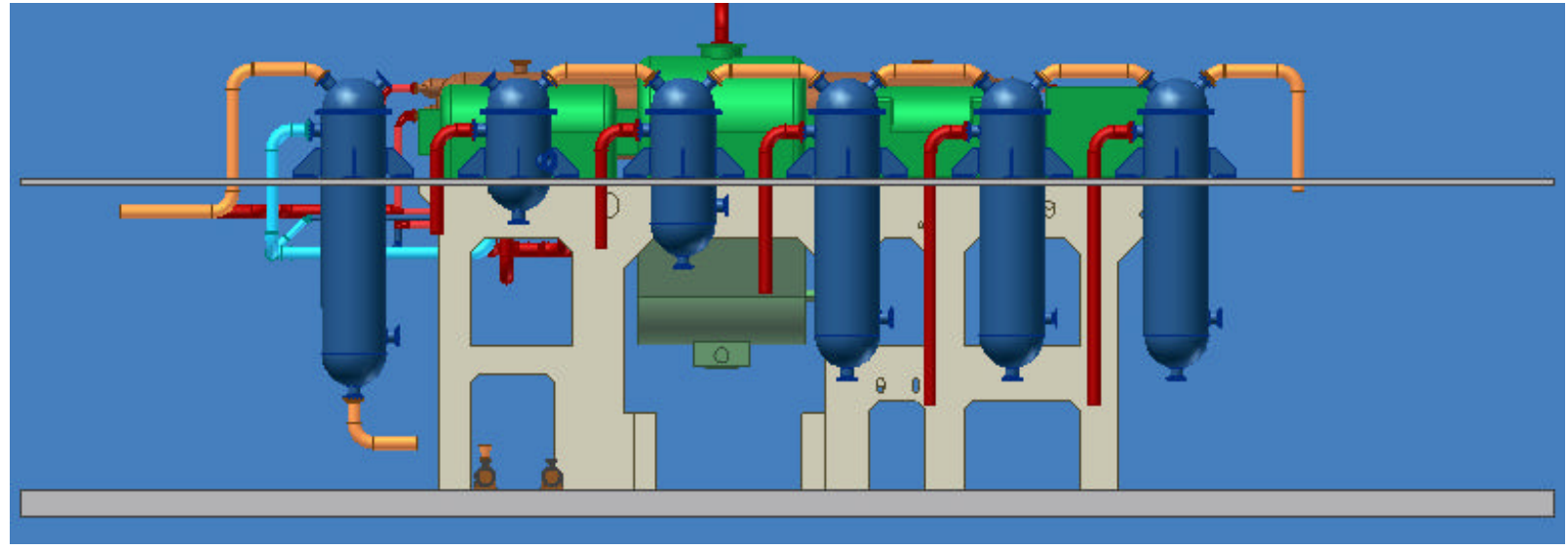

Figure 8 - IRIS Turbine Generator Barge. Elevation View 
NUCLEAR ENERGY RESEARCH INITIATIVE (NERI) PROGRAM

GRANT NUMBER DE-FG07-00SF22168

FINAL REPORT

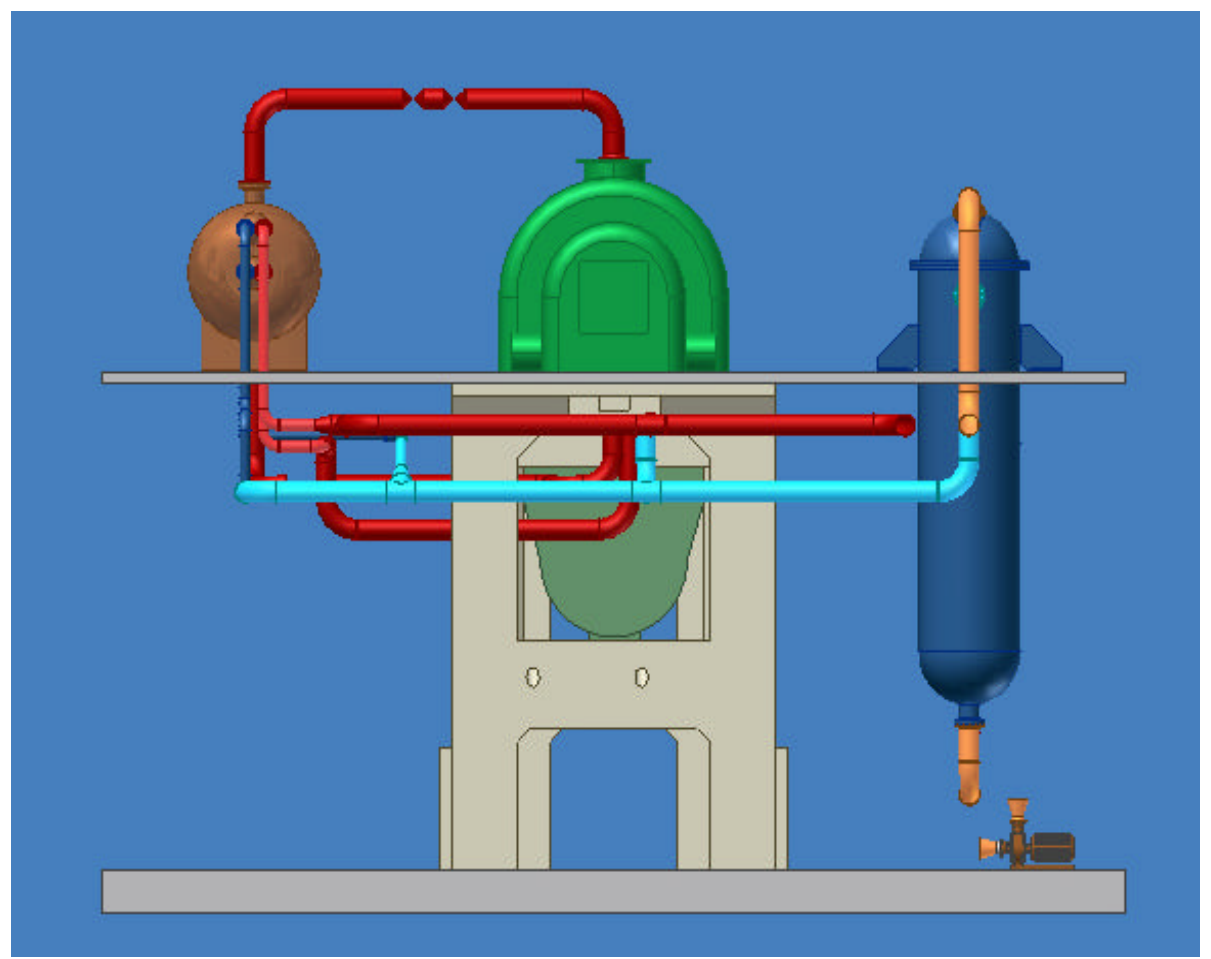

Figure 9 - IRIS Turbine Generator Barge, Elevation End View

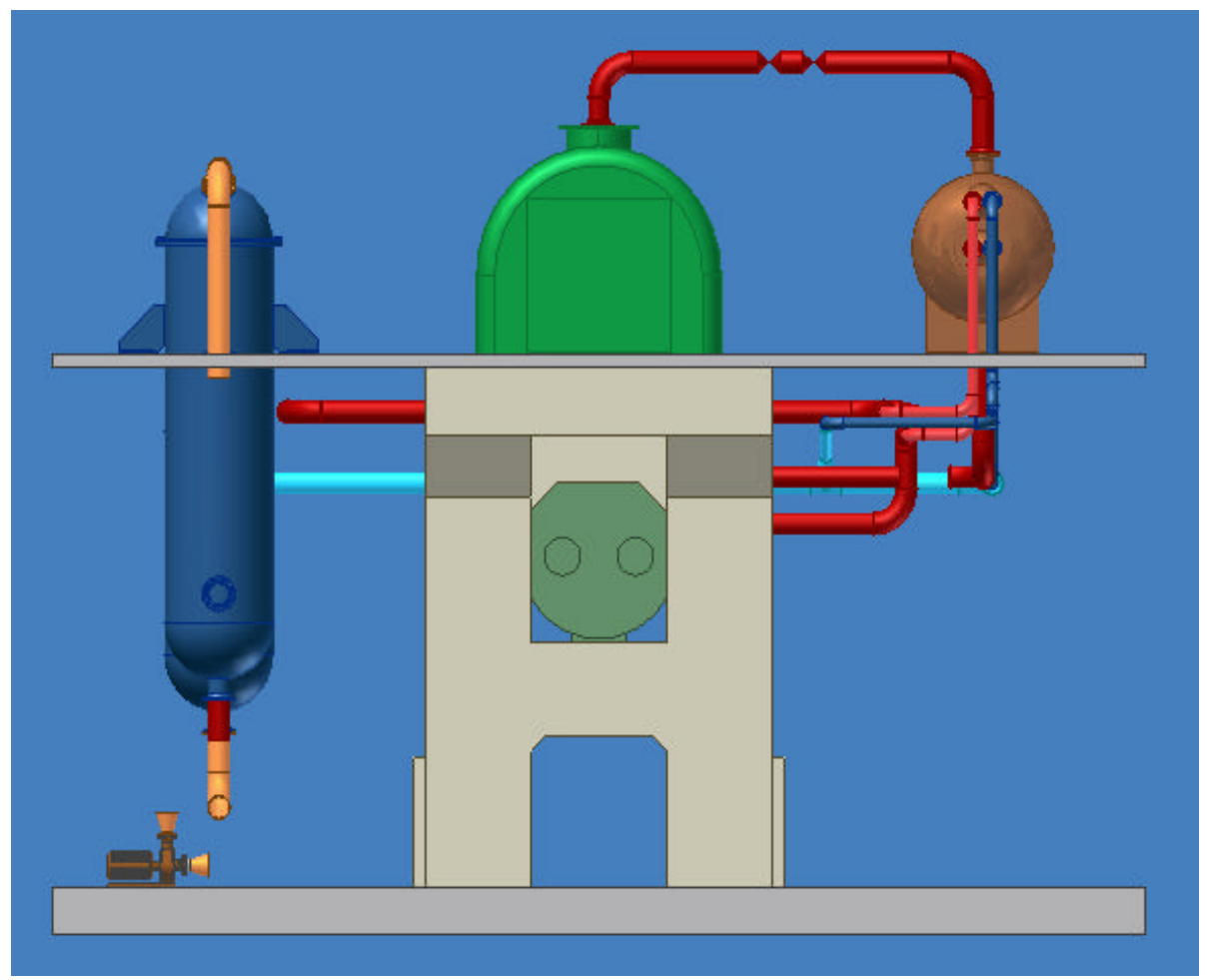

Figure 10 - IRIS Turbine Generator Barge, Elevation End View 


\section{NUCLEAR ENERGY RESEARCH INITIATIVE (NERI) PROGRAM \\ GRANT NUMBER DE-FG07-00SF22168 \\ FINAL REPORT}

\section{OBSERVATIONS AND CONCLUSIONS}

Below are provided the main observations and conclusions from this study:

1. The IRIS reactor can be adapted for barge mounted construction and transportation on major US rivers and waterways, since it employs an integral reactor coolant system and very compact containment design.

2. The IRIS turbine-generator-condenser and the associated steam and feedwater systems can also be barge mounted and are transportable.

3. The barge displacement limitations imposed by the shallow rivers ( 9 feet is minimum navigable river depth maintained in these river systems) severely limits the amount of structural concrete that can be included in a river navigable barge. Therefore, a large amount of concrete must be put in place after the barge has been founded at the final plant site.

4. The severe limitation in the amount of concrete that can be put in place at the shipyard requires that structural steel modules be utilized as permanent forms that can be filled with concrete at the final barge site. This type of construction is ideal for shipyard fabrication methods. 


\title{
NUCLEAR ENERGY RESEARCH INITIATIVE (NERI) PROGRAM \\ GRANT NUMBER DE-FG07-00SF22168 \\ FINAL REPORT
}

\section{Lead-Bismuth Cooled Reactor Concept and Layout}

\author{
Professor L. F. Miller \\ Mohammed Khan \\ Martin Williamson \\ Joe McConn
}

\section{INTRODUCTION}

A modest level of development effort for fast reactor technology has continued during the past fifty years. Several sodium-cooled reactors have operated very successfully in the United States, and more have operated in other countries. The Department of Energy (DOE) developed a remarkably good metallic fuel for fast reactors, and an advanced fuel reprocessing and fuel fabrication technology for fast reactors has been tested. Nevertheless, continued development of sodium cooled fast reactors was terminated, and the DOE is currently evaluating a number of reactor types for future use. Our effort includes consideration of lead-bismuth eutectic as the coolant.

The Former Soviet Union (FSU) chose to avoid some inherent problems with the chemical instability of sodium $(\mathrm{Na})$ and selected a lead-bismuth $(\mathrm{PbBi})$ eutectic as the coolant for some of their most advanced nuclear powered submarines, including the alpha class submarines ${ }^{16,48}$. The choice of $\mathrm{PbBi}$ relative to $\mathrm{Na}$ offers a number of advantages and disadvantages to consider. There is essentially no corrosion of steel with the use of $\mathrm{Na}$ as a coolant, and $\mathrm{Na}$ is a better heat transfer medium than $\mathrm{PbBi}$. Both lead and bismuth corrode most steels. However, recent experimental studies suggest that corrosion problems with $\mathrm{PbBi}$ can be effectively managed with proper chemistry, materials and operational controls, and lead-bismuth coolants have much higher boiling points than sodium, which results in some significant safety advantages. $\mathrm{PbBi}$ as a coolant also offers some nuclear fuel cycle advantages.

Sodium cooled fast reactors have been designed, built, and operated in pool-type and in loop-type configurations. In each case, these systems have used intermediate heat exchangers that utilize non-radioactive sodium to transfer heat from radioactive sodium to the working fluid for turbines. The pooltype designs place the intermediate heat exchangers in the vessel that houses the reactor core, whereas these heat exchangers are outside the vessel for loop-type designs. The intermediate heat exchangers are necessary to prevent radioactive sodium reactions with water in the case of steam generator tube failures; however, this intermediate heat exchanger may not be necessary for $\mathrm{PbBi}$ systems since neither lead nor bismuth react exothermically with water. Our first-round design does not use intermediate heat exchangers, but they may be preferred for overpressure protection in case of rupture of a primary to secondary pressure boundary and for radiological control issues. 


\section{NUCLEAR ENERGY RESEARCH INITIATIVE (NERI) PROGRAM \\ GRANT NUMBER DE-FG07-00SF22168 \\ FINAL REPORT}

Modular Generation IV reactors are expected to have a number of features that make them more attractive for commercial use than is the case for the current generation of power reactors. One important feature is that components and systems can be manufactured and shipped to the construction site with nominal special preparations for shipments. Other expected features include minimal production of radioactive waste, efficient utilization of resources, and proliferation resistance.

In order to accomplish the size limitation for reactor components, the proposed designs are constrained by a reactor vessel size that will be transportable on a standard rail car. This limits the height and width to about twelve feet, the length to about eighty feet, and the weight to about eighty tons. This should be adequate for producing 300 to $400 \mathrm{MW}$ electrical, depending on optimization of primary and secondary system performance, while satisfying all licensing requirements.

One advantage of $\mathrm{PbBi}$ as a coolant is that the reactor spectrum can be relatively hard, and this permits significant quantities of actinides to be used as fuel, which eliminates the need to dispose of them as waste. The nuclear characteristics of this design also permit operation for at least five years without refueling, or reshuffling, since the conversion ratio can be maintained very near unity. The time between refueling is limited by performance of fuel materials rather than by the ability to sustain the chain reaction. Another advantage of this design is that the nuclear energy option can be extended for thousands of years since it can use U-238 and Th-232 as fuel. Proliferation resistance is improved relative to the reactors in current commercial use since the $\mathrm{Pu} 239$ inventory can be held constant or be diminished, depending on fuel management choices.

Lead-bismuth cooled fast reactors offer significant opportunities for satisfying Generation IV objectives, and the design objectives cited herein represent a feasible system. More detailed design studies are needed, however, to assure that a candidate design is economically viable and that it satisfies licensing requirements.

\section{LITERATURE REVIEW}

Several papers ${ }^{1-5}$ address issues relative to basic reactor design of $\mathrm{Pb}$ and $\mathrm{PbBi}$ systems, while accelerator driven systems (ADS) that utilize $\mathrm{Pb}$ or $\mathrm{Pb} / \mathrm{Bi}$ are of particular interest for transmutation of radioactive waste ${ }^{6-7}$. The web site at kalla.fzk.de/kalla/projects/hgf.html describes activities on "Thermalhydraulic and Material Specific Investigations into the Realization of an Accelerator Driven System (ADS) to Transmute Minor Actinides." A web site at ippe.rssi.ru/generall/hlmc $98 . h t m l$ describes a conference held in Obninsk, Russia October 5-9, 1998 on "Heavy Liquid Metal Coolants in Nuclear Technologies" (HLMC'98). Information on these sites address issues such as the solubility of various metals in PbBi coolants, the chemistry of the coolant and surface phenomenon, the long term behavior of various materials, and the production of polonium from bismuth.

The use of $\mathrm{Pb}$, instead of $\mathrm{PbBi}$, eliminates radiological concerns for polonium production from bismuth, and it lessens corrosion problems. However, the use of $\mathrm{PbBi}$ as a coolant 


\section{NUCLEAR ENERGY RESEARCH INITIATIVE (NERI) PROGRAM \\ GRANT NUMBER DE-FG07-00SF22168 \\ FINAL REPORT}

has several important advantages relative to $\mathrm{Pb}$. One is that the $\mathrm{PbBi}$ eutectic has a much lower melting temperature than $\mathrm{Pb}$, and another is that the $\mathrm{PbBi}$ eutectic undergoes very little volumetric change when changing phase from solid to liquid. Neither $\mathrm{Pb}$ nor $\mathrm{PbBi}$ are chemically reactive, they have good thermal properties, and they are effective coolants for natural circulation.

Greenspan and others ${ }^{1-15}$ have performed preliminary thermal-hydraulic and neutronic studies for relatively low power (100 to $250 \mathrm{MWth}$ ) $\mathrm{PbBi}$ reactors and for accelerator systems that can use natural circulation or gas lift of the system coolant. Toshinsky ${ }^{16}$ of the Institute of Physics and Power Engineering, Obninsk, Russia, has transmitted a number of references ${ }^{17-33}$, and he has provided some comments on plant systems. The operational experience in Russia with $\mathrm{PbBi}$ systems, along with many additional studies in the United States, Korea, Japan and Europe, provide significant justification for the consideration of $\mathrm{PbBi}$ reactor systems for commercial production of electricity.

The following sodium-cooled reactor designs are reviewed and described in more detail in Appendix A:

1) Experimental Breeder Reactor II (EBR-II),

2) Integral Fast Reactor (IFR),

3) Clinch River Breeder Reactor (CRBR),

4) Fast Flux Test Facility (FFTF),

5) Power Reactor Inherently Safe Modular (PRISM),

6) SuperPRISM (S-PRISM), and

7) Sodium Advanced Fast Reactor (SAFR)

Experimental Breeder Reactor II (EBR-II) was a pool-type system, and it operated successfully for many years. Likewise the Pheonix and Super Pheonix systems built and operated in France were pooltype systems. The FFTF is a loop type system, and the CRBR design was a loop type system. The proposed PRISM, S-PRISM, IFR, and SAFR systems were pooltype designs. In all cases for sodium-cooled reactors, intermediate heat exchangers were included in the designs. In the case of loop-type they are external to the reactor vessel, and they are included in the vessel in the case of pool-type designs. Additional information on steam generation equipment, reactor vessels, various other components, and operational data is available, but it is not included in this report for convenience of publication.

The DOE liquid metal reactor (LMR) design study initiated in the mid 80s resulted in four designs: the Large-Scale Prototype Breeder (LSPB), General Electric's Power Reactor- Inherently Safe Module (PRISM), Rockwell's Sodium Advanced Fast Reactor (SAFR), and the Westinghouse's 1985 Low Cost Plant (LCP). Various alternative designs were explored. The $20 \mathrm{MW}_{\mathrm{e}}$ Experimental Breeder Reactor II, built in 1964, and the $400 \mathrm{MW}_{\mathrm{t}}$ Fast Flux Test Facility, built in 1980, have provided significant design and operations experience, and they provide a basis for cost estimates. 


\section{NUCLEAR ENERGY RESEARCH INITIATIVE (NERI) PROGRAM \\ GRANT NUMBER DE-FG07-00SF22168 \\ FINAL REPORT}

General Electric subsequently developed the S-PRISM design which had design objectives very similar to the DOE Generation IV program. The earlier 1980's PRISM design has undergone several modifications ${ }^{40-41}$, and the later PRISM designs are referred to as SuperPRISM. The SuperPRISM modular LMR plant is composed of one or more power blocks, each of which couple to a $1000 \mathrm{MW}_{\mathrm{t}}$ nuclear steam supply system (NSSS) which can operate independently, but they feed steam into a single superheat turbine generator system rated at $825 \mathrm{MW}_{\mathrm{e}}$ (net). The core inlet temperature is $700^{\circ} \mathrm{F}(370 \mathrm{C})$, and the core outlet temperature is $950^{\circ} \mathrm{F}(510 \mathrm{C})$. Each reactor module is rated at 380 $\mathrm{MW}_{\mathrm{e}}$, and the overall plant efficiency is estimated at $38 \%$ with an availability factor of $93 \%$.

The S-PRISM reactor vessel is made of $5 \mathrm{~cm}$ thick $316 \mathrm{SS}$. The reactor closure is $45 \mathrm{~cm}$ thick $304 \mathrm{SS}$, and the reactor module is approximately 20 meters tall and 10 meters in diameter. The intermediate heat transport system (IHTS) is a closed loop system that transports the reactor generated heat to the steam generator system (SGS) by circulating non-radioactive sodium between the IHX and the SG. The hot leg sodium at $485^{\circ} \mathrm{C}$ is transported in separate $72 \mathrm{~cm}$ OD $316 \mathrm{SS}$ pipes from the two IHXs to a single $1000 \mathrm{MWt}$ SG. Two high temperature EM pumps located in the cold legs return sodium to the IHX at $325^{\circ} \mathrm{C}$. The SGS is composed of the steam generator, startup circulation tank/pump, leak detection subsystem, and steam generator valves. The SG is vertically oriented with a helical coil, and it uses a sodium-to-water counter flow shell-and-tube exchanger which generates superheated steam at 165 atm and $462^{\circ} \mathrm{C}$. The feedwater temperature is $215^{\circ} \mathrm{C}$, and the sodium inlet temperature is $485^{\circ} \mathrm{C}$. The $\mathrm{SG}$ for the SuperPRISM is made of Mod 9 Cr-1 Mo steel.

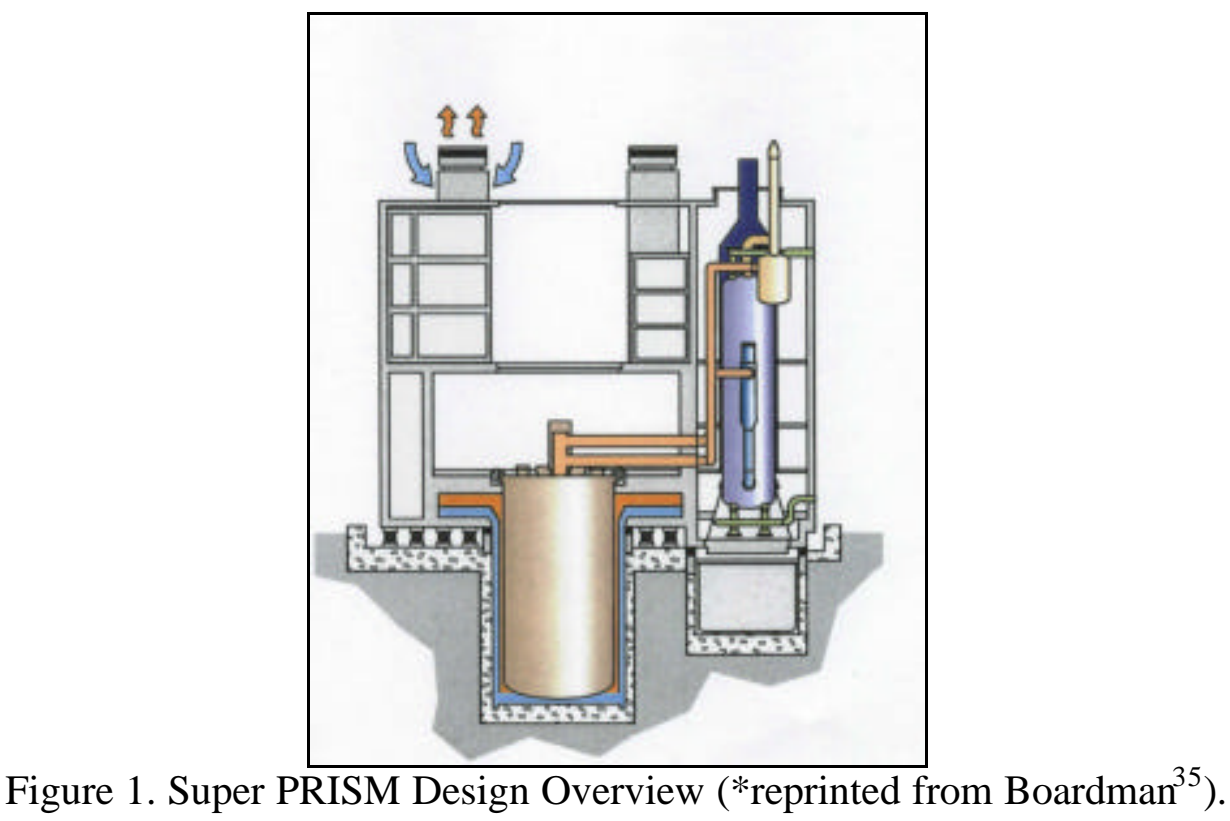




\section{DISCUSSION OF CANDIDATE SYSTEM CONFIGURATIONS}

When sodium is used for a primary coolant, most would agree that intermediate heat exchangers are necessary to minimize contamination problems in the case of a radioactive sodium-water reaction. In addition, the use of an intermediate heat exchanger simplifies overpressure protection for the core in case of a secondary to primary system leak. The situation with lead-bismuth coolant is not so clear, and the option of not using an intermediate heat exchanger appears to be plausible if overpressure protection requirements are satisfied. Thus, intermediate heat exchangers are probably needed to satisfy safety constraints established for design basis accidents. This position may be supported by operational experience of Russian PbBi submarine reactors, which apparently do not use intermediate heat exchangers ${ }^{16}$. Some general configurations considered are as follows:

1) a loop-type system with no intermediate heat exchangers where primary $\mathrm{PbBi}$ coolant is used to supply heat to steam generation equipment,

2) a block-type system with intermediate heat exchangers attached to the reactor vessel, and

3) a pool-type system with intermediate heat exchangers internal to the reactor vessel.

In the cases with intermediate heat exchangers, one could use $\mathrm{PbBi}$ or some other working fluid for the intermediate loop, such as sodium, various liquid metals, salt, or oil. Advantages for the use of sodium are that it is non-corrosive and that secondary steam generation equipment is already designed and tested. The main disadvantage is that sodium is highly reactive with water and air.

Two of the above configurations are evaluated in some detail. The first considered is a loop-type system with no intermediate heat exchanger, and the second is a block-type system with intermediate exchangers attached to the primary vessel, which is our reference design. Methods for performing neutronics calculations, and some results, are reported in Appendix B, and a description of the loop-type system, along with a discussion of design parameters, is given in Appendix C.

\section{DESCRIPTION OF THE REFERENCE SYSTEM}

Our reference design builds on much of the research and development for sodium cooled fast breeder reactors. For example, the metallic fuel developed and tested for the Experimental Breeder Reactor II (EBR-II) has some significant neutronic and heat transfer advantages relative to oxide fuel. The internal breeding ratio is higher for the more dense metal fuel than oxide fuel, and therefore metal fuel more easily maintains a conversion ratio of unity, which is an objective for the proposed design. In addition, the fuel refabrication technology developed by Argonne National Laboratory (ANL) for metallic fuel will result in much less radioactive waste than the PUREX process used for oxide fuel. The metal fuel also has better heat thermal conductivity and will therefore perform better during possible transients. However, oxide fuel generally has a larger 


\section{NUCLEAR ENERGY RESEARCH INITIATIVE (NERI) PROGRAM \\ GRANT NUMBER DE-FG07-00SF22168 \\ FINAL REPORT}

Doppler coefficient of reactivity than metallic fuel due to softening of the spectrum by the oxides.

For the case of $\mathrm{PbBi}$ cooled fast reactors, various physics, engineering, and economic factors may favor a loop type system with no intermediate heat exchanger; however, safety and radiological considerations probably favor the use of intermediate heat exchangers. Currently available commercial steels limit the maximum temperature for $\mathrm{PbBi}$ to about $500 \mathrm{C}$, because of nominal corrosion resistance; however, a value of $550 \mathrm{C}$ is a reasonable value for current design purposes, assuming nominal timely progress in materials research. This $(550 \mathrm{C})$ is low for state-of-the-art supercritical secondary systems used in fossil fuel plants, but it is very suitable for superheated steam secondary systems. An overall thermal efficiency of about forty percent can be obtained with a core inlet temperature of $350 \mathrm{C}$ and an outlet temperature of $550 \mathrm{C}$, but inlet and outlet temperatures of $300 \mathrm{C}$ and $500 \mathrm{C}$ are chosen since currently available materials appear to be capable of long term service at these temperatures.

An important safety feature of any nuclear reactor is a negative reactivity voiding coefficient in all locations of the core. This is not the case for many previously designed and operated sodium-cooled fast reactors, but safety concerns are less significant if all reactivity coefficients are negative, rather than positive. Many cylindrical and slab core designs were studied in an effort to identify a reactor core with and overall reactivity voiding coefficient.

Although the slab core design reduces the magnitude of the positive reactivity voiding coefficient relative to a cylindrical design, we were unable to obtain a negative voiding coefficient for a core fueled only with plutonium as the fissile fuel. For this reason, various design configurations based on combinations of thorium, uranium, and plutonium fuel types with slab core geometry were studied. One promising combination of fuels in slab geometry utilizes some uranium-thorium and some plutonium-uranium fuel assemblies that are laid out in an alternating pattern. The plutonium-uranium fuel is of the metallic type in which the content of $\mathrm{Pu}, \mathrm{U}$, and $\mathrm{Zr}$ are $9 \%, 81 \%$ and $10 \%$. The weight percentages of ${ }^{239} \mathrm{Pu},{ }^{240} \mathrm{Pu},{ }^{241} \mathrm{Pu}$, and ${ }^{242} \mathrm{Pu}$ in the $\mathrm{Pu}$ are $67.25 \%, 21.7 \%, 6.4 \%$, and $4.7 \%$ respectively. The uranium-thorium fuel is of the metallic type in which the content of $\mathrm{U}$, Th and $\mathrm{Zr}$ are $70 \%, 20 \%$ and $10 \%$. The weight percentages of ${ }^{235} \mathrm{U}$ and ${ }^{238} \mathrm{U}$ in the $\mathrm{U}$ are $25 \%$ and $75 \%$. The thorium is pure ${ }^{232} \mathrm{Th}$. Figure 2 shows the geometric configuration of the core, where each of the material regions is $20 \mathrm{~cm}$ thick. 


\section{NUCLEAR ENERGY RESEARCH INITIATIVE (NERI) PROGRAM \\ GRANT NUMBER DE-FG07-00SF22168 \\ FINAL REPORT}

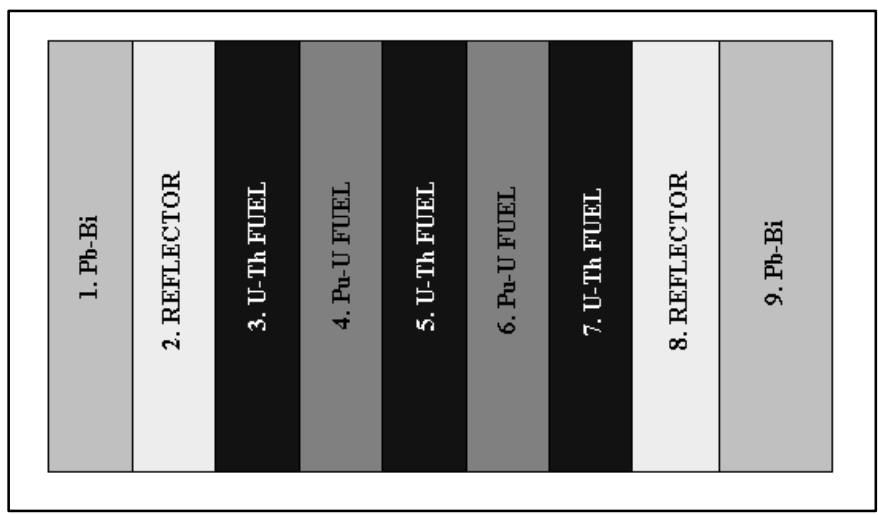

Figure 2. Slab Core Configuration with Alternative Fuel Types

Results from two-dimensional calculations obtain 1.01529 for the reference case and 1.0015 with the core one-half voided of coolant. Thus, the voiding coefficient for voiding half the core is -0.00136 , which demonstrates that a slab core design with alternative fuel types obtains a negative voiding coefficient.

Additional one-dimensional calculations were run to evaluate the effects of voiding in each row of fuel elements. Results for effective multiplication factors are listed in Table 1 and the associated reactivity coefficients are listed in Table 2. Note that the voiding coefficients are negative except for the center row of fuel assemblies.

Table $1 . \mathrm{k}_{\mathrm{eff}}$ for various configurations

\begin{tabular}{|l|l|}
\hline Base configuration & 1.00576 \\
\hline Only cooled with lead & 1.00920 \\
\hline $10 \%$ LBE voided throughout core & 1.00029 \\
\hline $10 \%$ of center row LBE voided & 1.00601 \\
\hline $10 \%$ of $\mathrm{Pu}$ U rows LBE voided & 1.00462 \\
\hline $10 \%$ of outer rows LBE voided & 1.00129 \\
\hline $50 \%$ LBE voided throughout core & 0.971056 \\
\hline
\end{tabular}

Table 2. Voiding coefficients (pcm / \%voids)

\begin{tabular}{|l|l|}
\hline $10 \%$ LBE voided throughout core & -0.05439 \\
\hline $10 \%$ of center row LBE voided & 0.000260 \\
\hline $10 \%$ of $\mathrm{Pu}$ U rows LBE voided & -0.001184 \\
\hline $10 \%$ of outer rows LBE voided & -0.004644 \\
\hline $50 \%$ LBE voided throughout core & -0.069011 \\
\hline
\end{tabular}




\section{NUCLEAR ENERGY RESEARCH INITIATIVE (NERI) PROGRAM \\ GRANT NUMBER DE-FG07-00SF22168 \\ FINAL REPORT}

In order $b$ make sure that the core is critical for an acceptable length of time, the calculations were performed in two steps. First, the number densities of the major nuclides in the reactor were found for $1 / 2$ year increments up to 30 years. This was accomplished by utilizing the SAS2 sequence of the SCALE 4.4a package. Input to SAS2 is first treated for resolved and unresolved resonances in BONAMI and NITAWL. The cross section data output from these two routines is then input into ORIGEN-S, which is a used to calculate the number densities of the nuclides in the reactor over the fuel's loading lifetime. The cross section data and number densities that are output from ORIGEN-S were used for input into a 3-D core model using KENO V.a, which calculates the effective multiplication factor of the system ( $\left.\mathrm{k}_{\text {effective }}\right)$. The number densities shown in Figure 3 are used to calculate the system $k_{\text {effective }}$ during a ten-year interval, as illustrated in Figure 4. It is concluded that core designs with a lead bismuth coolant can be designed to maintain criticality without refueling for a period up to 10 years. Metallurgical properties, which may be limiting, are not considered. Based on calculations for the cylindrical design, the fluence to cladding should probably be less than $4 \times 10^{23} \mathrm{n} / \mathrm{cm}^{2}$ and the fluence to the reactor vessel should be limited to less than $10^{19} \mathrm{n} / \mathrm{cm}^{2}$. Additional effort is needed to determine if the power distribution satisfies design objectives (relatively flat with a peak to average below a value of about 2) during a 10 year period. More details of neutronics calculations are described in Appendix B.

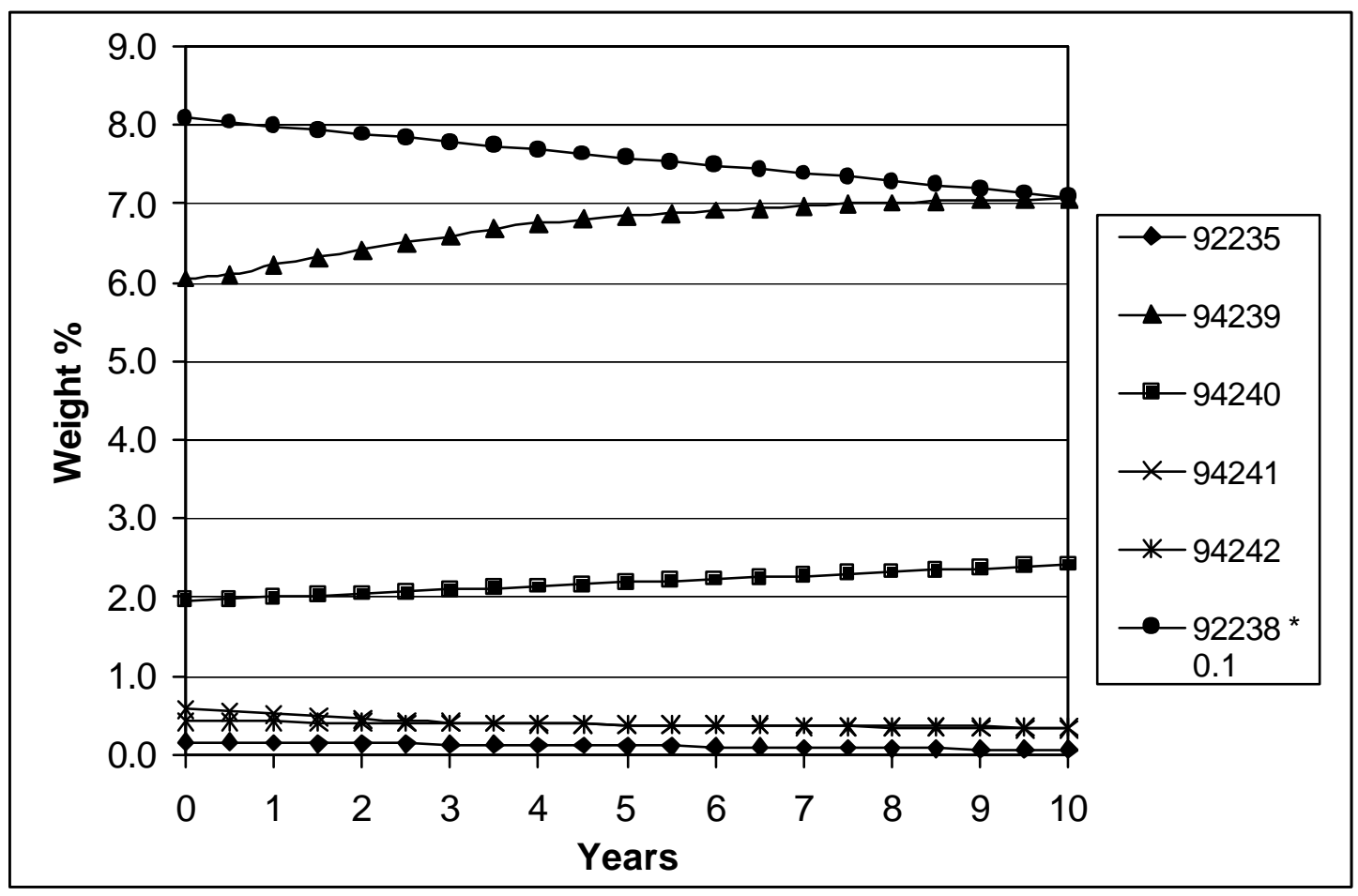

Figure 3. Fuel isotopes vs. time 


\section{NUCLEAR ENERGY RESEARCH INITIATIVE (NERI) PROGRAM \\ GRANT NUMBER DE-FG07-00SF22168 \\ FINAL REPORT}

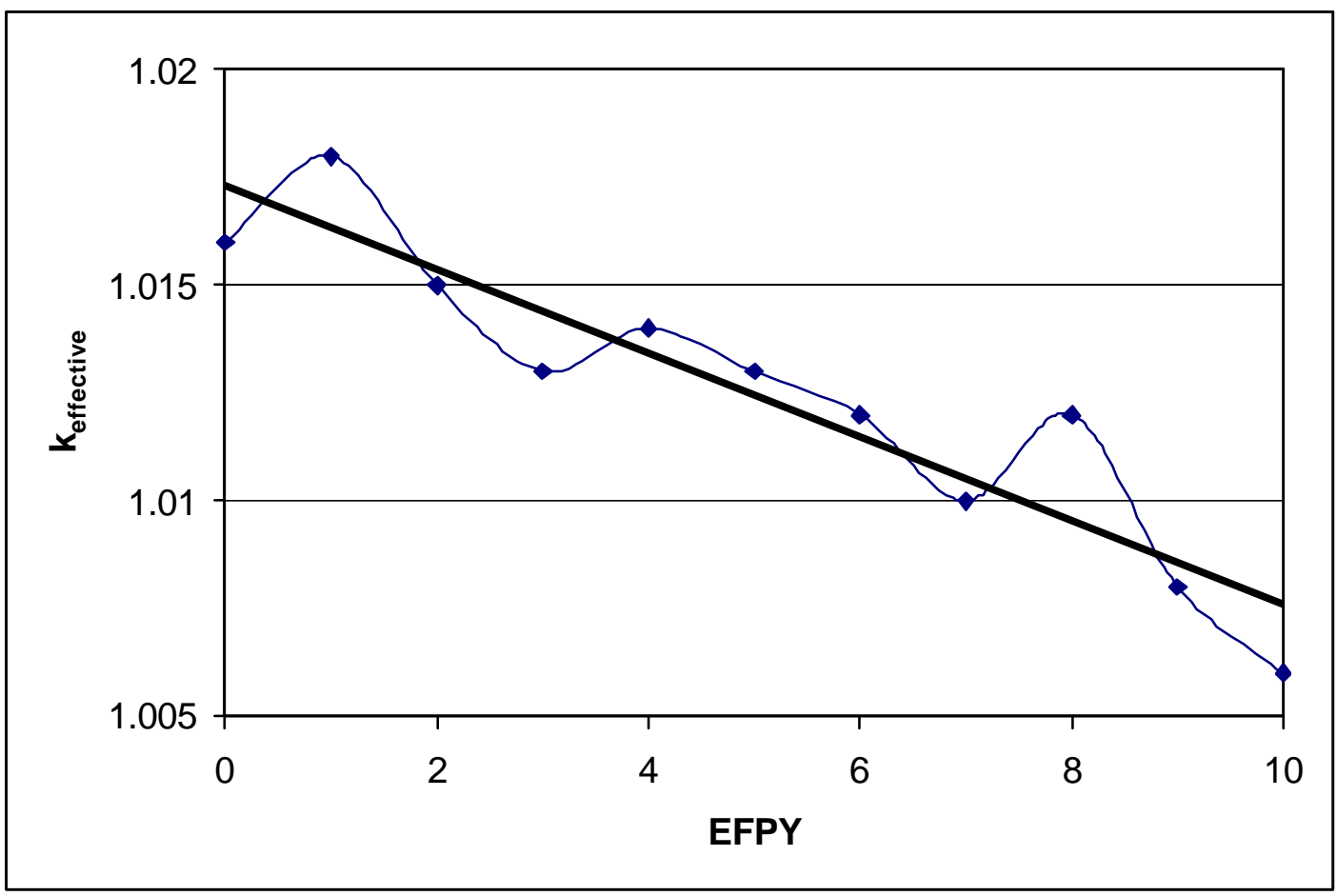

Figure 4 . $\mathrm{k}_{\text {effective }}$ vs. effective full power years

Design parameters for the reference system and for three variations from the reference design (Cases 1-3, shown below) are listed in Tables 47, and an overall solid model illustration of the primary and secondary system layout is given in Figure 5.

Table 3. Case Comparison

\begin{tabular}{|l|c|c|c|c|}
\hline Case & $\begin{array}{c}\text { Primary } \\
\text { Coolant }\end{array}$ & $\begin{array}{c}\text { Intermediate Hx } \\
\text { Coolant }\end{array}$ & $\begin{array}{c}\text { Reactor Inlet } \\
\text { Temperature }(\mathrm{C})\end{array}$ & $\begin{array}{c}\text { Reactor outlet } \\
\text { Temperature }(\mathrm{C})\end{array}$ \\
\hline Reference & $\mathrm{PbBi}$ & $\mathrm{PbBi}$ & 300 & 500 \\
\hline 1 & $\mathrm{~Pb}$ & $\mathrm{Na}$ & 400 & 550 \\
\hline 2 & $\mathrm{PbBi}$ & $\mathrm{Na}$ & 350 & 550 \\
\hline 3 & $\mathrm{PbBi}$ & $\mathrm{Na}$ & 300 & 500 \\
\hline
\end{tabular}

Case 1 considers the use of $\mathrm{Na}$ as an intermediate heat transfer fluid and $\mathrm{Pb}$ as a primary system coolant. Since $\mathrm{Pb}$ has a melting point of $327 \mathrm{C}$ (boiling point of $1620 \mathrm{C}$ ), it is necessary to increase the reactor inlet temperature to assure that it does not freeze during normal and transient conditions. Thus, the inlet temperature is increased to $400 \mathrm{C}$ and the reactor outlet temperature is increased to $550 \mathrm{C}$. The higher outlet temperature is slightly greater than is acceptable for current materials technology, but it is expected that this will be achievable in the near future. You may note from Table 4, that the size of the intermediate heat exchanger (IHX) is considerably smaller than the IHX for the reference case, which is due primarily to a larger temperature difference across the IHX. Case 2 uses $\mathrm{Na}$ as the intermediate heat transfer fluid with in increase of the $\mathrm{PbBi}$ primary coolant by $50 \mathrm{C}$. For this case, the size of the IHX is modestly increased relative to Case 


\section{NUCLEAR ENERGY RESEARCH INITIATIVE (NERI) PROGRAM \\ GRANT NUMBER DE-FG07-00SF22168 \\ FINAL REPORT}

1. Case 3 only substitutes $\mathrm{Na}$ for the IHX coolant. Note that the size of the IHX is decreased by about $25 \%$ relative to the reference system due to $\mathrm{Na}$ having a significantly larger heat transfer coefficient than $\mathrm{PbBi}$. The intermediate heat exchangers for cases 1 and 2 are much smaller because of the larger temperature difference across the IHX.

Figures 6-11 illustrate temperature profiles for the primary system, intermediate heat exchangers and the steam generators. The secondary system layout proposed for the $\mathrm{PbBi}$ study, as shown in Figure 12, is the one developed for the IRIS design. Component sizes are based on steam conditions produced by the PRISM steam generators, which are listed in Table 9. 


\section{NUCLEAR ENERGY RESEARCH INITIATIVE (NERI) PROGRAM \\ GRANT NUMBER DE-FG07-00SF22168 \\ FINAL REPORT}

Table 4. Reference Design: $\mathrm{PbBi}$ as both the primary coolant and the intermediate heat transfer fluid.

Parameters for Reactor Core (Base Case)

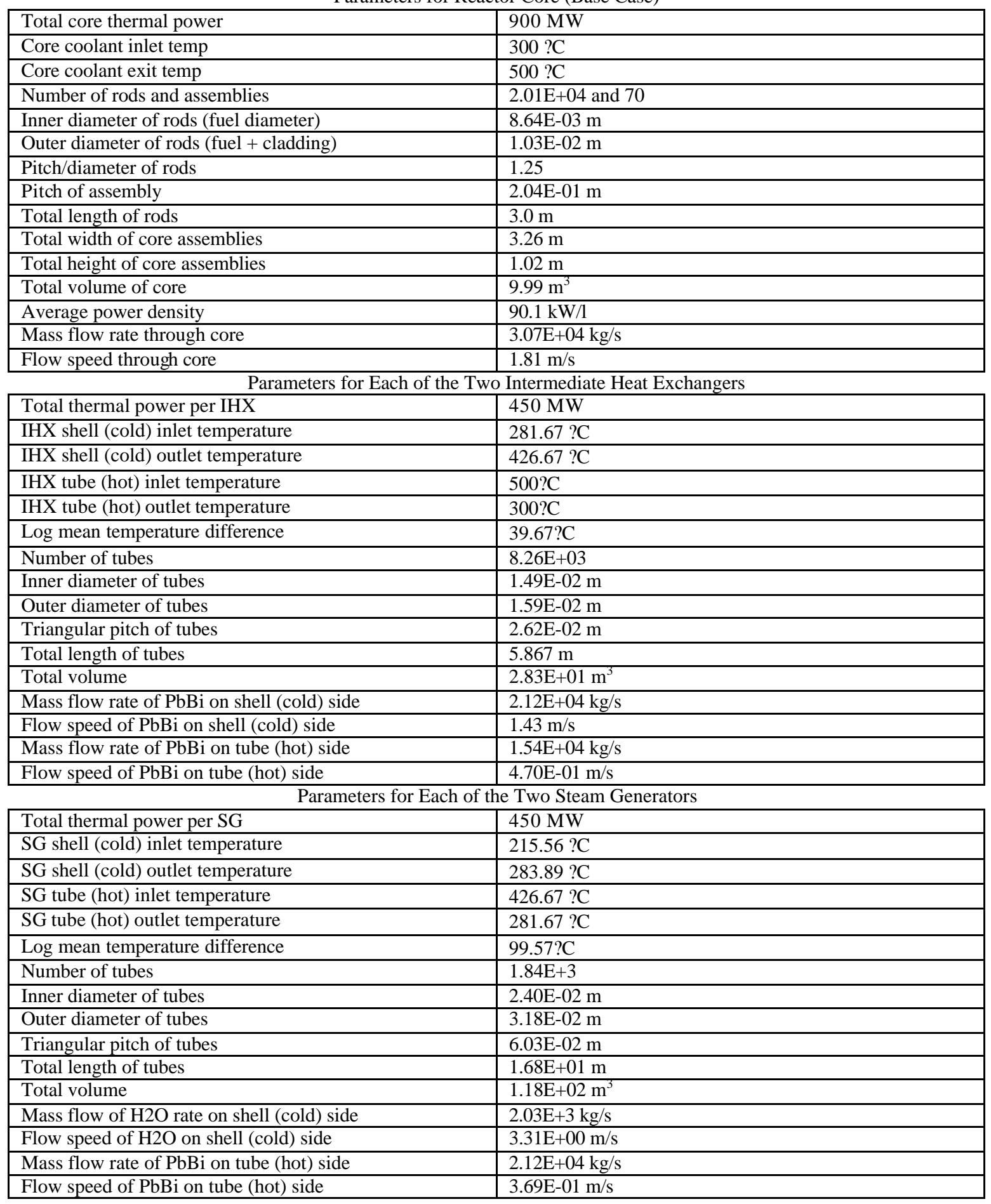




\section{NUCLEAR ENERGY RESEARCH INITIATIVE (NERI) PROGRAM \\ GRANT NUMBER DE-FG07-00SF22168 \\ FINAL REPORT}

\section{Table 5. $\mathrm{Pb}$ as primary coolant, $\mathrm{Na}$ as intermediate heat transfer fluid, core outlet temperature of $550 \mathrm{C}$.}

Parameters for Reactor Core (Case 1)

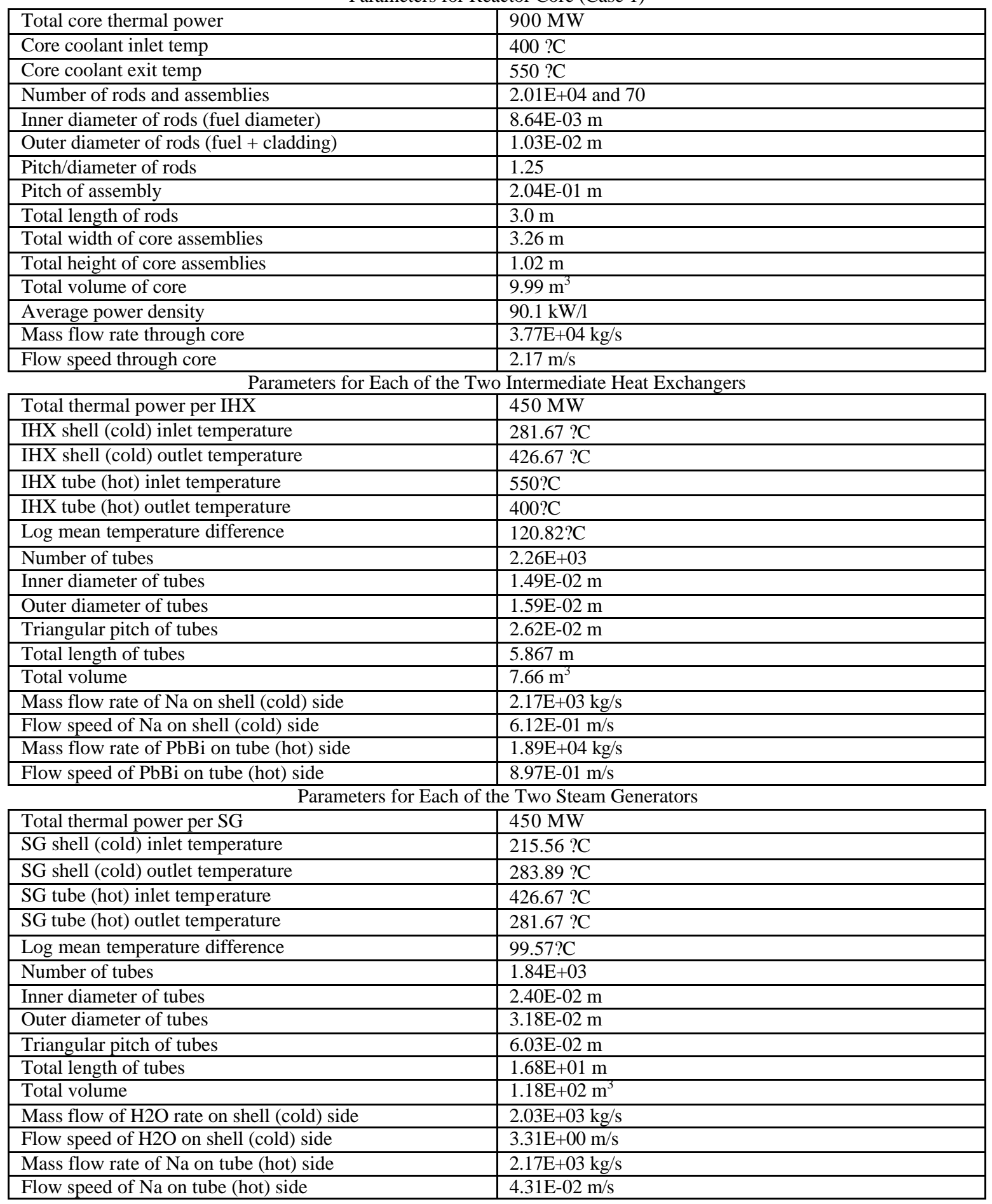




\section{NUCLEAR ENERGY RESEARCH INITIATIVE (NERI) PROGRAM \\ GRANT NUMBER DE-FG07-00SF22168 \\ FINAL REPORT}

\section{Table 6. PbBi as primary coolant, $\mathrm{Na}$ as intermediate heat transfer fluid, core outlet temperature of $550 \mathrm{C}$.}

Parameters for Reactor Core (Case 2)

\begin{tabular}{|c|c|}
\hline Total core thermal power & $900 \mathrm{MW}$ \\
\hline Core coolant inlet temp & $350 ? \mathrm{C}$ \\
\hline Core coolant exit temp & $550 ? \mathrm{C}$ \\
\hline Number of rods and assemblies & $2.01 \mathrm{E}+04$ and 70 \\
\hline Inner diameter of rods (fuel diameter) & $8.64 \mathrm{E}-03 \mathrm{~m}$ \\
\hline Outer diameter of rods (fuel + cladding) & $1.03 \mathrm{E}-02 \mathrm{~m}$ \\
\hline Pitch/diameter of rods & 1.25 \\
\hline Pitch of assembly & $2.04 \mathrm{E}-01 \mathrm{~m}$ \\
\hline Total length of rods & $3.0 \mathrm{~m}$ \\
\hline Total width of core assemblies & $3.26 \mathrm{~m}$ \\
\hline Total height of core assemblies & $1.02 \mathrm{~m}$ \\
\hline Total volume of core & $9.99 \mathrm{~m}^{3}$ \\
\hline Average power density & $90.1 \mathrm{~kW} / 1$ \\
\hline Mass flow rate through core & $2.83 \mathrm{E}+04 \mathrm{~kg} / \mathrm{s}$ \\
\hline Average flow speed through core & $1.68 \mathrm{~m} / \mathrm{s}$ \\
\hline \multicolumn{2}{|c|}{ Parameters for Each of the Two Intermediate Heat Exchangers } \\
\hline Total thermal power per IHX & $450 \mathrm{MW}$ \\
\hline IHX shell (cold) inlet temperature & $281.67 ? \mathrm{C}$ \\
\hline IHX shell (cold) outlet temperature & $426.67 ? \mathrm{C}$ \\
\hline IHX tube (hot) inlet temperature & $550 ? \mathrm{C}$ \\
\hline IHX tube (hot) outlet temperature & $350 ? \mathrm{C}$ \\
\hline Log mean temperature difference & 93.14?C \\
\hline Number of tubes & $2.67 \mathrm{E}+03$ \\
\hline Inner diameter of tubes & $1.49 \mathrm{E}-02 \mathrm{~m}$ \\
\hline Outer diameter of tubes & $1.59 \mathrm{E}-02 \mathrm{~m}$ \\
\hline Triangular pitch of tubes & $2.62 \mathrm{E}-02 \mathrm{~m}$ \\
\hline Total length of tubes & $5.867 \mathrm{~m}$ \\
\hline Total volume & $9.19 \mathrm{~m}^{3}$ \\
\hline Mass flow rate of $\mathrm{Na}$ on shell (cold) side & $2.17 \mathrm{E}+03 \mathrm{~kg} / \mathrm{s}$ \\
\hline Flow speed of $\mathrm{Na}$ on shell (cold) side & $5.19 \mathrm{E}-01 \mathrm{~m} / \mathrm{s}$ \\
\hline Mass flow rate of $\mathrm{PbBi}$ on tube (hot) side & $1.42 \mathrm{E}+04 \mathrm{~kg} / \mathrm{s}$ \\
\hline Flow speed of PbBi on tube (hot) side & $6.95 \mathrm{E}-01 \mathrm{~m} / \mathrm{s}$ \\
\hline \multicolumn{2}{|c|}{ Parameters for Each of the Two Steam Generators } \\
\hline Total thermal power per SG & $450 \mathrm{MW}$ \\
\hline SG shell (cold) inlet temperature & $215.56 ? \mathrm{C}$ \\
\hline SG shell (cold) outlet temperature & $283.89 ? \mathrm{C}$ \\
\hline SG tube (hot) inlet temperature & $426.67 ? \mathrm{C}$ \\
\hline SG tube (hot) outlet temperature & $281.67 ? \mathrm{C}$ \\
\hline Log mean temperature difference & $99.57 ? \mathrm{C}$ \\
\hline Number of tubes & $1.84 \mathrm{E}+03$ \\
\hline Inner diameter of tubes & $2.40 \mathrm{E}-02 \mathrm{~m}$ \\
\hline Outer diameter of tubes & $3.18 \mathrm{E}-02 \mathrm{~m}$ \\
\hline Triangular pitch of tubes & $6.03 \mathrm{E}-02 \mathrm{~m}$ \\
\hline Total length of tubes & $1.68 \mathrm{E}+01 \mathrm{~m}$ \\
\hline Total volume & $1.18 \mathrm{E}+02 \mathrm{~m}^{3}$ \\
\hline Mass flow of $\mathrm{H} 2 \mathrm{O}$ rate on shell (cold) side & $2.03 \mathrm{E}+03 \mathrm{~kg} / \mathrm{s}$ \\
\hline Flow speed of $\mathrm{H} 2 \mathrm{O}$ on shell (cold) side & $3.31 \mathrm{E}+00 \mathrm{~m} / \mathrm{s}$ \\
\hline Mass flow rate of $\mathrm{Na}$ on tube (hot) side & $2.17 \mathrm{E}+03 \mathrm{~kg} / \mathrm{s}$ \\
\hline Flow speed of $\mathrm{Na}$ on tube (hot) side & $4.31 \mathrm{E}-02 \mathrm{~m} / \mathrm{s}$ \\
\hline
\end{tabular}




\section{NUCLEAR ENERGY RESEARCH INITIATIVE (NERI) PROGRAM \\ GRANT NUMBER DE-FG07-00SF22168 \\ FINAL REPORT}
Table 7. $\mathrm{PbBi}$ as primary coolant, $\mathrm{Na}$ as intermediate heat transfer fluid, core outlet temperature of $500 \mathrm{C}$.
Parameters for Reactor Core (Case 3)

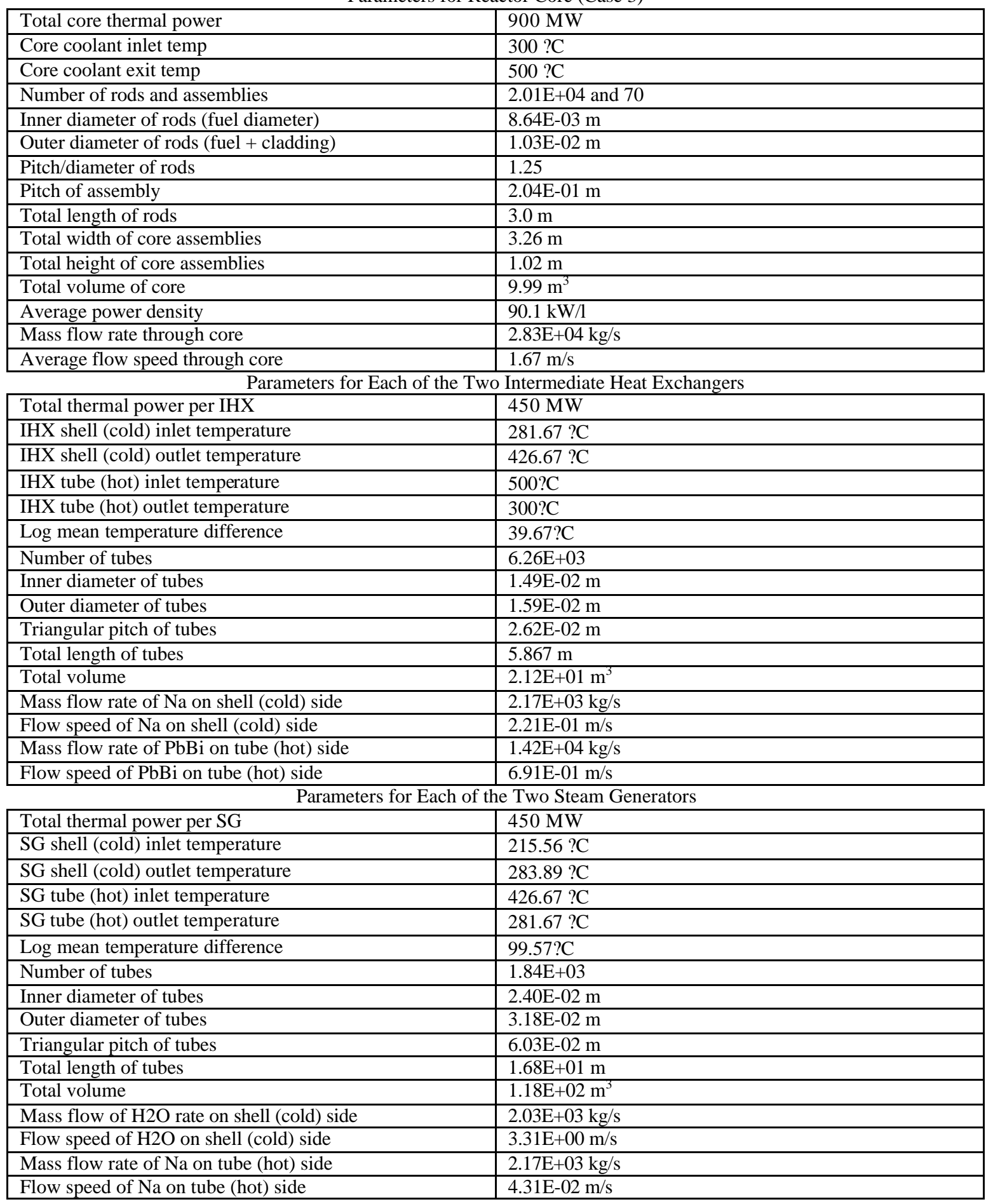


NUCLEAR ENERGY RESEARCH INITIATIVE (NERI) PROGRAM

GRANT NUMBER DE-FG07-00SF22168

FINAL REPORT

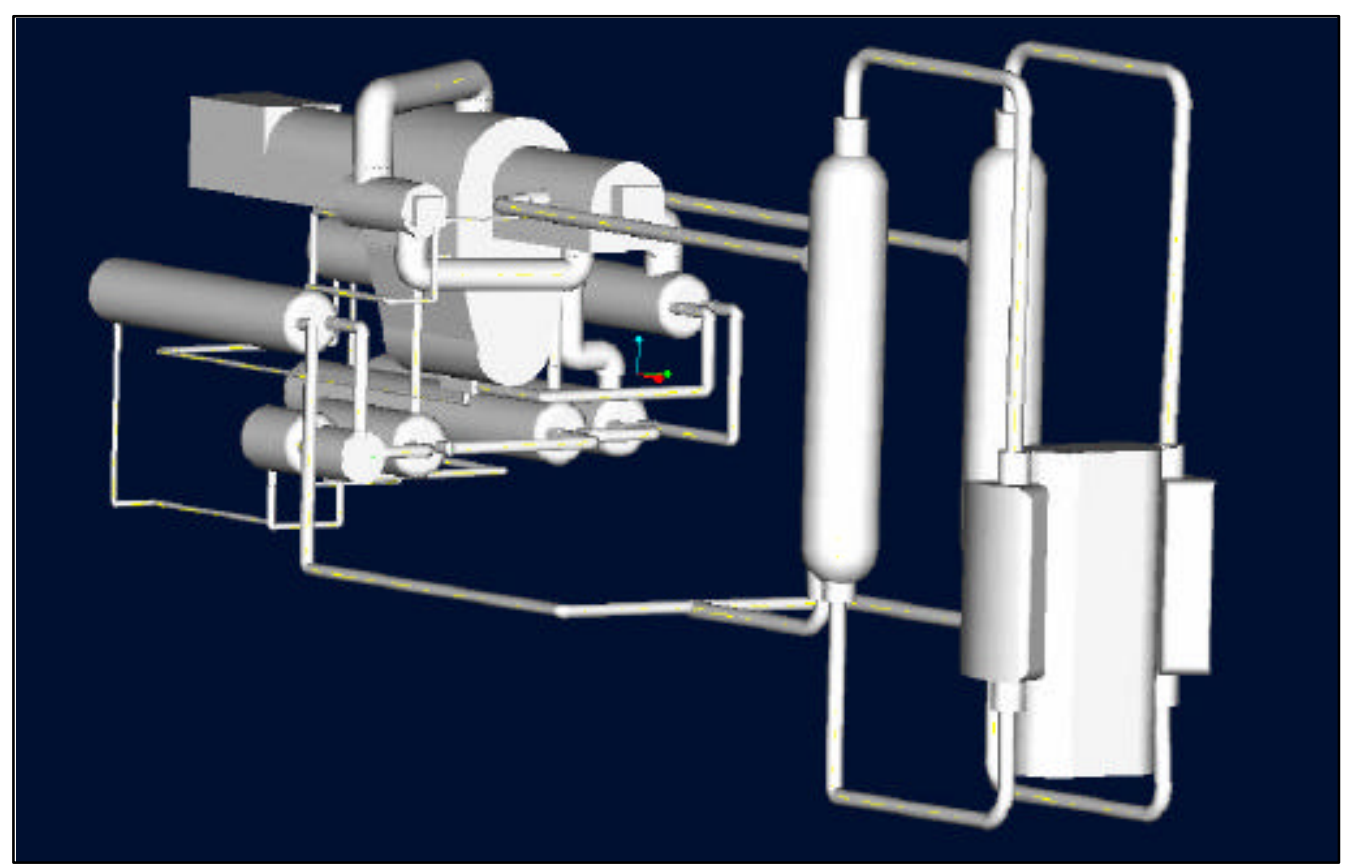

Figure 5. Solid model of the primary and secondary systems.

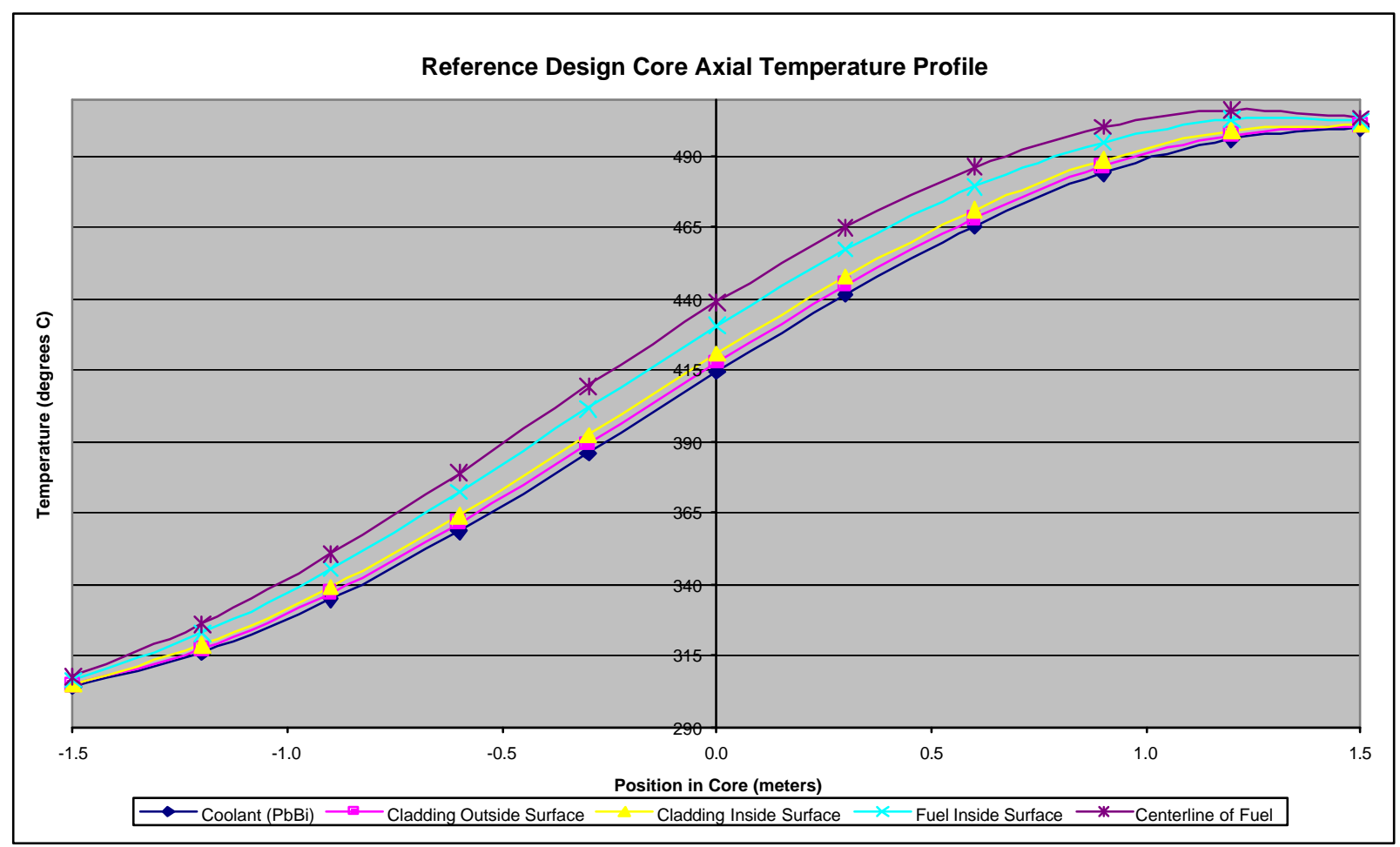

Figure 6. Axial Temperature Profiles for the Core of the Reference Design 


\section{NUCLEAR ENERGY RESEARCH INITIATIVE (NERI) PROGRAM GRANT NUMBER DE-FG07-00SF22168 \\ FINAL REPORT}

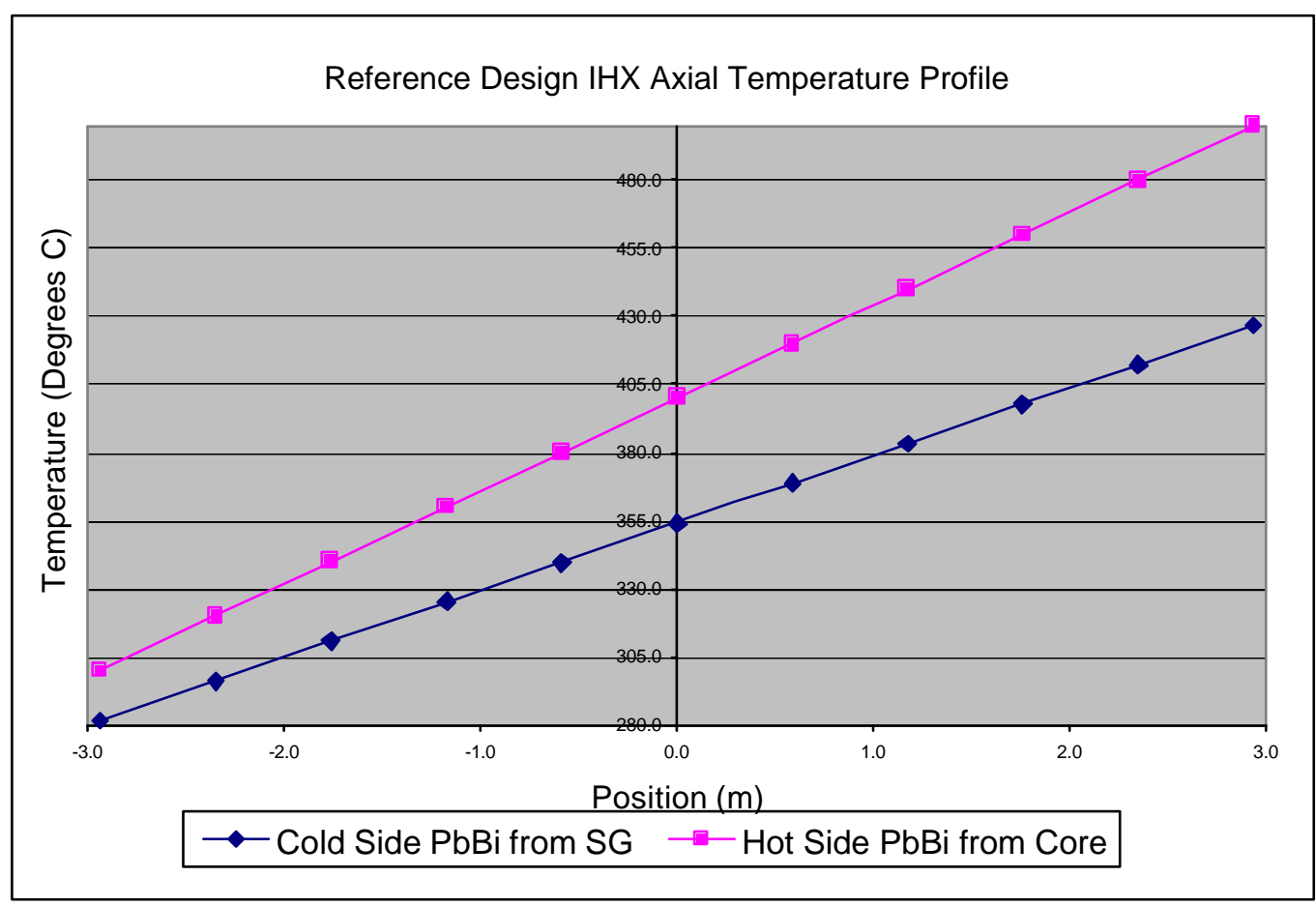

Figure 7. Reference case temperature profiles in the intermediate heat exchanger

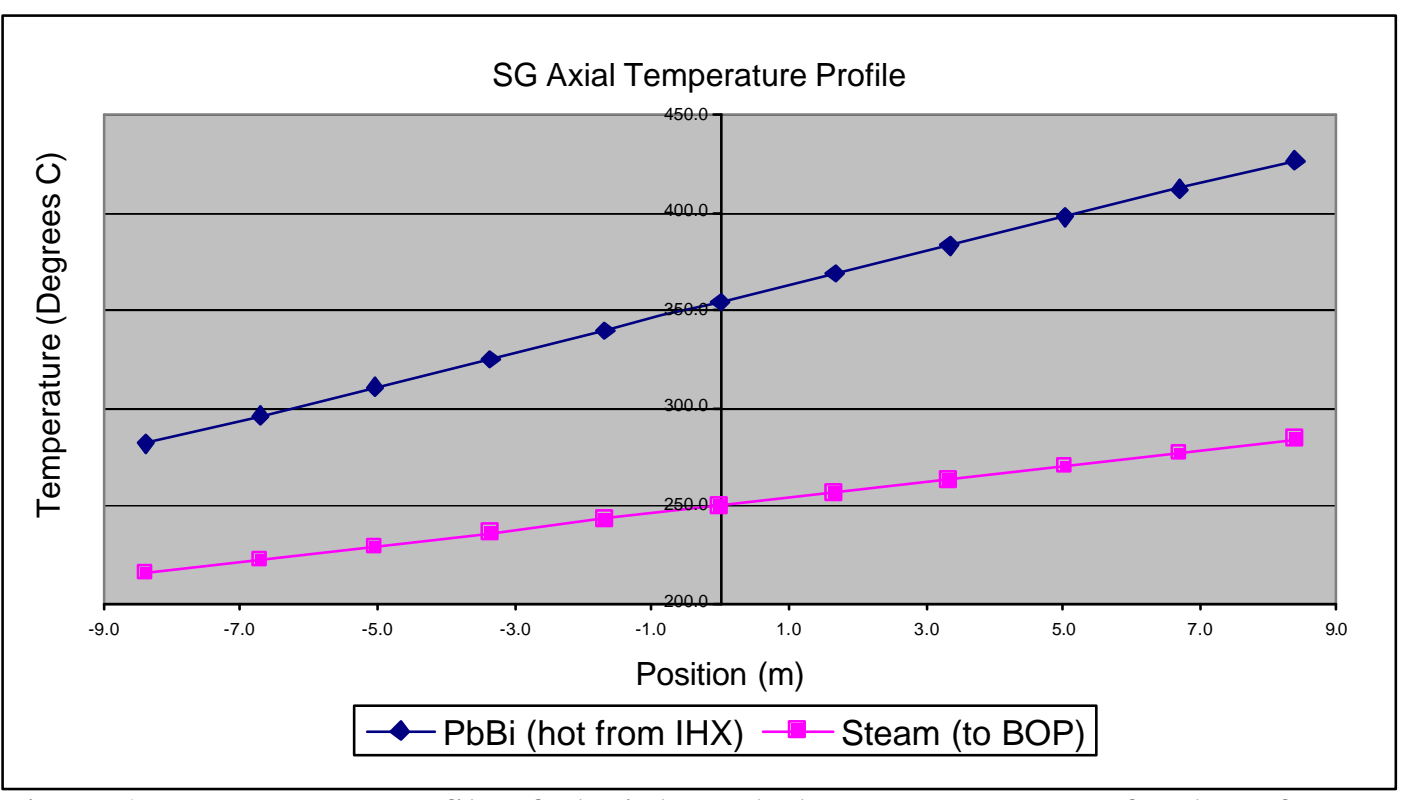

Figure 8. Temperature profile of $\mathrm{PbBi}$ through the steam generator for the reference design 


\section{NUCLEAR ENERGY RESEARCH INITIATIVE (NERI) PROGRAM GRANT NUMBER DE-FG07-00SF22168 \\ FINAL REPORT}

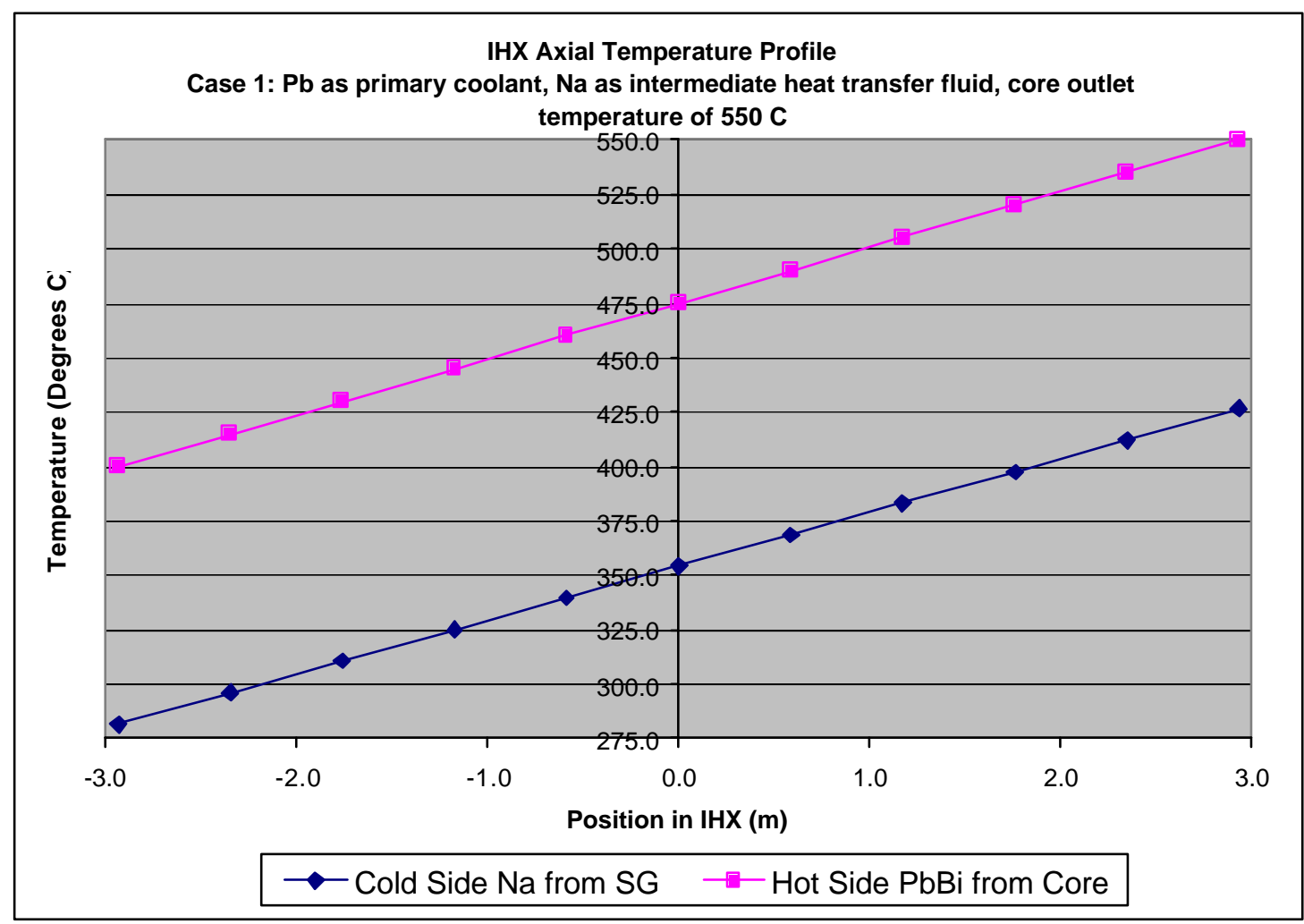

Figure 9. Case 1 temperature profiles in the intermediate heat exchanger

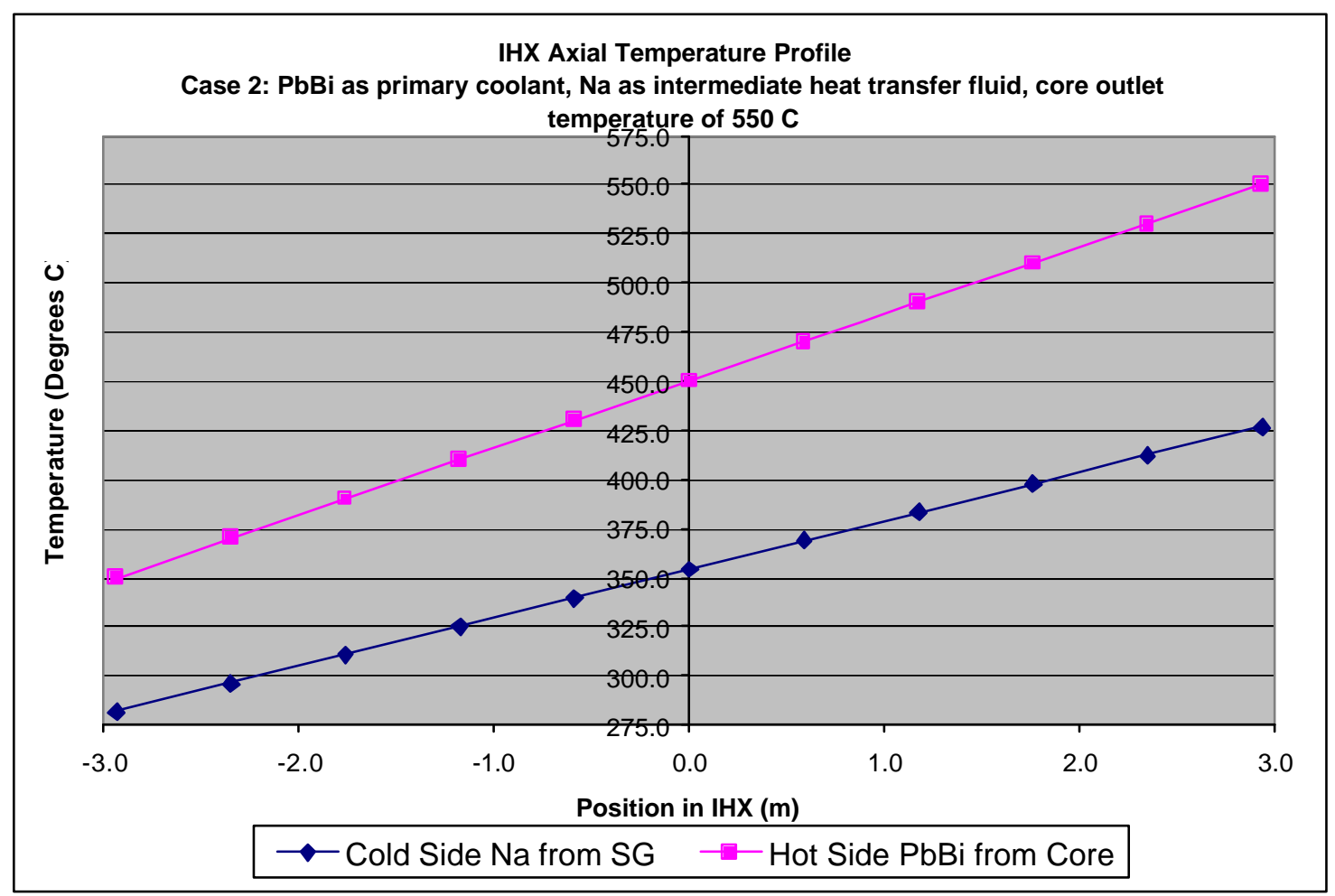

Figure 10. Case 2 temperature profiles in the intermediate heat exchanger 


\section{NUCLEAR ENERGY RESEARCH INITIATIVE (NERI) PROGRAM \\ GRANT NUMBER DE-FG07-00SF22168 \\ FINAL REPORT}

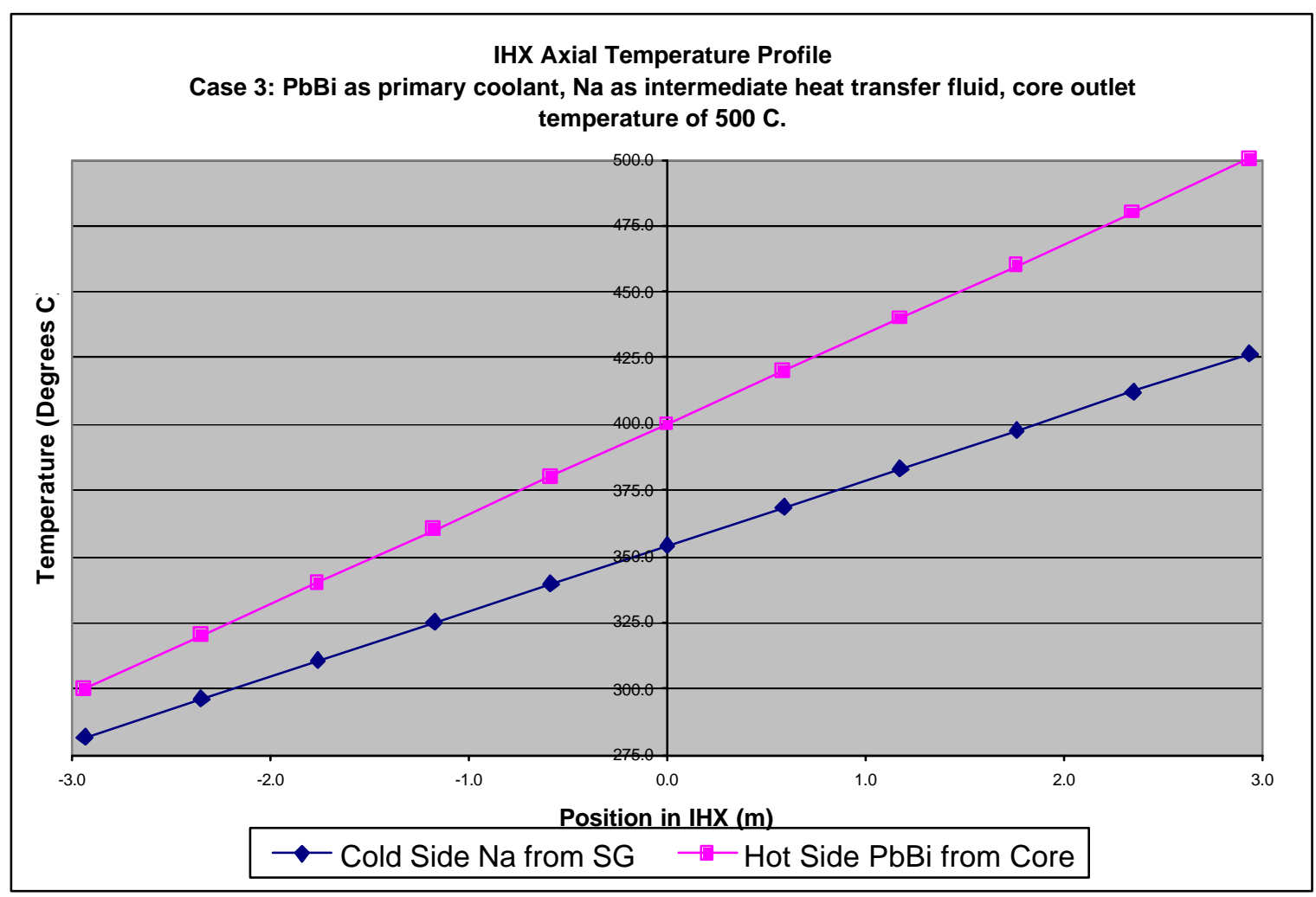

Figure 11. Case 3 temperature profiles in the intermediate heat exchanger 


\section{NUCLEAR ENERGY RESEARCH INITIATIVE (NERI) PROGRAM GRANT NUMBER DE-FG07-00SF22168 \\ FINAL REPORT}

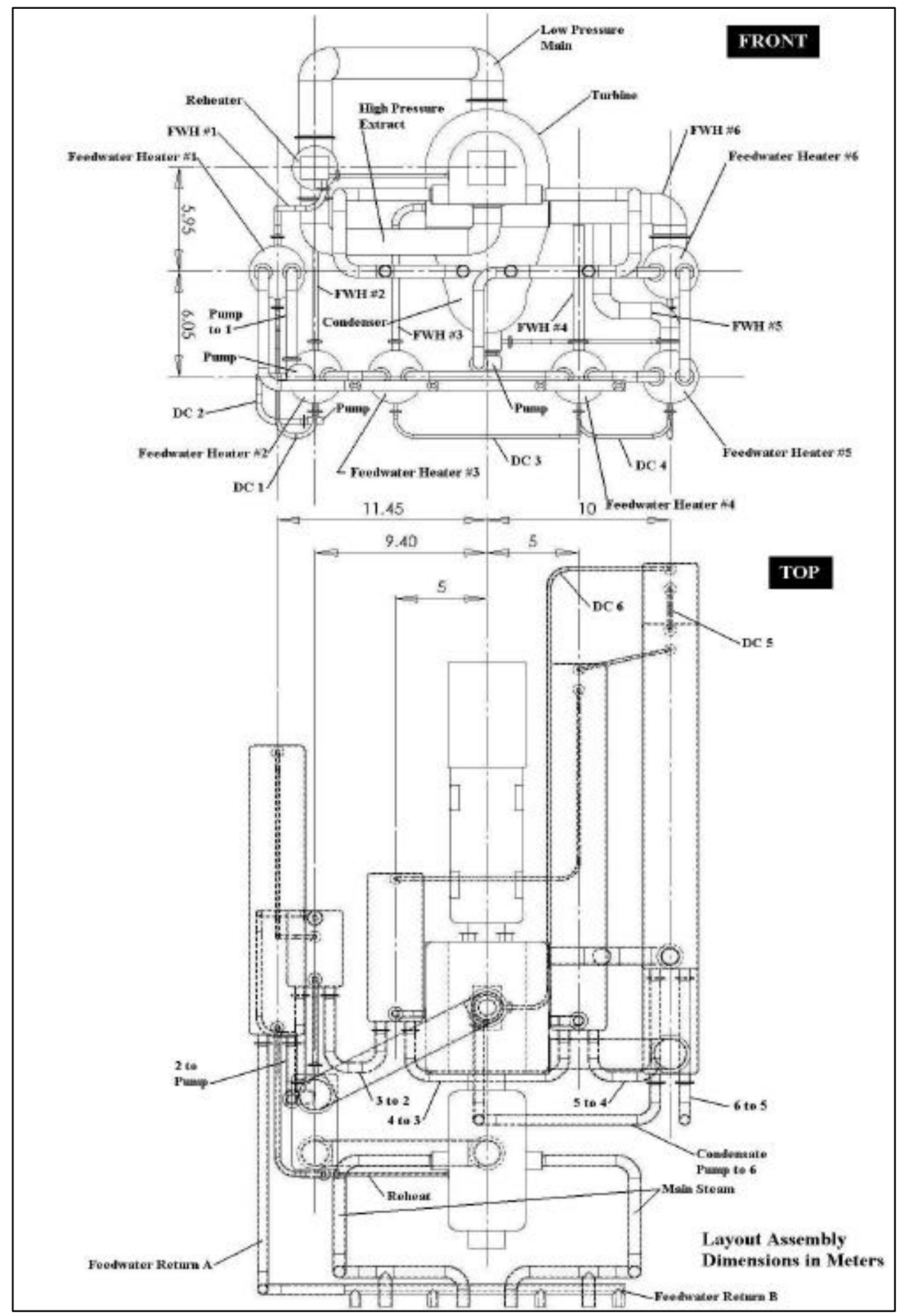

Figure 12. Layout assembly developed for the IRIS secondary system and adapted for the $\mathrm{PbBi}$ system. 


\section{NUCLEAR ENERGY RESEARCH INITIATIVE (NERI) PROGRAM \\ GRANT NUMBER DE-FG07-00SF22168 \\ FINAL REPORT}

Documentation on the PRISM secondary system reported in NUREG-1368 does not include size and layout information; thus, the system layout developed for the IRIS project is used for the PbBi reactor design, which is shown in Figure 10. Near saturated steam is supplied from the two steam generators to the high pressure turbine section. The steam exhausted from the high pressure turbine is directed to the two turbine low pressure sections via moisture separators and single-stage reheaters. Steam from low pressure sections is exhausted to a condenser. Condensate from the condenser is manifolded and pumped by three condensate pumps to a series of heat exchangers. Then, the condensate flows through four low pressure feedwater heaters. After passing through two high pressure feedwater heaters, the feedwater is discharged to the two steam generators.

Calculations for the secondary system defined by Table 8 , are based on steam conditions specified for PRISM and are accomplished using the Orcent2, a digital computer program that performs turbine cycle performance calculations. For these given input parameters, Orcent 2 outputs the net turbine cycle efficiency to be at $34.6 \%$. Parameters describing each of the individual components are listed in Table 9.

Table 8. Steam Turbine Cycle Data

\begin{tabular}{|l|l|}
\hline Steam Temperature From Steam Generator & 543 ?F \\
\hline Steam Pressure From Steam Generator & $956 \mathrm{psia}$ \\
\hline Steam Flow Rate From Steam Generator & $1.23 \mathrm{E}+6 \mathrm{lbm} / \mathrm{hr}$ \\
\hline Steam Moisture Percent by Weight from Steam Generator & $0.41 \%$ \\
\hline Feedwater Pump Isentropic Efficiency & $87.8 \%$ \\
\hline Feedwater Temperature & 420 ?F \\
\hline Feedwater Pump Turbine Efficiency & $77.0 \%$ \\
\hline Generator Power Factor & 0.90 \\
\hline Rotational Speed of the Turbine-Generator & $1800 \mathrm{rpm}$ \\
\hline Generator Output & $310.0 \mathrm{MWe}$ \\
\hline Condenser Pressure & $2.5 \mathrm{in}$. of Hg absolute \\
\hline \multicolumn{2}{|c|}{ Mechanical Losses in Turbine Cycle } \\
\hline Mechanical Losses & $1.41 \mathrm{MW}$ \\
\hline Generator Losses & $4.04 \mathrm{MW}$ \\
\hline
\end{tabular}




\section{NUCLEAR ENERGY RESEARCH INITIATIVE (NERI) PROGRAM \\ GRANT NUMBER DE-FG07-00SF22168 \\ FINAL REPORT}

Table 9. Balance of Plant Parameters

\begin{tabular}{|c|c|c|c|c|c|c|c|c|c|}
\hline & FW\#1 & FW\#2 & FW\#3 & FW\#4 & FW\#5 & FW\#6 & RH\#1 & RH\#2 & Condenser \\
\hline $\mathbf{T}_{\mathrm{HI}}\left({ }^{\circ} \mathbf{C}\right)$ & $2.15 \mathrm{E}+02$ & $1.83 \mathrm{E}+02$ & $1.61 \mathrm{E}+02$ & $1.44 \mathrm{E}+02$ & $1.06 \mathrm{E}+02$ & $7.47 \mathrm{E}+01$ & $2.84 \mathrm{E}+02$ & $2.84 \mathrm{E}+02$ & $4.46 \mathrm{E}+01$ \\
\hline $\mathrm{T}_{\mathrm{HO}}\left({ }^{\circ} \mathrm{C}\right)$ & $1.88 \mathrm{E}+02$ & $1.83 \mathrm{E}+02$ & $1.47 \mathrm{E}+02$ & $1.09 \mathrm{E}+02$ & $7.75 \mathrm{E}+01$ & $5.06 \mathrm{E}+01$ & $2.17 \mathrm{E}+02$ & $2.83 \mathrm{E}+02$ & $4.46 \mathrm{E}+01$ \\
\hline $\mathrm{T}_{\mathrm{CI}}\left({ }^{\circ} \mathrm{C}\right)$ & $1.82 \mathrm{E}+02$ & $1.58 \mathrm{E}+02$ & $1.41 \mathrm{E}+02$ & $1.04 \mathrm{E}+02$ & $7.19 \mathrm{E}+01$ & $4.51 \mathrm{E}+01$ & $1.85 \mathrm{E}+02$ & $2.03 \mathrm{E}+02$ & $3.22 \mathrm{E}+01$ \\
\hline $\mathrm{T}_{\mathrm{CO}}\left({ }^{\circ} \mathrm{C}\right)$ & $2.12 \mathrm{E}+02$ & $1.80 \mathrm{E}+02$ & $1.58 \mathrm{E}+02$ & $1.41 \mathrm{E}+02$ & $1.04 \mathrm{E}+02$ & $7.19 \mathrm{E}+01$ & $2.03 \mathrm{E}+02$ & $2.69 \mathrm{E}+02$ & $3.78 \mathrm{E}+01$ \\
\hline$m_{\text {hot }}(\mathrm{kg} / \mathrm{s})$ & $6.75 \mathrm{E}+01$ & $1.35 \mathrm{E}+02$ & $1.07 \mathrm{E}+01$ & $3.26 \mathrm{E}+01$ & $5.09 \mathrm{E}+01$ & $7.20 \mathrm{E}+01$ & $9.03 \mathrm{E}+00$ & $3.37 \mathrm{E}+01$ & $3.31 \mathrm{E}+02$ \\
\hline $\mathbf{m}_{\text {cold }}(\mathrm{kg} / \mathrm{s})$ & $4.66 \mathrm{E}+02$ & $3.31 \mathrm{E}+02$ & $3.31 \mathrm{E}+02$ & $3.31 \mathrm{E}+02$ & $3.31 \mathrm{E}+02$ & $3.31 \mathrm{E}+02$ & $3.30 \mathrm{E}+02$ & $3.30 \mathrm{E}+02$ & $2.81 \mathrm{E}+04$ \\
\hline$v_{\text {hot }}(\mathbf{m} / \mathbf{s})$ & $2.01 \mathrm{E}+00$ & $7.67 \mathrm{E}+00$ & $1.00 \mathrm{E}+00$ & $4.65 \mathrm{E}+00$ & $2.15 \mathrm{E}+01$ & $9.40 \mathrm{E}+01$ & $1.40 \mathrm{E}+00$ & $3.01 \mathrm{E}+00$ & $1.39 \mathrm{E}+02$ \\
\hline $\mathrm{v}_{\text {cold }}(\mathrm{m} / \mathrm{s})$ & $1.69 \mathrm{E}-01$ & $\begin{array}{l}1.16 \mathrm{E}-01 \\
\end{array}$ & $1.14 \mathrm{E}-01$ & $1.11 \mathrm{E}-01$ & $1.08 \mathrm{E}-01$ & $1.06 \mathrm{E}-01$ & $5.32 \mathrm{E}+01$ & $3.04 \mathrm{E}+01$ & $2.13 \mathrm{E}+00$ \\
\hline q (Watts) & $6.13 \mathrm{E}+07$ & $3.18 \mathrm{E}+07$ & $2.41 \mathrm{E}+07$ & $5.32 \mathrm{E}+07$ & $4.42 \mathrm{E}+07$ & $3.72 \mathrm{E}+07$ & $1.52 \mathrm{E}+07$ & $5.14 \mathrm{E}+07$ & $5.69 \mathrm{E}+08$ \\
\hline \# of Tubes & $7.22 \mathrm{E}+03$ & $7.22 \mathrm{E}+03$ & $7.22 \mathrm{E}+03$ & $7.22 \mathrm{E}+03$ & $7.22 \mathrm{E}+03$ & $7.22 \mathrm{E}+03$ & $4.00 \mathrm{E}+02$ & $7.00 \mathrm{E}+02$ & $1.40 \mathrm{E}+04$ \\
\hline Length (m) & $1.76 \mathrm{E}+01$ & $4.35 \mathrm{E}+00$ & $8.42 \mathrm{E}+00$ & $2.12 \mathrm{E}+01$ & $1.98 \mathrm{E}+01$ & $1.93 \mathrm{E}+01$ & $2.69 \mathrm{E}+00$ & $7.92 \mathrm{E}+00$ & $9.99 \mathrm{E}+00$ \\
\hline Diameter of & $2.54 \mathrm{E}-02$ & $2.54 \mathrm{E}-02$ & $2.54 \mathrm{E}-02$ & $2.54 \mathrm{E}-02$ & $2.54 \mathrm{E}-02$ & $2.54 \mathrm{E}-02$ & $2.54 \mathrm{E}-02$ & $2.54 \mathrm{E}-02$ & $2.54 \mathrm{E}-02$ \\
\hline Diameter of component (m) & $3.66 \mathrm{E}+00$ & $3.66 \mathrm{E}+00$ & $3.66 \mathrm{E}+00$ & $3.66 \mathrm{E}+00$ & $3.66 \mathrm{E}+00$ & $3.66 \mathrm{E}+00$ & $8.65 \mathrm{E}-01$ & $1.14 \mathrm{E}+00$ & $7.50 \mathrm{E}+00$ \\
\hline HT Area $\left(m^{2}\right)$ & $2.02 \mathrm{E}+04$ & $5.01 \mathrm{E}+03$ & $9.70 \mathrm{E}+03$ & $2.44 \mathrm{E}+04$ & $2.28 \mathrm{E}+04$ & $2.22 \mathrm{E}+04$ & $1.72 \mathrm{E}+02$ & $8.85 \mathrm{E}+02$ & $2.23 \mathrm{E}+04$ \\
\hline Weight (tons) & $1.63 \mathrm{E}+02$ & $4.73 \mathrm{E}+01$ & $8.30 \mathrm{E}+01$ & $1.95 \mathrm{E}+02$ & $1.83 \mathrm{E}+02$ & $1.79 \mathrm{E}+02$ & $2.68 \mathrm{E}+00$ & $1.01 \mathrm{E}+01$ & $2.05 \mathrm{E}+02$ \\
\hline
\end{tabular}

\section{CONCLUSIONS}

Neutronic and thermal-hydraulic calculations for two $\mathrm{PbBi}$ cooled reactor concepts are completed. It is determined that a $\mathrm{PbBi}$ cooled fast reactor that produces $310 \mathrm{MWe}$ can be designed with components that are all rail transportable. It is further determined that a practical $\mathrm{PbBi}$ cooled reactor that uses only $\mathrm{Pu}$ as fuel and that has a negative voiding coefficient, probably cannot be designed without the use of leakage-enhanced fuel assemblies. However, results to date indicate that a relatively high leakage slab core that uses a combination of $\mathrm{Pu}, \mathrm{U}$, and $\mathrm{Th}$ for fuel does have a negative coolant voiding coefficient. The reference system design uses PRISM steam generators coupled to a secondary system designed for IRIS as part of this NERI project and has an overall efficiency of about 35 percent, which could probably be increased to about 40 percent with additional design effort. $\mathrm{A} \mathrm{PbBi}$ cooled fast reactor provides a long term option for sustainable nuclear power, and it can be operated to produce very little transuranic waste if the IFR fuel cycle is utilized

\section{REFERENCES}

1. E. Greenspan, "The Encapsulated Nuclear Heat Source Reactor for Low-Waste Proliferation-Resistant Nuclear Energy," International Seminar on Advanced Nuclear Energy Systems toward Zero Release of Radioactive Waste, Susono City, Japan, Nov. 6-9, 2000

2. E. Greenspan, H. Shimada, M.S. Carelli, L. Conway, D.C. Wade, N.W. Brown, Q. Hossian, "The Encapsulated Nuclear Heat Source Reactor Concept," Proceedings of ICONE 8, $8^{\text {th }}$ International Conference on Nuclear Engineering, April 2-6, 2000, Baltimore, MD USA

3. E. Greenspan, H. Shimada and K. Wang, "Long-Life Cores With Small Burnup Reactivity Swing," Physor 2000; Int. Topical Mtg. On Advances in Reactor Physics and Mathematics, Pittsburgh, PA May 7-11, 2000 


\section{NUCLEAR ENERGY RESEARCH INITIATIVE (NERI) PROGRAM \\ GRANT NUMBER DE-FG07-00SF22168 \\ FINAL REPORT}

4. Zaki SU'UD and Hiroshi Sekimoto, "Design and Safety Aspect of Lead and Lead-Bismuth Cooled Long-Life Small Safe Fast Reactors for Various Cour Configurations," Journal of Nuclear Science and Technology, 32(9), pp. 834-845 (September 1995)

5. Hiroshi Sekimoto and Zaki SU'UD, "Design Study of Lead- and Lead-BismuthCooled Nuclear Power Reactors Using Metallic and Nitride Fuel," Nuclear Technology Vol. 109, Mar. 1995

6. Hartmut U. Wider, Johan Karlsson and Alan V. Jones, "Lead/Bismuth-Cooled, Thorium Based ADS and Critical Systems Meet Sceptic's Criteria," $3^{\text {rd }}$ International Conference on Accelerator Driven Transmutation Tecnologies and Applications, Praha-Czech Republic, June 7-11, 1999

7. E. Yefimov, B. Gromov, M. Leonchuk, Yu Orlov, and D. Pankratov, "Problems of Molten Lead-Bismuth Target Developments for Accelerator-Driven Systems," $3^{\text {rd }}$ International Conference on Accelerator Driven Transmutation Tecnologies and Applications, Praha-Czech Republic, June 7-11, 1999

8. Kevan D. Weaver, J. Stephen Herring and Phillp E. MacDonald, "Performance Modeling of Metallic and Nitride Fuels in Advanced Lead-Bismuth Cooled Fast Reactors," Proceedings fo ICONE $8,8^{\text {th }}$ International Conference on Nuclear Engineering, A pril 2-8, 2000 Baltimore, MD USA (ICONE-8014)

9. B.W. Spencer, R.N. Hill, D.C. Wade, D.J. Hill, J.J. Sienicki, H.S. Khaill, J.E. Cahaian, M.T. Farmer, V.A. Maroni, and L. Leibowitz, "An Advanced Modular HLMC Reactor Concept Featuring Economy, Safety, and Proliferation Resistance," Proceedings fo ICONE 8, $8^{\text {th }}$ International Conference on Nuclear Engineering, A pril 2-8, 2000 Baltimore, MD USA (ICONE-8145)

10. Cliff B. Davis and Arthur S. Shieh, "Overview of the use of ATHENA for Analysis of Lead-Bismuth Cooled Reactors," Proceedings fo ICONE $8,8^{\text {th }}$ International Conference on Nuclear Engineering, A pril 2-8, 2000 Baltimore, MD USA (ICONE-822)

11. Eric P. Loewen, Cliff B. Davis and Phillip E. MacDonald, "A Technique forDynamic Corrosion Testing in Liquid Lead Alloys," Proceedings fo ICONE 8, $8^{\text {th }}$ International Conference on Nuclear Engineering, A pril 2-8, 2000 Baltimore, MD USA (ICONE-8245)

12. J. Karisson and H. Wider, "New Aspects of Emergency Decay Heat Removal From a Pb/Bi-Cooled ADS by Auxiliary Cooling," Proceedings fo ICONE $8,8^{\text {th }}$ International Conference on Nuclear Engineering, A pril 2-8, 2000 Baltimore, MD USA (ICONE-8430 


\section{NUCLEAR ENERGY RESEARCH INITIATIVE (NERI) PROGRAM \\ GRANT NUMBER DE-FG07-00SF22168 \\ FINAL REPORT}

13. Bruce W. Spencer, "The Rush to Heavy Liquid Metal Reactor Coolants-Gimmick or Reasoned," Proceedings fo ICONE 8, $8^{\text {th }}$ International Conference on Nuclear Engineering, A pril 2-8, 2000 Baltimore, MD USA (ICONE-8729)

14. Dmitry V. Paramonov and Mario D. Carelli, "Novel, Integrated Reactor/Power Conversion System Concept," Proceedings fo ICONE 8, $8^{\text {th }}$ International Conference on Nuclear Engineering, A pril 2-8, 2000 Baltimore, MD USA (ICONE-8339)

A. Rineidki, E. Kiefhaber, B. Merk,W. Mashek and M. Flad, "Neutron Kinetics Development of the SIMMER-III Safety Code for ADS Applications," $3^{\text {rd }}$ International Conference on Accelerator Driven Transmutation Tecnologies and Applications, Praha-Czech Republic, June 7-11, 1999

15. Georgy Toshinsky, "Email Communications,” (September-November, 2000)

16. G.I. Toshinsky, "LMFBR Operation in the Nuclear Cycle Without Fuel Reprocessing".Proseedings of the International Topical Meeting on Advanced Reactors Safety (ARS'97), Vol.1, pp.39-44, Orlando, Florida, USA, June 1-5, 1997.

17. B.F. Gromov, Yu.I. Orlov, G.I. Toshinsky et al. "Use of lead-bismuth coolant in nuclear reactors and accelerator-driven systems", Nuclear Engineering and Design, 173, pp. 207-217, 1997.

18. E.I. Ignatenko, A.G. Kornienko, A.V. Zrodnikov, B.F. Gromov, G.I. Toshinsky, O.G.Grigoriev, V.I. Chitaikin, V.S. Stepanov, V.Z. Koocklin et al. "Renovating the First Generation NPP's Units Removed from Operation after Exhausting Their Service Life by Placing Them in Steam Generator Boxes of SVBR-75 RIs Using Liquid Metal Lead-Bismuth Coolant." Report at the Eighth. Annual Conference of Russia Nuclear Society. September, 15-19, 1997. Ekaterinburg-Zarechny, Russia.

19. V.S.Stepanov, O.G.Grigoriev, G.Toshinsky et al. "SVBR-75: A reactors module for renewal of VVER-440 decommissioning reactors - safety and economic aspects.” IAEA-TECDOC-1056, IAEA, Nov. 1998, p. 165.

20. B.F.Gromov, G.I.Toshinsky, V.V.Chekunov, Yu.I.Orlov, Yu.S.Belomytcev, I.N.Gorelov A.G.Karabash, M.P.Leonchuk, D.V.Pankratov, U.G.Pashkin. "Designing the Reactor Installation with Lead-Bismuth Coolant for Nuclear Submarines. The Brief History. Summarized Operation Results." Report in HLMC'98 conference, Obninsk, October 5-9, 1998.

21. B.F.Gromov, O.G.Grigoryev, A.V.Dedoul, A.V.Zrodnikov, G.I.Toshinsky, V.I.Chitaykin. "Use of Russian Technology of Naval Reactors with Lead-Bismuth 


\section{NUCLEAR ENERGY RESEARCH INITIATIVE (NERI) PROGRAM \\ GRANT NUMBER DE-FG07-00SF22168 \\ FINAL REPORT}

Coolant in Civil Nuclear Power." Report in HLMC'98 conference, Obninsk, October 5-9, 1998.

22. G.I.Toshinsky. "Concept of the Self-fuel-Providing LMFBR." Report in HLMC'98 conference, Obninsk, October 5-9, 1998.

23. E.I.Ignatenko, A.G.Kornienko, M.F.Rogov, V.Z.Kuklin, A.V.Sidorov, A.V.Zrodnikov B.F.Gromov, G.I.Toshinsky, O.G.Grigorjev, U.G.Dragunov, V.S.Stepanov. "Use of SVBR-75 Reactor Plant in Design of Renovation of NPP Units of the First Generation after Termination of their Service Life." Report in HLMC'98 conference, Obninsk, October 5-9, 1998.

24. V.S.Stepanov, N.N.Klimov, M.L.Koulikov, S.K.Legouenko V.I.Chitaykin, B.F.Gromov, O.G.Grigoriev. "Perspective Reactors with Lead-Bismuth Liquid Metal Coolant.” Report in HLMC'98 conference, Obninsk, October 5-9, 1998.

25. Stepanov, V.S., Klimov, N.N., Kulikov, M.L., Leguenko, S.K.,. Chitaykin, V.I., Gromov, B.F., Toshinsky, G.I., Grigorev, O.G., "Application in Electric Power Industry Technology of Transport Reactors with lead-Bismuth Coolant", IAEAAG-1021 IWGER/97, Obninsk, Russian Federation, July 1998.

26. Toshinsky, V., Sekimoto, H., Toshinsky, G., "Self-Fuel-Providing LMFBR: Design Problems and Their Possible Solutions". Proc. ICENES'98, Tel Aviv, Israel, 1998, Vol.1, p. 43.

27. B.F.Gromov， O.G.Grigoriev， A.V.Dedoul， G.I.Toshinsky， V.S.Stepanov, L.B.Nikitin. "The Analysis of Operation Experience of Reactor Installations Using Lead-Bismuth Coolant and Accidents Happened". Proceedings of the Conference "Heavy Liquid Metal Coolants in Nuclear Technology", held in Obninsk, Russia on October 5-9, 1998.

28. G.LToshinsky, V.I.Chitaykin. Inherent Safety Fast Reactor With Fuel Cycle Ensuring Pu Proliferation Resistance. Proc. ICENES'98, Tel-Aviv, Israel, 1998.

29. A.V Zrodnikov, B.F.Gromov, O.G.Grigoriev and others "Application of navy lead-bismuth cooled reactor technology in civil energy of Russia". Report in ? conference of Nucl. Soc.of Russia, Obninsk, 26.07 - 03.07, 1999.

30. A.V.Zrodnikov, O.G.Grigoriev, A.V Dedoul, G.I.Toshinsky, V.I.Chitaykin (SSC RF - IPPE, Obninsk, Kaluga reg.), V.S.Stepanov, (EDO “Gidropress", Podolsk, Moscow reg.). "Shore Small Power NPP with Lead-Bismuth cooled Reactor without on-site refueling". Report to the workshop "N'ocean 2000", February 2124, Tokyo, Japan. 


\section{NUCLEAR ENERGY RESEARCH INITIATIVE (NERI) PROGRAM \\ GRANT NUMBER DE-FG07-00SF22168 \\ FINAL REPORT}

31. A.V.Zrodnikov, V.I.Chitaykin, B.F.Gromov, O.G.Grigoriev, A.V.Dedoul, G.I.Toshinsky (SSC RF - IPPE), Yu.G.Dragounov, V.S.Stepanov (EDO "Gidropress"). "Multi-purpose reactor module SVBR-75/100". Report in ICONE 8 Conference held in Baltimore, USA on April 2-6, 2000.

32. Ribando, R. J. (1978). LONAC: A Computer Program to Investigate Systems Dynamics Under Conditions of Low Forced Flow and Natural Convection

33. Cho, Soung R. Modular Nuclear Steam Supply. Mechanical Engineering. V. 111. No. 10. Oct 1989, p 84-87.

34. Boardman, Charles E. Allen E. Dubberley, Douglas G. Carrol, Marvin Hui, Alan W. Fanning, Walter Kwant. Description of the Modular S-Prism Reactor. Proceedings of ICONE 8. $8^{\text {th }}$ internation Conference on Nuclear Engineering. April 20-6, 2000, Baltimore, MD. USA.

35. Pluta, P.R., Tippets, F.E. General Electric Innovative Liquid Metal Reactor Plant Concept PRISM. Fast Breeder Reactors: Experience and Trends. Proceedings of an International Symposium Organized by the International Atomic Energy Agency Held in Lyons, 22-28 July 1985. Volume 2. p443-450.

36. Chang, Yoon I. Progress and Status of the Integral Fast Reactor (IFR) Development Program. p506-509. Proceedings of the American Power Conference.

37. Chang, Y.I., Lineberry, M.J., Burris, L. Waters, C. Integral Fast Reactor Shows Its Mettle. Nuclear Engineering International. November 1987. p23-26.

38. Meyers, G.W., McDonald, J.S., "Design Modifications that Reduce Costs for Liquid Metal Pool Power Plants." Fast Breeder Reactors: Experience and Trends. Proceedings of an International Symposium Organized by the International Atomic Energy Agency Held in Lyons, 22-28 July 1985. Volume 2. P451-462.

39. Boardman, Charles E., et al, "Description of the Modular S-PRISM Fast Reactor," Proceedings of ICONE 8, $8^{\text {th }}$ International Conference on Nuclear Engineering, April 2-6, 2000

40. Dubberley, A.E. C.E. Boardman, K. Yoshida, T.Wu, "SuperPRISM Oxide and Metal Fuel Core Designs", Proceedings of ICONE 8. $8^{\text {th }}$ international conference on Nuclear Engineering April 2-6, 2000, Baltimore, MD USA.

41. Armijo, J.S., Arnold, W.H, Gibbs, D.C., Meyers, G.W., LMFBR Design Trends in the USA. Fast Breeder Reactors: Experience and Trends. Proceedings of an International Symposium Organized by the International Atomic Energy Agency Held in Lyons, 22-28 July 1985. Volume 2. P311-328. 


\section{NUCLEAR ENERGY RESEARCH INITIATIVE (NERI) PROGRAM GRANT NUMBER DE-FG07-00SF22168 \\ FINAL REPORT}

42. MacDonald, Philip, et al, Design of an Actinide Burning, Lead or Lead-Bismuth Cooled Reactor that Produces Low Cost Electricity, Annual Project Status Report, July 2000

43. Boardman, Chuck, Personal Communications, 2001

44. Toshinsky, Georgy, Personal Communications, 2001

45. Berryhill, Bob, Personal Communications, 2001

46. Duderstadt, James J. and Hamilton, Louis J., Nuclear Reactor Analysis, John Wiley and Sons, 1976

47. Zrodnikov A.V., Chitaykin V.I., Toshinsky G.I., Grigoriev O.G. (SSC RF IPPE), Dragunov Yu.G., Stepanov V.S., Klimov N.N. (EDO "Gidropress"), Malyshev A.B., Krushelnitsky V.N., Tah S.M. (GNIPKII "Atomenergoproekt") "LEAD-BISMUTH COOLED MODULAR NPP BASED ON FAST REACTORS,” Nucleonics Weeks, September 2001, p.14 


\title{
NUCLEAR ENERGY RESEARCH INITIATIVE (NERI) PROGRAM \\ GRANT NUMBER DE-FG07-00SF22168 \\ FINAL REPORT
}

\section{Modular Pebble Bed Reactor Concept and Layout}

\author{
Professor Andrew C. Kadak \\ Marc V. Berte \\ Nuclear Engineering Department \\ Massachusetts Institute of Technology
}

\section{INTRODUCTION}

For new reactors to be competitive, one must either take advantage of economies of scale or economies of factory production. As reactor designs get larger and larger costing more in absolute dollars, an alternative approach is suggested that relies on smaller units that can be factory built and site assembled allowing for speedy "lego" style assembly instead of time consuming, labor intensive and costly field "stick" construction. MIT has been working on the Modular Pebble Bed Reactor (MPBR - Figure 1) for several years focusing under on how to take advantage of modularity principles and virtual factory manufacturing.

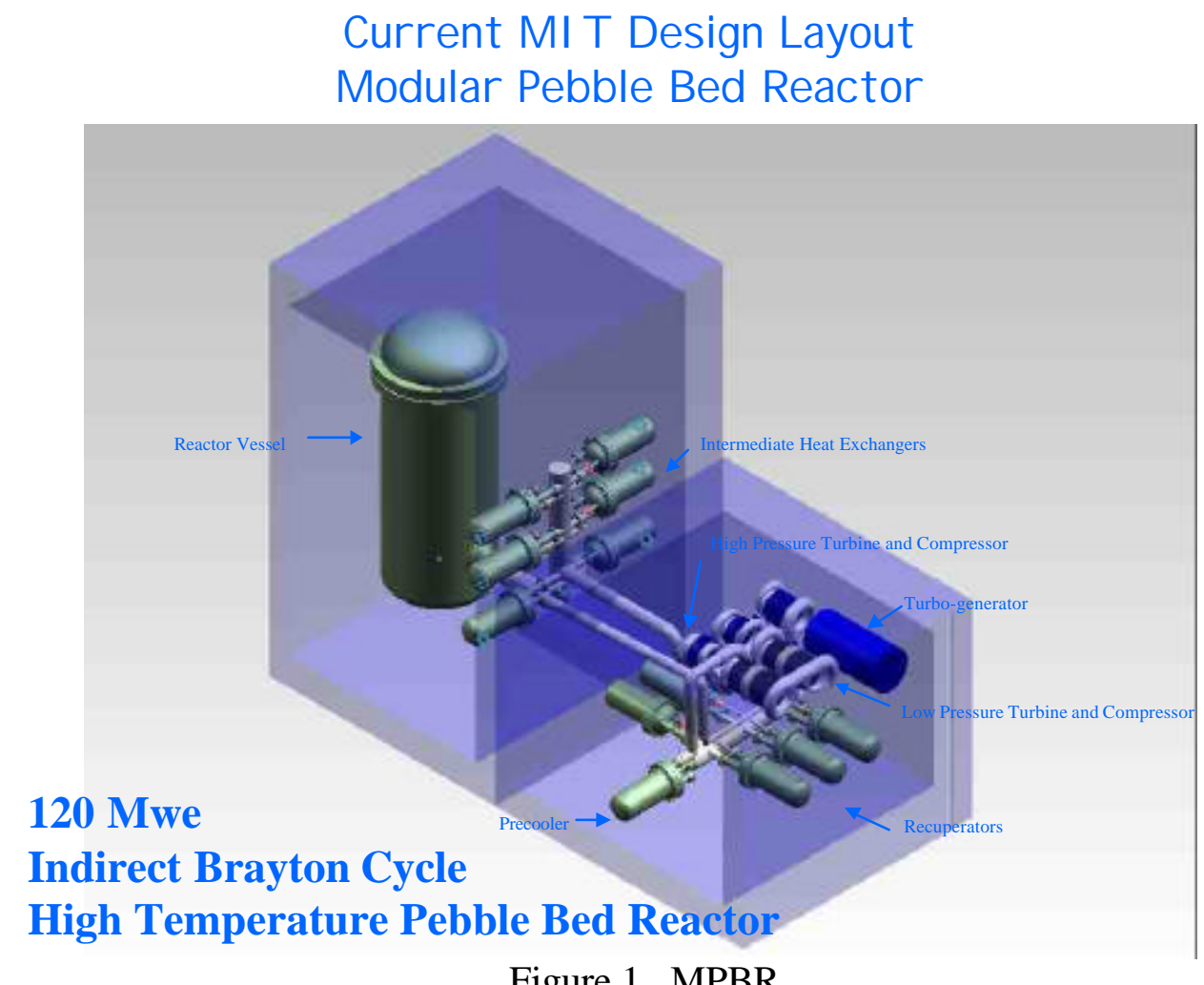

Figure 1. MPBR 


\section{NUCLEAR ENERGY RESEARCH INITIATIVE (NERI) PROGRAM \\ GRANT NUMBER DE-FG07-00SF22168 \\ FINAL REPORT}

The modularity and packaging studies performed for the MPBR project can be broken down into three tasks: 1. System layout and design (physical layout and packaging of the plant components), 2. System concept design for increased nodularity and decreased cost, and 3. Advanced component design concepts for future implementation. The first task involves defining the physical layout of the power plant itself, and the breakdown of any transportation issues involved in its construction. The second task involves making high level trade studies of the actual system, such as the number of intercoolers, limiting temperatures, and other system parameters. The third task involves searching for advanced component concepts that may aid in the other two tasks by making individual components simpler, cheaper, or more fault tolerant.

The present design utilizes existing technology that has been demonstrated. The resulting three shaft system is limited to a nominal demonstrated shaft horsepower. The modularity plan was developed in concert with another DOE supported NERI on balance of plant system design. A simple analysis was also performed that provides a comparative areal land use of an equivalent sized AP-1000 and the Modular Pebble Bed Reactor 10 modules. This shows that on a $\mathrm{kw} / \mathrm{ft}^{2}$ basis that the MPBR is capable of more generating capacity.

Included in this report are several new areas of investigation regarding the modularity concept being developed. Shipment of the reactor vessel, the modularity design of the online refueling system, spent fuel storage tanks, inventory control system and costs of the components of the plant including the intermediate heat exchangers, recuperators, turbines, generator, and precooler were considered. In addition, a construction deployment plan is presented with a vision for the actual building and manufacturing of the components of the power plant in a virtual factory with "just in time" delivery system to site.

\section{SYSTEM LAYOUT AND DESIGN}

The MPBR project is highly dependent on the ability to package the reactor, its IHX, and the remaining balance of plant in such a way to allow the MPBR plant to be transported via low cost means (truck as opposed to barge), easily assembled with minimal tooling and re-working, and operated in a small footprint commensurate with conventional power plants. Based on this dependency, the following requirements and assumptions can be made:

All components other than the reactor vessel and its associated mechanical support systems must be transportable by heavy lift tractor/trailer truck. While rail transportation would enable larger individual modules than truck transportable reactor modules, the requirement of rail access at destination areas may not be counted on. Assuming that heavy lift trucks are used to transport the BOP components to the plant location, the following limitations must be met. First, the maximum dimensions of any one module are 8' wide, 12' tall, and up to 60' long. Second, the maximum weight of a single module must be less than $\sim 200,000 \mathrm{lb}$. Finally, the modules must be contained in a steel 


\section{NUCLEAR ENERGY RESEARCH INITIATIVE (NERI) PROGRAM \\ GRANT NUMBER DE-FG07-00SF22168 \\ FINAL REPORT}

space frame to support the components within, and align those components to those in other modules.

The assembly on site of the modules must be limited to stacking the space-frames to align the various flanges and bolting the piping together. The reactor plant design must take transportation, modularity and assembly into account; thus any system components must fit within the volume and mass constraints of \#1, and be chosen in such a way as to simplify the layout.

The initial MPBR layout proposed was a two-module rail transport system based on early estimates of heat exchanger sizing, a two-shaft turbomachinery system, and early estimates of component masses. This layout is shown below in Figure 2.

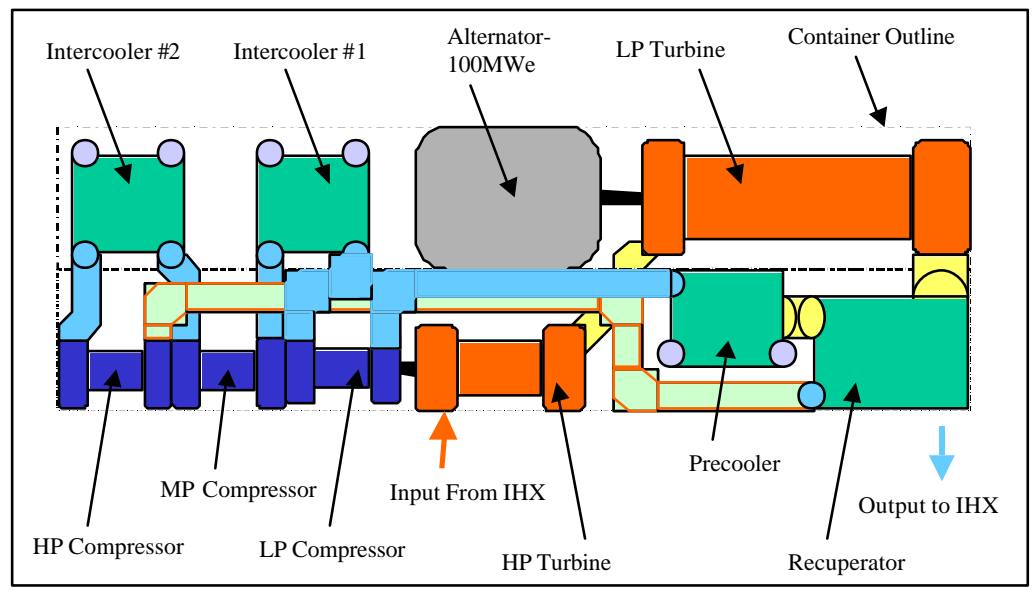

Figure 2. MPBR Layout

This layout was revised based on new information regarding the masses of the various components and certain specific code requirements. One significant change required was to encapsulate the IHX core inside a large pressure vessel (required to make the nuclear boundary of the system the vessel rather than the IHX core elements).

The latest revision of the MPBR plant layout and design is based on the current plant schematic and all available components sizing information. Figure 3 shows the current (three-shaft) plant schematic and the layout is described below. 


\section{NUCLEAR ENERGY RESEARCH INITIATIVE (NERI) PROGRAM \\ GRANT NUMBER DE-FG07-00SF22168 \\ FINAL REPORT}

\section{Current Design Schematic}

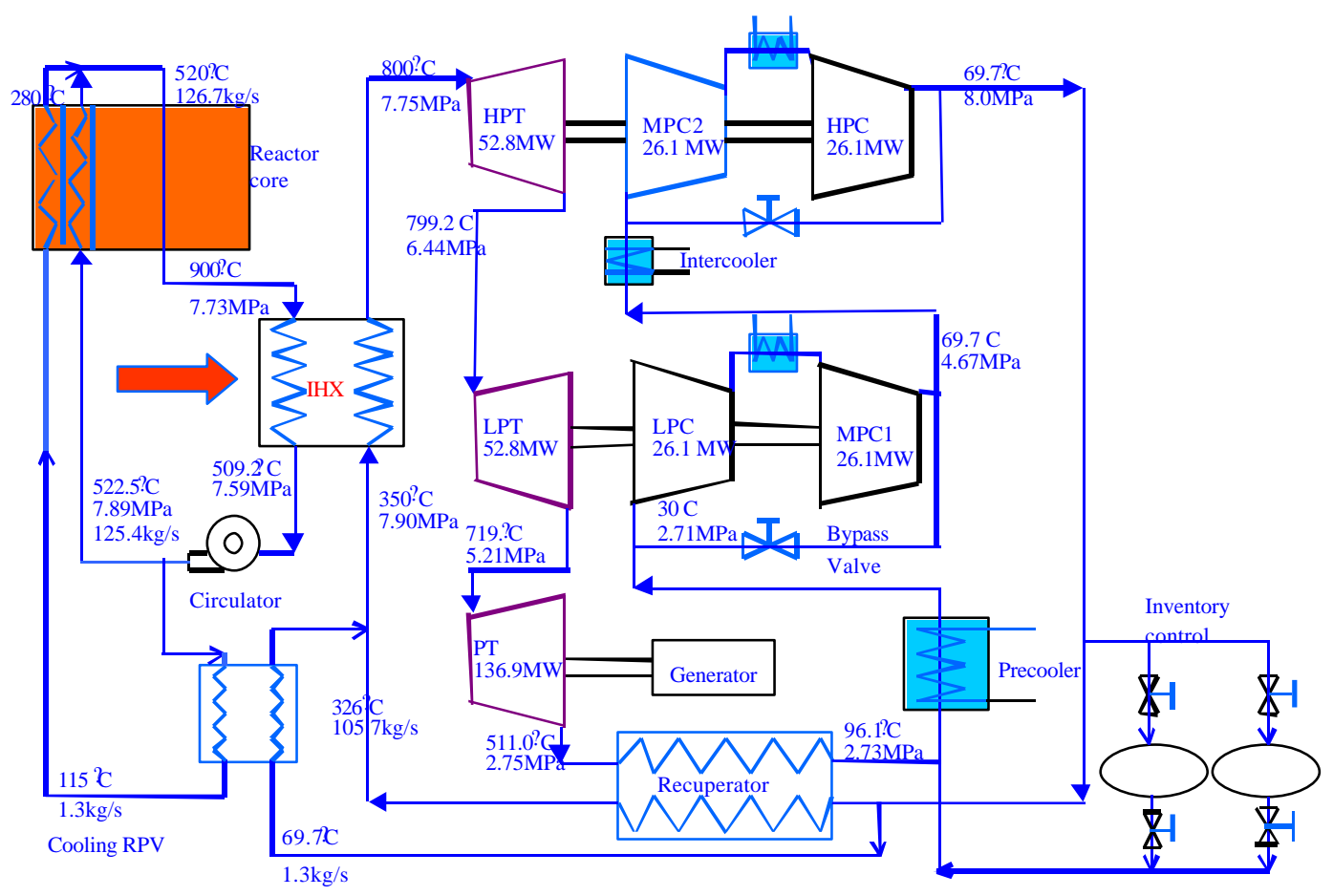

Figure 3. Current Plant Schematic - Three Shaft System

First, the overall system was changed from a two shaft (one high-speed shaft carrying a high-pressure turbine and all three compressor sets) to a three shaft (one low speed power shaft driving a generator and two separate turbo-compressor sets) system. This change was done to limit the shaft power of any one turbine to less than $\sim 36 \mathrm{MW}$ (to stay within existing turbomachinery designs). Additionally, by reducing the length of each individual turbocompressor set it becomes easier to layout the reactor plant as each shorter shaft can be positioned in adjacent modules, horizontally or vertically.

Second, the IHX was changed from a single large module to six smaller modules each with its own containment vessel. This was done to limit the weight of each module to within the 200klb truck limit. Additionally, by splitting the IHX up into smaller modules, if there is damage or failure to a part of the IHX, the smaller module can be removed and replaced. As the IHX will in all probability be contaminated by fission products or fuel pebble debris, the six module arrangement minimizes the cost of an IHX repair (as it is most likely damage requiring IHX removal would be confined to a single module).

Third, the recuperator is split up into six modules like the IHX. This enables each recuperator module to be closely located to a corresponding IHX module, limiting the amount of piping required between the two. The separate recuperator modules also permit easy maintenance and ease of replacement, like the IHX modules. 


\section{NUCLEAR ENERGY RESEARCH INITIATIVE (NERI) PROGRAM \\ GRANT NUMBER DE-FG07-00SF22168 \\ FINAL REPORT}

Based on these changes, the layout shown in Figures 4 and 5 is proposed. This layout seeks to maximize the modularity of the design by concentrating manifolds and plumbing in individual modules, while restricting each module to a single type of component (keeping turbomachinery in separate modules from heat exchangers whenever possible to minimize parasitic effects during maintenance).

While this type-specific module isolation increases the total number of modules in the system, it limits the amount of functioning components that have to be removed during replacement of a single component. This is necessary, as the current strategy for repair of this type of reactor facility is one of replacement rather than on-site repair. Each module will be built in a centralized factory, and is transportable by truck. Therefore, when a component fails on site, that specific module will be removed and returned to the factory for repair, with an identical replacement module taking its place. This layout also maximizes the effectiveness of this strategy as each of the IHX and recuperator modules are identical, thus, a single spare IHX or recuperator module can be used to replace any one of the six original modules.

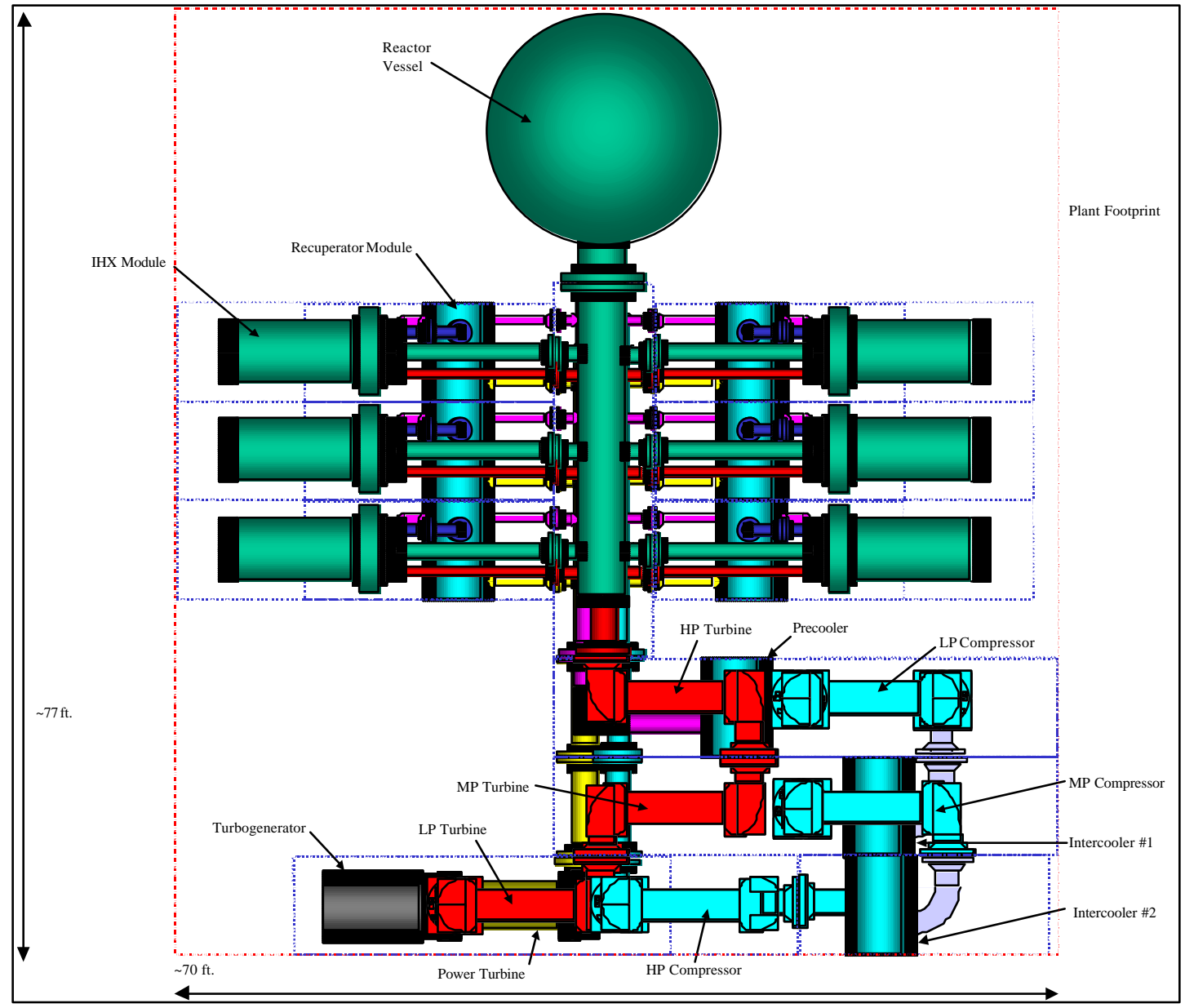

Figure 4. Current System Layout - Top View 


\section{NUCLEAR ENERGY RESEARCH INITIATIVE (NERI) PROGRAM \\ GRANT NUMBER DE-FG07-00SF22168 \\ FINAL REPORT}

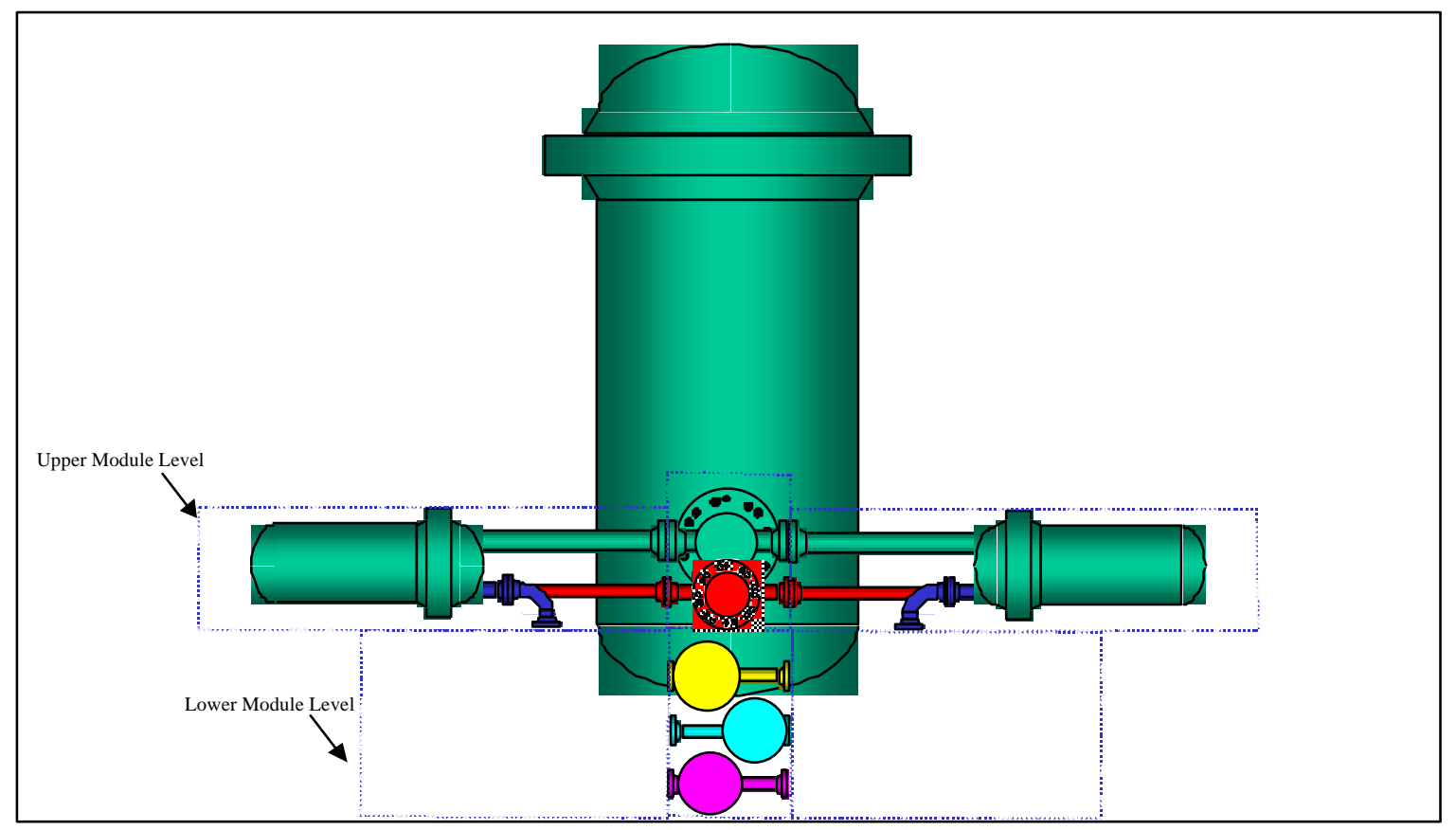

Figure 5. Current System Layout - Side View

Additionally, this layout is designed to minimize the number of modules that need to be removed to access any one module. To ensure this, the only modules whose replacement would necessitate the removal from the plant of a functioning module is the lower level manifold module, all other modules can be extracted either from above for the top level modules, or from the side (on sliding rails) for all the lower level modules. The two levels are shown in Figure 6.
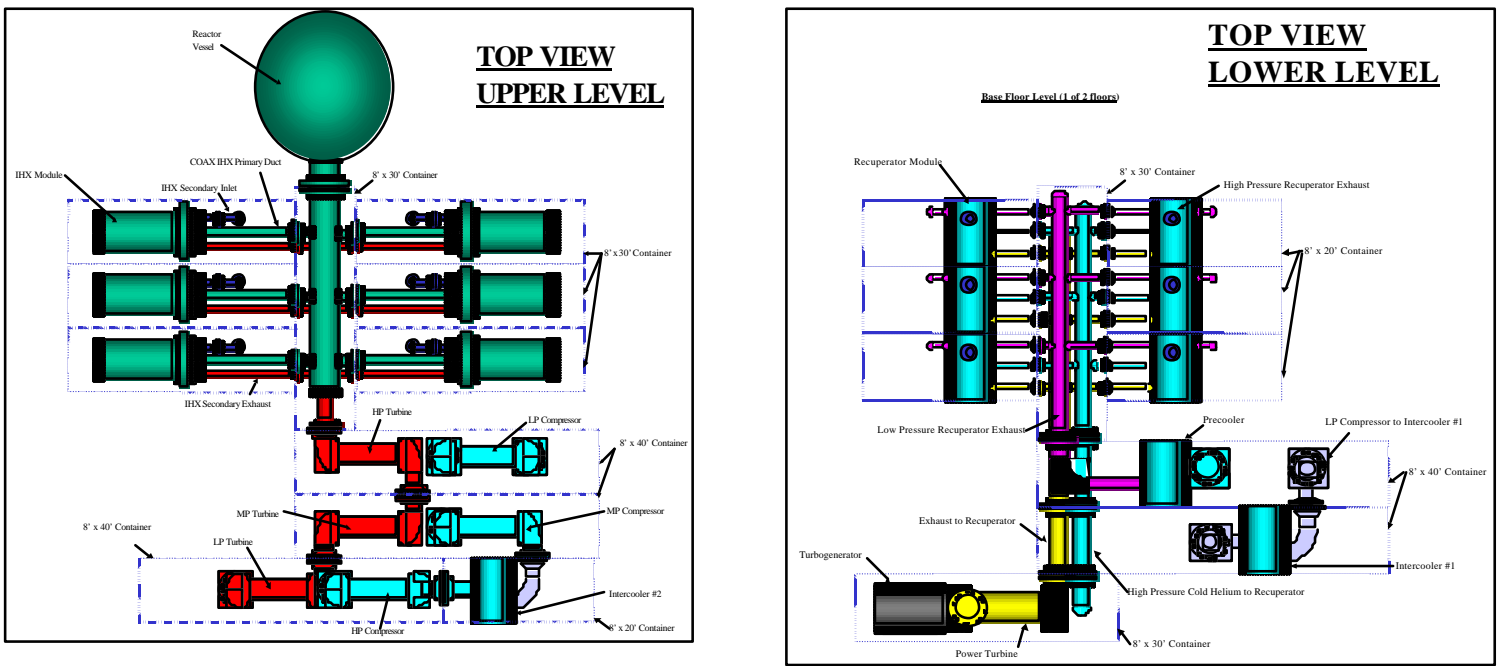

Figure 6. Upper and Lower Level Views 


\section{NUCLEAR ENERGY RESEARCH INITIATIVE (NERI) PROGRAM \\ GRANT NUMBER DE-FG07-00SF22168 \\ FINAL REPORT}

While it is not currently an element of this design, the incorporation of a trench under the lower level manifold module would enable it to be removed without affecting other modules. This layout also simplifies construction of the plant, as the only large machinery needed to emplace the modules is a crane to emplace the top-level modules. Given the low lift height and overhand needed to emplace these modules, such a crane could be limited to a hydraulic lift carriage, deliverable by truck that would grasp each module, lift it to the correct height, and slide it onto rails built into the lower modules. Using this type of assembly, the amount of site preparation for the BOP part of the facility is minimal (a suitable pad type foundation with the proper load bearing specifications) and the on-site tooling and machinery requirements are minimal (lift carriage, stud tensioner and flange assembly tools).

While not shown on this layout design, plant command and control facilities and electrical metering / distribution modules would be shipped in similar containers and also assembled on site in a similar fashion. The addition of these modules is what drove the location of the generator / power turbine module to its present location at the lower left of the layout, as additional power processing modules could be added adjacent to it without compromising the removal path of any other modules. Command and control modules could be added in two levels across from these modules (adjacent to the turbocompressor / intercooler modules).

Overall, this layout requires the use of 21 modules (not including command and control or power processing), each of which is truck transportable. The modules are shown in Figure 7. Table 1 shows the dimensions for the components.

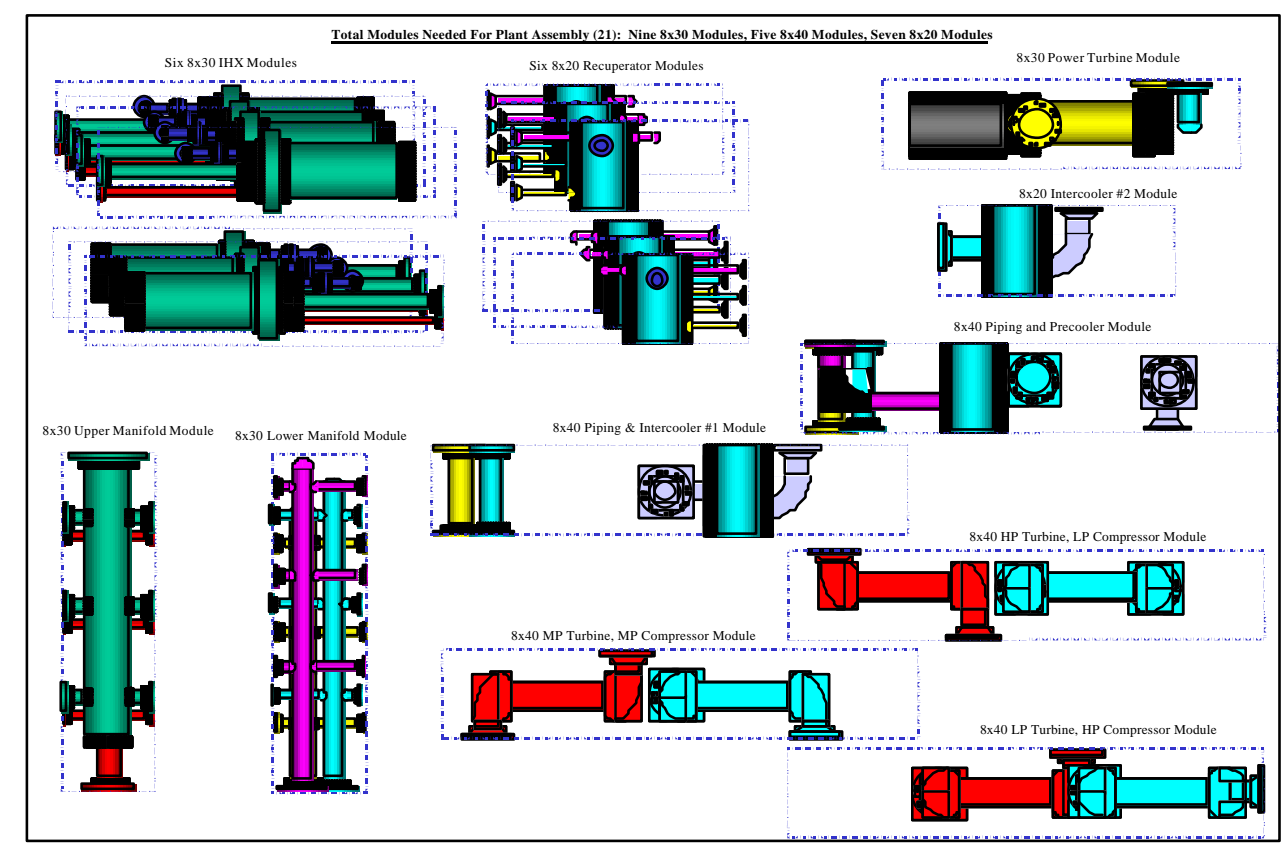

Figure 7. System Modules 


\section{NUCLEAR ENERGY RESEARCH INITIATIVE (NERI) PROGRAM \\ GRANT NUMBER DE-FG07-00SF22168 \\ FINAL REPORT}

Table 1. Component Dimensions

\begin{tabular}{|l|l|}
\hline Component & Dimensions \\
\hline Power Turbine & $5 \mathrm{ft}$ Dia x 15 ft. long \\
\hline $\begin{array}{l}\text { HP/MP/LP Turbine, HP/MP/LP Axial } \\
\text { Compressor }\end{array}$ & $4 \mathrm{ft}$ Dia. x 14 ft. long \\
\hline Generator & $5 \mathrm{ft}$ Dia. x 10 ft. long \\
\hline IHX & $6 \mathrm{ft}$ Dia. x 14 ft. long \\
\hline Recuperator & $8 \times 6 \times 6 \mathrm{ft}$ \\
\hline Intercooler / Precooler & $8 \times 6 \times 6 \mathrm{ft}$. \\
\hline
\end{tabular}

The entire single plant module fits in a footprint roughly $80 \mathrm{ft} \times 70 \mathrm{ft}$, a comparable size to $100 \mathrm{MWe}$ gas turbine facilities. This translates into an areal power of $17.9 \mathrm{~kW} / \mathrm{ft}^{2}$. A 1,100 MWe plant would consist of a $2 \times 5$ row of modules as shown in Figure 8 . The total plant footprint of $400 \times 250\left(100,000 \mathrm{ft}^{2}\right)$ would be required (including enough room to remove any module to a central "road" between the two lines of modules). This yields an areal power density of $10 \mathrm{kw} / \mathrm{ft}^{2}$. Given that conventional reactor containment buildings (not including the turbine shed and control facilities) consume nearly 40,000 $\mathrm{ft}^{2}$ on their own, this power density is equal to, if not greater than conventional facilities, including advanced gas turbine systems.

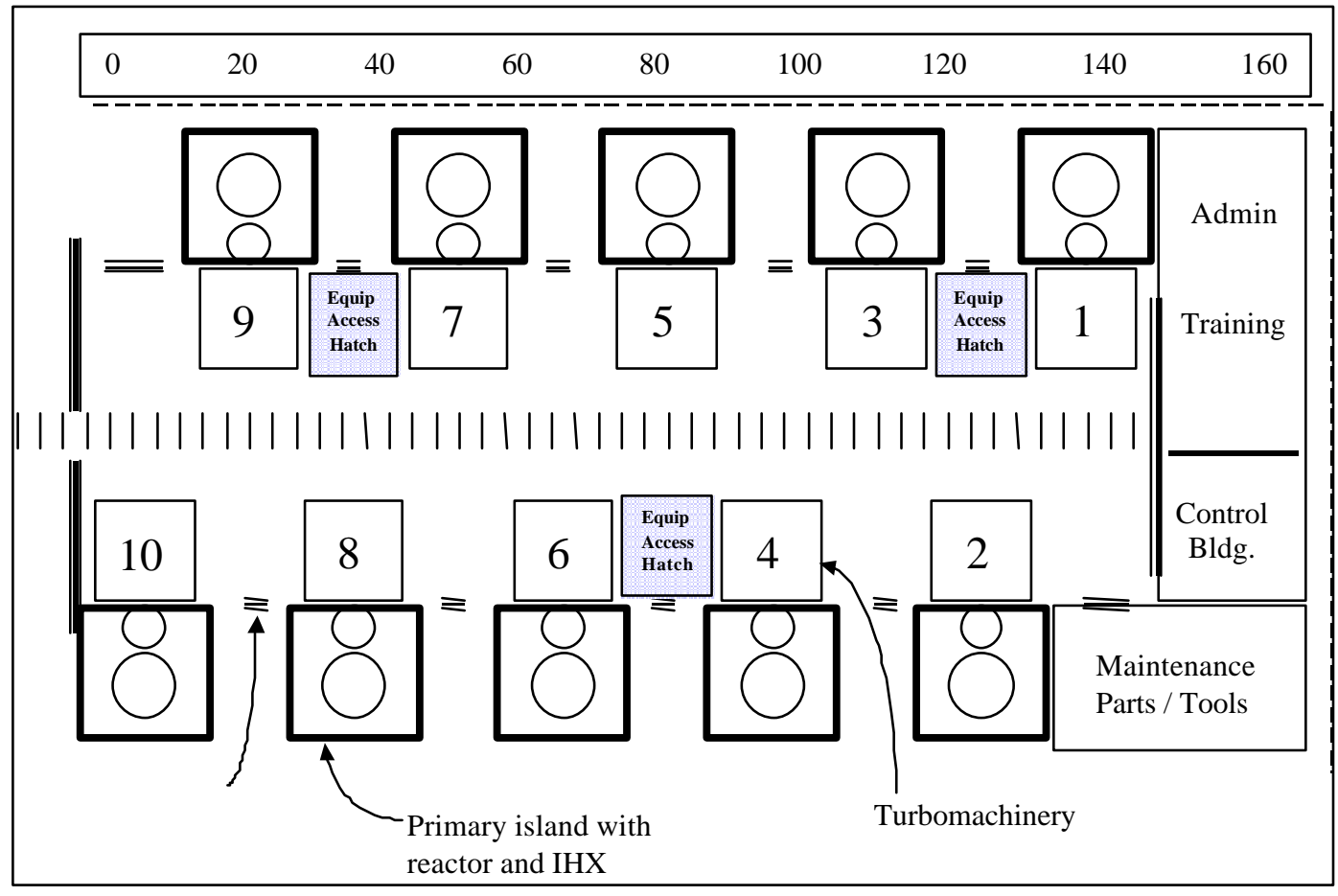

Figure 8. Ten Unit MPBR Plant Layout (Top View - Distance in meters) 


\section{NUCLEAR ENERGY RESEARCH INITIATIVE (NERI) PROGRAM \\ GRANT NUMBER DE-FG07-00SF22168 \\ FINAL REPORT}

The AP-1000 (about the same size as the AP-600) is roughly $560 \mathrm{ft}$ x $300 \mathrm{ft}$ (based on a $130 \mathrm{ft}$ diameter containment vessel and the image of an AP-600 scale model. Thus the AP-1000 has a power density of roughly $5.9 \mathrm{~kW} / \mathrm{ft}^{2}$. Even assuming a best case (eliminate the little administration building and push everything closer together), the turbine hall and reactor vessel alone are more than 400x200 ft; therefore, the pebble bed has a better areal power density. Shown on the figure below is the overlay of the 1100 MWe pebble bed plant on the footprint of the AP-1000 (shown without all the support buildings).

Additionally, the AP-600/1000 reactor vessel stands almost 250ft tall (based on the cross section of the containment vessel also attached). The MPBR is less than $80 \mathrm{ft}$ tall (assuming the core is completely above grade) and less than $30 \mathrm{ft}$ tall if the core is below grade. This makes the MPBR less expensive and reduces concerns about high winds and other natural disasters. A comparison of the footprints of the AP1000 and the 10 unit MPBR is shown in Figure 9.

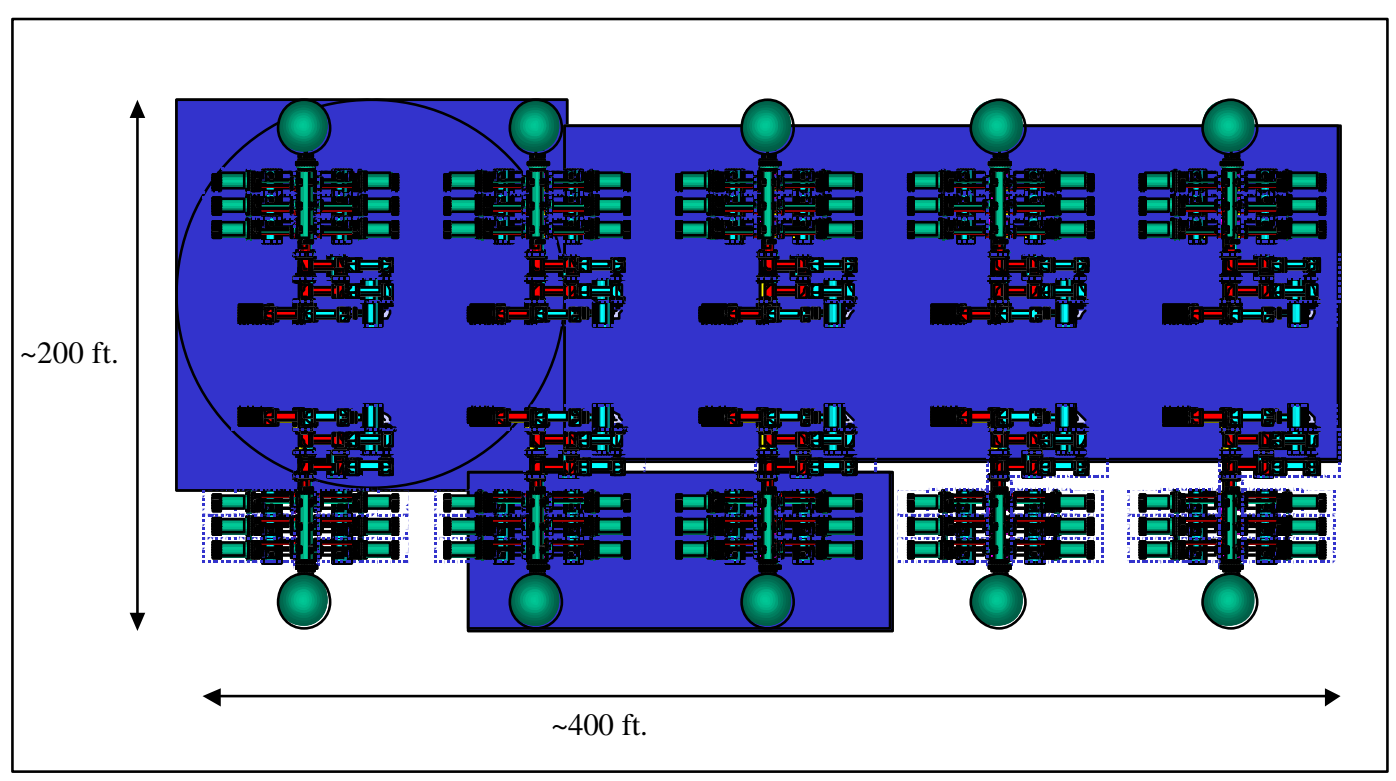

Figure 9. AP1000 Footprint vs. MPBR-1GW

New modularity features have been identified in the area of refueling systems and integrating the basic concept with a construction plan. More detailed understanding of the component designs and sizes has affected the layout proposed. Further refinements will undoubtedly become necessary as stress calculations on piping systems and auxiliary systems are considered (instrumentation, monitoring and control). At this point, the modularity concepts proposed still appear to be very practical and possible. 


\section{NUCLEAR ENERGY RESEARCH INITIATIVE (NERI) PROGRAM \\ GRANT NUMBER DE-FG07-00SF22168 \\ FINAL REPORT}

\section{BALANCE OF PLANT MODULARITY}

The primary concept that defines the innovation of this proposed MPBR modularity approach is the minimization, and where possible, elimination, of the new capital infrastructure facilities, on-site construction, and labor required to construct a nuclear power plant. This requires a new approach to how plant components are built and assembled. In the past nuclear power plant construction has been performed almost completely on site, as most of the components are far to large to transport assembled. For this new modularity concept to work, the plant size would have to be small ( 120 Mwe) allowing for road or rail shipment. The MPBR will be built in a "virtual" factory in which individual component manufacturers would be asked to provide all components, piping connections, electric power connections and electronics for the volume occupied by the component in a space designated by a "space frame" (Figure 10). These space frames would then be assembled at the plant site using a simple, bolt together, plug and play style assembly process. This should dramatically reduce construction time and costly field work.

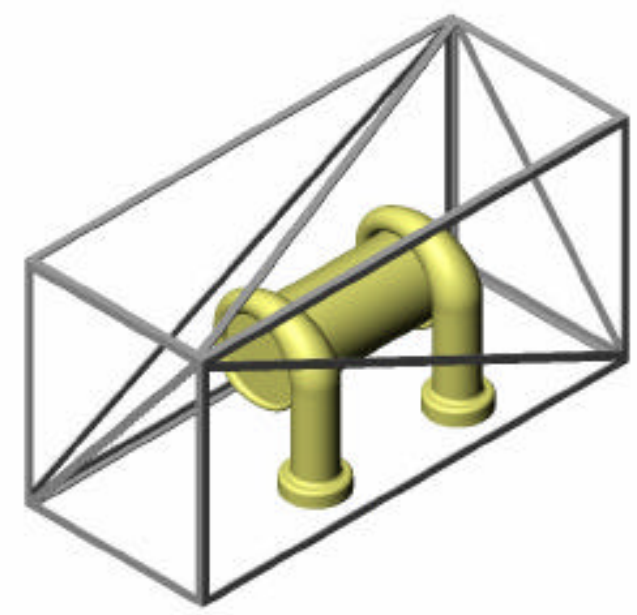

Figure 10. Space Frame Volume Design 


\section{NUCLEAR ENERGY RESEARCH INITIATIVE (NERI) PROGRAM \\ GRANT NUMBER DE-FG07-00SF22168 \\ FINAL REPORT}

\section{MANUFACTURING AND ASSEMBLY SEQUENCE}

In the past nuclear power plant construction has been performed almost completely on site, as most of the components are far too large to transport assembled. Each new plant was effectively a "new" plant, in that it shared little, even in "factory" plants, with its brethren. These plants also were putting a utility's eggs in one basket, as any component failure would eliminate all $1000 \mathrm{MW}+$ of generating capacity until the part could be replaced, and given the complexity and assembly techniques used, such a repair could take a substantial amount of time, and require parts that weren't off-the-shelf available.

The initial concept for the MPBR was to build all the parts in a central factory and ship them to the construction site, where they would be assembled in a simple, bolt together, plug and play fashion, loaded with fuel and powered up.

This concept is the next logical step in this evolution. By choosing components that are, where possible, already being produced, and by separating the remaining components into modules, there exists the possibility of eliminating the factory all together. This construction / modularity approach would work as follows:

This manufacturing and assembly sequence would work as follows.

A series of subcontractors would be selected for all the various components based on expertise / cost or the existence of a stock part - for example, P\&W, GE, could be selected to manufacture the turbomachinery (expertise and existing production capability), and Siemens could be selected for the circulator and inventory control motors (existence of a stock part).

Second, as each of the major subcontractors should have the capability of constructing a standard, low-tech space-frame, each module subcontractor would integrate their component into the standard frame along with all of the support equipment which would be designed with a limited number of inter-module interfaces.

Third, for those subcontractors without the capability of constructing the standard frame, or those that simply do not wish to do so, any local fabrication shop could be used to construct the frame and deliver it via conventional truck to the subcontractor.

Fourth, site preparation entailing excavation and concrete construction creating the "rooms" for space frames is simple and could be performed by a chosen local contractor.

Fifth, the transportation subcontractor would transport the finished modules (most designed to be either road or rail transportable) to the site where they would be assembled using minimum tools and equipment. Since the transportation subcontractor will move the same parts from the same locations to different destinations, a substantial learning curve can be developed as better routes can be mapped, escorts arranged in advance, etc. 


\section{NUCLEAR ENERGY RESEARCH INITIATIVE (NERI) PROGRAM \\ GRANT NUMBER DE-FG07-00SF22168 \\ FINAL REPORT}

Once the plant is in operation, if a space frame (component) needs replacement, it should be readily available, as the subcontractors will be producing the parts continuously, and the next one produced will simply be trucked to an "old" destination—at low cost since the route has been done many times before.

This process exemplifies all of the lean manufacturing lessons being pursued currently, as it minimizes inventory, maximizes commonality of interface (common space frame, etc), enables the complex component subcontracts to be awarded to large, fixed-location established companies, while using lower cost bcal resources for the simple components and tasks. Observing advanced modular nuclear submarine construction at Newport News Shipyard and General Dynamics Shipyard at Quonset Point, Rhode Island, provides additional confidence that the concepts being proposed are quite practical and have demonstrated substantial cost savings in the fabrication of nuclear submarines.

Trips to facilities that employ modularity concepts in the design and construction of nuclear submarines were made. The first was with a NERI industrial collaborator Newport News Shipbuilding (NNS) in Virginia and the second was at the General Dynamics Facility in Quonset Point Rhode Island. The unique opportunity provided by these two facilities was to visually see how modularity principles are applied in practice in the construction of nuclear submarines.

The submarines are assembled in two places - NNS and at the General Dynamics Shipyard in Groton Connecticut. The submarines are assembled in 12 major hull sections each containing key elements of the submarine. These modules also contain submodules that are built outside of the hull section at Quonset Point and NNS. The methodology that they use is they build interior modules containing compartments consisting of the weapons systems, power systems, habitability module, propulsion, bow and stern, etc. These modules are then inserted into the hull cylinders which are then welded together in the form of a submarine. The hull sections of the submarine are shipped from Quonset and NNS to either Groton or Newport News by barge for final assembly with each company being responsible for certain sections of each submarine.

The process of design and build incorporates significant engineering input to allow for efficient modular construction. Three dimensional models of the ship's design and construction plan are developed to allow for system installation on a critical path schedule to assure that all parts can be fit into the modules at the proper time.

One of the most important critical issues is establishing a central reference line around which to build and ultimately assemble the modules. Even with computer-automated design and construction, these reference lines become important to manage tolerances

and assure proper assembly. Having machined parts as line up connections is going to be expensive. Thus, in the space-frame design, it will become important to how much 


\section{NUCLEAR ENERGY RESEARCH INITIATIVE (NERI) PROGRAM \\ GRANT NUMBER DE-FG07-00SF22168 \\ FINAL REPORT}

machining and exact positioning of the components in all our interfaces between all our space frames will be required to keep the costs affordable.

The NNS facility tour and discussions provided reassurance that the approach being considered in the MIT modularity proposals was feasible. The construction of a submarine is very complex with limited space in which to install all equipment. Even within the modules, there is still a great deal of labor to run cables, for example. The vendor supplied equipment going into the submarine is tested as an integrated system outside of the submarine and then installed to assure functionality. This gives the MIT approach of a "virtual factory" more credibility since it appears that such system tests can be performed within the space frame environment that would not be as nearly so congested as a submarine.

At a subsequent tour was made at the General Dynamics Facility at Quonset Point where the other half of the nuclear submarines are made and assembled. This meeting was more focused on the engineering and modularity concepts being used in the construction of submarines. A factory tour was also part of the visit. The most significant and impressive information presented was the degree of labor and cost reduction possible using modularity techniques compared to the old "stick build" approaches. Even after some experience with modularity techniques which are still evolving, the first submarine using modularity techniques was able to reduce by $16 \%$ the labor costs. The second reduced those labor hours by an additional $23 \%$ with more expected as systems and fabrication approaches become more standardized.

Some interesting guidance provided included:

1. Weight handling is a big issue - avoid the use of big cranes - they are expensive.

2. Workers are trained in specific area modules to improve skills and identify areas for further cost reduction (learning curve).

3. People from operations are included in design teams.

4. Laser markings are being used for reference points instead of hand measurements.

5. Digital photogrametric techniques are used for lineups of matching submodules.

6. The decision whether to use flanges or welding depends on application.

7. Lasers are used to make weld lines for plates and structures reducing time and increasing accuracy.

8. Machines to bend pipes, tubes and make welds are preprogrammed to account for spring back, wall thinning, weld shrinkage, etc. to be sure that the final positions are exact. 


\section{NUCLEAR ENERGY RESEARCH INITIATIVE (NERI) PROGRAM \\ GRANT NUMBER DE-FG07-00SF22168 \\ FINAL REPORT}

9. System integrators are important (particularly for our application in the virtual factory environment). They are involved in the design process to be sure the when equipment and submodules arrive they have the same tolerances and quality expected to assemble the component without rework.

10. A "tech refresh plan" is prepared for the submarine to identify components that will have to be maintained and replaced such that their removal can be accomplished within the submarine structure when assembled.

11. Domain knowledge of technology and processes are important to be sure that unique issues in the application are identified in design and fabrication.

12. The construction of each component and its ins tallation is detailed in a step by step book for the craft to be sure that the key issues are identified and the fabrication is repeatable.

The tour of the facility provided evidence that the space frame concept will work. Several large frame structures were observed in the shop that contained large valves, motors and pipes that would be matched with other modules in the submarine subsection. The frames were used as "jigs" and in some cases actual structural supports that would be inserted into the submarine.

General Dynamics pioneered much of the modularity development in the construction of submarines. Their focus was and continues to be on reducing the complexity of the engineering and developing modular construction techniques that will reduce the cost of the construction of the submarines even further. Since General Dynamics is not a participant in the NERI, their willingness to host our visit was much appreciated. It is our hope that future work will include General Dynamics due to their unique expertise.

\section{$\underline{\text { Design Optimization }}$}

The present balance of plant design is based on a helium velocity of $120 \mathrm{~m} / \mathrm{sec}$. This results in thick large diameter pipes to meet code. A new reference design, increasing the flow velocity to $400 \mathrm{~m} / \mathrm{sec}$, is being developed which will be modeled for thermal stresses and support in the space frames to reduce the size and weight of the sub-modules. The code CAEPIPE is being used for these scoping calculations. This work is not within the original scope of the NERI but an additional effort.

\section{COMPONENT AND SHIPPING ASSESSMENT}

\section{$\underline{\text { Reactor Vessel }}$}

$\underline{\text { Design }}$ 


\section{NUCLEAR ENERGY RESEARCH INITIATIVE (NERI) PROGRAM \\ GRANT NUMBER DE-FG07-00SF22168 \\ FINAL REPORT}

The reactor vessel is the largest single component of the MIT pebble bed reactor plant. While it is tempting to segment the vessel into smaller flanged segments, it was chosen to keep the vessel intact with only the reactor vessel head shipped separately. This approach was selected based on the fact that similar sized vessels are shipped to existing power plant sites by barge or rail without difficulty. While this limits the number of sites available, this is not seen as an early impediment to deployment. Should it become necessary to segment the vessel into smaller axial sections or as the Germans have proposed and tested, a cast iron pre-tensioned vessel made up of pie shaped segments, this can always be adapted for more difficult site locations.

\section{$\underline{\text { Materials }}$}

All of the hot side components of the MPBR use a multilayer installation system to maintain the inner wall temperature of the pressure bearing shell to less than $553 \mathrm{~K}$ (536 F). As such, to maintain a reasonable maximum stress level at these temperatures, all the hot side pressure vessel walls will be constructed out of A508 steel which has an ASME limit stress at $536 \mathrm{~F}$ of approximately $10 \mathrm{ksi}$.

\section{$\underline{\text { Seals }}$}

The head (only the reactor vessel head is designed for removal) of the reactor vessel is secured by bolted flanges and sealed with nuclear rated omega o-ring seals.

\section{Support structure}

The vessel is designed to be supported by several support lugs spaced evenly around the circumference of the reactor vessel at the same elevation as the helium inlet and outlet pipes (approximately $1 / 3^{\text {rd }}$ of the way up the reactor vessel) These lugs must support the static load of the vessel and its fuel (approximately 750 tons including fuel). The lugs must also support any dynamic loads caused by seismic vibrations.

\section{$\underline{\text { Weight }}$}

Based on an internal pressure of $8 \mathrm{MPa}$, and an inner vessel diameter of $5 \mathrm{~m}$ (3m core, $1 \mathrm{~m}$ reflector), the wall thickness required is approximately $0.25 \mathrm{~m}$ ( 7" to 10 ") given a core vessel height of $\sim 16 \mathrm{~m}$, the overall vessel mass would be $>500$ tons, far to heavy to transport using conventional means. If the maximum stress level can be raised to $\sim 33 \mathrm{ksi}$ (ASME III.2\&3, VIII Division 1 limit for 630/17-4 precipitation hardened stainless steel @ $550 \mathrm{~F}$ ) either through a material change or by further decreasing the reactor vessel inner wall temperature, the wall thickness would be reduced to $\sim 7.5 \mathrm{~cm}$ and the vessel mass to $\sim 180$ tons (25 tons for the hemispherical end-caps). The graphite reflector would have a mass (assuming 25\% void fraction and a $1 \mathrm{~m}$ thick annulus with a $2 \mathrm{~m}$ thick top and bottom reflector $-16 \mathrm{~m}$ total reflector length) of $\sim 460$ tons. All these dimensions and weights are approximate until detailed analyses can be completed. The head (only the 


\section{NUCLEAR ENERGY RESEARCH INITIATIVE (NERI) PROGRAM \\ GRANT NUMBER DE-FG07-00SF22168 \\ FINAL REPORT}

reactor vessel head is designed for removal) of the reactor vessel is secured by bolted flanges and sealed with nuclear rated omega o-ring seals.

\section{Support structure}

The vessel is designed to be supported by several support lugs spaced evenly around the circumference of the reactor vessel at the same elevation as the helium inlet and outlet pipes (approximately $1 / 3^{\text {rd }}$ of the way up the reactor vessel) These lugs must support the static load of the vessel and its fuel (approximately 750 tons including fuel). The lugs must also support any dynamic loads caused by seismic vibrations.

\section{$\underline{\text { Weight }}$}

Based on an internal pressure of $8 \mathrm{MPa}$, and an inner vessel diameter of $5 \mathrm{~m}(3 \mathrm{~m}$ core, $1 \mathrm{~m}$ reflector), the wall thickness required is approximately $0.25 \mathrm{~m}$ ( 7" to 10") given a core vessel height of $\sim 16 \mathrm{~m}$, the overall vessel mass would be $>500$ tons, far to heavy to transport using conventional means. If the maximum stress level can be raised to $\sim 33 \mathrm{ksi}$ (ASME III.2\&3, VIII Division 1 limit for 630/17-4 precipitation hardened stainless steel @ $550 \mathrm{~F}$ ) either through a material change or by further decreasing the reactor vessel inner wall temperature, the wall thickness would be reduced to $\sim 7.5 \mathrm{~cm}$ and the vessel mass to $\sim 180$ tons (25 tons for the hemispherical end-caps). The graphite reflector would have a mass (assuming $25 \%$ void fraction and a $1 \mathrm{~m}$ thick annulus with a $2 \mathrm{~m}$ thick top and bottom reflector $-16 \mathrm{~m}$ total reflector length) of $\sim 460$ tons. All these dimensions and weights are approximate until detailed analyses can be completed.

\section{$\underline{\text { Modularity / transportation-limitations }}$}

As the reactor vessel is by far the largest and heaviest single component of the MPBR system, it drives the transportation requirements of the entire system. Since one of the design requirements of the MPBR is that all the components be able to be transported on conventional roads, the delivery and construction of the vessel must take this into account.

\section{$\underline{\text { Multi-modal transportation }}$}

While the "last-mile" defines the road-mobile transportation requirements, it is obvious that when given the chance, the vessel, and other components would be moved by cheaper, more convenient means when possible. Given that the other methods of vessel transportation (maritime vessels) are capable of transporting far larger loads, the limitations are thus defined by the last-mile.

Heavy load transportation has seen substantial strides in recent years given the importance of time critical delivery of even extreme loads. Currently the limit for singlelane ultra heavy load haulers (17 axle transporter with prime mover and multiple push trucks) is $\sim 165$ tons. Given the dimensions of the reactor vessel $\sim 5.25 \mathrm{~m}$ dia $\mathrm{x} 24 \mathrm{~m}$ long, the overall dimensions of the vehicle would be $\sim 5.25 \mathrm{~m}$ wide, $\sim 6 \mathrm{~m}$ tall, and $\sim 45 \mathrm{~m}$ long. 


\section{NUCLEAR ENERGY RESEARCH INITIATIVE (NERI) PROGRAM \\ GRANT NUMBER DE-FG07-00SF22168 \\ FINAL REPORT}

This size load has been moved over several hundred miles (http://www.contractorscargo.com/CCC/index.html) over normal roads with preparation limited to measurement and, where necessary, lifting of utility lines. Double lane ultra heavy haulers have moved loads upwards of 300,000kg over 10 miles through heavily built up areas (http://www.contractorscargo.com/CCC/column.html).

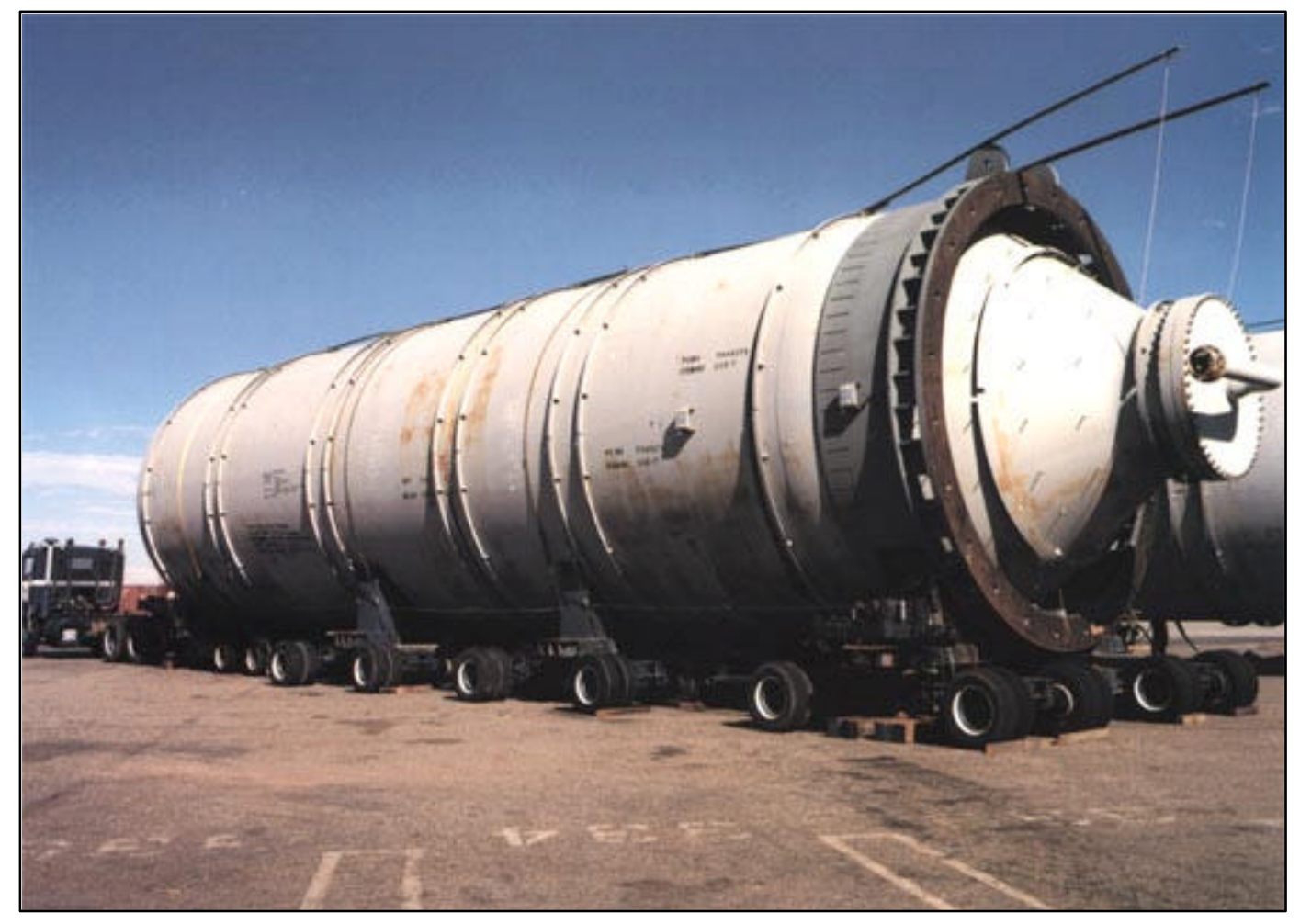

Figure 11. Ultra-heavy load hauler with load

Based on these capabilities, the existence of an extensive network of inland and coastal waterways, and the proximity of most population centers to waterways, it follows that there would be two modes of transporting the reactor vessel. If the target site was far from a waterway, the reactor vessel would be shipped without the reflector installed and without the top reactor vessel head. In this mode, the vessel (assuming the thinner 33ksi wall) could be transported by a conventional single lane (albeit wide load) transporter. The graphite reflector sections would be transported separately by conventional truck. Given a normal "low-boy" trailer capacity of $\sim 50$ tons, the reflector and end cap (the end cap would be a wide load, or outsize height load) could be transported with approximately 10 truck-loads.

(http://www.fontainetrailer.com/products/fsi\%20products/tl50.html). If the target site were close to a waterway, the vessel could be transported with nearly all of the reflector in place, the cost trade-off of this method (reduced on site construction cost vs. more expensive transportation cost) has not been performed, however, given the need to lift the 


\section{NUCLEAR ENERGY RESEARCH INITIATIVE (NERI) PROGRAM \\ GRANT NUMBER DE-FG07-00SF22168 \\ FINAL REPORT}

vessel into position in the containment building, it seems the first method would be cheaper to implement.

If the vessel were constructed with the thicker wall $(450,000 \mathrm{~kg}$ vessel with two $37,500 \mathrm{~kg}$ reactor vessel head) the transportation would be limited to the double lane, heavy hauler, and thus the cost for transportation would be substantially increased. Double lane haulers have been used to transport loads in this size range several hundred miles (http://perkinsonline.com/gallery2.asp?GRecno=12\&PNum=3) in the past, and so, given the limited number of components (one vessel per reactor) this heavier vessel would not invalidate the proposed "truck only" method of transportation.

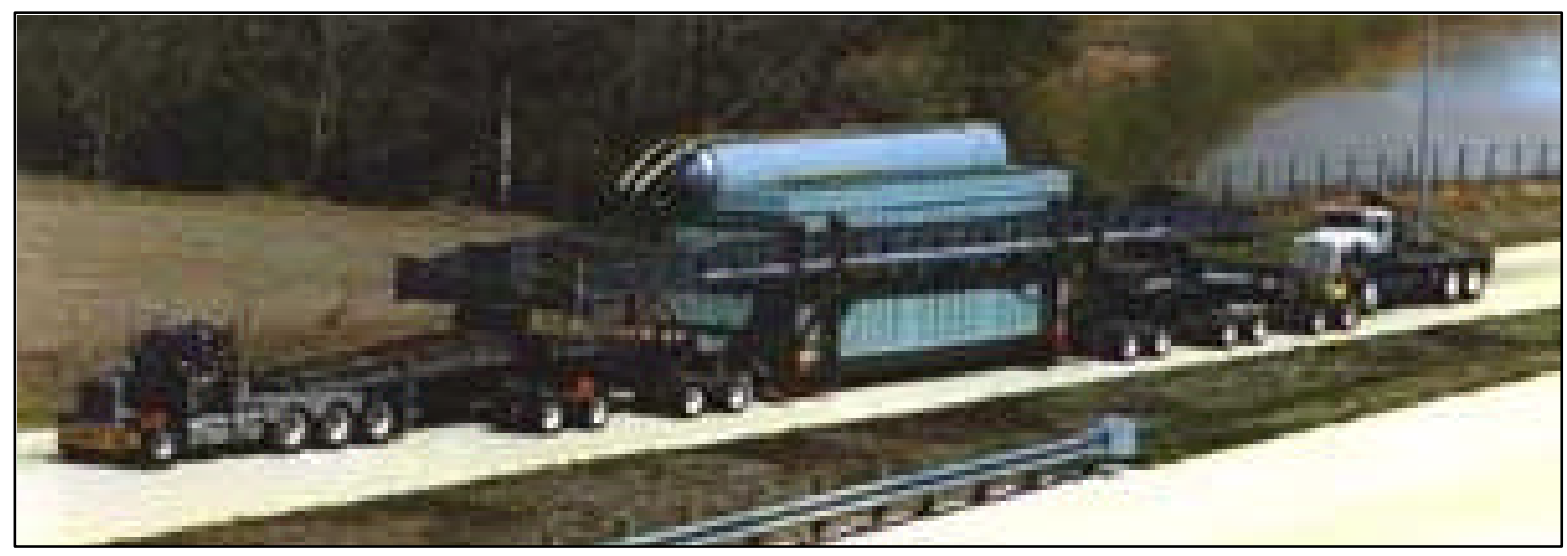

Figure 12. Multiple tractor ultra-heavy load hauler

\section{Estimated Cost for Reactor Vessel}

Given a fabricated cost for high temperature steels of $\sim \$ 7 / \mathrm{kg}(\$ 3 / \mathrm{lb})$, and nuclear graphite costs of $\sim \$ 5 / \mathrm{kg}$ (based on high purity graphite feedstock cost of $\$ 2.7 / \mathrm{kg}$ and a $100 \%$ fabrication cost overhead), the reactor vessel with reflector would range from $\sim \$ 3.5$ million to over $\$ 6$ million. Additionally, this unit cost figure may not adequately account for the additional capital expense to cast such a vessel, so the cost may be substantially higher.

The transportation cost for the vessel and graphite is also difficult to establish. As this type of transport is considered "custom" it is difficult to obtain a quote unless the exact route and payload is given. However, a quote was obtained for a $86,000 \mathrm{~kg}$ payload on a single lane transporter over a distance from St. Louis, MO to Seattle, WA of $\$ 50,000$. Given this figure and assuming a $300 \%$ increase in specific cost to cover the additional equipment, escort, and utility presence necessary for the double-lane transporters, a transportation figure of $\$ 0.6 \mathrm{M}$ (thin vessel) to $\$ 1.1 \mathrm{M}$ (thick vessel) for truck-only transportation can be estimated. These costs are only an estimate based on rough rules of thumb and example quoted costs. The costs for delivery may be higher, and as such, research into more accurately defining the cost estimation models is continuing. 


\section{NUCLEAR ENERGY RESEARCH INITIATIVE (NERI) PROGRAM \\ GRANT NUMBER DE-FG07-00SF22168 \\ FINAL REPORT}

Given a fabricated cost for high temperature steels of $\sim \$ 7 / \mathrm{kg}(\$ 3 / \mathrm{lb})$, and nuclear graphite costs of $\sim \$ 5 / \mathrm{kg}$ (based on high purity graphite feedstock cost of $\$ 2.7 / \mathrm{kg}$ and a $100 \%$ fabrication cost overhead), the reactor vessel with reflector would range from $\sim \$ 3.5$ million to over $\$ 6$ million. Additionally, this unit cost figure may not adequately account for the additional capital expense to cast such a vessel, so the cost may be substantially higher.

The transportation cost for the vessel and graphite is also difficult to establish. As this type of transport is considered "custom" it is difficult to obtain a quote unless the exact route and payload is given. However, a quote was obtained for a $86,000 \mathrm{~kg}$ payload on a single lane transporter over a distance from St. Louis, MO to Seattle, WA of $\$ 50,000$. Given this figure and assuming a 300\% increase in specific cost to cover the additional equipment, escort, and utility presence necessary for the double-lane transporters, a transportation figure of $\$ 0.6 \mathrm{M}$ (thin vessel) to $\$ 1.1 \mathrm{M}$ (thick vessel) for truck-only transportation can be estimated. These costs are only an estimate based on rough rules of thumb and example quoted costs. The costs for delivery may be higher, and as such, research into more accurately defining the cost estimation models is continuing.

\section{$\underline{\text { Fuel Tanks }}$}

The fresh and spent fuel storage tanks are incorporated into the design as standard size modules. Given a daily MPBR fresh fuel requirement of $\sim 340$ pebbles, and an equal amount of waste pebbles, each reactor module requires $\sim 0.1 \mathrm{~m} 3$ of fuel ( $~ 50 \%$ packing fraction) per day. Using a fresh fuel cask size of $\sim 1.75 \mathrm{~m}$ dia $\mathrm{x} 5 \mathrm{~m}$ long, approximately 50 days worth of fuel would be contained in each cask. A spent fuel cask approximately $1.8 \mathrm{~m}$ dia $\mathrm{x} 6 \mathrm{~m}$ long (http://www.geocities.com/ntirs/drycask.html) would contain approximately 50 days worth of spent fuel pebbles.

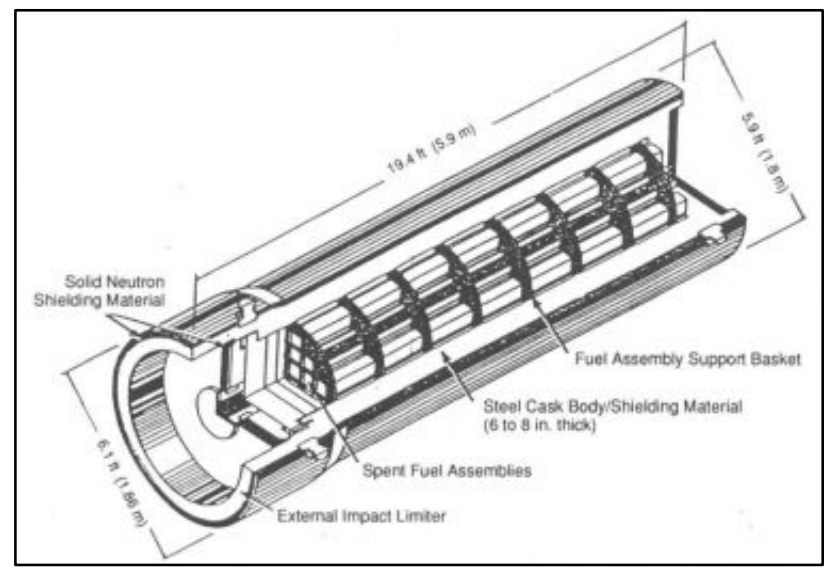

Figure 13. Example spent fuel storage container

This cask would also provide the shielding necessary for the spent fuel, eliminating the need for a separate shielded area within the reactor building to contain the spent fuel. 


\section{NUCLEAR ENERGY RESEARCH INITIATIVE (NERI) PROGRAM \\ GRANT NUMBER DE-FG07-00SF22168 \\ FINAL REPORT}

This concept is a notional one, once past research into this specific issue has been analyzed, a more accurate representation of the spent and fresh fuel storage can be generated.

\section{$\underline{\text { Size/Number }}$}

Given that the MPBR reactor modules would most likely be used in groups, a ten module reactor would need a new fuel module (containing two fresh fuel casks) and a replacement spent fuel module every 5 days. There is a substantial trade-off to be made regarding the amount of fresh fuel stored on site. On one hand, by limiting the fuel stored on site to a single fuel module per reactor and a single waste module, the amount of inactive fuel stored on site is reduced to a minimum. However, this requires regular deliveries of fuel to the site, complicating the delivery process if substantial escort or security is needed for the fuel. Given the goal that the MPBR reactors are common throughout the country, the just-in-time delivery method will optimize the interaction of the pebble fabrication facility (continuously manufacturing pebbles) and the reactors (requiring periodic re-loads).

\section{$\underline{\text { Modularity }}$}

In keeping with the modularity approach to the MPBR design, both the spent fuel cask and the fresh fuel cask are designed to be replaced in a "plug and play" manner.

\section{$\underline{\text { Replacement / Refueling }}$}

As the MPBR reactor is continuously refueled by the pebble handling system, replacement of either the fresh fuel feed tank or the spent fuel storage tank will not require a shutdown of the system. The fresh fuel tank, built into a standard size spaceframe module $(2.5 \times 2.5 \times 6 \mathrm{~m})$, will be installed at the top of the reactor where its pebbles can drain into the pebble handling system (through a fueling port). The spend fuel cask will also be installed into a standard size space-frame $(2.5 \times 2.5 \times 6 \mathrm{~m})$ and placed at the same level as the feed tank. When replacement of either of the modules is required, gate valves will be closed in both the casks and the fuel ports, and the containers moved to the loading area of the plant (outside the containment building) by the building's bridge crane. This plug-and-play process, along with the requirement that the fuelling system be at near atmospheric pressure and separate from the primary flow (through the use of a ball valve isolation system in both the feed and exhaust fuel lines) ensures that replacing the modules will not release any radiation. For additional radiation protection, the fuelling system piping can be purged with clean helium and evacuated prior to disconnecting the casks.

\section{$\underline{\text { Inventory Control }}$}




\section{NUCLEAR ENERGY RESEARCH INITIATIVE (NERI) PROGRAM \\ GRANT NUMBER DE-FG07-00SF22168 \\ FINAL REPORT}

The inventory control system is needed to recover the helium from both the primary and secondary sides during startup and shutdown, assuming that load following is performed with bypass control rather than inventory control. The total helium inventory of the system is approximately $200 \mathrm{~kg}$ each for the primary and secondary sides. At $8 \mathrm{MPa}$ and $330 \mathrm{~K}$ this is roughly $20 \mathrm{~m} 3$ each. The vessel size needed to contain this amount of helium is roughly $2.5 \mathrm{~m}$ dia $\times 6 \mathrm{~m}$ long (assuming similar insulated construction to the IHX vessels, as the inventory control system would, in a dump situation, be receiving hot helium). The inventory control system can thus be reduced to two containers, one for each side of the system. Each container would include the helium storage vessel $(\sim 13,000 \mathrm{~kg})$ and an electrically driven compressor to pump helium from the MPBR system. For the primary side system, a water cooler heat exchanger (similar to the precooler) is also included (such a heat exchanger would be $\sim 1.6 \times 0.8 \times 0.8 \mathrm{~m}$ and weight roughly $4000 \mathrm{~kg}$ ). For a pump-down time of $\sim 100$ seconds, roughly $7 \mathrm{MW}$ of heat would have to be removed. This pumping rate could be accommodated using a $\sim 1.7 \mathrm{MW}$ motor $(\sim 7000 \mathrm{~kg}, 2 \times 1.5 \times 1.5 \mathrm{~m}$ (Seimens frame 6811$))$. The overall module size would be $2.5 \times 2.5 \times 12 \mathrm{~m}$ and weight $\sim 25,000 \mathrm{~kg}$ without the space-frame.

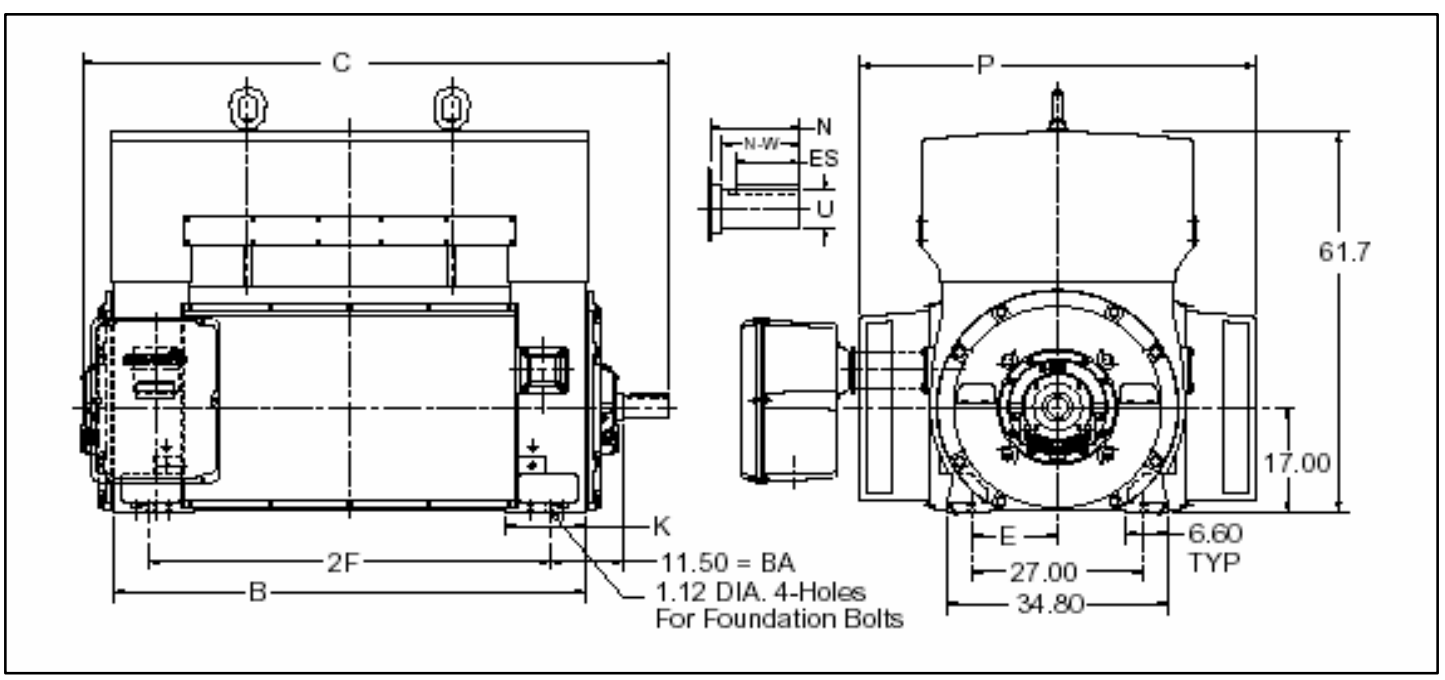

Figure 14. Seimens large frame motor (example for inventory control system compressor)

The cost of the inventory control system can be estimated using the specific costs of the vessel, heat exchanger and compressors along with the listed price of the compressor drive motor. The heat exchanger cost is $\sim \$ 16,000(\$ 4 / \mathrm{kg})$, the vessel cost is $\sim \$ 40,000$, the compressor cost of $\sim \$ 100,000$, and a motor cost of $\sim \$ 94,000$ yields an inventory control system cost of $\sim \$ 250,000$ for each module.

\section{$\underline{\text { Refueling System Modularity }}$}




\section{NUCLEAR ENERGY RESEARCH INITIATIVE (NERI) PROGRAM \\ GRANT NUMBER DE-FG07-00SF22168 \\ FINAL REPORT}

The refueling system is designed following the containerized approach used for the other MPBR modules. The refueling system is designed to remove a pebble from the reactor vessel, analyze its burnup, and either exhaust it to a spent fuel storage tank, or return the pebble to the top of the reactor vessel.

$\underline{\text { Module Location }}$

In order to maximize the replaceabilty of the refueling system, the amount of hardware installed below the reactor vessel is kept at a minimum (quite the opposite of the ESKOM PBMR design). The extent of the equipment installed below the reactor vessel is the isolation valve, purge valves, and pneumatic pebble conveyor. All of these components are integrated into the reactor vessel module, as is the piping to carry the pebbles up to the top of the reactor vessel. Installed directly on the top of the reactor vessel is a single refueling module. This module contains the equipment necessary to analyze the pebble burn-up and the pneumatic conveyor piping to transport the pebbles. The fresh fuel module is placed on top of this refueling module by the building's bridge crane, and the spent fuel module is placed directly beside it. Thus the number of connections to the reactor vessel from the refueling module is limited to the exhaust pebble tube ascending from the bottom of the reactor vessel, and the individual fuelling tubes to the top of the vessel.

\section{$\underline{\text { Replacement }}$}

Replacement of the refueling module is assumed as the moving parts necessary to isolate, analyze, and transport the pebbles will require maintenance or replacement during the life of the system. For replacement, the isolation valves are shut, the fresh fuel and spent fuel modules removed, the refueling module disconnected from the vessel, and removed. During this operation, the reactor can continue to operate (assuming the operation does not take an excessive amount of time) as the built-up pebbles can be removed at a slightly higher rate following installation of the replacement refueling system.

\section{CONSTRUCTION BUILD-OUT PLAN}

The construction plan of the MPBR reactor system follows a step by step process described below, and illustrated in schematic form.

\section{$\underline{\text { Excavation }}$}

The first step in the construction of the MPBR module is the excavation of the area for the containment / BOP building. There are two possibilities for the vertical layout of the MPBR plant. First, if it is necessary for the containment structure to be buried to the level of the top of the reactor vessel for accident heat transfer concerns, the excavation 


\section{NUCLEAR ENERGY RESEARCH INITIATIVE (NERI) PROGRAM \\ GRANT NUMBER DE-FG07-00SF22168 \\ FINAL REPORT}

will go to a depth of $\sim 19 \mathrm{~m}$, at this depth, approximately $9 \mathrm{~m}$ of the primary side containment building will protrude above ground level.

Foundation / walls

The MPBR containment building is separated into two volumes, the primary side (containing the reactor, IHX modules, and fuel handling apparatus) and the secondary side (containing the remainder of the BOP). Each of these volumes is enclosed with $1 \mathrm{~m}$ thick reinforced concrete walls, and a $2 \mathrm{~m}$ thick floor. This will provide the necessary protection of the MPBR system from outside projectiles, and contain any pressure buildups caused by catastrophic leaks. The primary side internal dimensions are approximately $15 \times 15 \times 25 \mathrm{~m}$ while the secondary side dimensions are $15 \times 15$ x 10m (for the above ground layout). For a fully submerged layout, the two volumes would have the same height). Given this internal volume, if the entire helium inventory were vented into the building, the internal pressure would only increase by approximately $100 \mathrm{kPa}$ (assuming zero cooling, once cooled, the pressure would only be $\sim 25 \mathrm{kPa}$ above ambient). Not shown in the building layout is the extension of the two volumes laterally at ground level by approximately $5 \mathrm{~m}$. This "shelf" is the loading area where modules are positioned on a hydraulic dolly to be moved outside of the containment structure (through a sliding, sealed, concrete door) for transportation.

Based on a reinforced concrete cost (delivered) of $\sim \$ 120 / \mathrm{m} 3$ (based on forta fiber reinforced, 4000psi concrete with $16 \mathrm{~m}$ of re-rod per $\mathrm{m} 3$ ), the material cost for the floor, walls, and concrete ceiling is approximately $\$ 1.3 \mathrm{M}$. Excavation to this depth and removal (conservative pricing to generalize across most earth types) costs of $\$ 10 / \mathrm{m} 3$ would yield an excavation cost of $\sim \$ 130,000$. Slip-form pouring of the concrete walls and floors would cost approximately $\$ 220,000$.

$\underline{\text { Vertical module supports (IHX, manifolds) }}$

In order to facilitate replacement of the IHX modules, a steel beam structure is erected in the primary side volume that supports the both the IHX modules and the manifold modules during normal operation. This structure extends in a stepped fashion toward the reactor vessel to provide rails to slide the IHX modules out for replacement. An additional steel beam structure encircles the top of the reactor module to support the fuel handling modules. The reactor vessel itself is supported by a steel and concrete ring extending upward from the floor of the primary volume. These support structures, along with a shelf-like loading dock structure, are not shown in the illustrations for clarity purposes.

$\underline{\text { Roof }}$

The roof of each volume is a steel reinforced concrete form designed to protect the MPBR modules from outside penetration, contain $>1$ atm internal pressure, and provide the mechanical support for an overhead beam gantry crane. Each volume has a similar 


\section{NUCLEAR ENERGY RESEARCH INITIATIVE (NERI) PROGRAM \\ GRANT NUMBER DE-FG07-00SF22168 \\ FINAL REPORT}

bridge crane that is used to install and remove the various modules. The roof of the primary side volume also incorporates two removable (non-motorized) concrete caps. One cap, approximately $7 \mathrm{~m}$ square is centered over the reactor vessel, while the other, approximately $3 \mathrm{~m}$ square is centered over the manifold module. These caps can be removed using an external crane to enable access to the reactor vessel. Once removed, the vessel and manifold module can be lowered into place. As the reactor vessel is centered roughly $5 \mathrm{~m}$ from the outer building wall, and (assuming $5 \mathrm{~m}$ from the top of the vessel to the lift point during installation) a crane height of more than $35 \mathrm{~m}$ is required, a $800 \mathrm{~T}$ capacity crane like the Liebherr LTM1800 would be able to lift approximately $250,000 \mathrm{~kg}$.

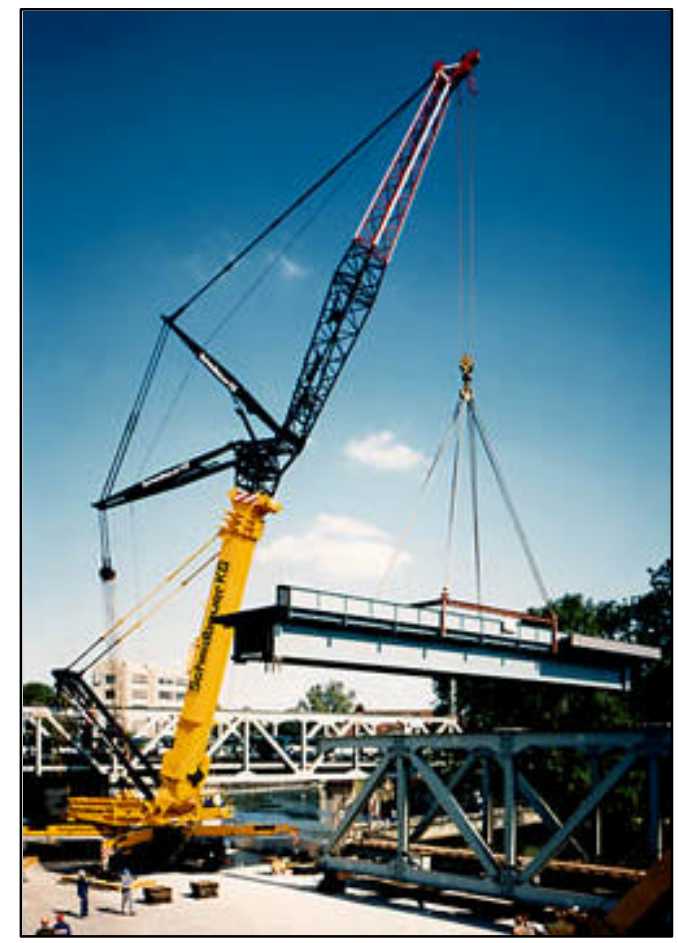

Figure 15. Heavy lift crane (example of type used to install vessel components)

The $7 \times 7 \times 1 \mathrm{~m}$ concrete cap would weigh between 110,000 and $120,000 \mathrm{~kg}$. The roof itself is steel beam reinforced cast-in-place reinforced concrete structure. The same crane would be used to install the roof support beams and the bridge cranes.

\section{$\underline{\text { Bridge Crane Installation / Requirements }}$}

The bridge cranes used to install and replace the various modules are required to emplace and remove the modules in each volume. The IHX modules are the heaviest modules in 


\section{NUCLEAR ENERGY RESEARCH INITIATIVE (NERI) PROGRAM \\ GRANT NUMBER DE-FG07-00SF22168 \\ FINAL REPORT}

the primary volume, with a mass of $\sim 40,000 \mathrm{~kg}$. A loaded spent fuel module will have a similar mass. On the secondary side, the heaviest module is the turbo-generator module which weighs approximately $300,000 \mathrm{~kg}$. However, the design for a suitable bridge crane to accommodate the generator module, the bridge crane can be sized for the next heaviest component, the turbo-compressor sets, which weigh approximately $45,000 \mathrm{~kg}$. The turbogenerator module, given its position at the edge of the layout, with no modules placed underneath it, enables it to be removed and lifted to surface level using a short span gantry / bridge crane. This crane will be able to lift the generator module vertically and move laterally to remove the generator module from the building.

During replacement operations, if a module is hiding the target module, the first module is removed and placed in one position on the loading shelf, while the target module is removed and replaced. Given the $<50,000 \mathrm{~kg}$ requirement of the bridge crane, there are many COTS products that could be used.

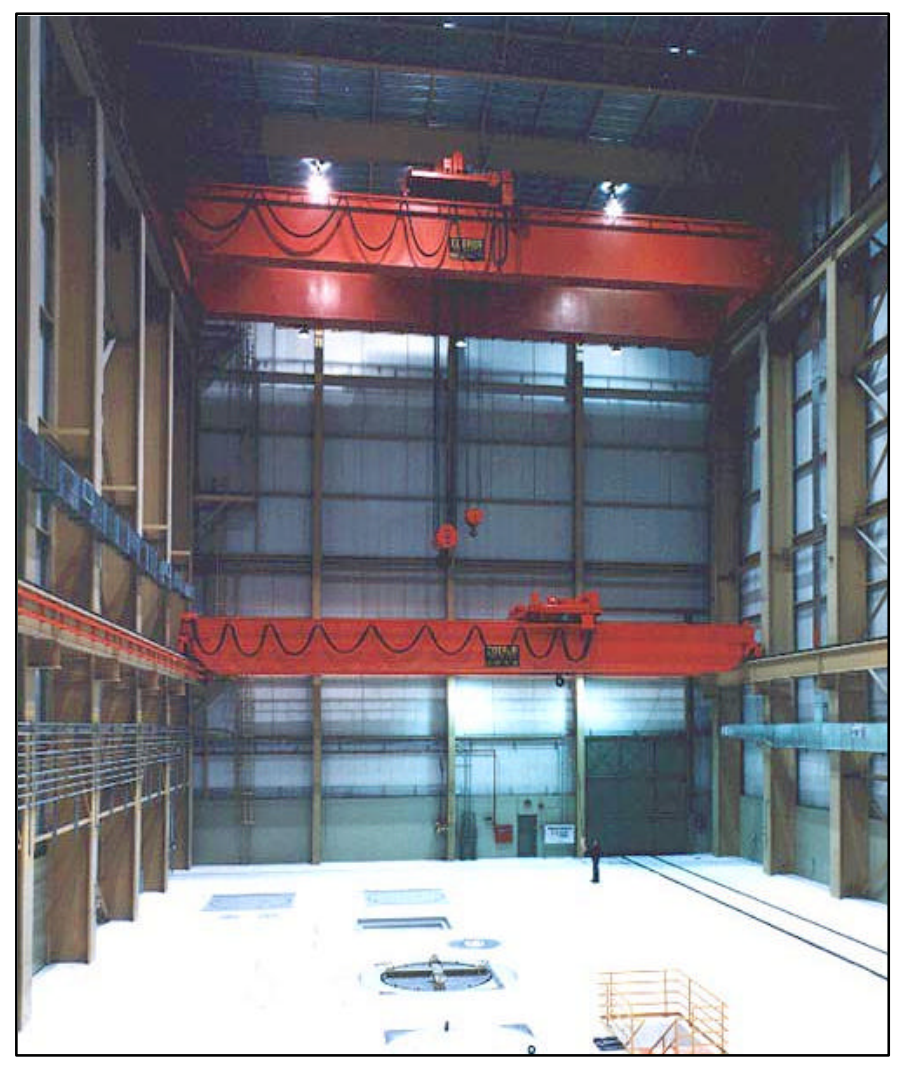

Figure 16. Overhead bridge crane used for module installation and removal 


\section{NUCLEAR ENERGY RESEARCH INITIATIVE (NERI) PROGRAM \\ GRANT NUMBER DE-FG07-00SF22168 \\ FINAL REPORT}

\section{COST ESTIMATE FOR OTHER COMPONENTS}

\section{$\underline{\text { IHX Modules }}$}

Based on a heat exchanger cost of $\$ 20 / \mathrm{kg}$ (HEATRIC) and a vessel material cost of $\$ 3 / \mathrm{kg}$, the six IHX modules will cost approximately $\$ 300,000$ each.

\section{$\underline{\text { Recuperator Modules }}$}

The recuperator modules are similar in size and weight to the IHX modules, however, their lower operational temperature allows the use of lower cost material, reducing the unit cost to $\sim \$ 4 / \mathrm{kg}$, for a single module (with vessel) cost of $\sim \$ 66,000$.

\section{Turbo-compressor Sets}

Based on estimates of $\$ 10.6$ million for each turbo-machine, $\$ 26,000$ for a $25 \mathrm{MW}$ class heat-exchanger $(\$ 4 / \mathrm{kg})$ and $\$ 50,000$ for the vessel and volute castings, each turbocompressor set will cost approximately $\$ 21.25$ million. With an turbine internal mass of $2000 \mathrm{~kg}$ (based on the $8000 \mathrm{~kg}$ weight of the LM6000 aero-derivative gas turbine and compensating for the difference in number of stages - the two have similar diameters), the turbo-machinery cost can be estimated as $\$ 5,000 / \mathrm{kg}$, or $\$ 0.25 / \mathrm{W}$. This cost appears to be quite high, and may be more indicative of a one-off cost rather than a mass production cost.

\section{Power turbine}

Again, assuming a turbo-machine estimated cost of $\$ 30$ million (based on $\sim \$ 0.25 / \mathrm{W}$ ), the power turbine vessel and volute castings will cost approximately $\$ 50,000$ for a total cost of approximately $\$ 30$ million. Again, this cost is more indicative of a one-off cost rather than a mass production product. However, adapting an aerospace learning curve to the turbomachinery shows a $100^{\text {th }}$ unit cost of approximately $\$ 10 \mathrm{M}$ for the power turbine and $\sim 3 \mathrm{M}$ for the smaller turbine sets.

\section{Generator}

The generator cost is estimated based on a cost of $\$ 50,000 / \mathrm{MW}$ for large frame synchronous motors. Scaling to a $125 \mathrm{MW}$ system would result in a generator cost of $\$ 7.5 \mathrm{M}$ (roughly $\$ 30 / \mathrm{kg}$ )

\section{Intercooler / Precooler}

The non-integral intercooler is roughly equal to $1 / 2$ of an equivalent IHX module, made out of 347SS instead of Incoloy as such, the intercooler, and its associated shortened vessel should cost approximately $\$ 50,000$. The precooler is roughly the size of an IHX module and thus should cost approximately $\$ 66,000$.

\section{Circulator}

Using a turbomachinery cost of $\$ 0.25 / \mathrm{W}$, the $14 \mathrm{MW}$ circulator cost is estimated to be $\sim 3.5 \mathrm{M}$. The cost of the synchronous motor to drive the circulator can be estimated 


\section{NUCLEAR ENERGY RESEARCH INITIATIVE (NERI) PROGRAM \\ GRANT NUMBER DE-FG07-00SF22168 \\ FINAL REPORT}

based on $\$ 30,000$ / MW figure. Using these figures, the estimated cost for the primary circulator is $\sim \$ 4 \mathrm{M}$

\section{External Support systems}

Cost estimation for the external support and refueling systems requires a level of design detail not possible at this point in the MPBR design.

\section{OVERALL SYSTEM COST AND LEARNING CURVE}

Based on the various cost estimates used for the MPBR design, the total cost of the components detailed here is as follows: (http://www.jsc.nasa.gov/bu2/learn.html)

Table 2. System Cost and Learning Curve

\begin{tabular}{|c|c|c|c|}
\hline & Cost $(\$ M)$ & Learning Curve & Cost @ 10 ${ }^{\text {th }}$ MPBR \\
\hline Reactor Vessel & $\$ 4.1-7.1$ & 0.95 & $\$ 3.2-5.6$ \\
\hline IHX & $\$ 1.8$ & 0.9 & $\$ 1$ \\
\hline Recuperator & \$0.4 & 0.9 & $\$ 0.3$ \\
\hline Turbo-compressor & $\$ 42.5$ & 0.85 & $\$ 19$ \\
\hline Generator & $\$ 7.5$ & 0.96 & $\$ 6$ \\
\hline Power Turbine & $\$ 30$ & 0.85 & $\$ 13.5$ \\
\hline Precooler/Intercooler & $\$ 0.1$ & 0.9 & $\$ 0.1$ \\
\hline Circulator & $\$ 4$ & 0.87 & $\$ 2$ \\
\hline Inventory Control & $\$ 0.5$ & 0.92 & $\$ 0.4$ \\
\hline Containment & $\$ 1.7$ & 0.96 & $\$ 1.5$ \\
\hline Bridge Cranes & $\$ 0.25$ & 0.96 & $\$ 0.2$ \\
\hline Transportation & $\$ 1.5$ & 0.96 & $\$ 1.2$ \\
\hline Total & $\$ 94.25$ & & $\$ 48.4$ \\
\hline
\end{tabular}

\section{OTHER TECHNICAL ISSUES}

\section{Helium Piping Velocity Issues}

As discussed in prior reports, the velocity of the Helium flow in the piping has been a point of design contention. The velocity should be kept as high as possible to minimize the size of the piping required by the system, however, as the velocity increases so do frictional losses, diffuser efficiency losses, and the possibility of damage due to entrainment of particulates in the pipe flow. In the ESKOM design, flow speed was limited to $120 \mathrm{~m} / \mathrm{s}$ to prevent "particle entrainment and erosion." In this MPBR design, the secondary side of the system is insulated from any possible graphite particulates 


\section{NUCLEAR ENERGY RESEARCH INITIATIVE (NERI) PROGRAM \\ GRANT NUMBER DE-FG07-00SF22168 \\ FINAL REPORT}

introduced by the pebbles by the IHX modules. As such, only the primary side should suffer the velocity limits imposed by particle entrainment. Given that the largest pipe in the system is the pipe from the power turbine to the recuperator (>35" ID) and the largest primary side pipe is the reactor to IHX hot flow pipe ( 26 " ID), a velocity increase in the secondary side pipe could substantially reduce the quantity of ultra-large heavy piping required. Reducing the quantity of these large pipes is important not only for cost control considerations, but also layout considerations, as the ASME code severely limits the radii of curvature of these types of pipes and the larger diameter pipes, with their large radii would severely impair the compact layout envisioned.

By increasing secondary side flow velocity to $220 \mathrm{~m} / \mathrm{s}$, the secondary side piping would be reduced in size so the maximum size on either side of the IHX would be $~ 26$ " ID. This velocity is still far below the speed of sound in helium at the temperatures encountered in the reactor system, and is not too much above the axial flow velocity in the turbo-machinery, minimizing diffuser losses.

\section{Plant Hotel Load Estimation}

The earlier estimates of the plant hotel load (ranging from 3-7 MWe) seemed extremely high, and were adversely affecting the overall efficiency of the plant. In order to derive the closest possible estimate for overall plant efficiency (which directly drives the economic profitability of the system), a better estimate for the hotel load is required. While a conventional nuclear power plant would require this high hotel load given the extremely large structure, internal lighting, command and control facilities, safety systems, personnel support systems (cafeteria, restrooms, etc), this plant is designed to be nearly autonomous in operation, sharing personnel resources with other reactor modules, and minimizing any non-productive power expenditures. As such, this plant in operation would require the bare minimum in hotel loading. Based on a conservative estimate of water loop pressure drop through the precooler and intercoolers, and a reasonable estimate of pumping efficiency, a cooling pump power level of $\sim 1-1.25$ MWe would be required. Including an additional 0.25 MWe for ancillary systems (valves, sensors, computing, minimal lighting, etc.) a hotel load figure of $\sim 1.5 \mathrm{MWe}$ can be derived. By using this more accurate figure of 1.5 MWe (which was calculated based on actual component efficiencies and load estimates) rather than the "scaled from other applications" figure of 3-7 MWe, the power production, and thus revenue, of the plant increases by over $1 \%$. The sharing of plant support facilities will also decrease the capital cost of the plant, further increasing profitability.

\section{Pipe Insulation / Flanged Joint Design}

The insulation system proposed previously has also been modeled in Solid Edge. The key points of the insulation system are as follows:

? Solid silica fiber composite insulator sandwiched between internal non-load bearing liner and exterior pressure bearing pipe.

? Internal liner need not be leak-tight, slip fittings possible to accommodate thermal expansion.

? Liner is pressure backed by bleed helium from HPC 


\section{NUCLEAR ENERGY RESEARCH INITIATIVE (NERI) PROGRAM \\ GRANT NUMBER DE-FG07-00SF22168 \\ FINAL REPORT}

? During normal operation near zero bleed helium flow (since the liner thermally expands more than the outer pipe, the slip fit liner joints will seal radially)

? Under accident case (liner and insulation are torn away), arteries provide a high flow rate path for cold helium to shield exterior pipe until system can be shut down.

? $\quad 2 \mathrm{~cm}$ of COTS silica fiber insulation is required to reduce the inside temperature of the pressure bearing pipe to $\angle 280 \mathrm{C}$ based on natural convection cooling of a smooth exterior pipe. If necessary fins can be added to the exterior of the piping to further reduce the temperatures with insignificant impact on overall efficiency (the heat flow through the insulation to maintain pipe temperatures of $<280 \mathrm{C}$ is on the order of 500-1000 W per meter of pipe).

? Low helium flow pressure backed insulation system reduces cooling parasitic losses to $<<500 \mathrm{~kW}(\sim 1 \mathrm{~kW} / \mathrm{m}$ of pipe).

? Since the entire exterior shell of the plant piping and vessels can be maintained at a much lower temperature, this minimizes thermal expansion design issues.

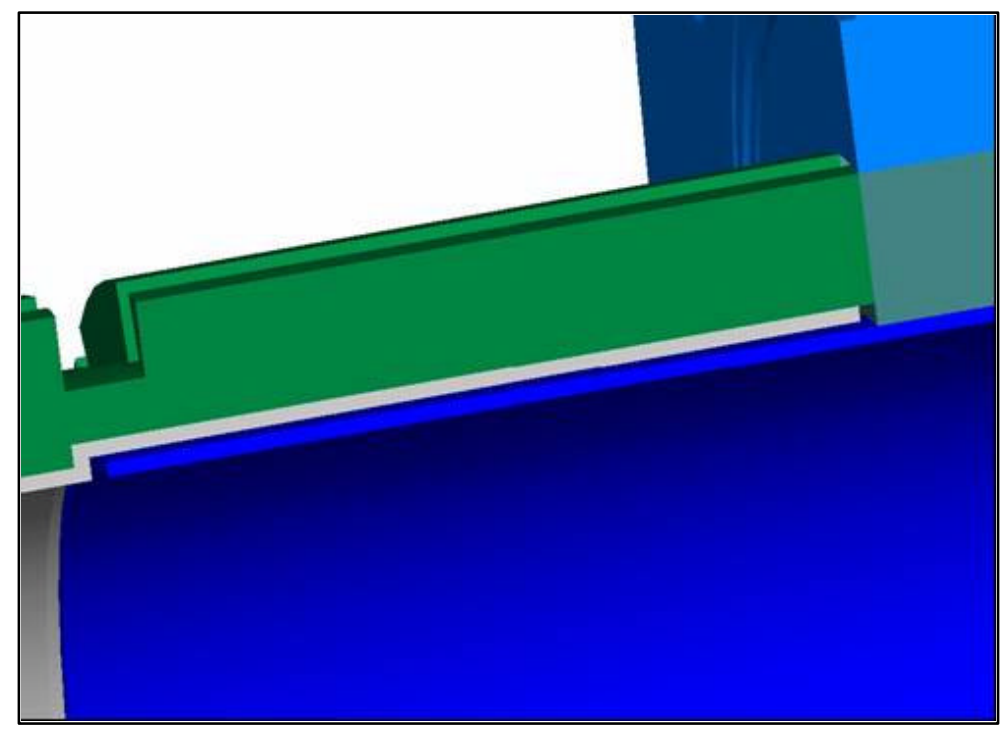

Figure 17. Close up view of insulation / liner joint

Additionally, since the exterior piping is maintained at a constant $280 \mathrm{C}$ throughout the hot-side of the system, differential expansion is minimized (since the internal flow ranges from $>900 \mathrm{C}$ to $\sim 500 \mathrm{C}$ ). The drawing below illustrates the insulation design proposed. The brown and light grey components are the internal liners (this picture is of a joint between two pipes). The green and dark grey components are the insulation tiles themselves, and the blue component is the outer pressure bearing pipe (thicknesses are not to scale and are shown enlarged to illustrate the design). The first drawing is an enlarged image of the slip-joint itself. The joint is a multiple tongue and groove joint, where the inner liner of one side (brown) fits within the liner of the other side (grey), while the insulation tiles of the grey side (green insulation) fit within the insulation tiles 


\section{NUCLEAR ENERGY RESEARCH INITIATIVE (NERI) PROGRAM \\ GRANT NUMBER DE-FG07-00SF22168 \\ FINAL REPORT}

of the brown side (dark grey). This type of joint minimizes the leakage flow from the interior of the liner. Assembly of this type of structure is surprisingly easy, as the insulation can be held to the interior liner by simple tension bands. The banded insulation / liner can be slipped inside the exterior pipe during assembly (if necessary, the insulation / liner structure can be cooled and the exterior pipe heated to facilitate this insertion). Under operation, since the liner and insulation are far hotter than the exterior pipe, thermal expansion forces the interior structures against the exterior pipe, mechanically stabilizing the system.

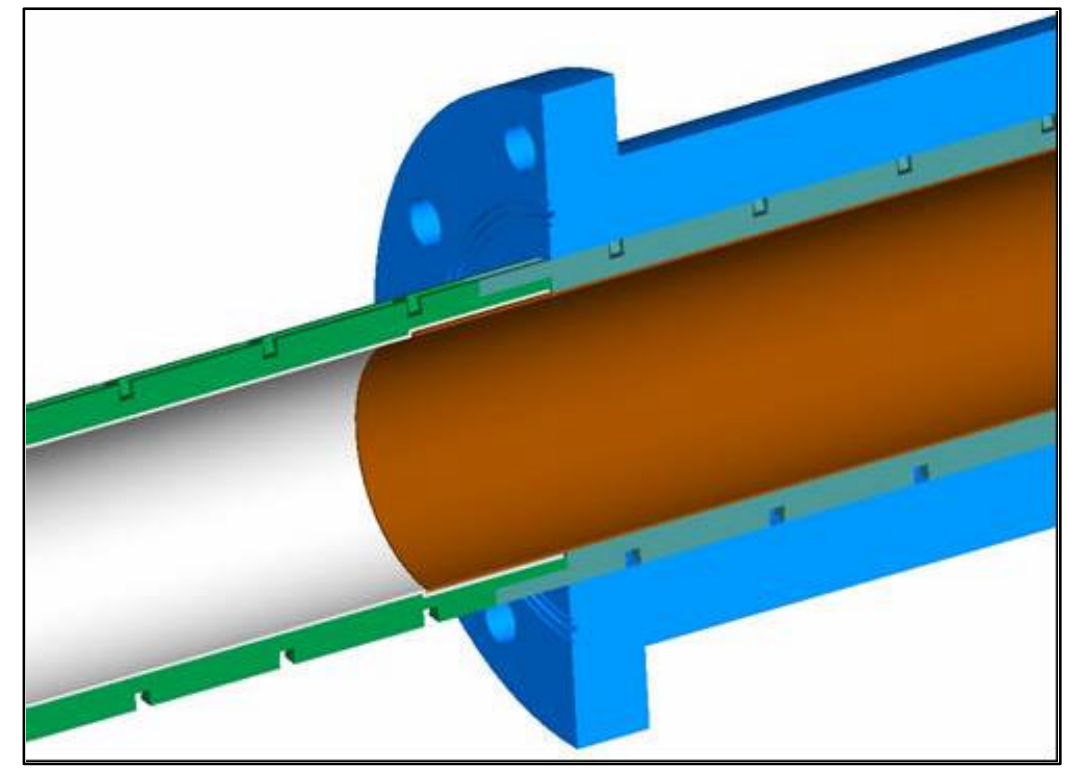

Figure 18. Diagram of flanged insulated joint

The non-welded flanged joint is also illustrated in the drawing above. This flange design makes it possible to achieve near perfect sealing of the internal helium flow without the need for seal welds, simplifying assembly of the plant on site. The design incorporates a standard bolted ASME flange with scavenged multiple oring seal. The seal itself is composed of at least two o-rings (possibly metallic knife-edge o-ring seals similar to UHV copper seals) and an intermediate scavenged chamber. As shown in the flange drawing, the innermost o-ring bears the pressure loads of the helium flow. This o-ring does not need to be leak-tight, as any helium that leaks past is pumped from the scavenging groove (which is maintained at sub-atmospheric pressure by a scavenging pump). The outer o-ring prevents atmospheric gasses from leaking into this scavenging 


\section{NUCLEAR ENERGY RESEARCH INITIATIVE (NERI) PROGRAM GRANT NUMBER DE-FG07-00SF22168 \\ FINAL REPORT}

system, and does not need to bear substantial pressure loads, increasing its sealing power. This o-ring also does not need to be perfectly leak-tight, as any atmospheric gasses leaking into the system are scavenged along with the leaking helium. This system assures that there is no helium leakage into the atmosphere and no atmospheric leaks into the helium system (which could result in corrosion or oxidation of system components).

The scavenged gasses are passed through a cryogenic separator which can easily separate any contaminant gasses from the helium flow. The scavenged helium is compressed and returned to the system at the pre-cooler exhaust pipe (the lowest pressure of the system), while the atmospheric gases are condensed, and returned to the atmosphere. 


\title{
Heat Exchanger Manufacturing Simulations
}

\author{
Professor Rapinder Sawhney \\ Jacob Fife
}

\section{INTRODUCTION}

Throughout the past year, a student and professor from the University of Tennessee Industrial Engineering (IE) group began evaluating the impact of mass production on the construction of nuclear power plants. The goal of the research was to study the feasibility of modularization in Generation IV nuclear reactor plant concepts with an emphasis on manufacturing. The members from the IE team began creating and studying manufacturing simulations to better evaluate modularity in reactor design concepts.

Due to the physical size and number of components in a nuclear power plant, the research was limited in scope in order to gather more detailed information. The Nuclear Engineering and IE teams agreed upon researching the manufacturing of heat exchangers as a representative component of the nuclear plant design. Knowledge gained from the study of the manufacturing of heat exchangers could then be inferred to other components.

Nuclear Energy has evolved from its' experimental infancy in World War II to supplying $17 \%$ of the world's electricity. Over the past two decades, however, nuclear growth has stalled in the U.S. and around the world while the demand for electric power continues to outstrip the supply. [1] Nuclear power is criticized by many as not being an economically feasible energy alternative. Nuclear power plants have a history of being costly with large upfront capital expenditures, long construction periods and many long-term costs associated with the operating, maintaining, and decommissioning of plants. As initial capital investments have been completed and nuclear plants have begun to get_regulatory approval for life extensions, the existing nuclear power plants have become economically attractive.

Due to the costly experiences and nuclear safety concerns, many power providers have steered clear of new nuclear plant construction. Traditional nuclear plants are large with typical electric generation capacities of 1000 Megawatts or more. Nuclear power plants have historically taken from six to more than ten years to build and achieve operating licenses. The large capital investments have been difficult to recover over that long of time. These cost factors have driven research to create an economically feasible design. Older power plants were built on the philosophy of building the largest, safest, and most economically feasible plant to meet power needs. This philosophy along with flexible construction codes, created an environment of minimal standardization. Nuclear plants were custom-built much like the first cars.

The equipment needs of a nuclear power plant are driven by reactor size and design. Modern reactor designs have evolved from nearly a half-century of experience. These 


\section{NUCLEAR ENERGY RESEARCH INITIATIVE (NERI) PROGRAM \\ GRANT NUMBER DE-FG07-00SF22168 \\ FINAL REPORT}

newer designs have greater inherent safety and will be more efficient to operate than older models. Newer designs such as the IRIS are attempts at creating a smaller more economically feasible nuclear power plant and addressing the issue of minimizing nuclear weapons proliferation if sold to foreign countries.

In today's competitive market, understanding the manufacturability of nuclear power plants is essential to the future of the industry. There is a need for research into whether nuclear plants can be manufactured at factories with minimum on-site construction. After studying the technical feasibility of factory fabrication, the economic feasibility must then be considered. Components that are custom built incur different costs than those that are factory-fabricated in quantity.

Having appropriate costing information, especially on large capital investments, is absolutely vital to the growth and sustainability of the nuclear power industry. Through using more accurate cost information, leaders of the electric power industry and manufacturing will be able to make more informed decisions about the future of the nuclear power industry. The costing differences between constructing large custom plants (1000 MW) and those of smaller, factory-fabricated plants (100-600 MW) are very important.

In regards to nuclear power, electric power providers have historically trusted the economies of scale philosophy where "bigger is better" when deciding what size plant is needed. By increasing power output, companies have believed that cost per unit would be driven down. Yet, this philosophy may not always hold true. As the size and complexity of a nuclear power plant increases, the cost per-unit may not continue to decrease. Next generation design concepts are based on factory-fabricated modules that may be a cheaper way to build smaller more cost-effective nuclear plants. Factoryfabricated modules have driven the cost down dramatically in many areas of manufacturing. The U.S. Navy has taken advantage of modular construction in the building of ships and submarines. This research provides necessary cost information considerations for the mass-production of heat exchangers for small nuclear power plants. Pressure vessels are found through out all nuclear power plants. Thus shell-and-tube heat exchangers are a logical starting point to study when observing the impact of massproduction on the relative cost of plants. Due to the need for replacement components the demand for heat exchangers has continued to grow despite the lack of demand from new nuclear plant construction, so heat exchangers still make up a considerable piece of today's market. This helps in providing accurate up-to-date information from the heat exchanger industry for the purpose of this research. Heat exchangers are currently custom-built in job shop environments. However, modern production techniques suggest that if a product is to be standardized and mass produced then the job shop environment is not the most efficient. In order to make a decision on the financial return of a nuclear power investment, detailed costs of power plant subsystems must be provided to the leaders in the electric power industry. 


\section{NUCLEAR ENERGY RESEARCH INITIATIVE (NERI) PROGRAM \\ GRANT NUMBER DE-FG07-00SF22168 \\ FINAL REPORT}

\section{The Elements of Research}

\section{$\underline{\text { Research Question }}$}

Are modular factory-fabricated nuclear plants more reliable, cheaper, and quicker $\mathbf{b}$ assemble than plants that are larger and constructed to the needs of a particular location?

\section{Research Purpose}

The purpose of this research is to provide the Nuclear Energy Research Initiative (NERI) relevant information regarding the economics in the fabrication of next generation power plants. This research will also be beneficial to the heat exchanger and electric power industry for purposes of future decision-making in the nuclear power industry.

\section{Research Objective}

The objective of this research is to study modern manufacturing philosophies and techniques that should be considered when modularizing nuclear power plants. A costing model using simulation modeling will be created to determine the economics of massproducing modular subcomponents of next generation nuclear plant designs. Cost information and other various production metrics on subcomponents will be inferred from the representative subcomponent (heat exchanger).

\section{Scope of the Research}

The study entails a literature review regarding simulation modeling and modularity in nuclear design. Moreover, cost information relevant to older, larger nuclear power plants, and cost factors inherent to next generation reactor designs are provided. A literature review on the different production paradigms, modern construction techniques, and designing for modularity is included.

This research includes the development of a simulation model that mimics the current and desired production paradigms of shell-and-tube heat exchanger manufacturing. The model uses information gathered from industry experts who have defined necessary processes for manufacturing. These processes have been modeled in the Rockwell Software package (C) ARENA 5.0. Each paradigm is to be tested at various levels of demand with respect to nuclear plant demand within this research. The simulation model is also working in conjunction with a costing model. The combined models will help heat exchanger manufacturers improve production as well as provide component more accurate cost information to nuclear power providers.

The simulation model along with the cost model can be used to improve decisions made in the heat exchanger industry. The model divides the manufacturing cost into key components. The simulation model can then be run at different levels of demand to generate different costing figures. This cost information will impact to what degree onsite construction will be done and what economic efficiency can be gained. 


\section{NUCLEAR ENERGY RESEARCH INITIATIVE (NERI) PROGRAM \\ GRANT NUMBER DE-FG07-00SF22168 \\ FINAL REPORT}

\section{LITERATURE REVIEW}

No literature regarding the economics of mass-producing shell-and-tube feedwater heat exchangers was found. This literature review briefly discusses the concepts of modularity and prefabrication.

A module "is an interchangeable building unit used in construction." This definition also stated, "these units are mass-produced and therefore easily replaced and economical." [2] This paper will study what mass-production in modularity means in the construction of a small nuclear power plant. The goal of modular designs is to take full advantage of prefabrication. Prefabrication "is a technique whereby large units of a building are produced in factories to be assembled, ready-made, on the building site." [3]

Modularity in Nuclear construction is a relatively old concept but has not been implemented in recent times mainly due to the overall lack of nuclear construction. Modular nuclear designs breakdown the complex nuclear system into smaller standardtype subsystems that can be more readily fabricated in a controlled environment such as a factory. The economics of a smaller, modular plant design are believed to be much better than traditional larger designs. The Nuclear Energy Agency published a book called Reduction of Capital Cost of Nuclear Power Plants which outlined many different opportunities for the nuclear power industry to reduce capital costs in order to make nuclear power a more competitive and economically attractive investment for electric power providers. The report briefly discusses the use of modularity as a key area where overall capital investment cost would be reduced.

Historically, nuclear plant construction has been handled much like any older type construction. The majority of construction is done on-site in a stick building or craft-type manner. Modern manufacturing has shown that this is not the most efficient paradigm for repetitive construction. A study (Borcherding) was conducted at five separate nuclear plants in 1980, which examined the factors contributing to low productivity. These factors included low material availability, low tool availability, high rework rates, needless interferences with other crews, overcrowded work areas, and time consuming inspection delays.

Modularity would be a means by which to improve all of these factors that have previously decreased productivity, decreased quality, and increased cost. Modular design moves modules into factories where manufacturers can do what they do best. The environment of a factory is much more controlled and specialized for doing this type of work. Reducing on-site labor is one way to reduce overall capital cost investments, which would make nuclear investments more attractive.

Choosing the proper modules is an extensive process that will not be discussed in detail in this paper. However, it is assumed that the heat exchangers located in the Secondary (electric generating, non-radioactive) side of the plant would be a module for purposes of this report. The heat exchanger will illustrate the advantages and disadvantages of modularity. When deciding what should or should not be a module in a plant, one must 


\section{NUCLEAR ENERGY RESEARCH INITIATIVE (NERI) PROGRAM \\ GRANT NUMBER DE-FG07-00SF22168 \\ FINAL REPORT}

consider a way in which to minimize overall labor in assembly, the amount of piping done, and creating a standard size or geometry to have consistency in construction. (Golay) The heat exchanger chosen for this research was a shell-and-tube heat exchanger.

Modularity in this paper is a term to describe the ability of a particular plant design to be broken down into standardized units for factory-fabrication. Prefabrication refers to the process of building modules in the factory so that they may be later assembled together on-site. Tables 1 and 2 list the advantages and disadvantages, respectively, from prefabrication taken from Golay. The following sections will go into greater detail on how these gains are realized in a manufacturing facility and how the impact of the disadvantages can be minimized.

Table 1. Advantages of Prefabrication/Preassembly

\begin{tabular}{|l|l|}
\hline Advantage & Explanation \\
\hline Improved Quality & $\begin{array}{l}\text { Use of high-accuracy machinery leads to greater manufacturing } \\
\text { precision and better process control }\end{array}$ \\
\hline $\begin{array}{l}\text { Improved Production } \\
\text { Control }\end{array}$ & $\begin{array}{l}\text { Programmed production and coordinated material delivery reduce } \\
\text { inventory. }\end{array}$ \\
\hline Inventory Control & $\begin{array}{l}\text { Factory settings gives more control of small parts production with } \\
\text { better tracking of materials }\end{array}$ \\
\hline $\begin{array}{l}\text { Improved Labor } \\
\text { Control }\end{array}$ & $\begin{array}{l}\text { Coordination between labor trades is enhanced, the labor force is } \\
\text { made more stable and the factory environment increases labor } \\
\text { morale and productivity }\end{array}$ \\
\hline $\begin{array}{l}\text { Improved work site } \\
\text { climate control }\end{array}$ & $\begin{array}{l}\text { Work continues to be performed throughout the seasons and is not } \\
\text { dependent upon weather conditions. }\end{array}$ \\
\hline
\end{tabular}

Table 2. Disadvantages of Prefabrication/Preassembly

\begin{tabular}{|l|l|}
\hline Disadvantage & Explanation \\
\hline Increased initial cost & $\begin{array}{l}\text { A greater initial capital investment is needed in order to erect } \\
\text { buildings and obtain machinery for fabrication of modules }\end{array}$ \\
\hline $\begin{array}{l}\text { More complete } \\
\text { engineering required }\end{array}$ & $\begin{array}{l}\text { More engineering effort is needed initially in order to develop } \\
\text { more complete project plans and to account for the concerns of } \\
\text { manufacturing in the design of the facility }\end{array}$ \\
\hline $\begin{array}{l}\text { Greater discipline } \\
\text { required }\end{array}$ & $\begin{array}{l}\text { Greater discipline is needed in planning to coordinate all of the } \\
\text { factors involved with production and assembly at the site. }\end{array}$ \\
\hline $\begin{array}{l}\text { Increased } \\
\text { vulnerability to } \\
\text { changes }\end{array}$ & $\begin{array}{l}\text { Plant changes during design and construction are more costly to } \\
\text { accommodate }\end{array}$ \\
\hline
\end{tabular}

\section{RESEARCH METHODOLOGY}

The previous section discussed modularity and prefabrication in the construction industry. The primary purpose of this research is to study and compare the fabrication, 


\section{NUCLEAR ENERGY RESEARCH INITIATIVE (NERI) PROGRAM \\ GRANT NUMBER DE-FG07-00SF22168 \\ FINAL REPORT}

costs of modular components to that of non-modular design concepts with primary emphasis on feedwater heat exchangers.

In this section, the shell-and-tube feedwater heat exchangers from the IRIS Light-Water Reactor Design are studied with respect to the advantages and disadvantages of prefabrication and mass-production. The methodology used to compare the massproduction of heat exchangers modules to that of traditional construction jobs is described in this section of the report.

\section{IRIS Heat Exchangers}

The first step in studying the impact of factory-fabrication on any component is to first understand the design specifications required. Below in Figure 1 is a picture of a feedwater heater, which is one of four types of heat exchangers in the IRIS design. The other heat exchangers of similar design are the reheaters, Moisture Separator Reheaters (MSR), and the condenser. The heat exchangers are shell-and-tube design with dimensions and material listed in Table 3 below.

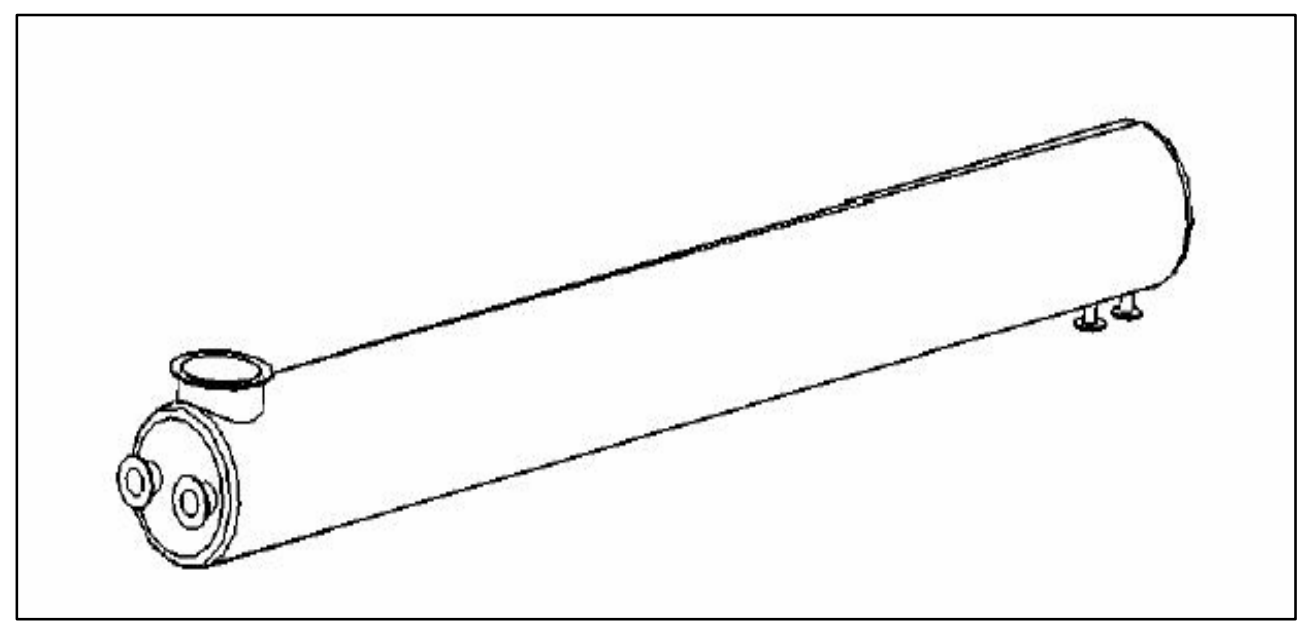

Figure 1 Feedwater Heater

Table 3 below has the dimensions of each of the heat exchanger modules needed in the IRIS plant design. The material of the heat exchanger shell and tubes are also listed below. 


\section{NUCLEAR ENERGY RESEARCH INITIATIVE (NERI) PROGRAM \\ GRANT NUMBER DE-FG07-00SF22168 \\ FINAL REPORT}

Table 3. Dimensions of IRIS Heat Exchangers

\begin{tabular}{|c|c|c|c|c|c|c|c|c|}
\hline & \multicolumn{5}{|c|}{ Shell } & \multicolumn{3}{|c|}{ Tubes } \\
\hline & $\begin{array}{l}\text { Diameter } \\
(\mathrm{ft})\end{array}$ & Length (ft) & $\begin{array}{l}\text { Weight } \\
\text { (tons) }\end{array}$ & Material & Thickness & Number & OD & Material \\
\hline FW\#1 & 10.0 & 39.4 & 42.6 & SS 316 & $1 "$ & 3020 & 1" & $18 \mathrm{BWG}$ \\
\hline FW\#2 & 10.0 & 23.6 & 10.2 & SS 316 & $1 "$ & 990 & $1 "$ & $18 \mathrm{BWG}$ \\
\hline FW\#3 & 10.0 & 31.5 & 18.3 & SS 316 & $1 "$ & 1470 & $1 "$ & $18 \mathrm{BWG}$ \\
\hline$\overline{\mathrm{FW}}$ & 10.0 & 39.4 & 35.7 & SS 316 & $1 "$ & 2490 & $1 "$ & $18 \mathrm{BWG}$ \\
\hline FW\#5 & 10.0 & 39.4 & 36.6 & SS 316 & $1 "$ & 2560 & $1 "$ & $18 \mathrm{BWG}$ \\
\hline FW\#6 & 10.0 & 23.6 & 47.3 & SS 316 & $1 "$ & 5470 & 1" & $18 \mathrm{BWG}$ \\
\hline RH\#1 & 0.2 & 12.3 & 4.0 & SS 316 & $1 "$ & 600 & $1 "$ & $18 \mathrm{BWG}$ \\
\hline RH\#2 & 0.2 & 13.1 & 6.3 & SS 316 & $1 "$ & 1000 & $1 "$ & $18 \mathrm{BWG}$ \\
\hline Cond & 21.4 & 42.5 & 236.0 & SS 316 & $1 "$ & 15000 & 1" & $18 \mathrm{BWG}$ \\
\hline
\end{tabular}

Defining the Heat Exchanger Components

Once the specifications and the design of the product have been established, the next step is to break the product down into its' subcomponents. Below in Figure 2 is a product tree listing each component and each sub-assembly needed to build the heat exchangers mentioned above. The green boxes represent components normally manufactured inhouse while the yellow boxes represent components generally outsourced. [7]

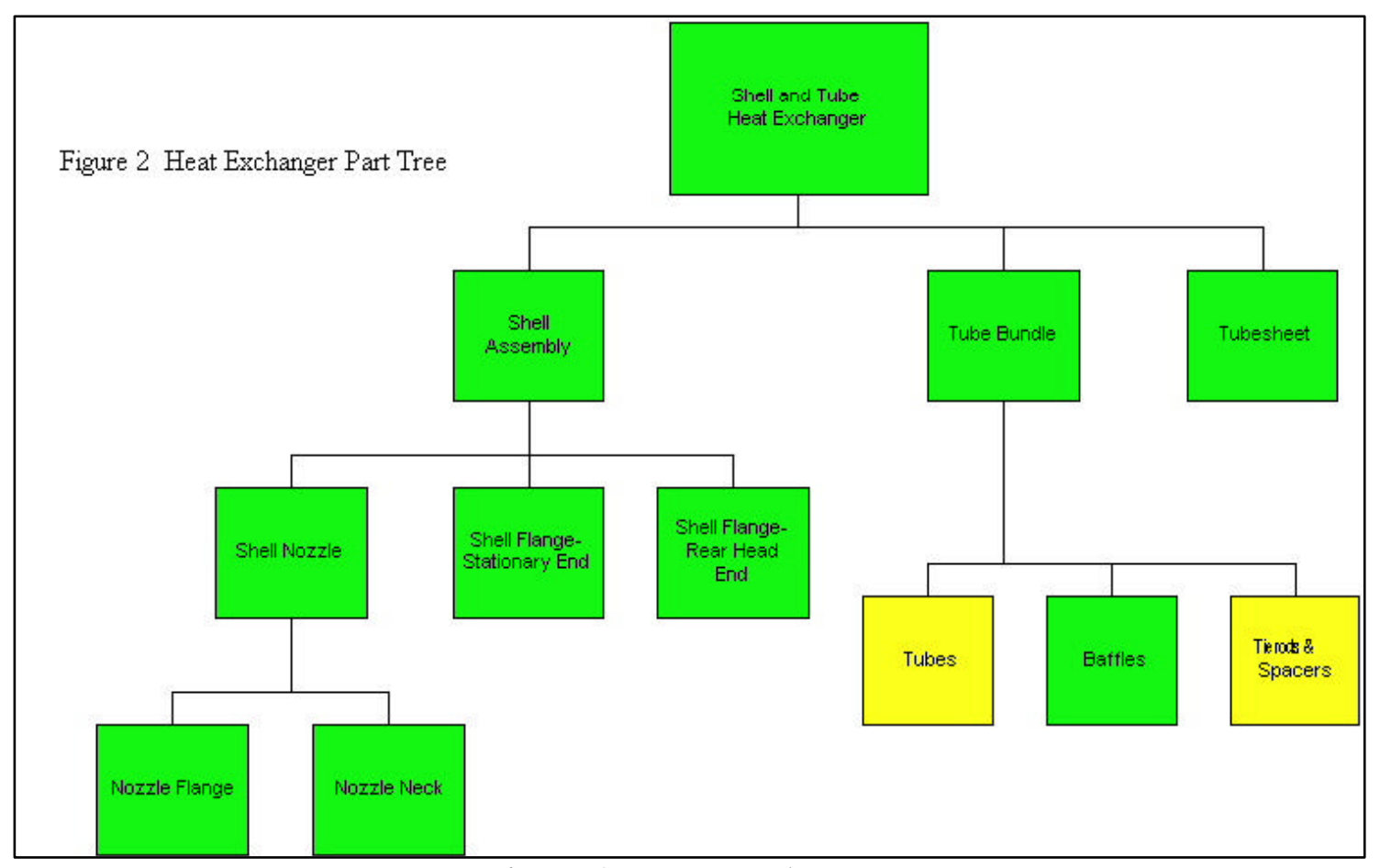

Figure 2. Heat Exchanger Part Tree 


\section{NUCLEAR ENERGY RESEARCH INITIATIVE (NERI) PROGRAM \\ GRANT NUMBER DE-FG07-00SF22168 \\ FINAL REPORT}

The next step in determining the raw material needs of a product is to create the bill of materials for each component. The components required in order to manufacturer a heat exchanger are shown above in the Heat Exchanger Part Tree above.

\section{The Manufacturing Process}

In order to understand the impact of mass-production on any product, the processes that create the product must be understood. Shell-and-tube heat exchangers are made in many different sizes, but the basic processes used to create them are basically the same. The processes can be broken down into three basic categories: machining, welding, and assembly. [7] Within these categories are more specific processes such as milling, drilling, submerged-arc welding, turning, etc. This information has been taken from experts in the heat exchanger industry.

After defining each process, then standard times were collected on each individual operation. The standard times for common industry operations such as welding, and different types of machining were taken from time standard books. Standard times of some operations that were more heat exchanger specific such as loading the tubes into the tube-bundle were taken from expert information in industry.

\section{Introducing Simulation}

Simulation modeling is a means by which to represent a system without having to incur the time and cost of replicating the entire system or changing an existing one. Simulation modeling allows the user to model a current state and then manipulate input parameters to see the effect upon desired outputs. The goal of this research is to understand the impact of mass production on heat exchangers. This can most effectively be done by modeling current manufacturing facilities that do not normally mass-produce heat exchangers and then compare that to a facility that would be setup specifically to handle the creation of prefabricated modules.

Simulation modeling is a multi-step process in which a system is created and represented by the elements that are found to be the most relevant to the performance of the system. These key factors are then translated into a simulation software package and can then be used to observe the current system and make improvements. The book SIMAN [5] outlines a step-by-step procedure on how to formulate a simulation model. The approach is used in defining the simulation used for the purposes of this research.

Problem Definition: The first section described the research question, which in essence attempts to determine whether modular design is better than non-modular design. The simulation model has a much more precise problem definition in order to provide relevant information to make the decision of which design is better. The simulation model is studying the manufacturing of shell-and-tube heat exchangers and the impact of varying different key factors described in this section.

System Definition: The boundaries of the simulation model are limited to the physical boundaries of the heat exchanger manufacturing facility. Two simulation models will be 


\section{NUCLEAR ENERGY RESEARCH INITIATIVE (NERI) PROGRAM \\ GRANT NUMBER DE-FG07-00SF22168 \\ FINAL REPORT}

created: one to represent the current production style and one to represent more ideal styles.

Conceptual Model Formulation: A written conceptual model of all manufacturing processes was created from expert industry information. This model is attached in Appendix D.

Input Data Preparation: Much of the information came from handbook for standard time while some of the information came from industry experts.

Model Translation: The conceptual model along with standard time information was then translated into ARENA 5.0.

Verification and Validation: The model was reviewed and checked for bugs to verify that it works as intended. There was double-checking with information provided by industry to ensure that the model itself was valid and a good representation of a heat exchanger manufacturing facility.

Experimentation: The next section goes into detail on the experimentation of the different key factors defined in this section of the report.

\section{Modeling the Current State}

Heat exchanger manufacturing facilities are setup in a Job Shop environment where similar machining operations are grouped together into functional departments. This is commonly accepted as the appropriate production paradigm for a low volume-high variety product demand. However, this production style typically does not create very good product flow and normally has a negative impact on quality. The high variety of products can lead to high variety of quality problems in manufacturing.

The manufacturing processes described in Appendix $\mathrm{D}$ were grouped into three functional departments mentioned above. These three departments are machining, welding, and assembly. The processes along with their respective times were modeled in ARENA 5.0 ( ). Below in Figure 3 is a snapshot of the ARENA software used to model the making of heat exchangers. 


\section{NUCLEAR ENERGY RESEARCH INITIATIVE (NERI) PROGRAM \\ GRANT NUMBER DE-FG07-00SF22168 \\ FINAL REPORT}

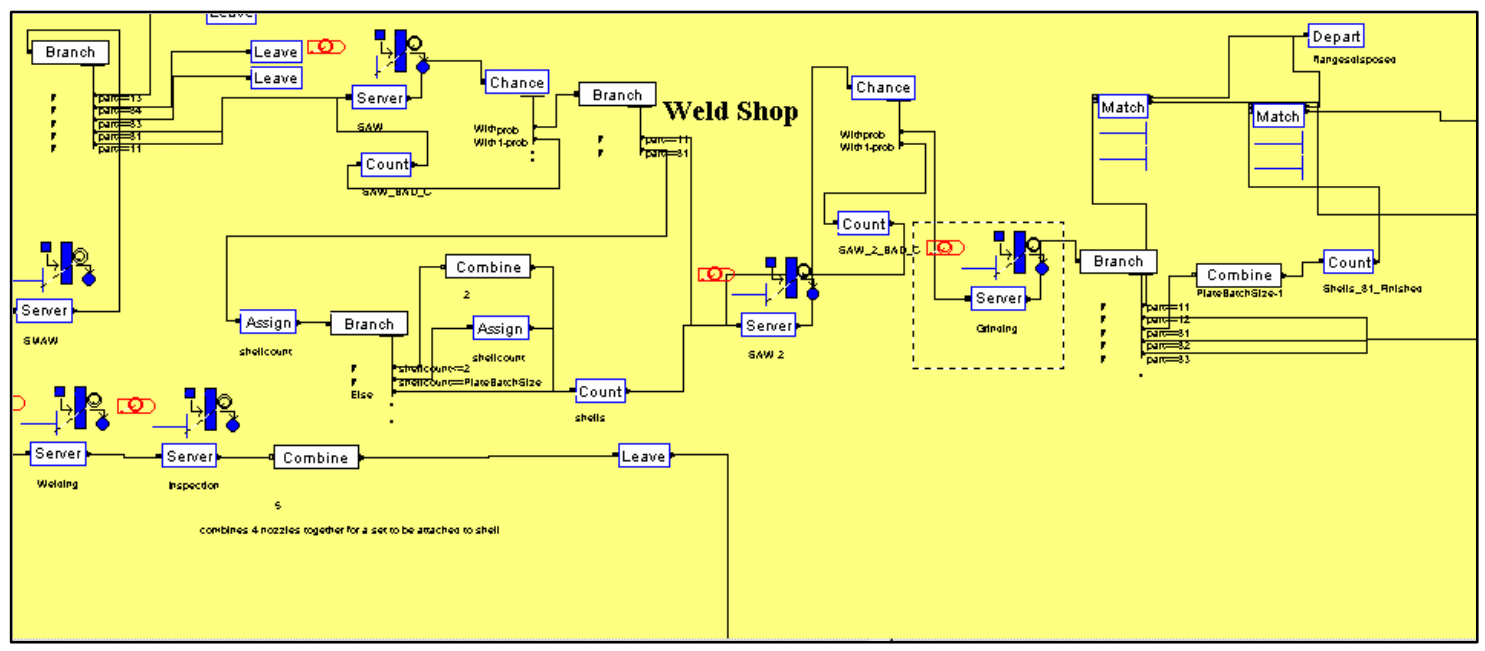

Figure 3. Modeling of Weld Shop in Manufacturing Facility

\section{Introducing the Key Factors}

Once the heat exchanger manufacturing processes were modeled then factors were identified that appeared to have the most impact on deciding whether to mass-produce modules or customize the construction. These key factors are decision variables that will help in determining whether heat exchangers should be constructed in a modular fashion or continual to be custom-built. The following seven decision variables are believed to be of the most relevance in determining how heat exchangers will be most economically produced. These include: (1) Annual Demand, (2) Engineering Design Changes after release, (3) Equipment Reliability, (4) Learning Curves, (5) Process Variability, (6) Procurement, and (7) Production Paradigm.

Annual Demand: The demand of a product plays a crucial role into the overall cost of manufacturing. Product demands that are very low will not necessitate the dedication of machines and floor space in order for production. Suppose a heat exchanger manufacturer were to receive an order for 2 heat exchangers to be delivered 3 months from now, it probably would not be in there best interest to redesign their current facility and order special machinery to meet that demand. However, if the demand were sufficiently large enough, then the manufacturer may consider creating a specialized production line dedicated to that particular product or part number.

Therefore, there are two major components of demand that impacts production and thus impacts the cost of manufacturing. These two components are demand volume and demand certainty. Demand volume is the annual number of units that are needed by the nuclear power customer. Demand certainty refers to the likelihood that the demand volume and schedule will be a known value. Heat exchanger manufacturers would more likely make capital investments into specialized production systems if a contract was established which order a large number of heat exchangers over several years thus fixing the volume and certainty of the demand. 


\section{NUCLEAR ENERGY RESEARCH INITIATIVE (NERI) PROGRAM \\ GRANT NUMBER DE-FG07-00SF22168 \\ FINAL REPORT}

Engineering Design Changes: Engineering Design Changes (EDC) are changes to engineering drawings or specifications that impact the functional use of a product. Design changes typically change the way product is manufactured and thus impact manufacturing costs. If design changes occur after release of product, impact on the cost of manufacturing is much more significant. This research will not go into a quantitative analysis of this impact but rather a qualitative analysis by drawing from the information taken from the literature survey. EDC after release emphasize the importance of having a reviewed, tested, and approved engineering design before full-scale production occurs.

Equipment Reliability: The reliability of equipment used in manufacturing products is key to the overall cost of production. Unreliable equipment not only incurs time resources, but also can have a negative impact on quality. [8] Reliable machines require increased capital inve stments but improve availability, decrease downtime and associated maintenance costs, improve secondary failure costs, and result in a better chance for making money because the equipment is free from failures for longer periods of time.

Learning Curve: Learning curves also known as experience curves play a vital role in manufacturing. In this research, learning curves will be applied to the various manufacturing operations. There are three areas of interest when understanding the impact of learning curves for the purposes of this research. These are the time to standard rate, the curve function, and the criticality of the learning curve relative to the operation base. Each of these critical components will be explained in Section IV of the research.

Quality: Quality is a measure of the ability of a process to meet customer requirements. Assuming that subsequent processes are customers to preceding processes, then this statement translates in the ability to meet specifications of down-stream processes. This factor is concerned with losses in time, material, and money, because of rework and scrap. In this research the manufacturing processes will be assigned a pair of quality values in order to perform sensitivity analysis on the impact of high and low quality processes.

Procurement: Procurement refers to the way in which nuclear power plants interact with tier suppliers. Tier suppliers are all the companies within the supply chain that support the completion of components and/or modules that will be integrated into the construction of the nuclear power plants.

Production Paradigm: There are many different ways in which a manufacturing facility can be physically setup. However, there are basically two generally accepted ways in which the construction of heat exchangers would ever be considered. The construction could take place in a Job Shop or a Flow Shop. These production paradigms differ in that Job Shops are process-oriented while Flow Shops are product-oriented. This research will examine the ideal production paradigm for a given demand and will study the impact of production on modular design. 


\section{NUCLEAR ENERGY RESEARCH INITIATIVE (NERI) PROGRAM \\ GRANT NUMBER DE-FG07-00SF22168 \\ FINAL REPORT}

\section{Defining the Response Variables}

Each key factor mentioned above can be varying levels or conditions in order to generate an experimental response. Some of the key factors will be a given when construction of nuclear plants begin. Other key factors can be studied for their overall impact in the manufacturing system. This research will analyze the change in response variables when key factors are varied. Response variables have been divided into the two categories below; quantitative and qualitative responses.

Quantitative Response: Quantitative responses are those outputs that can be numerically estimated with some degree of accuracy from the research. Example of quantitative responses for this research include: cost, production lead-time, number of defects, inventory levels, etc. These values will be taken from the simulation model created for the purposes of this research.

Qualitative Response: Qualitative responses are those outputs that cannot be explicitly measured but by implicit means determine which direction the impact will occur. A qualitative response may prove that the overall installation cost of a heat exchanger will be reduced by an improved production system, but the actual numerical amount may be too difficult or costly to determine. Qualitative responses are concerned with the type of change whether it be positive or negative and the magnitude of the change whether it be significant, minor, or negligible.

\section{Establishing the Criteria}

The goal of this research is to look at varying levels of demand for heat exchangers and decide whether modular or non-modular design would be the most cost-effective. Every simulated set of factors will be evaluated in terms of (1) overall cost, and (2) production time. The basic questions of how much, how long, and how easy to implement are the foci of this research with special considerations given to the manufacturing side.

\section{Developing the Cost Model}

This research has identified significant cost components of a representative shell-andtube heat exchanger manufacturing facility. The cost components listed below have been taken from the book Economic Evaluation of Advanced Technologies: Techniques and Case Studies. [9] This book has a case study done by Dr. Sawhney in which he created a manufacturing facility of printed wire boards (PWB) using simulation modeling. In a similar framework, a cost model has been created of a hypothe tical heat exchanger manufacturing facility.

The cost categories along with descriptions are listed below. A detailed matrix can be found in Appendix E providing necessary equipment needed for a hypothetical heat exchanger manufacturing facility. The matrix will have vendor quotes for prices.

Capital Cost: This section is broken down into three components. These include primary equipment, installation, and facility. The primary equipment component lists all major machines and resources needed to perform each manufacturing operation. The 


\section{NUCLEAR ENERGY RESEARCH INITIATIVE (NERI) PROGRAM \\ GRANT NUMBER DE-FG07-00SF22168 \\ FINAL REPORT}

equipment is annualized and a 7-year equipment life is assumed along with depreciation. Salvage value is assumed to be zero because of lack of information on equipment. The installation cost is gathered for as many machines as possible. These quotes are taken directly from vendors or manufacturers who have had similar experience installing the equipment. Facility costs are based on floor space requirements given from vendors along with standard costs per unit of area for good work practices. Appendix E has a list of primary equipment and capital cost investments used for the analysis in this research.

Material Cost: This category includes all the steel that is purchased from suppliers for the standard heat exchanger design described later in this research. The majority of the raw material comes in the form of plate steel of various shapes and sizes and is machined to meet specifications. Vendor quotes are also gathered from the steel industry. The raw materials of heat exchangers basically consist of plate steel for the shell, the tubesheets, baffles, and the nozzles. The tubes are generally purchased and not made in-house. Appendix E has a list of the main material costs of components of the heat exchanger.

Production Cost: The Production Cost category specifically looks into the repetitiveness of labor and shows the impact of learning on a manufacturing environment. A standard labor rate is applied to the different skilled areas of the plant. Some of the work required is very specialized and a higher rate would be more appropriate. Labor hours and costs are given in Appendix E.

Utility Cost: This research will not include utility cost data because it is currently unavailable but it is explained here. Due to the excessive welding and machining included in the manufacturing, electricity costs are very important. Machine power requirements were not provided. Machine utilization can be taken from standard labor hours needed per operation.

Maintenance Cost: Since this cost is extremely difficult to predict due to the lack of reliability data on given machines, cost analysis of maintenance will not be done in this research.

Quality Cost: Quality is an area that is extremely important and should be considered when evaluating the cost of a product. However, this research is limited in doing any extensive cost analysis into quality. The literature turned up some important information into the performance of shell and tube heat exchangers similar to the ones used in nuclear plants. Lyondell Chemical Co. spent over 12 million dollars in unplanned downtime because of unreliable heat exchangers at their plant. Tube failure accounted for $31 \%$ of unplanned downtime, which is a horrendous problem. [9]

Obviously, quality is very important in many aspects of heat exchangers and the nuclear energy as a whole. A quality problem at a nuclear plant that causes a complete loss of power generation capacities results in over a million dollars of lost revenue per day. Even partial losses in efficiencies in power generation due to quality problems in any component have a direct impact on revenues. Heat exchangers like many other 


\section{NUCLEAR ENERGY RESEARCH INITIATIVE (NERI) PROGRAM \\ GRANT NUMBER DE-FG07-00SF22168 \\ FINAL REPORT}

components in a nuclear plant have many opportunities in their fabrication to experience quality problems. Welding, machining, rolling, drilling, and assembly are all areas where defects can be introduced.

Moving inspection processes into the factory and attempting to "build quality" into a product through more specialized workers and better workflow is the goal of outsourcing nuclear modules to factories for construction. Quality problems are known to decrease when fabrication moves from a sporadic job shop environment where many products are made to a more specialized flow shop where Group Technology is utilized. [10]

\section{ANALYSIS}

The previous section introduced key factors studied in the mass production of feedwater heat exchangers. This section shows the experimentation and results from the simulation models mentioned in the methodology. As mentioned earlier, a representative heat exchanger facility was created using ARENA. The model was meticulously created to best represent a theoretical feedwater heat exchanger manufacturing facility. Using the quantitative experimental factors discussed in the previous section, a $2^{\wedge} 4$ experimental design pattern was chosen as a systematic way to study the impact of varying key factor levels on the unit cost of feedwater heat exchangers.

\section{$\underline{\text { Key Factors Levels }}$}

Of the seven factors discussed in the previous section, four were deemed very quantitative in nature and an easily manipulable factor in the manufacturing simulations. Factors not directly studied in the simulation models will be discussed and expert information will be provided on each factor not directly simulated. The four factors chosen for experimentation include: (1) Annual Demand, (2) Equipment Reliability, (3) Learning Curve, and (4) Quality.

\section{Choosing the Factor Levels}

Choosing the appropriate factor level for any experiment is one of the most difficult tasks an engineer will do. The choice of appropriate factor levels is based on knowledge of the process or the product and the conditions of the study. "It is desirable to set the levels of the factors far enough apart that the effects of the factors will be large relative to the variation caused by the nuisance variables." [11] Table 4 shows the factors listed above and levels used.

Table 4. Factors and Levels

\begin{tabular}{|l|l|c|c|}
\cline { 3 - 4 } \multicolumn{1}{c|}{} & \multicolumn{1}{c|}{ Factors } & \multicolumn{2}{c|}{ Levels } \\
\hline A & Demand & 48 & - \\
\hline B & Learning Curve & High & Low \\
\hline C & Reliability & $95 \%$ & $90 \%$ \\
\hline D & Quality & $95 \%$ & $90 \%$ \\
\hline
\end{tabular}




\section{NUCLEAR ENERGY RESEARCH INITIATIVE (NERI) PROGRAM \\ GRANT NUMBER DE-FG07-00SF22168 \\ FINAL REPORT}

Annual Demand: Using feedwater heat exchangers from the 300 MW plant described in section three, the above demands represent the equivalent plant demand of $2400 \mathrm{MW}$ and 1200 MW respectively. There are 6 feedwater heat exchangers per plant design thus demand figures are in multiples of 6. Annual Demand values were chosen at the above levels in order to evaluate a conservative yet realistic annual nuclear power demand over the next several years.

Equipment Reliability: Equipment reliability was chosen as a factor in order to understand the impact of machine downtime. Manufacturers that experience frequent machine outages, tend to have higher manufacturing costs because products have to wait on machines to be fixed before they can be up and running again. This model assumed a $5 \%$ and $10 \%$ downtime for the two levels. This is actually a relatively low amount of downtime for typical manufacturing environments. Equipment reliability impacts inventory holding costs, labor costs, and late-delivery costs that may affect customer relations. Labor costs were the only costs considered in the simulation-based cost model for this factor.

Learning Curve: Learning curve values chosen for the manufacturing simulations are process-specific and can be obtained from the simulation model. Learning curve values are primarily based on the amount of automation involved in a process and the amount of manual labor being performed. Processes that are highly automated have high learning rates and proceed to the standard time much quicker. Processes that are labor-intensive tend to have lower learning rates and take much more time to get to the standard time.

A good example of this phenomenon in the research is comparing the drilling of tubesheet holes and the creation of tube-bundles. Tubesheets are machined on large milling machine with no human intervention other than setup. Tube-bundles are assembled completely by hand. Thus, the machining of tubesheets realizes much less learning than the workers assembling tube-bundles.

The experiments containing low values of learning actually have practically no learning rate at all. This was chosen because of the literature on different production paradigms. [2] Learning occurs when activities are repetitive and forgetting occurs when activities are spaced out. This research assumes where a job shop environment with sporadic orders occurs, no learning happens.

Quality: The percent defects chosen for this experimentation were 5\% and $10 \%$ respectively. With $95 \%$ good quality being high and $90 \%$ good quality being low. This model assumed that due to the nature and size of the component parts, the pieces that were defective in processing could be reworked and used. Thus, no scrap costs were incorporated into the cost model but rework costs did make an impact into the unit cost. 


\section{NUCLEAR ENERGY RESEARCH INITIATIVE (NERI) PROGRAM \\ GRANT NUMBER DE-FG07-00SF22168 \\ FINAL REPORT}

\section{Running the Experiments}

Using the $2^{\wedge} 4$ experimental design mentioned above, the experimental pattern and randomized run order, seen in Table 5, was created. The Raw Unit Cost response seen in the last column is a Before Tax Cash Flow estimate. The cash flows used to generate this estimate include capital costs, production costs, quality costs, material costs, and maintenance costs. Utility costs were purposefully left out because of the lack of detailed power information for the equipment. Appendix $\mathrm{F}$ has the results from the simulation model used in developing the cost estimates below.

Table 5. Design Matrixes for the Feedwater Heat Exchanger Simulation Model

\begin{tabular}{|c|c|c|c|c|c|c|}
\hline Experiment & $\begin{array}{c}\text { Run } \\
\text { Order }\end{array}$ & Demand & LC & Quality & Reliability & $\frac{\text { Raw Unit }}{\text { Cost }}$ \\
\hline 1 & 1 & - & + & + & + & $\$ 211,406$ \\
\hline 2 & 12 & - & + & + & - & $\$ 211,816$ \\
\hline 3 & 14 & - & - & + & + & $\$ 242,538$ \\
\hline 4 & 10 & - & - & + & - & $\$ 242,557$ \\
\hline 5 & 8 & - & + & - & + & $\$ 213,049$ \\
\hline 6 & 7 & - & + & - & - & $\$ 212,299$ \\
\hline 7 & 13 & - & - & - & + & $\$ 242,991$ \\
\hline 8 & 3 & - & - & - & - & $\$ 243,005$ \\
\hline 9 & 15 & + & + & + & + & $\$ 195,336$ \\
\hline 10 & 9 & + & + & + & - & $\$ 195,547$ \\
\hline 11 & 5 & + & - & + & + & $\$ 227,165$ \\
\hline 12 & 4 & + & - & + & - & $\$ 227,283$ \\
\hline 13 & 6 & + & + & - & + & $\$ 195,972$ \\
\hline 14 & 16 & + & + & - & - & $\$ 195,526$ \\
\hline 15 & 11 & + & - & - & + & $\$ 227,585$ \\
\hline 16 & 2 & + & - & - & - & $\$ 227,582$ \\
\hline
\end{tabular}

The Raw Unit Cost also averages out the drastic differences in costs between feedwater heat exchangers. Below in Table 6 is a detailed material cost per feedwater heat exchanger used in the IRIS BOP. As can be seen by the relatively large Average Material Cost, raw materials make up a large portion of the overall cost per heat exchanger. This is very important to consider in the fabrication and analysis of heat exchangers. 


\section{NUCLEAR ENERGY RESEARCH INITIATIVE (NERI) PROGRAM \\ GRANT NUMBER DE-FG07-00SF22168 \\ FINAL REPORT}

Table 6. Summaries of Material Costs for Feedwater Heat Exchangers

Tubes Unit Cost Tube Cost \# of Plates Plate Cost Total Material Cost/HE

\begin{tabular}{|r|c|c|c|c|r|r|}
\hline FW\#1 & 3020 & $\$ 17.28$ & $\$ 52,181.29$ & 7 & $\$ 50,354.38$ & $\$ 206,906.31$ \\
\hline FW\#2 & 990 & $\$ 10.37$ & $\$ 10,263.47$ & 3 & $\$ 21,580.45$ & $\$ 94,466.30$ \\
\hline FW\#3 & 1470 & $\$ 13.82$ & $\$ 20,319.60$ & 4 & $\$ 28,773.93$ & $\$ 132,590.04$ \\
\hline FW\#4 & 2490 & $\$ 17.28$ & $\$ 43,023.65$ & 6 & $\$ 43,160.90$ & $\$ 190,555.18$ \\
\hline FW\#5 & 2560 & $\$ 17.28$ & $\$ 44,233.15$ & 6 & $\$ 43,160.90$ & $\$ 191,764.68$ \\
\hline FW\#6 & 5470 & $\$ 10.37$ & $\$ 56,708.28$ & 9 & $\$ 64,741.35$ & $\$ 184,072.00$ \\
\hline
\end{tabular}

Average Material Cost

$\$ 170,975.75$

Analyzing the Results

The average unit costs results from the experiment in Table 6 were placed in statistical analysis software named JMP version 5.0. The results of that analysis are attached in Appendix G. The analysis showed that 2 of the 4 key factors were very significant, 1 was somewhat significant and 1 had very little impact on the unit cost of the heat exchanger. Below in Table 7 is a list of the factors and their significance.

Table 7. Factors and Effects

\begin{tabular}{|l|l|l|}
\cline { 2 - 3 } \multicolumn{1}{l|}{} & Factors & Effect \\
\hline A & Demand & Hi Impact \\
\hline B & Learning Curve & Hi Impact \\
\hline C & Reliability & No Impact \\
\hline D & Quality & Med Impact \\
\hline
\end{tabular}

The numerical effect of each factor and the t-test results are given in Appendix G. The analysis shows that Demand and Learning Curve have the greatest impact on the unit cost of heat exchangers. In order to see the range of impact that the above factors have, a comparison of the best and worst results is given below in Table 8 .

Table 8. Comparisons of Factors at Best/Worst Levels

\begin{tabular}{|l|l|l|}
\hline Factors & Level \\
\hline Demand & + & - \\
\hline Learning Curve & + & - \\
\hline Reliability & $+/-$ & $+/-$ \\
\hline Quality & + & - \\
\hline Unit Cost & $\$ 195,442$ & $\$ 242,998$
\end{tabular}

The prediction profiler in Figure 4.1 shows the amount of change that can be ascribed to that particular factor. The profiler gives a graphical analysis of the factors and effects at the high and low levels. The mean is shown as $\$ 165,851.50$. These values are taken from a Present Worth Cash Flow Analysis at a MARR of 10\%. The cash flows can be 


\section{NUCLEAR ENERGY RESEARCH INITIATIVE (NERI) PROGRAM \\ GRANT NUMBER DE-FG07-00SF22168 \\ FINAL REPORT}

seen in Appendix F. The percent savings mentioned about Table 4.5 still hold true for the After Tax Cash Flow analysis in Appendices F and G.

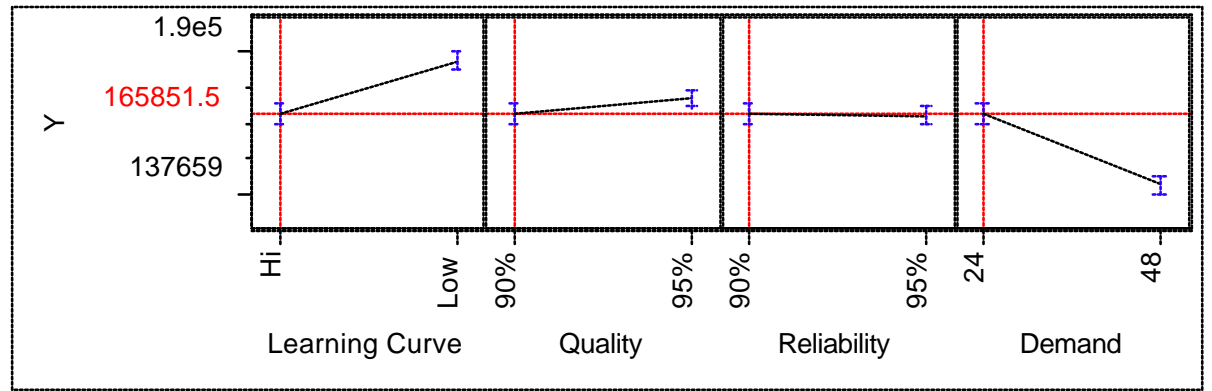

Figure 4. Prediction Profiler of Key Factors

\section{Considering the Manufacturing Environment}

As can be seen in Table 4.5, the impact of the factors at their best and worst levels is very significant. There is a $19.8 \%$ savings per heat exchanger by optimizing the above factors. This result can be further considered as a comparison between flow shop manufacturing and job shop manufacturing. Typically, heat exchangers would be made in a job shop. Meaning that production lines would not be dedicated to just producing heat exchangers. This would be best typified by the $\$ 242,998$ unit cost heat exchanger in Table 4.5. There would be no or little learning because jobs would not be set done repetitively. The quality is usually lower because of the high variety of products typically made in a job shop.

A flow shop environment however would experience high levels of learning because of the nature of the setup. Workers would have a more repetitive environment and be able to build quality into the products as well. Flow shops and jobs shops are not decisions made by nuclear power plant providers. However, these factors could be discussed in the future with suppliers. It is obvious from above that the impact of the cost savings is huge and these factors should be considered in the future.

\section{CONCLUSION}

The simulation cost models for the manufacturing of heat exchangers is completed. It is determined that demand and learning curve have the greatest impact upon the unit cost of mass-producing a feedwater heat exchanger. This concept should hold true for most any pressure vessel being outsourced and mass-produced. Quality as expected had an impact on the unit cost per heat exchanger. However, it was a surprise that machine reliability had no significant impact on the unit cost of heat exchangers. This could have been due to the fact that the range of values chosen for the levels was too small.

This research has opened a new and important path between industrial engineering and nuclear engineering disciplines. Drawing from the skills of both disciplines, nuclear power providers will be able to make better decisions involving the advent of nuclear 


\section{NUCLEAR ENERGY RESEARCH INITIATIVE (NERI) PROGRAM GRANT NUMBER DE-FG07-00SF22168 \\ FINAL REPORT}

power. This research has helped show the importance of designing for manufacturing and how integrating manufacturers in the making of nuclear plant components is essential in reducing the cost of plants. 


\section{NUCLEAR ENERGY RESEARCH INITIATIVE (NERI) PROGRAM \\ GRANT NUMBER DE-FG07-00SF22168 \\ FINAL REPORT}

\section{REFERENCES}

1. Title: Role of small and medium-sized reactors; Authors: Kupitz-J; Mourogov-V; Source: Nuclear Energy. v 38 n 4 Aug 1999, p 239-247.

2. (http://www.bartleby.com/65/mo/module.html)

3. (http://www.bartleby.com/65/pr/prefabri.html)

4. Interview in October 2002 with Stan Kitchens, Engineer for Steeltek Corporation.

5. Introduction to Simulation Using SIMAN. Pegden, Dennis; Shanon, Robert; Sadowski, Randall. $2^{\text {nd }}$ Edition. McGraw Hill Publishing.

6. http://www.barringer1.com/pdf/lcc_rel_for_pe.pdf

7. Expert Information from Different Mfgs.

8. Shell and Tube exchanger failures spur reliability programs. Carlos Gamio, F Walter Pinto. Oil \& Gas Journal; Tulsa; Aug 9, 1999.

9. Automation and Production Systems, Methodologies and Applications edited by Hamid Parsaei. Economic Evaluation of Advanced Technologies: Techniques and Case Studies, edited by Lavelle, Liggett, Parsaei.

10. Production variability and shop configuration: An experimental analysis. Andrea D'Angelo, Massimo Gastaldi, Nathan Levialdi. International Journal of Production Economics. Volume 68. 2000. pp 43-57.

11. Quality Improvement through Planned Experimentation. Moen, Ronald D. Nolan, Thomas F. Provost, Lloyd P. $2^{\text {nd }}$ Edition. McGraw Hill Publishing. 


\title{
Construction and Cost Impacts of Proposed Modular Designs
}

\author{
Todd Sedler \\ Northrop Grumman Newport News
}

\section{EXECUTIVE SUMMARY}

Northrop Grumman Newport News reviewed the modular aspects of the three reactor designs. The designs emphasize low cost construction and operation by utilizing more efficient power production methods, some material and component selections, and modular construction. Little was addressed in the designs for automated component production or quality manufacturing processes. Some of the designs discussed ease of major maintenance through module replacement instead of repair. Ease of routine maintenance was not addressed. The modular aspects of the Pebble Bed Reactor design were best described in the reporting. We have therefore focused the review on this design. The comments made on the Modular Pebble Bed Reactor are applicable to the other designs as well.

Submarine construction comes closest to modular nuclear power plant construction because of its complexity, pressure tight integrity requirements, nuclear propulsion plant, quality controls, and safeguard requirements. Our experience has been that while modular construction can reduce fabrication/installation labor costs on some components by as much as one order of magnitude the overall benefit is a labor cost reduction factor of 2 (i.e. a modular constructed ship is one half the labor cost of a regularly constructed ship). The reason this factor is not larger is because of the increased overhead associated with modular construction. Much more planning time is required, more engineering must be performed, and there is a substantial capital outlay for equipment to assemble and move the modules into position.

Based upon our review of the modular features in the submitted designs an acquisition labor cost reduction factor of two is considered achievable. If additional steps are taken to make the modules and components more amenable to automated fabrication and by using manufacturing processes that result in near nominal production dimensions, then further cost reductions are possible. Devising a connecting scheme for the modules that allows for adjustment in all six degrees of freedom during connection and developing construction processes that result in the module connection points always being at nominal dimensions are the two most important aspects of successful modular construction. We make several recommendations on how to achieve these two important criteria in this report.

This review did not ascertain the life cycle cost benefits of the modular design features. We do concur that module replacement (with defective modules returned to the factory or certified maintenance depot for repair or refurbishment) will result in a substantial 


\section{NUCLEAR ENERGY RESEARCH INITIATIVE (NERI) PROGRAM \\ GRANT NUMBER DE-FG07-00SF22168 \\ FINAL REPORT}

lifecycle cost benefit, but we have no way to quantitatively evaluate this aspect of the designs.

\section{GENERAL APPROACH TO LOW COST CONSTRUCTION}

Achieving a capable low cost modular nuclear power plant design is a challenge that requires a fully integrated approach. This means not only designing for minimum cost but manufacturing for minimum cost as well. The two are interrelated and both must be addressed if cost is to be reduced without jeopardizing performance or safety. Plant design impacts cost in four basic ways; first is in power output and technology selection, second is in producibility, or ease of construction, third is in its material and component selection, and fourth is in its reliability and ease of maintenance. When construction methods are examined from the 10,000 ft. level they can be categorized by their general impact. Modular construction for example yields a cost reduction because it improves access for manufacturing. Automation yields a cost reduction because it removes people from the manufacturing process. Statistical Process Quality Control yields a cost reduction because it reduces fit-up time and re-work. Production Efficiency Methods reduce cost by removing the overhead costs of warehousing, and the issuing of tools, drawings, and work packages. Efficiency Methods also create tools to develop and retain the learning curve benefits and develop jigs and fixtures to improve manufacturing efficiency and repeatability.

Modular construction in submarines has been implemented in a phased approach where first automation was used to reduce manpower requirements and improve quality. Second, modular construction was used to speed assembly and eliminate costs. This effort was manifested in the construction of the Automated Frame and Cylinder Manufacturing Facility at Quonset Point. This automation reduced the cost of submarine parallel middle body construction by two thirds. The output of this facility set the size of the modules which subsequently set the infrastructure acquisitions for cranes and transport facilities. Studies at Bath Iron Works and Japanese shipyards have shown that the improved accessibility of modular construction lowers erection man-hours by one order of magnitude. Early shipyard modular construction experience showed that much of the savings were being lost to increased overhead. This was due to the additional planning required, the acquisition of special tools for handling the modules, and poor work practices that resulted in the modules not fitting together at final assembly. Programs were put in place to improve the dimensional quality control of the modules (hence eliminating re-work at final assembly) through statistical process quality control, jigs and fixtures. Work practices were improved by moving tool cribs and drawing vaults to the work sites. Experienced production people are now incorporated into the design process to help develop designs that are build friendly. 


\section{NUCLEAR ENERGY RESEARCH INITIATIVE (NERI) PROGRAM \\ GRANT NUMBER DE-FG07-00SF22168 \\ FINAL REPORT}

\section{ANALYSIS OF PEBBLE BED REACTOR MODULAR CONSTRUCTION}

\section{Module Breakdown and Alignment Concerns}

The three reactor designs have been divided into modules based upon transport weight and natural boundaries. The Modular Pebble Bed Reactor (MPBR) was the most aggressive in that it required that "All components other than the reactor vessel and its associated mechanical support systems must be transportable by heavy lift tractor/trailer truck." Transport is an excellent starting point for this modular design given the end goal of providing power for developing nations with limited infrastructure. This decision limited MPBR module size and weight to ' ...8' wide, 12' tall, and up to 60' long . . . maximum weight of a single module must be less than 200,000 lb." Applying these criteria resulted in the MPBR being devised as follows:

\section{Current Design Schematic}

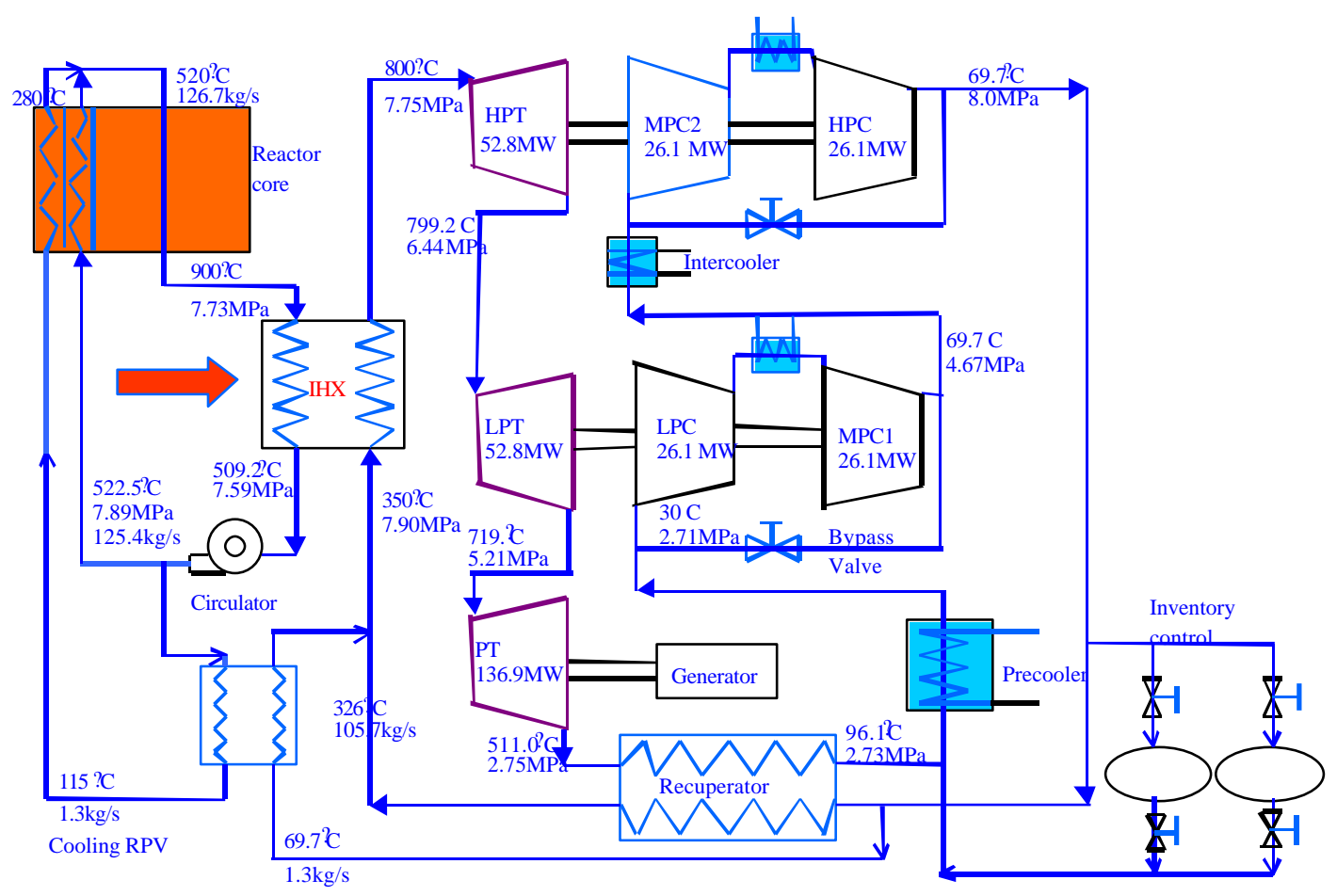

Figure 1. Current Plant Schematic - Three Shaft System 


\section{NUCLEAR ENERGY RESEARCH INITIATIVE (NERI) PROGRAM \\ GRANT NUMBER DE-FG07-00SF22168 \\ FINAL REPORT}

MIT notes that "This layout seeks to maximize the modularity of the design by concentrating manifolds and plumbing in individual modules, while restricting each module to a single type of component (keeping turbo-machinery in separate modules from heat exchangers whenever possible to minimize parasitic effects during maintenance)." We note that this concept has certain construction benefits as well. It allows fabrication areas, or "factories", to be set up for each module's construction. These "factories can be in different buildings, the same building, or in different facilities around the country. The key is that the factory is the center of manufacturing excellence for the particular module. The "factory" not only has the specific equipment needed for the module's construction but it retains the learning experience of the module's construction and repair. Retaining the learning experience and having a specific area optimized for each module's manufacture greatly enhance cost reduction.

MIT also notes "While this type-specific module isolation increases the total number of modules in the system, it limits the amount of functioning components that have to be removed during replacement of a single component. This is necessary, as the current strategy for repair of this type of reactor facility is one of replacement rather than on-site repair. Each module will be built in a centralized factory, and is transportable by truck. Therefore, when a component fails on site, that specific module will be removed and returned to the factory for repair, with an identical replacement module taking its place." Newport News notes that for this concept to work the replacement module's connection points have to be able to line up exactly with the previous module's attachment points. This kind of interchangeability requires a precise manufacturing process that delivers superb repeatability. This can only be achieved through the use of "module factories" and statistical process quality control. Key components in such a manufacturing process are the use of processes that result in components being built with no significant statistical deviation from nominal dimensions and jigs and fixtures that insure hole layouts and component positioning is exact. Even with all this, the space frames will require an attachment scheme that allows adjustment in all six degrees of freedom. This is because structural elements will shift over time due to inherent stress relief, strain buildup, and settling. There are no guarantees that identical modules will fit into the same slot on the plant after twenty years of operation. 


\section{NUCLEAR ENERGY RESEARCH INITIATIVE (NERI) PROGRAM \\ GRANT NUMBER DE-FG07-00SF22168 \\ FINAL REPORT}

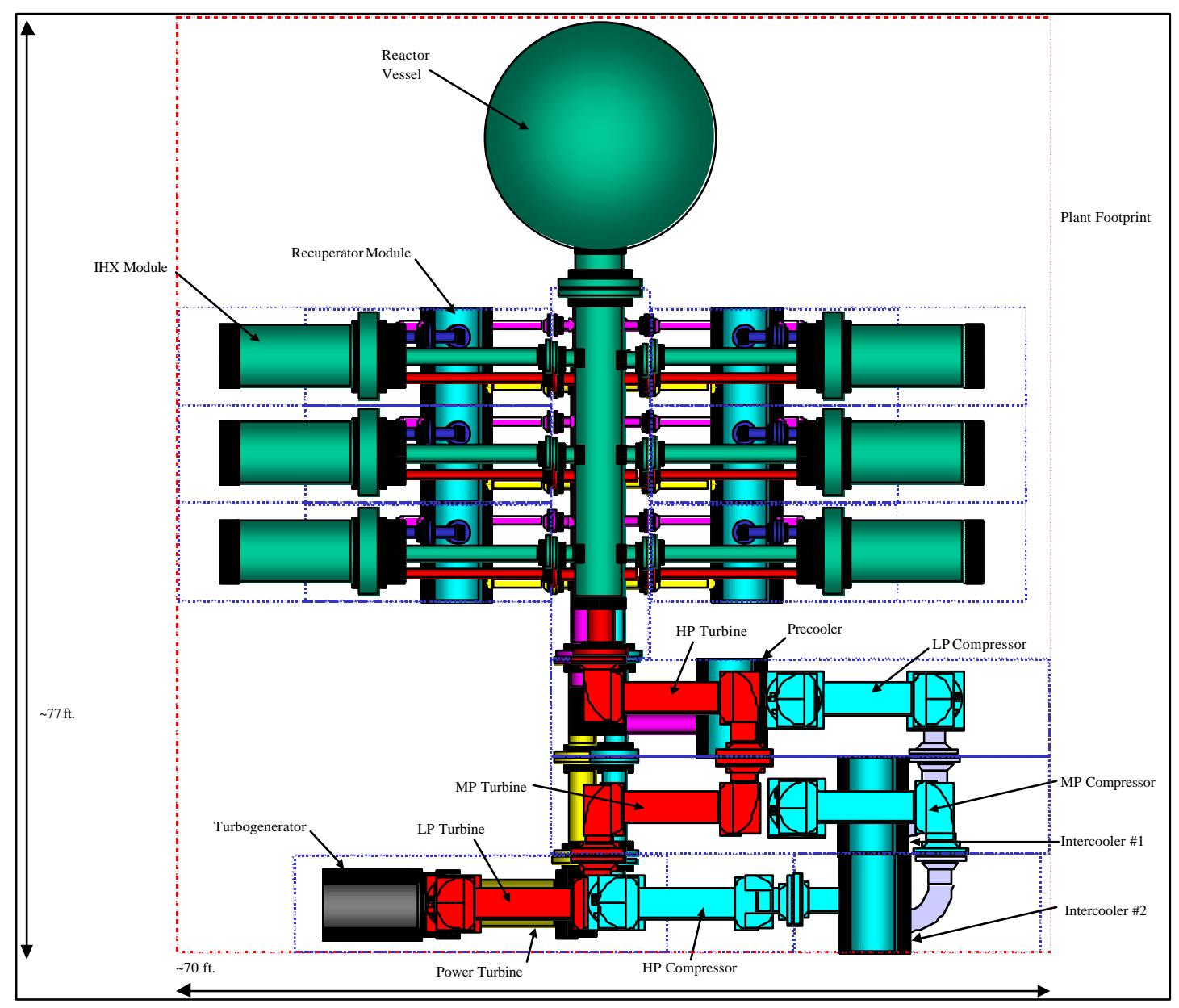

Figure 2. Modular Pebble Bed Reactor Physical Layout

The MPBR physical layout, shown above, is constructed from 21 modules, excluding the reactor vessel. The modules are divided into three sizes. These are: 8'x12'x 40' (five modules), 8'x12'x30' (nine modules), and 8'x12'x20' (seven modules). Each module has a number of flange connections that must be made up at final assembly. Each flange connection has sixteen bolt holes that must line up. The following tables show the modules based upon size with a break down of the number of connections and number of boltholes that must be aligned. Additionally, the table gives a qualitative assessment on how difficult it will be to get the connections aligned and bolted. The physical layouts of the two plant levels are shown in the figure below. 

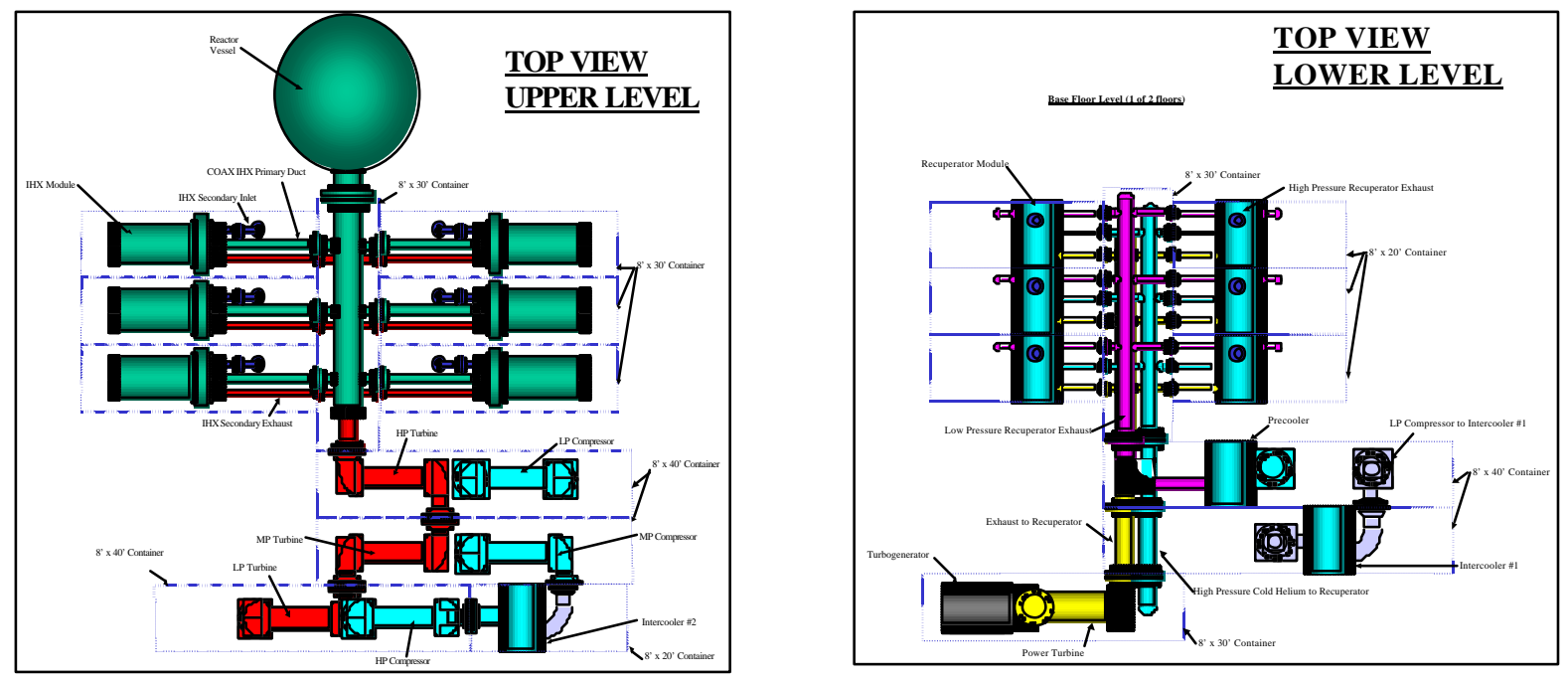

Figure 3. Top Views of Upper and Lower Levels

Table 1. Upper Level - 8'x12'x40' Modules

\begin{tabular}{|c|c|c|c|}
\hline & $\begin{array}{c}\text { \# of } \\
\text { Connections }\end{array}$ & $\begin{array}{l}\text { \# of Bolt } \\
\text { holes }\end{array}$ & $\begin{array}{l}\text { Alignment } \\
\text { Difficulty }\end{array}$ \\
\hline HP Turbine \& LP Compressor & $\begin{array}{l}4 \text { flanges on } 3 \\
\text { sides }\end{array}$ & 64 & High \\
\hline MP Turbine \& MP Compressor & $\begin{array}{l}4 \text { flanges on } 3 \\
\text { sides }\end{array}$ & 64 & High \\
\hline LP Turbine \& HP Compressor & $\begin{array}{l}4 \text { flanges on } 3 \\
\text { sides }\end{array}$ & 64 & High \\
\hline
\end{tabular}




\section{NUCLEAR ENERGY RESEARCH INITIATIVE (NERI) PROGRAM \\ GRANT NUMBER DE-FG07-00SF22168 \\ FINAL REPORT}

Table 2. Upper Level - 8'x12'x30' Modules

\begin{tabular}{|c|c|c|c|}
\hline & \# of Connections & $\begin{array}{c}\text { \# of Bolt } \\
\text { holes }\end{array}$ & $\begin{array}{l}\text { Alignment } \\
\text { Difficulty }\end{array}$ \\
\hline IHX Module \#1 & $\begin{array}{l}3 \text { flanges on } 2 \\
\text { sides }\end{array}$ & 48 & Moderate \\
\hline IHX Module \#2 & $\begin{array}{l}3 \text { flanges on } 2 \\
\text { sides }\end{array}$ & 48 & Moderate \\
\hline IHX Module \#3 & $\begin{array}{l}3 \text { flanges on } 2 \\
\text { sides }\end{array}$ & 48 & Moderate \\
\hline$\overline{\mathrm{IH}}$ & $\begin{array}{l}3 \text { flanges on } 2 \\
\text { sides }\end{array}$ & 48 & Moderate \\
\hline IHX Mod & $\begin{array}{l}3 \text { flanges on } 2 \\
\text { sides }\end{array}$ & 48 & Moderate \\
\hline IHX Module \#6 & $\begin{array}{l}3 \text { flanges on } 2 \\
\text { sides }\end{array}$ & 48 & Moderate \\
\hline Upper Centerline Manifold & $\begin{array}{l}14 \text { flanges on } 4 \\
\text { sides }\end{array}$ & 224 & Extreme \\
\hline
\end{tabular}

Table 3. Upper Level 8'x12'x20' Module

\begin{tabular}{|c|c|c|c|}
\hline & \# Of Connections & \# of Bolt holes & Alignment Difficulty \\
\hline Intercooler Module & 2 Flanges on 2 sides & 32 & Moderate \\
\hline
\end{tabular}

Table 4. Lower Level 8'x12'x40' Modules

\begin{tabular}{|l|l|c|c|}
\hline & \multicolumn{1}{|c|}{$\begin{array}{c}\text { \# of } \\
\text { Connections }\end{array}$} & $\begin{array}{c}\text { \# of Bolt } \\
\text { holes }\end{array}$ & $\begin{array}{c}\text { Alignment } \\
\text { Difficulty }\end{array}$ \\
\hline LP Compressor \& Precooler & $\begin{array}{l}8 \text { flanges on } 3 \\
\text { sides }\end{array}$ & 128 & Extreme \\
\hline
\end{tabular}




\section{NUCLEAR ENERGY RESEARCH INITIATIVE (NERI) PROGRAM \\ GRANT NUMBER DE-FG07-00SF22168 \\ FINAL REPORT}

\begin{tabular}{|l|l|l|l|l|}
\hline & & & & \\
\hline In Helium to Recuperator and & $\begin{array}{l}\text { 6 flanges on 4 } \\
\text { sides }\end{array}$ & 96 & Extreme \\
\hline
\end{tabular}

Table 5. Lower Level 8'x12'x30' Modules

\begin{tabular}{|l|l|c|c|}
\hline & \# of Connections & $\begin{array}{c}\text { \# of Bolt } \\
\text { holes }\end{array}$ & $\begin{array}{c}\text { Alignment } \\
\text { Difficulty }\end{array}$ \\
\hline \begin{tabular}{|l|l|}
\hline Lower Centerline Manifold \\
\hline Power Turbine
\end{tabular} & $\begin{array}{l}\text { Extreme } \\
\text { sides }\end{array}$ & 320 & \\
\hline & 3 flanges on 3 & & \\
\hline
\end{tabular}

Table 6. Lower Level 8'x12'x20' Modules

\begin{tabular}{|l|c|c|c|}
\hline & \# of Connections & \# of Bolt holes & Alignment Difficulty \\
\hline Recuperator Module \#1 & 4 flanges on 2 sides & 64 & Moderate \\
\hline & & & \\
\hline Recuperator Module \#2 & 4 flanges on 2 sides & 64 & Moderate \\
\hline & & & \\
\hline Recuperator Module \#3 & 4 flanges on 2 sides & 64 & Moderate \\
\hline 0 & & & \\
\hline
\end{tabular}




\section{NUCLEAR ENERGY RESEARCH INITIATIVE (NERI) PROGRAM \\ GRANT NUMBER DE-FG07-00SF22168 \\ FINAL REPORT}

\begin{tabular}{|l|l|c|c|}
\hline Recuperator Module \#5 & 4 flanges on 2 sides & 64 & Moderate \\
\hline \begin{tabular}{l} 
Recuperator Module \#6 \\
\hline
\end{tabular} & 4 flanges on 2 sides & 64 & Moderate \\
\hline
\end{tabular}

The six tables show that 21 modules with 107 flanges and 1,712 bolt holes must be aligned for final assembly, excluding the reactor vessel.

\section{Module Erection Sequence}

In terms of an assembly process clearly everything must be aligned to the reactor pressure vessel. Ideally the pressure vessel should be the first item installed and aligned. The second step would be to place the Upper Level Centerline Manifold module in place and bolt it to the reactor pressure vessel. The third step would be to bolt Recuperator Module \#1 to IHX Module \#1 and Recuperator Module \#6 to IHX Module \#6. The fourth step would be to connect these two subassemblies to the Upper Level Centerline Manifold. Since the IHX module alone is $200,000 \mathrm{lbs}$. the resulting IHX/Recuperator will be well over this and it will impact the size of the crane being used to set the modules, as well as the module to crane connection point design. The fifth step would then be to install the Lower Level Centerline Manifold Module and to connect the IHX/Recuperator subassemblies to it. This sequence is intended to minimize rework costs buy aligning the controlling and most difficult modules first. The Upper Level Centerline Manifold gets aligned to the reactor pressure vessel, and the Lower Level Centerline Manifold gets aligned to the Upper Level Centerline Manifold through its connections to two IHX/Recuperator subassemblies, which are located at opposite ends and opposite sides of the Upper Level Centerline Manifold. The sixth step would be to create subassemblies from the remaining IHX/Recuperator modules and then attach them between the upper and lower level centerline manifolds. The reason for this approach is that it places all the flanges for final attachment on the same side and allows the flexibility of the longer pipe runs to be used to help with final fit up and connection between the manifolds and the subassemblies. The seventh step would be to connect the lower level LP Compressor and Precooler module to the upper level HP Turbine and LP Compressor module forming a subassembly. This subassembly would then be attached between the upper level and lower level manifolds. Again this sequence places all the attachments between the main assembly and the subassembly along one side. The eighth step would be to create a subassembly between the lower level Intercooler \#1 Module and the upper level MP Turbine-MP compressor Module. This subassembly would then be connected to the previous subassembly. The ninth step would be to connect the lower level Power Turbine module to the upper level LP Turbine-HP Compressor Module to form a subassembly. This subassembly would then be connected to the main assembly. The $10^{\text {th }}$ and final step would be to connect the upper level Intercooler \#2 Module to the main assembly. Trying to line up so many holes on different faces of so many modules is very 


\section{NUCLEAR ENERGY RESEARCH INITIATIVE (NERI) PROGRAM \\ GRANT NUMBER DE-FG07-00SF22168 \\ FINAL REPORT}

difficult, even under the best of conditions. This sequence suggested as the best overall approach. The sequence defines what the maximum crane load will be for planning purposes. It also suggests how the final plant drawings must be dimensioned for modular erection.

\section{MANUFACTURING TECHNIOUES FOR MODULAR CONSTRUCTION}

\section{Space Frame Design and Construction}

The module's space frame is required to support the module's components statically and dynamically during transport, erection, and over the life of the plant. The space frame must also allow a limited amount of linear and rotational motion across all six degrees of freedom to align the connecting flanges on the different faces. The final assemblage of space frames that form the plant must be strong enough to resist environment loads such as those arising from seismic activity or high winds. The resulting assemblage of space frames must also be resistant to local and global buckling modes. The space frame will also have to have good corrosion resistance to avoid structural failure or replacement over the life of the plant. Design of the space frame will be critical to the success of the plant's construction and achievement of the projected cost savings.

The scope of this study does not include designing space frames for each module. However generic concepts that apply across all the module space frames can be stated. The space frames require two translation systems, one for linear movement along the $x$, $\mathrm{y}$, and $\mathrm{z}$ axes and the other for rotation about the $\mathrm{x}, \mathrm{y}$, and $\mathrm{z}$ axes for each component within the module. The linear system should provide for approximately \pm 0.5 " of motion along each axis and the rotational system \pm 3 degrees around each axis. The adjustment ranges typical and based upon assuming that the components have been built using statistical process quality control and that component position within the space frame as well as flange locations were set using jigs and fixtures and optical tooling. Rotational and linear motions can be accomplished using jacking bolts built into the space frame. The jacking bolts along with locking nuts or lock wire can be used to hold alignment during transport. Once the space frame is inserted into the main assembly, and all the flange connections made, the jacking bolts can be welded or an epoxy bedding compound used to permanently secure the component within the space frame. Construction of the space frame needs to be exact in order to have any hope of module interchangeability. Each space frame structural element should be precision measured (to $\pm 1 / 32$ ”) and cut. It is recommended that the structural elements be powder coated for maximum corrosion protection. Weld preparation on the ends should be done using an automated process that delivers consistent and repeatable results. The structural elements should be placed into a jig and then welded using an automatic process that is controlled for minimum distortion.

The Modular Pebble Bed Reactor is a gas cooled reactor and as such high quality seals at each flange connection are very important. The real issue on final installation is getting all the flanges to line up across the multiple faces. Flange lineup means getting all 32 


\section{NUCLEAR ENERGY RESEARCH INITIATIVE (NERI) PROGRAM \\ GRANT NUMBER DE-FG07-00SF22168 \\ FINAL REPORT}

bolt holes (16 per side) to line up sufficiently such that all 16 bolts can be inserted and that the opposing flange faces are parallel and with in a specified offset. Even with the linear and rotational adjustment available this is difficult to do. It is noted that many of the components within the modules have relatively long pipe runs between the component's main body and the terminating flange at the face of the module. It is recommended that when manufacturing the components, the pipe run between the component and the flange not be welded at either end and that some extra length be added on to the pipe run. The space frame with its components should be placed into a fixture that locks the flanges into place on each side of the space frame. Then each pipe run is fit between the component body and its flange. After the pipe run is trimmed, and welded at both ends the same fixture is used to drill the bolt holes through each connecting flange. Such a process greatly increases the probability that there will be good fit up between modules at initial plant construction and later during maintenance.

\section{Reference Dimensioning System}

Reference lines are a three-dimensional grid system, permanently marked on the inside of plant. This grid system is composed of top, bottom, port and starboard centerlines, longitudinal and horizontal plane lines. These lines are used by the trades to assemble units, and to install structure and components. They are used by Quality Control to verify contract specification compliance. The evolution of modular construction has caused reference lines to take on tremendous importance. Reference lines established in one module for the placement of components within the module may or may not line up with the reference lines in an adjoining module. Disagreement between individual or local reference line systems results in structural misalignments and components being off location. This paper discusses how reference lines should be developed for the plant and modules, and how they are influenced by the fabrication processes used.

Reference lines form an internal, three-dimensional grid. They are dependent upon the asbuilt condition of the modules and plant foundations, and are permanently marked on them. Drawing dimensions are always based on a perfectly, square, three-dimensional, paper grid system. Physical placement of components within modules and the modules themselves, however, is to a grid system that must be frequently compromised. Trade offs must routinely be made between grid accuracy and construction requirements. If the designer's paper axes and the builder's reference line axes could be brought into perfect agreement, there would be no misalignment of modules or connections between modules. Improving the agreement between the drawing and the as built condition has many beneficial effects. These include meeting schedule, reduced re-work, and better performance. Structure and component misalignments are major problems in the modular construction of large, complex structures. Design practices that are not modular construction oriented are frequently to blame for the misalignments and subsequent rework. Contributing to the lines problem is the way drawings are dimensioned and toleranced. Drafting practices such as dimensioning across module boundaries are detrimental to construction. Tolerances on dimensions that cross module boundaries frequently are not realistic. Drafting practices must be used that account for module boundaries, as built structure, and erection sequence. In the early days of modular ship 


\section{NUCLEAR ENERGY RESEARCH INITIATIVE (NERI) PROGRAM \\ GRANT NUMBER DE-FG07-00SF22168 \\ FINAL REPORT}

construction it was an all too common sight to see mated modules being ripped apart to get components or structure on location.

Lines would be installed in two phases: initial and construction. Ideally both sets of lines should fall on top of each other. Each set of lines however, is a compromise between different factors and they rarely agree. Tools and measuring techniques combine with construction criteria in establishing the accuracy of reference lines.

After a module's space frame structural elements have been made (i.e., plates and tubing cut and shaped) some coordinate system is needed for assembly. Typically initial lines will be installed on both the plating and tubing. To help in this process, and to produce consistent size space frames for a given type of module, the use of a jig or fixture is recommended for holding the various structural members in position and with proper root gaps prior to welding. Neither the plating nor tubing is dimensionally perfect. Therefore an optical tool technician will use his judgment in laying out the initial lines. The number of lines laid out will be held to a minimum, just enough to confirm that all the structural elements are positioned to produce a space frame of the correct outer dimensions and that the sides are close to being square. Once fitted, the space frame structural elements will be tack welded in place. If the space frame is designed from high strength steel it may require preheating prior to welding. This means that the steel must be heated to several hundred degrees F. Preheating from 70 degrees F to 370 degrees F will cause steel to grow 1/4" for every $10 \mathrm{ft}$. This thermal growth will cause some shifting of the initial alignment. This may or may not be significant. More important is the impact on the root gap and weld volume. A linear increase in the root gap has a non-linear increase in weld volume. Unequal weld volumes cause asymmetric weld shrinkage, and increased weld distortion. As long as thermal growth is symmetrical at the root, the at-tack, ambient temperature shape 'is the final, fully welded, ambient temperature shape. The space frame is released from its fixture after welding and removing any preheat. At this point built up stresses and asymmetries in the welding process will cause some shrinkage and warping of the space frame. If statistical process quality control has been performed for all the fabrication processes than the shrinkage and warpage will be unsubstantial and result in space frame production with no significant statistical deviation from nominal in any of its dimensions. A new set of lines that reflect the as-built condition of the space frame must be installed. These are called construction lines, and are discussed next.

Construction lines are necessary so that components can be placed in the space frame to form the module. The construction line grid must be accurate and contain all of the grid lines needed for component placement. Parallel grid lines must typically be accurate to within 1/16". Such accuracy is required to meet drawing and contract specification tolerances. The initial lines are no longer any good. Welding the space frame will have changed the shape. Developing the construction lines requires trading off construction criteria, specifications, and grid quality. Construction grid points are labeled and prick punched and scribed onto the structural elements of the space frame. An initial point is set on the space frame by the optical tool technician. This point will be the point used to initially line the module up for subassembly and/or placement into the main plant 


\section{NUCLEAR ENERGY RESEARCH INITIATIVE (NERI) PROGRAM \\ GRANT NUMBER DE-FG07-00SF22168 \\ FINAL REPORT}

assembly. The optical tool technician will then place a best-fit three-dimensional grid system into the space frame. He does this by using some type of theodolite, transit, and level. The orthogonality and dimensional quality of the grid are subject to compromise depending on the dimension quality of the space frame and any warping that may have occurred. Component insertion can start once the construction grid is in place. It is strongly recommended that the components be inserted without their mating flanges and external pipe runs being welded. After the components are installed the module should be inserted into a fixture that precisely positions the connecting flanges at each face on the module. The pipe runs between any given component and its connecting flanges can either be templated at this point or if pre-fabricated it can be trimmed to fit and installed and welded at both ends. It is recommended that after the welding is complete the same fixture be used to precisely locate and drill the bolting holes for the flanges. It may be desirable to leave some extra facing material on the flange so that some final machining could be done at final fitup between modules. This would be very expensive and is recommended only if the fabrication processes cannot be controlled close enough to make the extra material unnecessary.

Mating a module with its surrounding modules will require that the following criteria examined and compromises or re-work performed:

1. proper root gaps for welding the modules together

2. proper mating flange gaps and parallelism

3. proper bolt hole alignments

4. proper structural alignments between modules

5. proper system alignments (piping, shafting)

Bolt hole alignment for the mating flange connections usually supersedes all other alignment criteria. Generally, it is possible to align the flange bolt holes and take the misalignments up in the module to module structure.

\section{COST IMPLICATIONS}

Modular construction of large complex structures is most fully represented by the modular construction of nuclear powered submarines. In many cases modular submarine construction represents the extreme problems that can be encountered due to the large number of mechanical, piping, and electrical systems that cross module boundaries. Nuclear submarines also carry the onus that every component must be verified on location via a master reference line system that is passed through the completed vessel. The lessons learned by the shipyard in modular construction could prove invaluable for this NERI effort. Much of the shipyard's cost reduction experience in implementing modular construction is transferable to the NERI program.

Many shipyards have reported that module, or on-block construction reduces component installation cost over stick building by an order of magnitude or more. While this result is impressive, it quickly shrinks when the program is reviewed as a whole. It was stated earlier that for the modules to be successfully mated fabrication processes needed to be studied and improved so that the modules can be produced with no significant statistical 


\section{NUCLEAR ENERGY RESEARCH INITIATIVE (NERI) PROGRAM \\ GRANT NUMBER DE-FG07-00SF22168 \\ FINAL REPORT}

deviation from nominal. This requires upfront engineering and planning time and an investment in infrastructure. The infrastructure investment takes the form of optical tooling, automated cutting and grinding machines, automated welding machines, jigs and fixtures. The investment does not have to be spread equally across all the modules. Clearly in the case of the Modular pebble Bed Reactor Plant the Upper and Lower Centerline Manifold Modules need to be dimensionally near perfect. Any dimensional or planar defects will ripple through the main assembly as subassemblies try to attach between the two centerline modules. These modules need special fabrication processes that result in high quality. Modules that tie on at the very end of the main assembly do not need as much special care, such as the Power Turbine Module or the Intercooler \#2 Module. Another cost increase that is imposed on this concept, and which will be felt in every plant construction is the cost of the space frames. As was noted earlier, the space frame is not just a truss. The space frame has to act as both transport container and final foundation for its components. It also has to have an adjustable support system that allows component adjustment in six degrees of freedom. The space frames will not be insignificant. Their cost will only be recouped if they allow the modules to mate smoothly with no re-work and later allow easy maintenance through module swap out.

A typical number that has been discussed in the literature on modular construction is that the cost of jigs and fixtures should be approximately 5-10 \% of the lead ship's contract price. In the case of the Modular Pebble Bed Reactor, each type of module required one jig and one fixture. The jig was used to position and hold the space frame's structural elements for welding, and the fixture was used to position the mating flanges on the faces of the space frame for welding and bolt hole drilling. There are 21 total modules in the plant but only 13 types of modules are present. These are listed in the following table along with the investment that should be placed in the module's fabrication infrastructure relative to the other modules.

Table 7. Jig Data

\begin{tabular}{|c|c|c|c|c|}
\hline $\begin{array}{lll}\text { Jig for } & \text { Type of } \\
\text { Module } & & \\
\end{array}$ & $\begin{array}{l}\text { \# per } \\
\text { Plant }\end{array}$ & Jig Size & $\begin{array}{l}\text { Fixture } \\
\text { Complexity }\end{array}$ & $\begin{array}{l}\text { Infrastructure } \\
\text { Investment }\end{array}$ \\
\hline Starboard IHX Module & 3 & 8'x12'x30' & $\begin{array}{l}3 \text { flanges on } 2 \\
\text { faces }\end{array}$ & Moderate \\
\hline Port IHX Module & 3 & $8^{\prime} \times 12^{\prime} \times 30 '$ & $\begin{array}{l}3 \text { flanges on } 2 \\
\text { faces }\end{array}$ & Moderate \\
\hline Upper Manifold & 1 & 8'x12'x30' & $\begin{array}{l}14 \text { flanges on } 4 \\
\text { faces }\end{array}$ & High \\
\hline Lower Manifold & 1 & 8'x12'x30' & $\begin{array}{l}21 \text { flanges on } 3 \\
\text { faces }\end{array}$ & High \\
\hline $\begin{array}{l}\text { Starboard Recuperator } \\
\text { Module }\end{array}$ & 3 & $8^{\prime} \times 12^{\prime} \times 20^{\prime}$ & $\begin{array}{l}4 \text { flanges on } 2 \\
\text { faces }\end{array}$ & Moderate \\
\hline $\begin{array}{ll}\text { Port } & \text { Recuperator } \\
\text { Module } & \end{array}$ & 3 & $8^{\prime} \times 12^{\prime} \times 20^{\prime}$ & $\begin{array}{l}4 \text { flanges on } 2 \\
\text { faces }\end{array}$ & Moderate \\
\hline Power Turbine Module & 1 & 8'x12'x30' & Three flanges on & Low \\
\hline
\end{tabular}




\section{NUCLEAR ENERGY RESEARCH INITIATIVE (NERI) PROGRAM \\ GRANT NUMBER DE-FG07-00SF22168 \\ FINAL REPORT}

\begin{tabular}{|l|c|c|l|c|}
\hline & & & 2 faces & Low \\
\hline Intercooler \#2 Module & 1 & $8^{\prime} \times 12^{\prime} \times 20 '$ & $\begin{array}{l}2 \text { flanges on 2 } \\
\text { faces }\end{array}$ & High \\
\hline $\begin{array}{l}\text { Piping and Precooler } \\
\text { Module }\end{array}$ & 1 & $8^{\prime} \times 12^{\prime} \times 40^{\prime}$ & $\begin{array}{l}8 \text { flanges on 4 } \\
\text { faces }\end{array}$ & High \\
\hline $\begin{array}{l}\text { Piping and Intercooler } \\
\text { \#1 Module }\end{array}$ & 1 & $8^{\prime} \times 12^{\prime} \times 40^{\prime}$ & $\begin{array}{l}6 \text { flanges on 4 } \\
\text { faces }\end{array}$ \\
\hline $\begin{array}{l}\text { HP Turbine \& LP } \\
\text { Compressor Module }\end{array}$ & 1 & $8^{\prime} \times 12^{\prime} \times 40^{\prime}$ & $\begin{array}{l}4 \text { flanges on 3 } \\
\text { faces }\end{array}$ & Moderate \\
\hline $\begin{array}{l}\text { MP Turbine \& MP } \\
\text { Compressor Module }\end{array}$ & 1 & $8^{\prime} \times 12^{\prime} \times 40^{\prime}$ & $\begin{array}{l}4 \text { flanges on 3 } \\
\text { faces }\end{array}$ & Moderate \\
\hline $\begin{array}{l}\text { LP Turbine \& HP } \\
\text { Compressor Module }\end{array}$ & 1 & $8^{\prime} \times 12^{\prime} \times 40^{\prime}$ & $\begin{array}{l}4 \text { flanges on 3 } \\
\text { faces }\end{array}$ \\
\hline
\end{tabular}

The increased overhead costs, capitol outlays for jigs and fixtures, and the increased cost of space frames over normal foundations all act to reduce the savings incurred by modular construction. The general trend for modular construction in shipbuilding is that it will decrease total project manhours by $50 \%$ but increase overhead. How much overhead increases is very dependent upon how efficient the shipyard is in its planning and engineering.

It is assumed that the Modular Pebble Bed Reactor Plant would be a new start up and a large infrastructure investment would be required no matter what. On this basis it can be said that modular construction would reduce total project manhours by $50 \%$ over a more traditional construction method. The Modular Pebble Bed Reactor concept appears to have fewer construction issues than is seen in nuclear submarine production, assuming the seals at the flanges are not an issue. It is probable that the savings will be greater for the Modular Pebble Bed Reactor concept than what is realized in nuclear submarine construction. The savings will be bounded between the nuclear submarine experience (a reduction factor of two) and the raw on-block savings (a factor of 10).

\section{RECOMMENDATIONS}

It has been noted that nuclear submarine modular construction comes closest to the type and complexity of the modular construction proposed for the Modular Pebble Bed Reactor. Our experience with modular ship construction would suggest that the modular aspects of the design will decrease construction manhours by at least a factor of two, but no more than a factor of 10 . The cost savings realizable from modular construction are greatly influenced by how well the modules fit together during final assembly. The following actions are strongly recommended for maximum cost benefits:

A. Design Drawing Development:

1. All space frame structural element locations should be referenced to point on one of the space frame's structural elements. 


\section{NUCLEAR ENERGY RESEARCH INITIATIVE (NERI) PROGRAM \\ GRANT NUMBER DE-FG07-00SF22168 \\ FINAL REPORT}

2. All module component locations should be reference to a construction reference line system installed on the module's completed space frame.

3. Module placement locations in the final assembly should be referenced through the flange connections and based upon the erection sequence.

4. The planning must support the erection sequence and the drawings must be established to support and agree with the module construction work packages.

B. Space Frame Design

1. Capable of sustaining all normal transport and placement loads with out damage

2. Provide appropriate pickup points for movement by crane or truck

3. Have a built in six degree of freedom adjustment system for each component mounted to it.

4. Form a final assembly grillage capable of sustaining seismic, accident, and wind loads with out failing in yield or buckling.

5. Provide the space frame structural elements with a good corrosion prevention coating, such as powder coating.

C. Module Construction

1. Utilize a jig for each module type to construct the space frame.

2. Utilize a fixture for each type of module that the space frame sits in to establish the location of the mating flanges along each face of the module. Use this fixture to weld the flanges to the component and to drill the flange bolt holes.

3. Pay special attention to, and make extra investment in the fabrication of the Upper and Lower Centerline Manifold Modules and the Piping and Precooler Module.

4. Develop statistical process quality control and make infrastructure investments to develop fabrication processes that yield modules with no significant dimensional deviation from nominal.

The Modular Pebble Bed Reactor Concept requires 1,712 bolt holes to be aligned. While not impossible, it is recommended that a suitable and less alignment critical method of attachment at the module boundaries be found. One possible concept might be the use of marmon clamps in place of the bolts. 


\section{NUCLEAR ENERGY RESEARCH INITIATIVE (NERI) PROGRAM \\ GRANT NUMBER DE-FG07-00SF22168 \\ FINAL REPORT}

\section{Appendix A - Review of Relevant Reactor Systems}

\section{CLINCH RIVER BREEDER REACTOR (CRBR)}

The Clinch River Breeder Reactor Plant was designed by a joint Government and industry effort in the mid to late 70's to be the Nation's first large-scale Liquid Metal Fast Breeder Reactor for use as a source of electrical generation in a utility environment. Although it was never fully constructed, the entire plant was designed and many components were fabricated and shipped to the site in Oak Ridge, TN.

CRBR was a $975 \mathrm{MW}_{\text {th }}\left(375 \mathrm{MW}_{\mathrm{e}}\right)$ three loop, liquid sodium cooled reactor. The fuel material was an oxide of Plutonium enriched to $33 \%$ and Uranium, which was made into pellets and loaded into stainless steel fuel assemblies. Liquid sodium was pumped through three, independent, closed cooling loops to intermediate heat exchangers (IHX) located within the containment building. Heat was transferred to three intermediate sodium loops, each of which passed through a superheater and two evaporators to create steam. The steam from all three loops was carried along to a common turbine generator and condensed into feedwater to be distributed back to the three steam drums.

\section{Reactor Vessel:}

The vessel is 54 feet high with a 20 foot diameter and constructed of stainless steel and containing 156 fuel assemblies, 208 blanket assemblies, 306 radial shield assemblies, and 15 control rods. The vessel is designed so all of the assemblies can be removed as needed during refueling. The active core is $3.0 \mathrm{ft}$ high and $6.2 \mathrm{ft}$ in diameter.

\section{Intermediate Heat Exchangers}

Each vertical counterflow unit is $52 \mathrm{ft}$ tall with a rating of $325 \mathrm{MW}_{\text {th }}$ and contains 2,850 tubes across which to transfer heat. Primary SODIUM flows downward on the shell side while intermediate sodium flows upward on the tube side. The intermediate sodium is at a slightly higher pressure than the primary to ensure any leakage will be to the primary side, thus helping to keep the core covered and preventing contamination of the intermediate sodium. Primary sodium enters the IHX at $995 \mathrm{~F}$ and exits at $730 \mathrm{~F}$. Intermediate sodium enters at $651 \mathrm{~F}$ and is raised to $936 \mathrm{~F}$ before flowing to the superheater.

\section{Steam Generators}

The superheaters and evaporators are of identical design: vertical, counterflow, shell and tube heat exchangers with a 90 degree bend in the top of the shell and tube bundle. They are both $65 \mathrm{ft}$ long containing 757 tubes and are made from 2 1/4 Cr-1 Mo steel. Intermediate sodium flows down the shell side while water or steam flows up the tube side. The superheater is rated at $92.0 \mathrm{MW}_{\text {th }}$ while the evaporators are rated at 116.5 $\mathrm{MW}_{\text {th }}$. 


\section{NUCLEAR ENERGY RESEARCH INITIATIVE (NERI) PROGRAM \\ GRANT NUMBER DE-FG07-00SF22168 \\ FINAL REPORT}

Table A-1. Clinch River Breeder Reactor Summary

\begin{tabular}{|l|r|}
\hline Generator output (gross) & $375 \mathrm{MW}$ \\
\hline Thermal Power & $975 \mathrm{MW}$ \\
\hline Containment diameter & $186 \mathrm{ft}$ \\
\hline Core height & $3 \mathrm{ft}$ \\
\hline Core diameter & $6.2 \mathrm{ft}$ \\
\hline Primary sodium flow rate & $175 \mathrm{psi}$ \\
\hline Primary pressure & $730 ? \mathrm{~F}$ \\
\hline Primary sodium inlet Temp & $995 ? \mathrm{~F}$ \\
\hline Primary sodium outlet Temp & $651 ? \mathrm{~F}$ \\
\hline Intermediate sodium flow rate & $936 ? \mathrm{~F}$ \\
\hline IHX sodium inlet Temp & $885 ? \mathrm{~F}$ \\
\hline IHX sodium outlet Temp & \\
\hline Superheater sodium outlet Temp & gpm \\
\hline
\end{tabular}

\section{POWER REACTOR INHERENTLY SAFE MODULAR (PRISM)}

Power Reactor Inherently Safe Modular (PRISM), or more commonly referred to as the Advanced Liquid Metal Reactor (ALMR) design, grew out of a part of a US Department of Energy (DOE) \$90 Million Dollar program in 1985 [33]. The program was designed to look at various nuclear-fueled power generation options at the time. The key objectives under these programs were the designing of reactors that would be inherently safe, modular, and could be installed very quickly and less expensively than current reactors. Under these key objectives, DOE chose PRISM developed by a team of 10 companies lead by General Electric (GE). Foster Wheeler (FW) Corp, being one of these companies, was the sole producer of the Intermediate Heat Exchangers (IHX) required for this project along with IHXs for the Clinch River Breeder Reactor (CRBR) plant and the Fast Flux Test Facility (FFT) in Richland, Washington.

PRISM was chosen by DOE because of its ability to substantially reduce cost while maintaining safety and being able to provide for long term energy production capability very quickly for the future when needed without long term financial obligations and delay times due to construction. The PRISM modular design was envisioned as a 425 $\mathrm{MW}_{\mathrm{t}}\left(133 \mathrm{MW}_{\mathrm{e}}\right)$ pool-type liquid metal fast breeder reactor that could be made in a factory and shipped as a unit by rail. The reactor vessel was designed to be $19 \mathrm{ft}$ in diameter and $62 \mathrm{ft}$ in length, thus, making it feasible for transportation by rail. The vessel weighs about 1100 tons, including internal heat exchangers and pumps, and 800 tons without pumps and heat exchangers. Each power block could produce as much as 400 $\mathrm{MW}_{\mathrm{e}}$ with as many as three reactor modules being coupled together. Up to three power blocks could be coupled together to produce as much as $1200 \mathrm{MW}_{\mathrm{e}}$ with 9 reactor modules.

The placement of individual reactor module was below grade in a silo which is physically separated from the steam-generating system. Safety devices would include the reactor 


\section{NUCLEAR ENERGY RESEARCH INITIATIVE (NERI) PROGRAM \\ GRANT NUMBER DE-FG07-00SF22168 \\ FINAL REPORT}

cooling auxiliary system and seismic isolators. The reactor and steam-generating components are interconnected by piping running through below grade tunnels, as shown in Figures A-1 and A-2, reprinted from Boardman [34]. Figure A-3 shows the later GE SuperPRISM design which is a slight departure from the earlier PRISM designs.

\section{Reactor Vessel}

PRISM fuel consists of mixed-oxide designs similar to those of developed for the Clinch River Breeder Reactor [35]. The active core is 1.3 meters in diameter, 1.0 meter in height, and consists of 53 fuel assemblies. The containment vessel is 5.8 meters in diameter and 19.5 meters high. The entire assembly, less fuel and sodium, weighs about 950 tonnes. The reactor module can be fabricated in a factory and shipped to site by barge, rail, or road [35].

\section{Intermediate Heat Exhangers}

U-238 is used as the primary fuel and the energy from the reactor is transferred to the secondary system via the use of two kidney shaped IHXs. It is these IHXs which serve as the primary barriers between the radioactive primary sodium and the intermediate secondary (non-radioactive) sodium. This new IHXs developed by FW uses liquid sodium as the coolant. The two modules (IHX) are rated at $238 \mathrm{MW}$ each for a combined rating of $477 \mathrm{MW}$ for the module [33]. The IHX is designed to fit in an annular space between the reactor vessel thermal liner and reactor shield barrel.

The IHX consists of upper and lower tube sheets made of austenitic stainless steel. Straight tubes separate the sheets with a central down comer for incoming intermediate sodium and a riser for outgoing sodium. The primary sodium that enters into the IHX enters at $485^{\circ} \mathrm{C}$ and is cooled to $338^{\circ} \mathrm{C}$ when it leaves and flows into the reactor plenum. The cold incoming sodium which enters the IHX enters at $282^{\circ} \mathrm{C}$ and is heated to $443^{\circ} \mathrm{C}$ before flowing out. The IHX within this module are designed to withstand 7.0 Mpa (1000-psig) steam pressure during a sodium/water-reaction event in the steam generator.

The IHX themselves are enclosed within the containment vessel and the reactor vessels. The IHXs are kidney shaped and occur in pairs (238 MW each) with an estimated (a rough estimate) length of 3.1 meters and a width of .7 meter and a cross section of about $2.2 \mathrm{~m}^{2}$ with a total height of about $2 / 3$ of the core length $(\sim 40 \mathrm{ft})$. There are two IHX in total per reactor module on opposite sides of the reactor.

\section{Intermediate Heat Transport System}

The Intermediate Heat Transport System (IHTS) within the PRISM module is used primarily to transfer the thermal energy to the steam generating system. The steam generator is rated at $479 \mathrm{MW}$ and converts the high-pressure, subcooled water into supersaturated steam using the energy supplied by the IHTS. The steam generator also cools the IHTS sodium to temperature levels needed for safe cooling of the reactor during a transient and during steady-state operations. 


\section{NUCLEAR ENERGY RESEARCH INITIATIVE (NERI) PROGRAM \\ GRANT NUMBER DE-FG07-00SF22168 \\ FINAL REPORT}

\section{Steam Generator}

The PRISM design employs one steam generator per reactor module. The steam generator is positioned in a vertical manner as a straight shell and tube heat exchanger constructed of a 2-1/4 Cr-Mo steel, with steam/water in upflow on the tube side and sodium at $800^{\circ} \mathrm{F}$ inlet temperature in downflow on the shell side.

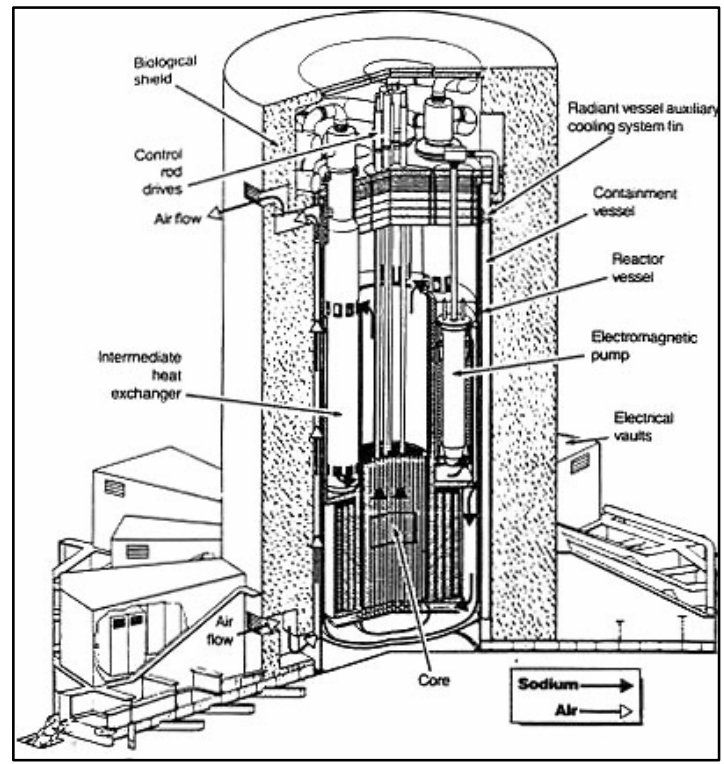

Figure A-1: PRISM Containment Vessel

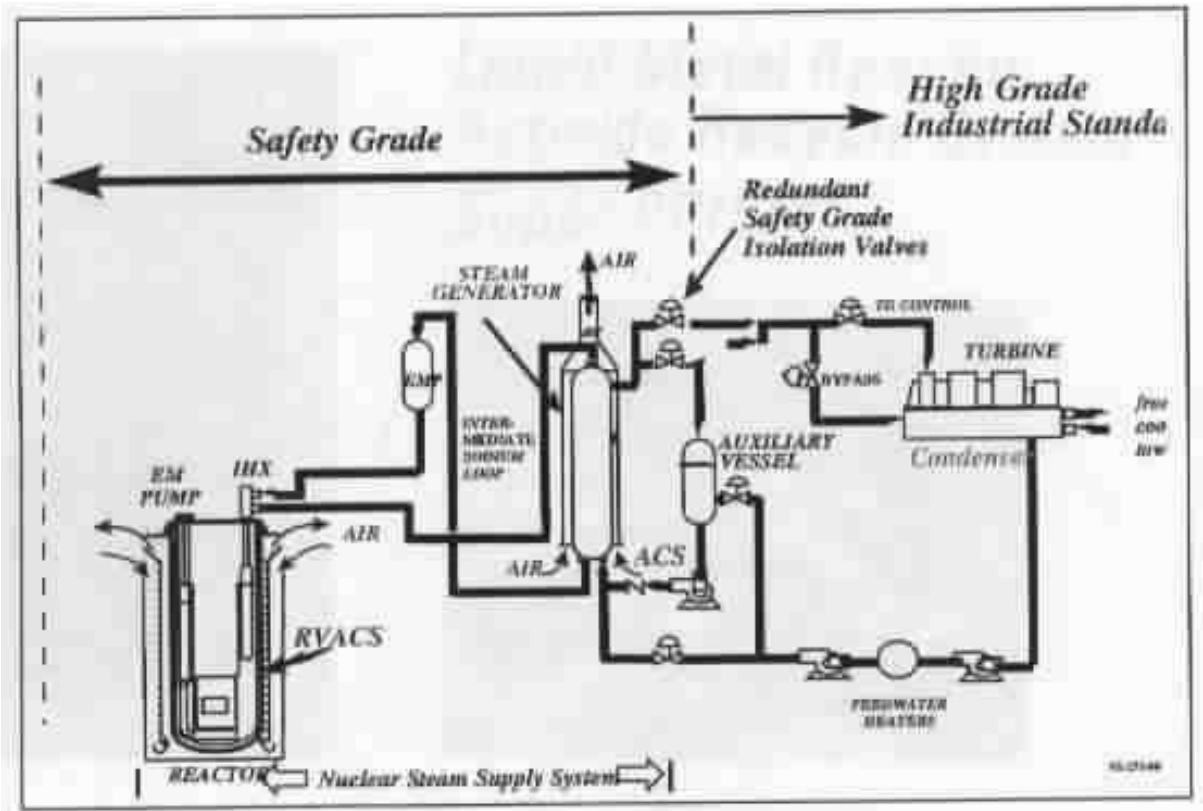

Figure A-2. PRISM Plant Layout 


\section{NUCLEAR ENERGY RESEARCH INITIATIVE (NERI) PROGRAM \\ GRANT NUMBER DE-FG07-00SF22168 \\ FINAL REPORT}

\section{SUPERPRISM}

The earlier 1980's PRISM design has undergone several modifications B9,40]. The current PRISM designs are referred to as SuperPRISM. The SuperPRISM, shown in Figure A-3, is a modular LMR plant composed of one or more power blocks, each of which couples two $1000 \mathrm{MW}_{\mathrm{t}}$ nuclear steam supply systems (NSSS) which can operate independently, but feed steam to a single superheat turbine generator system rated at 825 $\mathrm{MW}_{\mathrm{e}}$ (net). The core inlet temperature is $700^{\circ} \mathrm{F}$ and the core outlet temperature is $950^{\circ} \mathrm{F}$. Each reactor module is rated at $380 \mathrm{MW}_{\mathrm{e}}$ and the overall plant efficiency is estimated at $38 \%$ with an availability factor of $93 \%$.

The reactor vessel is made of $5 \mathrm{~cm}$ thick $316 \mathrm{SS}$. The reactor closure is a $45 \mathrm{~cm}$ thick $304 \mathrm{SS}$ and the reactor module is approximately 20 meter tall and 10 meter in diameter. The intermediate heat transport system (IHTS) is a closed loop system that transports the reactor generated heat to the steam generator system (SGS) by circulating nonradioactive sodium between the IHX and the SG. The hot leg sodium at $485^{\circ} \mathrm{C}$ is transported in separate $72 \mathrm{~cm}$ OD $316 \mathrm{SS}$ pipes from the two IHXs to a single $1000 \mathrm{MWt}$ SG. Two high temperature EM pumps located in the cold legs return sodium to the IHX at $325^{\circ} \mathrm{C}$. The SGS is composed of the steam generator, startup circulation tank/pump, leak detection subsystem, and steam generator valves. The SG is ertically oriented, helical coil, sodium-to-water counter flow shell-and-tube exchanger and generates superheated steam at $165 \mathrm{~atm}$ and $462^{\circ} \mathrm{C}$. The feedwater temperature is $215^{\circ} \mathrm{C}$ and the sodium inlet temperature is $485^{\circ} \mathrm{C}$. The $\mathrm{SG}$ for the SuperPRISM is made of Mod $9 \mathrm{Cr}-1$ Mo steel.

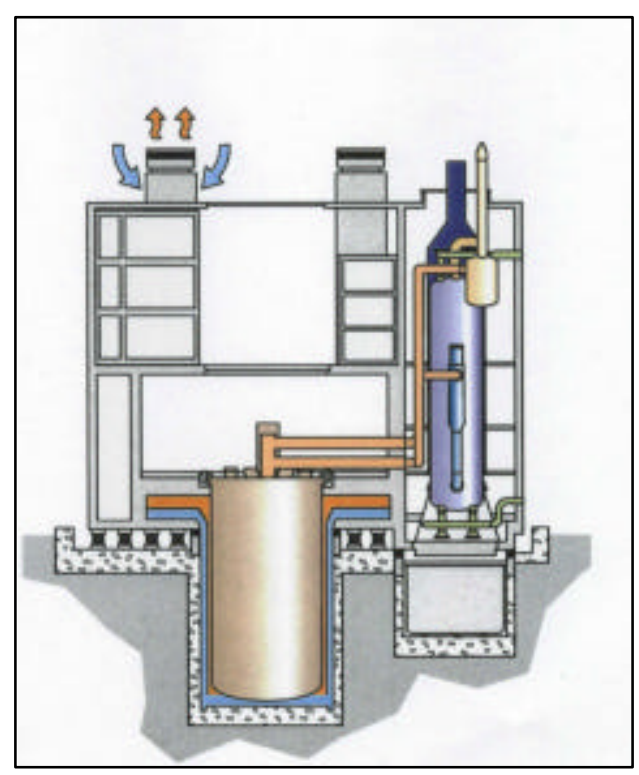

Figure A-3. Super PRISM Design Overview (*reprinted from Boardman ${ }^{34}$ ). 


\section{NUCLEAR ENERGY RESEARCH INITIATIVE (NERI) PROGRAM \\ GRANT NUMBER DE-FG07-00SF22168 \\ FINAL REPORT}

\section{INTEGRAL FAST REACTOR (IFR)}

The Integral Fast Reactor concept developed by Argonne National Lab is based on technology first developed at EBR-II. IFR is a pool-type primary system that uses metallic-alloy fuel and a novel approach to fuel cycle closure.

The fuel cycle is based on high temperature metal reprocessing. An overview of the plant layout is shown in Figure A-4. (references 37 and 38).

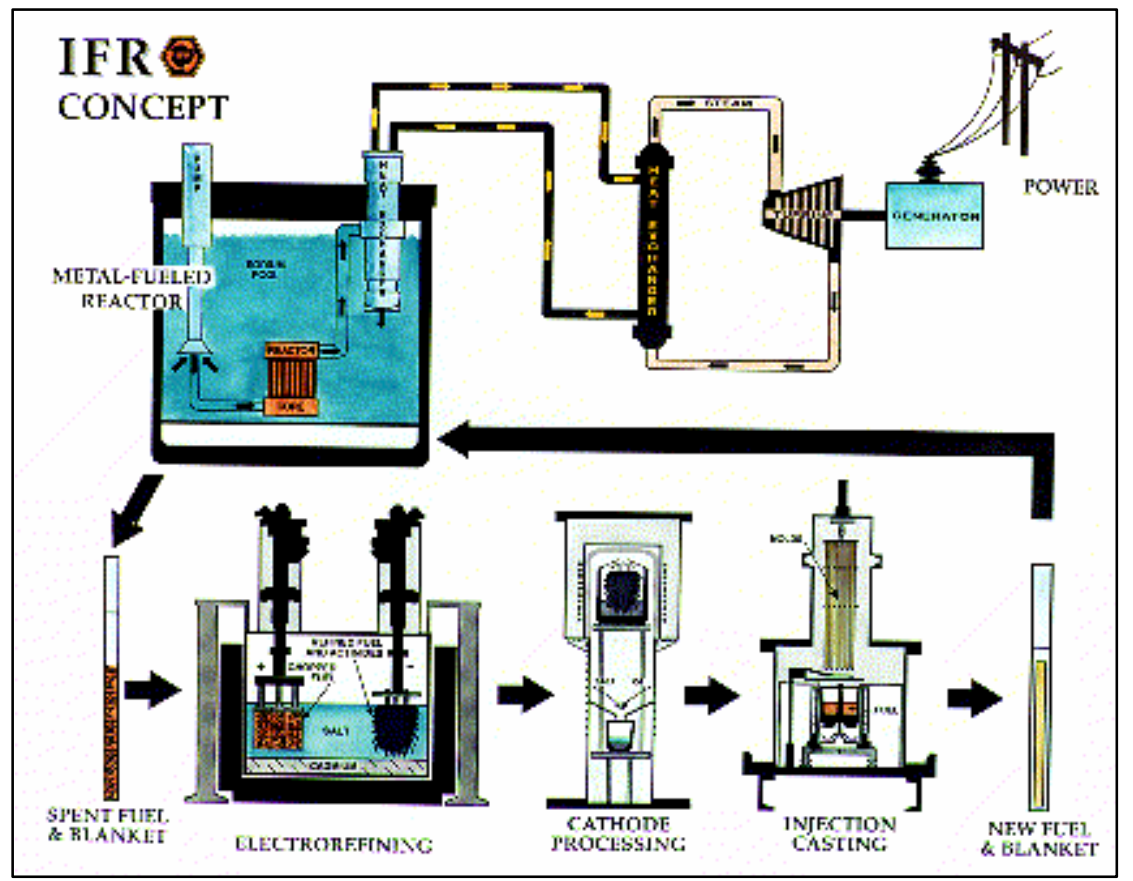

Figure A-4. Integral Fast Reactor System Layout

\section{FORT SAINT VRAIN NUCLEAR GENERATING STATION}

The Public Service of Company of Colorado undertook the construction project of a 842 MW thermal (330 MW electric) gas cooled nuclear power plant in 1968. The design objectives took advantage of the High Temperature Gas Cooled Reactor 40 MW(e) prototype built at Peach Bottom, Pennsylvania. Fort St. Vrain employees a ${ }^{235} \mathrm{U}$-thorium fuel cycle with a graphite moderator, fuel cladding, core structure, and reflector. Helium serves as the primary coolant. The turbine building design is a conventional design that uses $1000^{\circ} \mathrm{F}$ superheated and $1000^{\circ} \mathrm{F}$ reheated steam. The turbine plant throttle steam pressure is $2400 \mathrm{psig}$ at $1000^{\circ} \mathrm{F}$. Hot reheat steam pressure is $600 \mathrm{psia}$ at $1000^{\circ} \mathrm{F}$. The overall net station efficiency is $39.2 \%$. Shown in Figure A-5 is an overview of the plant layout of Fort St. Vrain. 


\section{NUCLEAR ENERGY RESEARCH INITIATIVE (NERI) PROGRAM \\ GRANT NUMBER DE-FG07-00SF22168 \\ FINAL REPORT}

\section{Reactor Vessel}

The reactor consists of 1482 fuel elements, 74 control rods, and is $19.6 \mathrm{ft}$ in diameter with a fuel element stack height of $15.6 \mathrm{ft}$. The reactor vessel inside diameter is $31 \mathrm{ft}$ while the length is $75 \mathrm{ft}$.

\section{Steam Generator}

Steam generator output is $342.0 \mathrm{MW}$ electric with a helium flow rate of 3,410,040 lb/hr. The outlet pressure is 686 psia with an inlet temerpature of $1427^{\circ} \mathrm{F}$ and an outlet temperature of $742^{\circ} \mathrm{F}$. The feedwater/main steam has a flow rate of $2,305,320 \mathrm{lb} / \mathrm{hr}$ with an outlet pressure of $2512 \mathrm{psia}$, an inlet temperature of $403^{\circ} \mathrm{F}$ and an outlet temperature of $1005^{\circ} \mathrm{F}$. The reheat steam has a flow rate of $2,245,800 \mathrm{lb} / \mathrm{hr}$, an outlet pressure of 600 psia, an inlet temperature of $673{ }^{\circ} \mathrm{F}$ an outlet temperature of $1002{ }^{\circ} \mathrm{F}$. Shown in Figures 3 and 4 are the design details of a steam generator module as used in Fort St. Vrain Nuclear Power plant and the plant layout, respectively. There are a total of 2 steam generators each consisting of six identical modules.

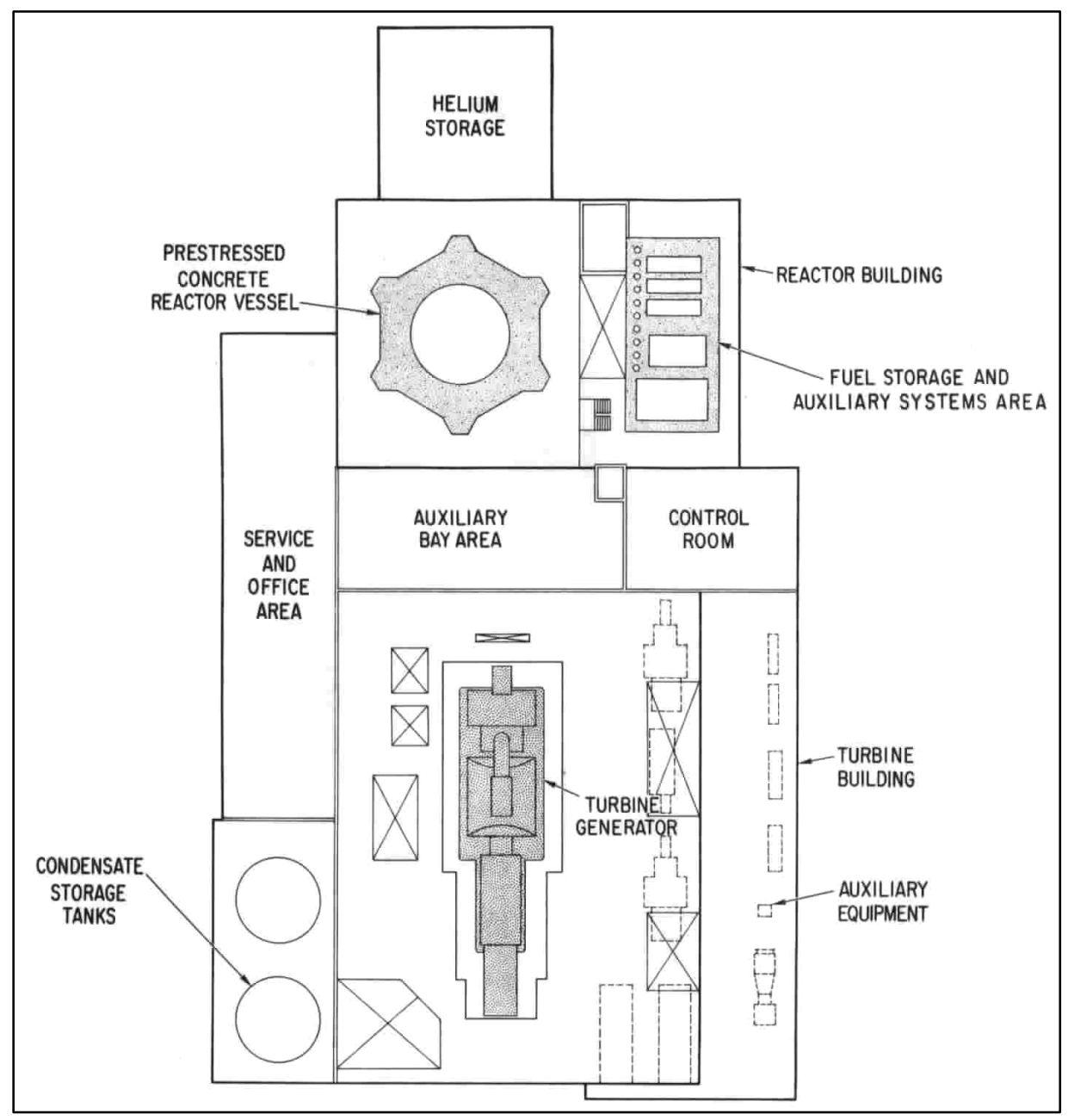

Figure A-5. Ft. St. Vrain Plant Layout 


\section{NUCLEAR ENERGY RESEARCH INITIATIVE (NERI) PROGRAM GRANT NUMBER DE-FG07-00SF22168 \\ FINAL REPORT}
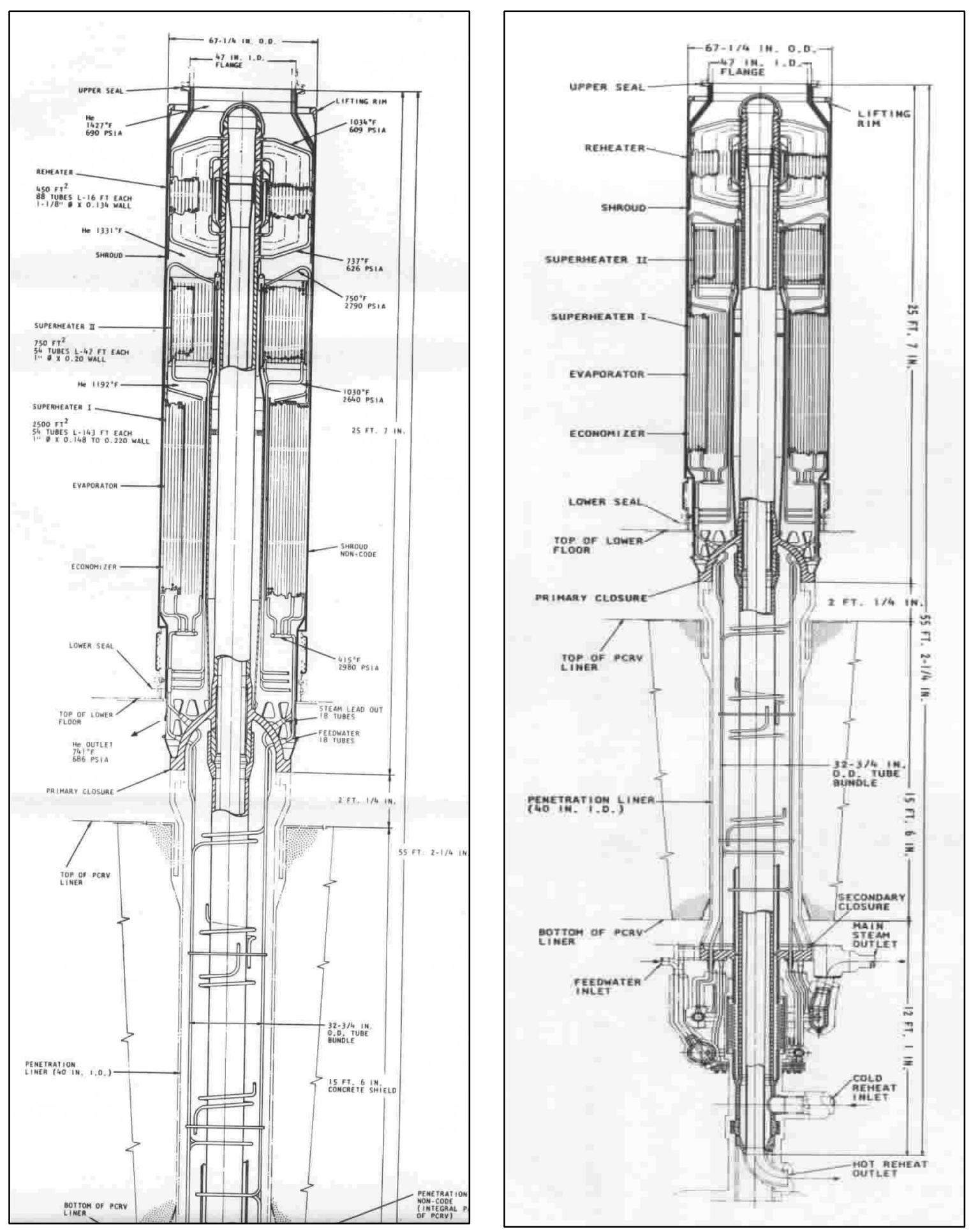

Figure A-6. Ft. St. Vrain Steam Generator Module Detail 


\section{NUCLEAR ENERGY RESEARCH INITIATIVE (NERI) PROGRAM \\ GRANT NUMBER DE-FG07-00SF22168 \\ FINAL REPORT}

\section{SODIUM ADVANCED FAST REACTOR (SAFR)}

Sodium Advanced Fast Reactor (SAFR) is a result of a team effort with Rockwell International supported by Combustion Engineering and Bechtel as major subcontractors, and by the national laboratories, particularly Argonne. SAFR employes $350 \mathrm{MW}_{\mathrm{e}}$ power modules which can be factory-built and barge-shipped to the plant site. Construction times for such a plant are estimated to be short. Shown in Figure A-7 is an overview of the SAFR plant design. This $350 \mathrm{MW}_{\mathrm{e}}$ module was chosen since it was estimated to provide the optimum balance of plant factors, including cost, schedule, and quality advantages of shop fabrication [41]. SAFR uses a pool-type reactor with two primary pumps and four intermediate heat exchangers within the pool. The heat exchangers are connected with two intermediate heat transfer systems, each of which contains one steam generator. The SAFR reactor is design as such to be able to use either oxide fuel or metal fuel. The $350 \mathrm{MW}_{\mathrm{e}}$ power module is similar in a "power pack" concept to that of PRISM in that several of these power modules can be combined to provide for various power demands as necessitated by need. Four of these $350 \mathrm{MW}_{\mathrm{e}}$ power modules can be combined to provide up to $1400 \mathrm{MW}_{\mathrm{e}}$. The following table provides a list of SAFR plant characteristics [38].

Table A-2. SAFR Characteristics

\begin{tabular}{|l|c|}
\hline Single Power Pak Capacity $\left(\mathrm{MW}_{\mathrm{e}}\right)$ & 350 \\
\hline Multiple Power Packs $\left(\mathrm{MW}_{\mathrm{e}}\right)$ & $700,1050,1400$, etc. \\
\hline Reactor Exit Temperature & $950^{\circ} \mathrm{C}$ \\
\hline Steam Cycle/Conditions & Benson, $850^{\circ} \mathrm{F} / 2700 \mathrm{lbf} / \mathrm{in}^{2}(\mathrm{~g})$ \\
\hline Fuel Type & $\mathrm{U}-\mathrm{Zr}$ Metal, U-Pu-Zr Metal, or U-Pu Oxide \\
\hline Pumps/Power Pack & 4 \\
\hline IHXs/Power Pack & 2 \\
\hline IHTS/SGs & Passive RACS, Passive DRACS \\
\hline Shutdown Heat Removal & $\begin{array}{c}\text { Diverse, Redundant Active Systems, Inherent Self- } \\
\text { Shutdown for Extremely Unlikely Accidents }\end{array}$ \\
\hline Reactor Shutdown & Decoupled from Reactor Safety Conventional \\
Construction
\end{tabular}


NUCLEAR ENERGY RESEARCH INITIATIVE (NERI) PROGRAM

GRANT NUMBER DE-FG07-00SF22168

FINAL REPORT

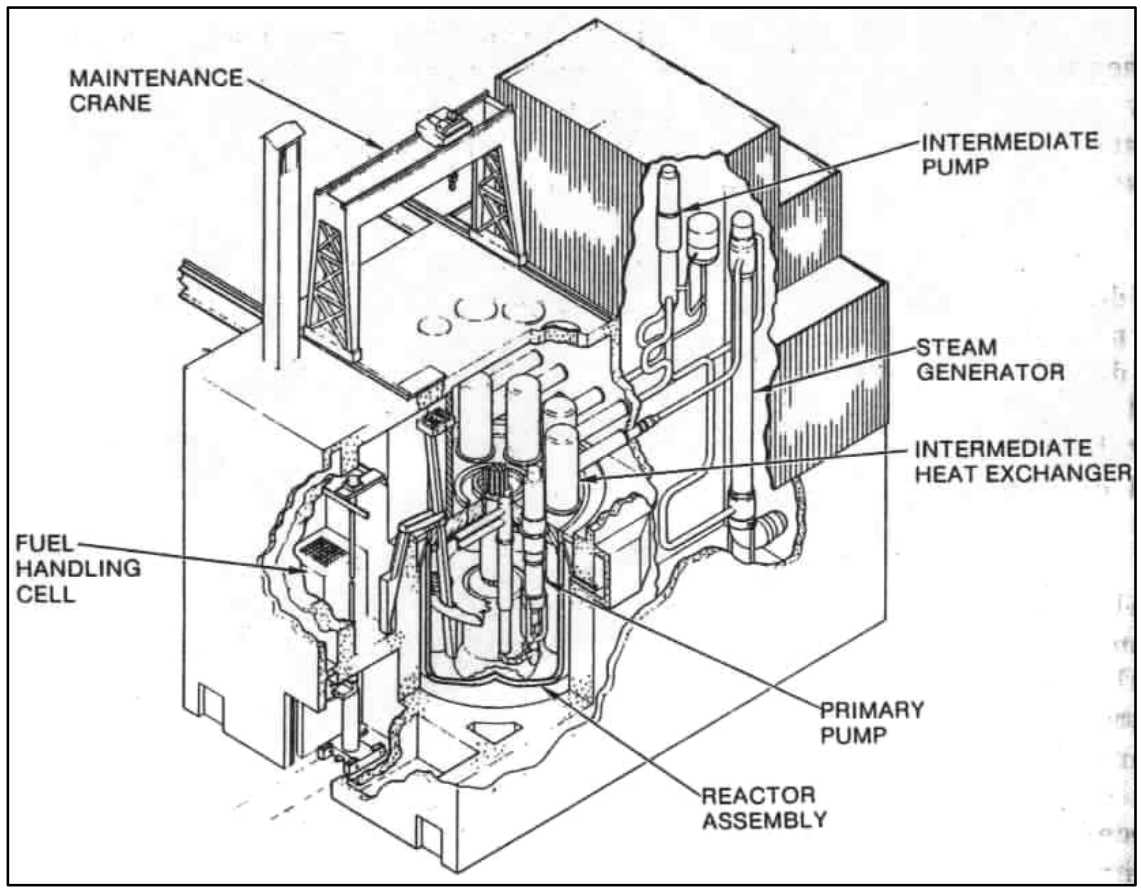

Figure A-7: SAFR Plant Design Layout 


\section{NUCLEAR ENERGY RESEARCH INITIATIVE (NERI) PROGRAM \\ GRANT NUMBER DE-FG07-00SF22168 \\ FINAL REPORT}

\section{Appendix B - Neutronics Calculations}

\section{OVERVIEW}

There are five steps to the calculation sequence: resonance correction, cross section weighing, conversion and formatting, transport, and analysis. The resonance correction is done with BONAMI and NITAWL. Cross section weighting is performed with XSDRN-PM. The conversion and formatting of the cross sections are accomplished in ALPO and GIP and the transport is calculated by DORT. A flow chart of this sequence can be seen in Figure B-1. It can be seen that some of these codes used are part of the larger packages SCALE and DOORS.

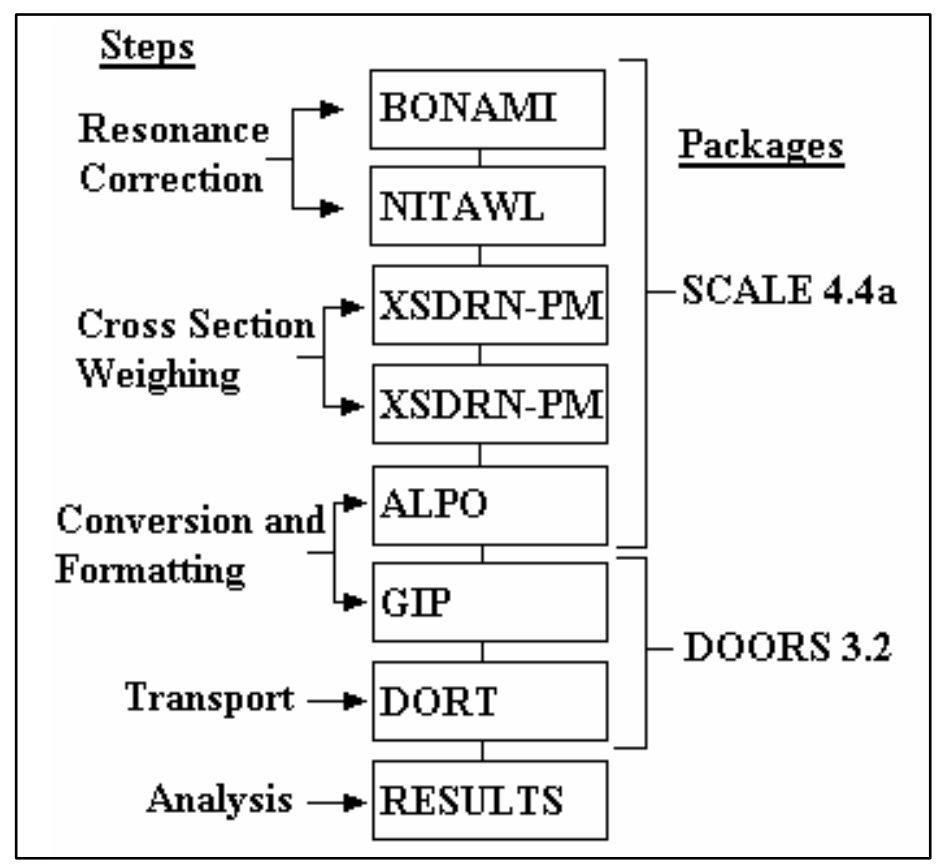

Figure B-1. Computational sequence

Using these codes, calculations are performed using three separate models. A cell model is used to represent the fuel rod in a coolant channel in BONAMI and NITAWL for resonance processing. A one-dimensional model of the core is used for generating weighted cross sections in XSDRN-PM. A two-dimensional, RZ, model is used in DORT for neutron transport calculation.

SCALE 4.4a is a code package developed at the Oak Ridge National Laboratory (ORNL) based on the older AMPX system. The AMPX system had both control modules to control calculation sequencing and functional modules to perform the calculations. SCALE acts as an AMPX driver thus allowing a bypass of the control modules for direct input into the functional modules. DOORS 3.2 is another code package from ORNL. It performs both 2 and 3 dimensional discrete ordinance transport (DORT and TORT). 


\section{NUCLEAR ENERGY RESEARCH INITIATIVE (NERI) PROGRAM \\ GRANT NUMBER DE-FG07-00SF22168 \\ FINAL REPORT}

\section{Resonance processing}

As stated above BONAMI (BONdarenko AMpx Interpolation) is used to process unresolved resonances using the Bondarenko method, an interpolation from a table of calculated cross sections as a function of temperature. Heterogeneous effects are accounted for by adding effective leakage cross sections. The Dancoff factors are also used by the code to correct for multiple pin or cell lattice structure effects.

NITAWL (Nordheim's Integral Treatment And Working Library) is a code for, as the name states, Nordheim integral treatment and working library creation. The Nordheim treatment determines neutron flux as a function of energy in the presence of an absorber and up to two moderators and thus corrects cross sections with the resolved resonance. Multiple absorbers are accounted for by the Dancoff factors.

\section{Cross section weighting}

Due to the heterogeneous material effects it is necessary to perform cross section weighting. First there is cell weighting which adjusts the cross sections as if the flux was in an infinite array of cells. This adjusts the cross sections in the fuel region where the lattice structure makes this an appropriate approximation. Secondly there is a region weighting which accounts for the boundaries near absorbers and reflectors along with the external border. These weightings are performed in XSDRN-PM.

XSDRN-PM is a one dimensional discrete ordinates transport code. XSDRN takes the original cross sections from the NITAWL output and performs the transport calculation in order to weight and collapse cross sections. One run is done for the cell weighting and collapsing and a second run for the region weighting. In the cell weighting XSDRN starts with the working library and collapses it to 44 groups. Then the region weighting is done on a one-dimensional model of the reactor design in question. The cross sections are treated with fifth order scattering and eighth order angular quadrature calculations. It outputs in AMPX format the resulting cross sections for the conversion and formatting stage. The fission neutron spectrum is also calculated for input into the DORT code.

\section{Conversion and Formatting}

The cross sections must now be converted to ANISN format and arranged into the proper input format of the DORT code. ALPO performs the conversion and then GIP generates the macroscopic material cross sections from the microscopic nuclide cross-sections. ALPO (ANISN Library Production Option) is a module used in converting the AMPX working libraries to ANISN format. The advantage of using ALPO is that it generates a table of contents in the output file. This table of contents describes the nuclides of the ANISN library that are needed for the input to GIP. GIP as stated above produces the macroscopic cross sections. These are ordered by group, across all materials in the same fashion as a DORT calculation. This reduces computational time by removing the mixing of cross sections inside the DORT calculation. It thus allows for multiple runs of 


\section{NUCLEAR ENERGY RESEARCH INITIATIVE (NERI) PROGRAM GRANT NUMBER DE-FG07-00SF22168 \\ FINAL REPORT}

the DORT code to be performed simultaneously if the same materials are used as in the GIP file.

\section{Transport}

A discrete ordinates transport code (DORT) is used to calculate the two-dimensional neutron transport. Using the cross sections generated as stated earlier, DORT iteratively converges on the 44 group fluxes on an inner iteration and the $k_{\text {eff }}$ eigenvalue in outer iterations. It then generates fission production rates and neutron balance tables. These can be used to calculate the peak-to-average power ratios, which is important for thermal design constraints. The mathematics behind DORT is the solution of the twodimensional integral-differential neutron transport equation by implementation of the discrete ordinates method. 


\section{Appendix C - Description of a Loop-Type Cylindrical Reactor System Design with no Intermediate Heat Exchangers}

\section{OVERVIEW}

The NSSS design is a two-loop type design with the core in a thin-walled low-pressure vessel. The center of the core contains $\mathrm{Pb}$ - $\mathrm{Bi}$ to allow for internal leakage control and to provide shut down margin. The core region consists of standard 12' long 17x17 squarepitch fuel assemblies. The core and vessel includes the following: a steel barrel around the core to direct and distribute coolant flow, an upper and lower plenum to help distribute coolant flows, and reflectors with control elements for possible leakage control (materials for these components are not selected at this time). The flow is distributed between two loops, each capable of running at approximately $60 \%$ of full capacity. These loops each have their own steam generators and pumps. The steam outputs could be combined for a single set of turbines or two complete power plants for each loop.

Figure C- 1 shows the general layout of the primary system and Figure C-2 illustrates the configuration of the secondary system. The PbBi enters the vessel, flows down around the sides and up through the core. The hotleg flow is split between the superheater (67\% of total flow) and the reheater (33\%). It is then recombined and supplies heat to the boiler. The $\mathrm{PbBi}$ exits the steam generator and flows through the saturated liquid preheater before returning to the vessel. Results that define most of the important parameters associated with the reference system are listed in Table C-1.

Table C-2 lists temperatures and pressures that relate to Figure $\mathrm{C}-2$. The $\mathrm{Pb}$ - $\mathrm{Bi}$ inflow temperature coming out of the reactor and entering in the superheater and the reheater is $550 \mathrm{C}$. Sixty-seven percent of the $\mathrm{Pb}-\mathrm{Bi}$ enters the superheater while $33 \%$ of it enters the reheater. The $\mathrm{Pb}-\mathrm{Bi}$ then enters the steam generator at $458 \mathrm{C}$ and exits at $403 \mathrm{C}$ and enters the saturated liquid section where it is further cooled to $351 \mathrm{C}$ before entering back into the reactor core. Much of this heat from the $\mathrm{Pb}-\mathrm{Bi}$ is used to convert water into supersaturated steam which is pumped out to the high pressure and low pressure turbines. Calculations for the component sizes for the secondary system are being revised and are not reported at this time.

It is of significance to point out that the proposed design for the secondary systems makes efficient use of the reactor heat, whereas CRBR and S-PRISM designs do not include direct primary heat to supply a reheater or feed water heaters. This creates some engineering and operational problems, but it increases thermal efficiency. However, an economic analysis, where fuel costs are relatively low, may favor simpler systems as chosen for the S-PRISM, for example.

Numerous core geometries and compositions were studied. The cylindrical core consists of ninety-two 17 x 17 pin assemblies, placed into a cylinder with a twelve foot $(3.66 \mathrm{~m})$ outer diameter. Ninety-two $17 \times 17$ pin assemblies can fit in a vessel of this size; thus, we are limited to 26,588 rod positions. Each of these assemblies is $11.48 \mathrm{ft}(3.5 \mathrm{~m})$ in active 


\section{NUCLEAR ENERGY RESEARCH INITIATIVE (NERI) PROGRAM \\ GRANT NUMBER DE-FG07-00SF22168 \\ FINAL REPORT}

length and has a volume of $51.56 \mathrm{ft}^{3}\left(0.146 \mathrm{~m}^{3}\right)$ on a 1.15 pitch-to-diameter ratio. Thus, the total fuel volume is $476 \mathrm{ft}^{3}\left(13.5 \mathrm{~m}^{3}\right)$, and the average power density must be $56 \mathrm{~kW} / \mathrm{l}$ in order to obtain $300 \mathrm{MWe}$ with a secondary system of about forty percent efficiency.

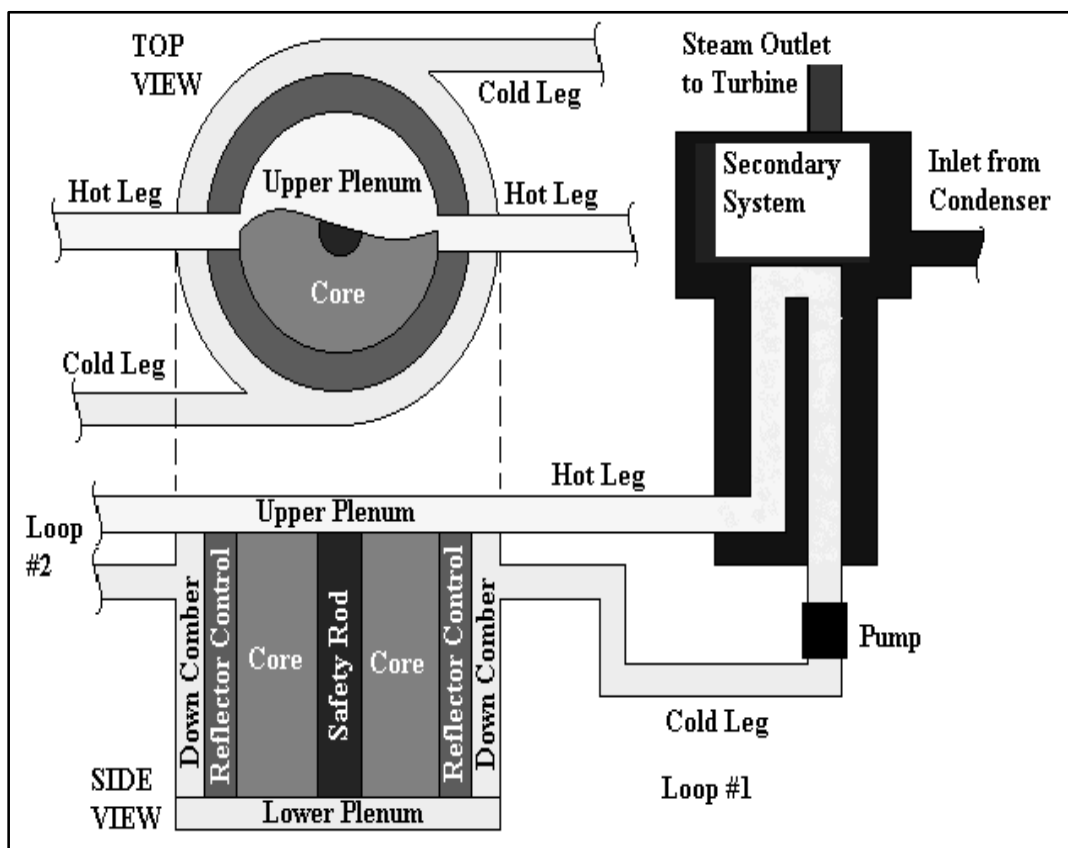

Figure C-1. Block Diagram of a Two Loop PbBi Cooled Reactor

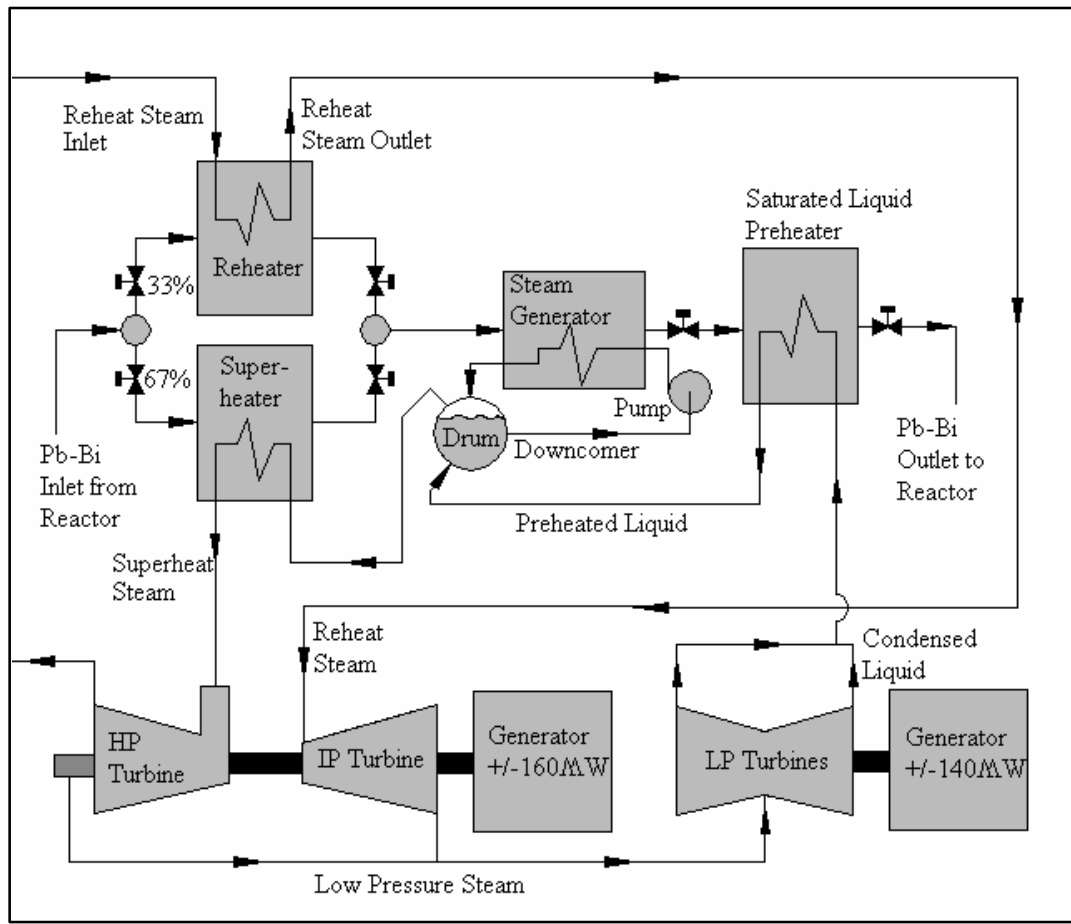

Figure C-2. Illustration of the secondary system. 


\section{NUCLEAR ENERGY RESEARCH INITIATIVE (NERI) PROGRAM GRANT NUMBER DE-FG07-00SF22168 \\ FINAL REPORT}

Table C-1: Primary System Overview

\begin{tabular}{|l|l|}
\hline Total core thermal power & $750 \mathrm{MW}$ \\
\hline Thermal efficiency & $40 \%$ \\
\hline Average power density & $56 \mathrm{~kW} / 1$ \\
\hline Average yearly burnup & $4 \mathrm{GWd} / \mathrm{MTHM} / \mathrm{Yr}$ \\
\hline Core coolant inlet temp & $350 ? \mathrm{C}$ \\
\hline Core coolant exit temp & $550 ? \mathrm{C}$ \\
\hline Flow rate through core & $25,600 \mathrm{~kg} / \mathrm{s}$ \\
\hline Vessel outer diameter & $12 \mathrm{ft}$ \\
\hline Fuel pellet diameter & $0.864 \mathrm{~cm}$ \\
\hline Clad thickness & 0.063 \\
\hline Gap thickness & $0.02 \mathrm{~cm}$ \\
\hline Pin outer diameter & $1.03 \mathrm{~cm}$ \\
\hline Pitch of rods & $1.18 \mathrm{~cm}$ \\
\hline Assembly pitch & $20.4 \mathrm{~cm}$ \\
\hline Rod locations per assembly & $17 \mathrm{x} 17$ \\
\hline Control locations per assembly & 49 \\
\hline Volume of assembly & $146 \mathrm{liters}$ \\
\hline Mass of fuel per rod & $3.1 \mathrm{~kg}$ \\
\hline Number of assemblies & 92 \\
\hline Mass of fuel per assembly & $744 \mathrm{~kg}$ \\
\hline Coolant flow area & $1.6 \mathrm{~m}$ \\
\hline Volume of core & $13.5 \mathrm{~m}$ \\
\hline Coolant flow speed in the core & $1.6 \mathrm{~m} / \mathrm{s}$ \\
\hline Active fuel height & $3.5 \mathrm{~m}$ \\
\hline Pitch to diameter ratio & 1.15 \\
\hline Cold leg pipe diameter & $0.60 \mathrm{~m}$ \\
\hline Hot leg pipe diameter & $0.65 \mathrm{~m}$ \\
\hline Total primary loop piping & $20 \mathrm{~m}$ \\
\hline Mass of heavy metal & $68,400 \mathrm{~kg}$ \\
\hline
\end{tabular}




\section{NUCLEAR ENERGY RESEARCH INITIATIVE (NERI) PROGRAM \\ GRANT NUMBER DE-FG07-00SF22168 \\ FINAL REPORT}

Table C-2: Secondary Pressures and Temperatures

\begin{tabular}{|l|l|l|l|l|l|l|}
\hline & Superheater & Reheater & $\begin{array}{l}\text { Steam } \\
\text { Generator }\end{array}$ & Drum & FeedWater & Reactor \\
\hline $\begin{array}{l}\text { Pb-Bi Inflow } \\
\text { Temperature }\end{array}$ & $550^{\circ} \mathrm{C}$ & $550^{\circ} \mathrm{C}$ & $458^{\circ} \mathrm{C}$ & & $403^{\circ} \mathrm{C}$ & $351^{\circ} \mathrm{C}$ \\
\hline $\begin{array}{l}\text { Pb-Bi Outflow } \\
\text { Temperature }\end{array}$ & $457^{\circ} \mathrm{C}$ & $459^{\circ} \mathrm{C}$ & $403^{\circ} \mathrm{C}$ & & $351^{\circ} \mathrm{C}$ & $550^{\circ} \mathrm{C}$ \\
\hline$\%$ Pb-Bi bleed off & $67 \%$ & $33 \%$ & & & & \\
\hline $\begin{array}{l}\text { Steam/Water Pressure } \\
\text { In (PSIA) }\end{array}$ & 2523 & 477 & & 2523 & 2900 & \\
\hline $\begin{array}{l}\text { Steam/Water Pressure } \\
\text { Out (PSIA) }\end{array}$ & 1740 & 530 & & 2532 & 2708 & 2712 \\
\hline Enthalpy In (J/kg) & $2.55 \mathrm{e} 6$ & $2.97 \mathrm{e} 6$ & & $8.59 \mathrm{e} 5$ & $9.5 \mathrm{e} 5$ & \\
\hline Enthalpy Out $(\mathrm{J} / \mathrm{kg})$ & $3.4 \mathrm{e} 6$ & $3.5 \mathrm{e} 6$ & & $1.09 \mathrm{e} 6$ & $1.09 \mathrm{e} 6$ & \\
\hline \begin{tabular}{l} 
Flow (lb/hr)in \\
\hline
\end{tabular} & & $1,619,92$ & & & $1,846,913$ & \\
\hline Reactor Power & 9 & $15 \%$ & $27.7 \%$ & & $25.4 \%$ & \\
\hline
\end{tabular}

\section{FUEL}

We have selected Integral Fast Reactor (IFR) metallic fuel with $\mathrm{Pu}$ (and possibly uranium) as the fissile material. The fuel pin outside diameter is 0.406 in $(1.03 \mathrm{~cm})$, the gap thickness is 0.00787 in $(0.02 \mathrm{~cm})$, the cladding thickness is 0.0248 in $(0.063 \mathrm{~cm})$, and the bonding material is $\mathrm{Pb}-\mathrm{Sn}-\mathrm{Bi}$ at $33 \%$ each. It does not appear that this bonding material has been tested, but it is recommended in an INEEL report ${ }^{11}$. The original IFR fuel uses sodium as the bonding material. Toshinsky ${ }^{21}$ recommends oxide fuel, since he believes that material compatibility problems exist between metal fuel and $\mathrm{PbBi}$. However, there are significant neutronic and thermal hydraulic advantages to metal fuel relative to oxide fuel. Given the alternatives, we have chosen metal fuel in 17x17 square pitch fuel assemblies with the provision of including some pin locations for reactivity control.

The metallic fuel developed and tested for the Experimental Breeder Reactor II (EBR-II) has some significant neutronic and heat transfer advantages relative to oxide fuel. The internal breeding ratio is higher for the more dense metal fuel than oxide fuel, and therefore metal fuel more easily maintains a conversion ratio of unity, which is an objective for the proposed design. In addition, the fuel refabrication technology developed by Argonne National Laboratory (ANL) for metallic fuel will result in much less radioactive waste than the PUREX process used for oxide fuel. The metal fuel also has better heat thermal conductivity and will therefore perform better during possible transients. However, oxide fuel generally has a larger Doppler coefficient of reactivity than metallic fuel due to softening of the spectrum by the oxides.

The metallic IFR type fuel is used for our proposed design since it has more potential of increasing the power density due to its better thermal conductivity and since it has some better neutronic characteristics than oxide fuel. The fission to capture cross-section ratios 


\section{NUCLEAR ENERGY RESEARCH INITIATIVE (NERI) PROGRAM \\ GRANT NUMBER DE-FG07-00SF22168 \\ FINAL REPORT}

will be greater for metallic fuels than for oxide fuels due to the harder neutron spectrum. Therefore, higher reactivity can be obtained for the metallic fuel compared to oxide fuel given similar enrichments. The standard composition of the metallic fuel consists of about 9 weight percent $\mathrm{Pu}, 81$ weight percent $\mathrm{U}$, and 10 weight percent $\mathrm{Zr}$. The lower initial enrichment gives the advantages of safety and proliferation resistance. The density of the UPuZr fuel is $15.2 \mathrm{~g} / \mathrm{cm}^{3}$. Its initial conversion ratio for an infinite array of fuel at the time equal to zero for the enrichment was 1.8, which is nearly double the desired 1.0. The one-group effective fission cross-section of ${ }^{239} \mathrm{Pu}$ is 1.636 barn and the capture crosssection is about 0.282 barn. The outer diameter of the fuel rod is 0.4055 in $(1.03 \mathrm{~cm})$ and the thickness of the cladding is .0248 in $(0.063 \mathrm{~cm})$. The gap material contains by weight $33 \% \mathrm{~Pb}, 33 \% \mathrm{Sn}$, and $33 \% \mathrm{Bi}$ and is $0.007874 \mathrm{in}(0.02 \mathrm{~cm})$. The active height of the fuel is $11.48 \mathrm{ft}(3.5 \mathrm{~m})$.

\section{FUEL RODS AND FUEL ASSEMBLY}

The fuel assembly is of standard square pitch design with a $17 \times 17$ array of the IFR type fuel rods with 49 locations allocated for control rods. Given a fixed reactor power, a larger $\mathrm{p} / \mathrm{d}$ could mean that the reactor will become larger. This tends to reduce the possibility of neutron leakage. On the other hand, a larger $\mathrm{p} / \mathrm{d}$ tends to increase the average neutron mean free path. The calculation results listed in Table C-3 show that the larger $\mathrm{p} / \mathrm{d}$ lowers the $\mathrm{k}_{\mathrm{eff}}$ but would increase the reactor size or reduce the power. In order to have a suitable tradeoff between a small core and to keep adequate neutron leakage in order to have small voiding coefficients, $\mathrm{p} / \mathrm{d}$ is chosen to be 1.15 .

Table C-3. $\mathrm{k}_{\text {eff }}$ as an effect of $\mathrm{p} / \mathrm{d}$ and reactor height

\begin{tabular}{|c|c|c|}
\hline Core Height (meters) & keff for P/D = 1.15 & keff for P/D = 1.6 \\
\hline 2 & 1.14 & 1.027 \\
\hline 4 & 1.16 & 1.04 \\
\hline
\end{tabular}

\section{PITCH-TO-DIAMETER RATIO}

Our calculations for reactivity coefficients, heat transfer, fluid flow, and pumping power use a pitch-to-diameter ratio (p/d) of 1.15; although, a value of about 1.25 is more typical of fast reactor designs. Most fast reactor fuels appear are wire wrapped to assure reliable pin spacing. The smaller $\mathrm{p} / \mathrm{d}$ reduces the coolant voiding reactivity coefficient, but it reduces the flow area in the core, lowers the energy sink in the core, and increases the pumping power. Given that our preliminary results for pumping power, heat transfer, and fluid flow indicate no problems with a p/d of 1.15, we selected a value that favors neutronic considerations. It is possible, however, that performance requirements for design basis transients would favor a larger $\mathrm{p} / \mathrm{d}$ and that a larger value is required to assure reliable pin spacing. Reliable pressure drop data for $\mathrm{PbBi}$ coolants for either square pitch or hexagonal pitch fuel assemblies are not currently available. 


\section{NUCLEAR ENERGY RESEARCH INITIATIVE (NERI) PROGRAM \\ GRANT NUMBER DE-FG07-00SF22168 \\ FINAL REPORT}

\section{CORE GEOMETRY AND POWER DENSITY}

Most fast reactor designs favor relatively short cores of approximately 1.5 meters, which are often referred to as pancake designs. This option provides a relatively high surface to volume ratio, which lowers coolant voiding reactivity coefficients, and it reduces pumping power requirements. However, core volume can be increased by increasing the height, and the surface to volume ratio can be maintained high in the radial, or transverse, direction rather than the axial direction.

Given a pitch of $1.15 \mathrm{~cm}$ with $17 \times 17$ pins in each assembly, and a fueled section of $11.48 \mathrm{ft}(3.5 \mathrm{~m})$ in length, each assemble has a volume of $5.155 \mathrm{ft}^{3}\left(0.146 \mathrm{~m}^{3}\right)$. In order to produce $300 \mathrm{MWe}$, plant will operate at forty percent efficiency, which is consistent with a primary system that produces $750 \mathrm{MWth}$. If we assume that the system will operate safely at a power density of $100 \mathrm{~kW} / \mathrm{l}$, fifty-one assemblies are required. This permits one to utilize a variety of geometrical configurations in a containment vessel with an outer diameter of twelve feet. If the average power density is $100 \mathrm{~kW} / 1$, only 51 assemblies are required to produce $750 \mathrm{MW}$ th of power.

Typical PWRs have power densities of about $100 \mathrm{~kW} / 1$ and the value listed for an LMFBR by Duderstadt ${ }^{24}$ is $380 \mathrm{~kW} / \mathrm{l}$. The heat transfer coefficient for $\mathrm{PbBi}$ is about one-half that of $\mathrm{Na}$, and the heat capacity is less. Thus, a value typical of PWRs should provide sufficient the rmal hydraulic conservatism. Toshinsky ${ }^{21}$ suggests that $\mathrm{PbBi}$ cooled reactors can be operated with average power densities of about $150 \mathrm{~kW} / \mathrm{l}$, which is approximately the value cited for INEEL designs. This value is most likely limited by transients, which have not been studied. A relatively low power density of $100 \mathrm{~kW} / \mathrm{l}$ is expected to permit eight years of operation without refueling if the peak fuel burnup can be $150,000 \mathrm{MW}-\mathrm{d} / \mathrm{MTHM}$, the core volume of less than 15 cubic meters, and the cladding fluence limit is $4 \times 10^{23} \mathrm{n} / \mathrm{cm}^{2}$.

\section{REACTIVITY CHARACTERISTICS}

One significant concern regarding fast reactors is that coolant voiding may increase reactivity. Thus, if some coolant voiding occurs, one must rely on the control system to assure that reactor power does not continue to increase. Designs described in an INEEL report $^{43}$ use fuel assemblies with a central void region to achieve a core design that has a negative $\mathrm{PbBi}$ coolant voiding reactivity coefficient. Our reference cylindrical design uses standard IFR fuel in assemblies with 17 x 17 pins on a square pitch with no central void. This configuration has a slightly positive coolant voiding reactivity coefficient. However, if some uranium-thorium fuel is substituted for plutonium-uranium fuel, and the core configuration is changed to a slab, a negative voiding coefficient is obtained. Additional studies may show that a negative reactivity voiding coefficient may also be attainable with a cylindrical design. Our calculations obtain a reactivity change of about three dollars during an eight-year period, which should be easily controllable by mechanical rods or leakage control; although, a reactivity change of near zero over this time could probably be obtained with an improved core design. 


\section{NUCLEAR ENERGY RESEARCH INITIATIVE (NERI) PROGRAM \\ GRANT NUMBER DE-FG07-00SF22168 \\ FINAL REPORT}

\section{INTERMEDIATE HEAT EXCHANGER}

An intermediate heat exchanger offers overpressure protection, and it eliminates the need to fill out a radiation work permit each time maintenance is performed on the secondary system. However, it reduces thermal efficiency, probably decreases reliability, and it adds cost. Toshinsky ${ }^{45}$ advises that an intermediate heat exchanger is not necessary, and Boardman $^{44}$ advises that one is very useful for overpressure protection.

\section{MAXIMUM FUEL AND CLAD TEMPERATURES}

A report from INEEL $^{43}$ recommends that the maximum fuel temperature should be kept below $1400 \mathrm{C}$, and it cites steady state and transient limits for the clad as $650 \mathrm{C}$ and 750 $\mathrm{C}$, respectively. Transients are assumed to begin at one-half of the initial power.

\section{CORE VOLUME}

Our reference core consists of ninety-two $17 \times 17$ pin assemblies, placed into a cylinder with a twelve foot outer diameter. Ninety-two $17 \times 17$ pin assemblies can fit in a vessel of this size; thus, we are limited to 26,588 rod positions. Each of these assemblies is 3.5 meters in active length and has a volume of $0.146 \mathrm{~m}^{3}$ on a 1.15 pitch-to-diameter ratio. Thus, the total fuel volume is $13.5 \mathrm{~m}^{3}$, and the average power density must be $56 \mathrm{~kW} / \mathrm{l}$ in order to obtain 300 MWe with a secondary system of forty percent efficiency.

A slab core design with five rows of fuel assemblies permits 54 assemblies to be placed in a vessel 12 feet in diameter so that the fluence the pressure vessel should not exceed 1 $\mathrm{x} 10^{19} \mathrm{n} / \mathrm{cm}^{2}$ in thirty years. The volume of this core is $7.9 \mathrm{~m}^{3}$; thus, an average power density of $95 \mathrm{~kW} / \mathrm{l}$ will generate $750 \mathrm{MWth}$ of power, and this produces $300 \mathrm{MWe}$ if the secondary system operates at $40 \%$ efficiency.

\section{INLET AND OUTLET TEMPERATURES}

Chuck Boardman $^{44}$ suggested that the outlet temperature should be no higher than $510 \mathrm{C}$ to prevent fuel cladding damage during design-basis transients, based on analyses of the sodium cooled PRISM system. Also, Toshinsky ${ }^{45}$, from IPPE, suggest that the outlet temperature should be no higher than $500 \mathrm{C}$ for a long-lived core to operate with acceptable levels of corrosion. Nevertheless, we have selected $550 \mathrm{C}$ as the outlet temperature with the expectation that nominal progress in materials technology will be forthcoming and that our relative low power density will mitigate over-temperature problems during design-basis transients. This judgment that $550 \mathrm{C}$ is an acceptable value for the outlet temperature for a $\mathrm{PbBi}$ cooled reactor is based on review of papers and on conversations and presentations at recent ANS meetings. A core outlet temperature of $500 \mathrm{C}$ and an inlet temperature of $350 \mathrm{C}$ would be in very close agreement with SuperPrism specifications.

One important consideration regarding core inlet temperature is the possibility that $\mathrm{PbBi}$ may freeze during a plausible transient, and another issue is thermal stresses induced during transients. Inlet and outlet temperatures range from about 300-400 $\mathrm{C}$ and $450-550$ $\mathrm{C}$ for sodium cooled reactors, and sodium freezes at a slightly lower temperature than a 


\section{NUCLEAR ENERGY RESEARCH INITIATIVE (NERI) PROGRAM \\ GRANT NUMBER DE-FG07-00SF22168 \\ FINAL REPORT}

$\mathrm{PbBi}$ eutectic. The heat capacity per unit volume is probably about the same for $\mathrm{Pb}$ and $\mathrm{Na}$, but the thermal conductivity of $\mathrm{Na}$ is about a factor of two higher; thus, $\mathrm{Pb}$ should be less of a problem for thermal transients than is the case for Na. Based on qualitative reviews of other metal cooled fast reactors, we believe that $350 \mathrm{C}$ for the inlet temperature should be acceptable to prevent freezing and excessive stresses during transients.

\section{THERMAL-HYDRAULICS}

A one-channel analysis gives the core coolant mass flow rate as $25,600 \mathrm{~kg} / \mathrm{s}$ and a flow speed of $1.6 \mathrm{~m} / \mathrm{s}$ averaged across the reactor. This will maintain the core coolant outlet temperature below $550 \mathrm{C}$ with an inlet temperature of $350 \mathrm{C}$. The thermal-hydraulics design is accomplished by single channel analysis for the non-zone loaded design. The design also follows some other guidelines and assumptions. The inlet and outlet plenum are assumed to be able to disperse the fluid flow evenly as desired and well mixed in order to prevent cold slug accidents along with thermal shock accidents. The maximum fuel temperature is restricted to $1400 \mathrm{C}$ to prevent damage. The cladding is designed to maintain less than $650 \mathrm{C}$ for normal operation and less than $750 \mathrm{C}$ for transients and less than $850 \mathrm{C}$ for an unlikely event. It is also believed that the power flattening possible due to the leakage control will allow for more uniform fluid properties in the vessel. This will also allow for much lower flow speeds due to lower peak to average power ratios. Current results for pumping power only include the pressure drop across the core and the effect of wire wrapping on the fuel is not considered; thus, they are incomplete and are not reported at this time.

\section{SECONDARY SYSTEM}

The superheaters and evaporators for CRBR, which is of about the same thermal power as our proposed design, were of identical design: vertical, counterflow, shell and tube heat exchangers with a 90 degree bend in the top of the shell and tube bundle. They are both $65 \mathrm{ft}(19.812 \mathrm{~m})$ long containing 757 tubes and are made from 2 1/4 Cr-1 Mo steel. Intermediate sodium flows down the shell side while water or steam flows up the tube side. The superheater is rated at $92.0 \mathrm{MW}_{\text {th }}$ while the evaporators are rated at 116.5 $\mathrm{MW}_{\text {th }}$. Since there were three loops, the CRBR design employed six of these units. Also, the CRBR did not reheat interstage turbine steam; thus, no reheater was used. Sodium is a better heat transfer medium than is $\mathrm{PbBi}$, but the size of the steam generator should be determined by the heat transfer characteristics rather than by $\mathrm{PbBi}$, due to relative heat transfer capability of PbBi compared to water. SuperPRISM used a single steam generator of a design similar to $\mathrm{CRBR}$, without a reheater.

An intermediate heat exchanger offers overpressure protection, and it eliminates the need to fill out a radiation work permit each time maintenance is performed on the secondary system. However, it reduces thermal efficiency, probably decreases reliability, and it adds cost. Toshinsky ${ }^{45}$ advises that an intermediate heat exchanger is not necessary, and Boardman $^{44}$ advises that one is very useful for overpressure protection. We currently do not propose an intermediate heat exchange in our reference design, but the opinion of our industrial partners may result in changing this option in the design. 


\section{NUCLEAR ENERGY RESEARCH INITIATIVE (NERI) PROGRAM \\ GRANT NUMBER DE-FG07-00SF22168 \\ FINAL REPORT}

Based on conversations with Berryhill ${ }^{23}$, a reactor outlet temperature of $550 \mathrm{C}$ is too low for a supercritical water system. Thus, we have selected a system based on relatively old fossil fuel plants with some evident variations. In order to optimize thermal efficiency, we propose to use $\mathrm{PbBi}$ for reheating steam from a high pressure turbine and for heating feed water. This is counter to the advice of Boardman ${ }^{22}$, for example, who suggests that the additional pipes and valves necessary to support this option are not worth the effort. Neither CRBR nor PRISM design used turbines that utilize reheated inter-stage turbine exhaust. Instead, this energy was used to drive feed water reheaters. We have estimated the efficiency for our proposed secondary system to be forty-two percent but it could be as high as forty-five percent, which is somewhat higher than values of 38 and $39 \%$ cited for CRBR and SuperPRISM, respectively.

\section{MATERIALS}

Research on materials compatible with $\mathrm{Pb}$ or $\mathrm{PbBi}$ cooled systems remains an active area of study. Steels with high nickel content are less corrosion resistant to $\mathrm{Pb}$ than ironcarbide steel, based on micrographs and material tests recently obtained from corrosion studies conducted at INEEL and at MIT. The inclusion of silicon above about $3 \%$ may form glassy surfaces that effectively inhibit corrosion. It is generally understood that steels used in Russian PbBi systems are of significant silicon content. Currently available commercial steels probably limits the reactor outlet temperature to no more than $500 \mathrm{C}$ for a $\mathrm{PbBi}$ cooled vessel to function for 30 years. The most corrosion-resistant material to date appears to be $\mathrm{Zr}-705$, and this result has motivated additional studies on other zirconium alloys. It is also of interest to note that results from corrosion tests are rather sensitive to impurities of arsenic and antimony in the coolant. Disadvantages of SS-316 include high nickel content and swelling due to neutron exposure (information presented or obtained through discussions at the 2001 Summer and Winter Meetings of the American Nuclear Society and other personal discussions).

\section{PUMPING POWER AND PIPE SIZES}

Current results for pumping power only include the pressure drop across the core and the effect of wire wrapping on the fuel is not considered; thus, they are incomplete and are not reported at this time. The selection of pipe sizes depends on acceptable flow rates, pumping power and various stresses of interest.

\section{STEAM GENERATOR SIZING}

The superheaters and evaporators for CRBR, which is of about the same thermal power as our proposed design, were of identical design: vertical, counterflow, shell and tube heat exchangers with a 90 degree bend in the top of the shell and tube bundle. They are both $65 \mathrm{ft}$ long containing 757 tubes and are made from 2 1/4 Cr-1 Mo steel. Intermediate sodium flows down the shell side while water or steam flows up the tube side. The superheater is rated at $92.0 \mathrm{MW}_{\text {th }}$ while the evaporators are rated at $116.5 \mathrm{MW}_{\text {th }}$. Since there were three loops, the CRBR design employed six of these units. Also, the CRBR did not reheat interstage turbine steam; thus, no reheater was used. Sodium is a better 


\section{NUCLEAR ENERGY RESEARCH INITIATIVE (NERI) PROGRAM \\ GRANT NUMBER DE-FG07-00SF22168 \\ FINAL REPORT}

heat transfer medium than is $\mathrm{PbBi}$, but the size of the steam generator should be determined by the heat transfer characteristics rather than by $\mathrm{PbBi}$, due to relative heat transfer capability of $\mathrm{PbBi}$ compared to water. SuperPRISM used a single steam generator of a design similar to CRBR, without a reheater.

\section{COOLANT SUPPLY}

By summing the amount of coolant needed to fill the core region, the hot and cold legs of the system and the steam generator, a rough estimation of the coolant supply can be obtained. It is determined that the design will need approximately $550,000 \mathrm{~kg}$ of leadbismuth coolant for the primary system.

\section{DESIGN OF REACTOR INTERNALS}

It is determined through a rough sizing calculation that 92 standard $17 \times 17$ fuel assemblies can fit into the 12 foot diameter vessel, with adequate space to protect the pressure vessel from embrittlement during thirty to forty years of operation. Figure C-3 shows an illustration of the vessel with 92 standard $17 \times 17$ fuel assemblies in it. The upper righthand-side of this figure shows a detailed view of one of the fuel assemblies.

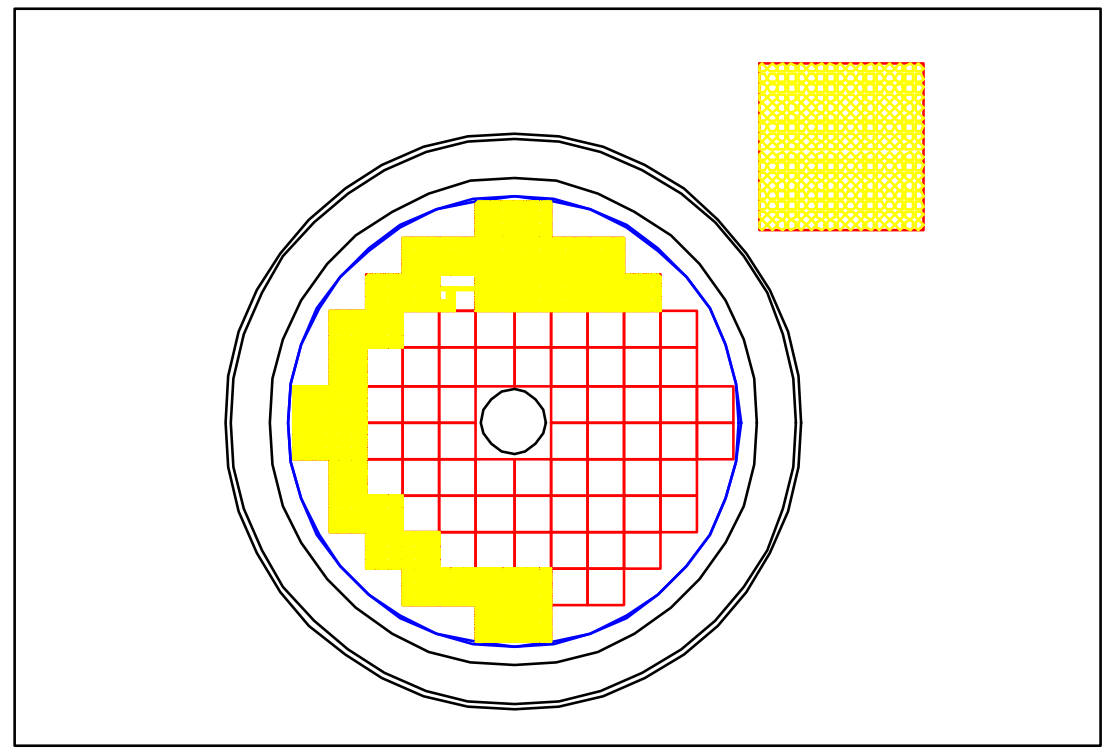

Figure C-3. Core layout used in thermal hydraulic analysis

\section{CORE FLOW RATE AND INLET TEMPERATURE}

One channel analysis gives the core coolant mass flow rate as $25,600 \mathrm{~kg} / \mathrm{s}$ and a flow speed of $1.6 \mathrm{~m} / \mathrm{s}$ averaged across the reactor. This will maintain the core coolant outlet temperature below $550^{\circ} \mathrm{C}$ with an inlet temperature of $350^{\circ} \mathrm{C}$. Figure $\mathrm{C}-4$ shows a plot of the flow speed as it changes with the input temperature. The flow speed is considered ineffective past $5 \mathrm{~m} / \mathrm{s}$. This flow rate would be difficult to achieve with lead-bismuth. The corresponding mass flow rate is $105,000 \mathrm{~kg} / \mathrm{s}$. 
NUCLEAR ENERGY RESEARCH INITIATIVE (NERI) PROGRAM

GRANT NUMBER DE-FG07-00SF22168

FINAL REPORT

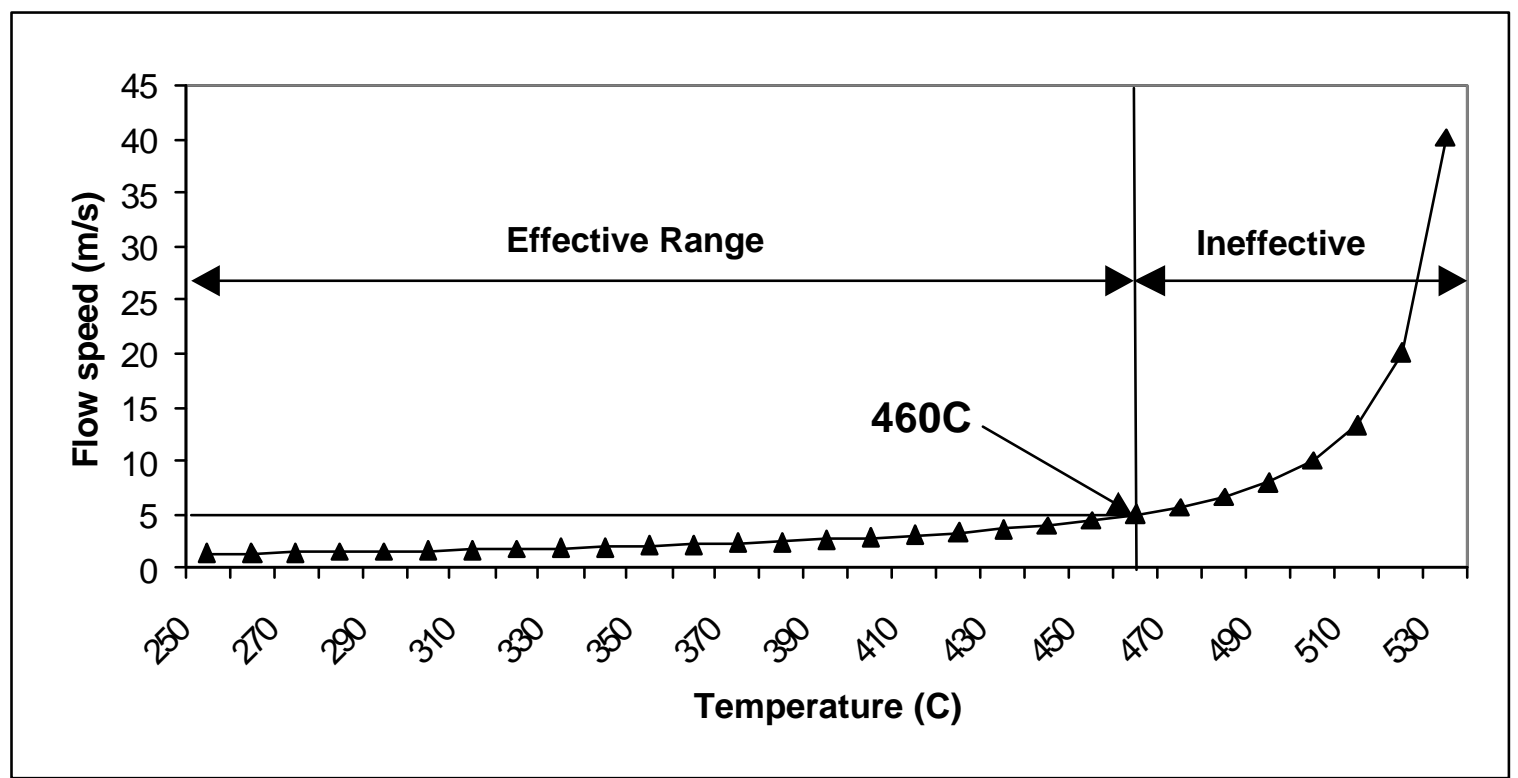

Figure C-4. Effective flow speed versus inlet temperature 


\section{NUCLEAR ENERGY RESEARCH INITIATIVE (NERI) PROGRAM \\ GRANT NUMBER DE-FG07-00SF22168 \\ FINAL REPORT}

\section{Appendix D - Manufacturing Process of a Heat Exchanger}

The following information is an outline of the manufacturing processes required to create a feedwater shell-and-tube heat exchanger. Stan Kitchens of Steeltek Heat Exchanger Company created this outline.

\section{MACHINE SHOP:}

1. Machine and Drill the bolt circle in all body flanges from rough forgings

2. Machine and Drill the bolt circle in flat channel cover from either rough forging or plate. Machine the pass partition grooves.

3. Machine the tubesheet from either rough forgings or plate. Drill, ream, and ring groove the tube holes. Drill and Tap the tie rod holes. Drill the bolt circle. Machine the pass partition grooves

4. Stack the baffles plates for drilling. Drill tube holes and tie rod holes in baffles. Unstack and machine the O.D. of the baffles.

\section{WELD SHOP:}

1. Burn all required parts from plate. Burn all weld bevels on the edges.

2. Roll all cylinders and.

3. Weld long seam, tack weld, and reroll.

4. Fit and weld cylinders together to make required shell length. Grind inside welds flush.

5. Fit and weld body flanges and/or elliptical head to shell ends. Perform NDE (radiography, MT, PT, etc.) as required on all shell long seams and round seams.

6. Layout location of all shell nozzles and attachments. Burn all nozzle openings and bevel.

7. Fit and weld nozzle flanges to nozzle necks.

8. Fit and weld nozzles to shell cylinder. Grind inside welds flush. Perform NDE (radiography, MT, PT, etc.) as required on all nozzle welds.

9. Fit and weld supports. Fit and weld support pad to shell. Fit and weld supports to pad. 


\section{NUCLEAR ENERGY RESEARCH INITIATIVE (NERI) PROGRAM GRANT NUMBER DE-FG07-00SF22168 \\ FINAL REPORT}

10. Repeat 2 through 8 for the channel. Also, fit and weld the pass partition plates to the inside of the channel.

11. Fit and weld lifting lugs and miscellaneous attachments as required.

\section{ASSEMBLY SHOP:}

1. Cut and thread the tie rods. Cut and deburr the spacers.

2. Deburr the tube holes in the baffles

3. Assemble the bundle skeleton (tubesheet, baffles, tie rods, and spacers).

4. Load the tubes in the tube bundle.

5. Set the tube projections and expand the tubes using a torque controlled expanding tool.

6. Install the tube bundle into the shell.

7. Install the channel on the tubesheet.

8. Fill the shell with water and hydrostatic test the shell. Observe the face of the tubesheet through the channel for tube joint leaks.

9. Install the channel cover.

10. Fill the tubeside with water and hydrostatic test.

11. Drain both sides

12. Surface prep and paint the exterior

13. Prep for shipment and ship. 


\section{NUCLEAR ENERGY RESEARCH INITIATIVE (NERI) PROGRAM \\ GRANT NUMBER DE-FG07-00SF22168 \\ FINAL REPORT}

\section{Appendix E - 1 - Demand 24}

Below is an After Tax Cash Flow Analysis and Break-even Analysis at Minimum Attractive Rates of Returns (MARR) of 8\%, 10\%, and 12\% for each experiment described in the Analysis Section of this report. The annual demand for the experiments is 24 heat exchangers.

Experiment 1

\begin{tabular}{|r|r|r|r|r|r|}
\hline & & Depreciation & Taxable Income & Taxes $(35 \%)$ & ATCF \\
\hline 0 & $-\$ 3,680,599$ & & $\$ 0$ & & $-\$ 3,680,599$ \\
\hline 1 & $-\$ 5,175,739$ & $\$ 525,800$ & $-\$ 5,701,539$ & $-\$ 1,995,539$ & $-\$ 3,180,201$ \\
\hline 2 & $-\$ 5,175,739$ & $\$ 525,800$ & $-\$ 5,701,539$ & $-\$ 1,995,539$ & $-\$ 3,180,201$ \\
\hline 3 & $-\$ 5,175,739$ & $\$ 525,800$ & $-\$ 5,701,539$ & $-\$ 1,995,539$ & $-\$ 3,180,201$ \\
\hline 4 & $-\$ 5,175,739$ & $\$ 525,800$ & $-\$ 5,701,539$ & $-\$ 1,995,539$ & $-\$ 3,180,201$ \\
\hline 5 & $-\$ 5,175,739$ & $\$ 525,800$ & $-\$ 5,701,539$ & $-\$ 1,995,539$ & $-\$ 3,180,201$ \\
\hline 6 & $-\$ 5,175,739$ & $\$ 525,800$ & $-\$ 5,701,539$ & $-\$ 1,995,539$ & $-\$ 3,180,201$ \\
\hline 7 & $-\$ 5,175,739$ & $\$ 525,800$ & $-\$ 5,701,539$ & $-\$ 1,995,539$ & $-\$ 3,180,201$ \\
\hline
\end{tabular}

\begin{tabular}{|lr|}
\hline PW(8\%) & $-\$ 20,237,900.40$ \\
AW(8\%) & $-\$ 3,887,142.13$ \\
BE Rev & $\$ 161,964$ \\
\hline PW(10\%) & $-\$ 19,163,147.61$ \\
AW(10\%) & $-\$ 3,936,215.91$ \\
BE Rev & $\$ 164,009$ \\
\hline PW(12\%) & $-\$ 18,194,260.41$ \\
AW(12\%) & $-\$ 3,986,685.15$ \\
BE Rev & $\$ 166,112$ \\
\hline
\end{tabular}

Experiment 2

\begin{tabular}{|r|r|r|r|r|r|}
\hline & & Depreciation & Taxable Income & Taxes $(35 \%)$ & ATCF \\
\hline 0 & $-\$ 3,680,599$ & & $\$ 0$ & & $-\$ 3,680,599$ \\
\hline 1 & $-\$ 5,185,574$ & $\$ 525,800$ & $-\$ 5,711,374$ & $-\$ 1,998,981$ & $-\$ 3,186,593$ \\
\hline 2 & $-\$ 5,185,574$ & $\$ 525,800$ & $-\$ 5,711,374$ & $-\$ 1,998,981$ & $-\$ 3,186,593$ \\
\hline 3 & $-\$ 5,923,363$ & $\$ 525,800$ & $-\$ 6,449,163$ & $-\$ 2,257,207$ & $-\$ 3,666,156$ \\
\hline 4 & $-\$ 5,923,363$ & $\$ 525,800$ & $-\$ 6,449,163$ & $-\$ 2,257,207$ & $-\$ 3,666,156$ \\
\hline 5 & $-\$ 5,197,164$ & $\$ 525,800$ & $-\$ 5,722,964$ & $-\$ 2,003,037$ & $-\$ 3,194,127$ \\
\hline 6 & $-\$ 5,197,164$ & $\$ 525,800$ & $-\$ 5,722,964$ & $-\$ 2,003,037$ & $-\$ 3,194,127$ \\
\hline 7 & $-\$ 5,934,108$ & $\$ 525,800$ & $-\$ 6,459,908$ & $-\$ 2,260,968$ & $-\$ 3,673,141$ \\
\hline
\end{tabular}

\begin{tabular}{|lr|}
\hline PW(8\%) & $-\$ 21,298,137.47$ \\
AW(8\%) & $-\$ 4,090,784.41$ \\
BE Rev & $\$ 170,449$ \\
\hline PW(10\%) & $-\$ 20,140,725.06$ \\
AW(10\%) & $-\$ 4,137,015.70$ \\
BE Rev & $\$ 172,376$ \\
\hline PW(12\%) & $-\$ 19,097,728.83$ \\
AW(12\%) & $-\$ 4,184,651.10$ \\
BE Rev & $\$ 174,360$ \\
\hline
\end{tabular}

Experiment 3

\begin{tabular}{|r|r|r|r|r|r|}
\hline & & Depreciation & Taxable Income & Taxes $(35 \%)$ & ATCF \\
\hline 0 & $-\$ 3,680,599$ & & $\$ 0$ & & $-\$ 3,680,599$ \\
\hline 1 & $-\$ 5,922,910$ & $\$ 525,800$ & $-\$ 6,448,710$ & $-\$ 2,257,049$ & $-\$ 3,665,862$ \\
\hline 2 & $-\$ 5,922,910$ & $\$ 525,800$ & $-\$ 6,448,710$ & $-\$ 2,257,049$ & $-\$ 3,665,862$ \\
\hline 3 & $-\$ 5,922,910$ & $\$ 525,800$ & $-\$ 6,448,710$ & $-\$ 2,257,049$ & $-\$ 3,665,862$ \\
\hline 4 & $-\$ 5,922,910$ & $\$ 525,800$ & $-\$ 6,448,710$ & $-\$ 2,257,049$ & $-\$ 3,665,862$ \\
\hline 5 & $-\$ 5,922,910$ & $\$ 525,800$ & $-\$ 6,448,710$ & $-\$ 2,257,049$ & $-\$ 3,665,862$ \\
\hline 6 & $-\$ 5,922,910$ & $\$ 525,800$ & $-\$ 6,448,710$ & $-\$ 2,257,049$ & $-\$ 3,665,862$ \\
\hline 7 & $-\$ 5,922,910$ & $\$ 525,800$ & $-\$ 6,448,710$ & $-\$ 2,257,049$ & $-\$ 3,665,862$ \\
\hline
\end{tabular}

\begin{tabular}{|lr|}
\hline PW(8\%) & $-\$ 22,766,431.85$ \\
AW(8\%) & $-\$ 4,372,803.24$ \\
BE Rev & $\$ 182,200$ \\
\hline PW(10\%) & $-\$ 21,527,549.28$ \\
AW(10\%) & $-\$ 4,421,877.02$ \\
BE Rev & $\$ 184,245$ \\
\hline PW(12\%) & $-\$ 20,410,699.46$ \\
AW(12\%) & $-\$ 4,472,346.25$ \\
BE Rev & $\$ 186,348$ \\
\hline
\end{tabular}

Experiment 4

\begin{tabular}{|r|r|r|r|r|r|}
\hline & & Depreciation & Taxable Income & Taxes $(35 \%)$ & ATCF \\
\hline 0 & $-\$ 3,680,599$ & & $\$ 0$ & & $-\$ 3,680,599$ \\
\hline 1 & $-\$ 5,923,363$ & $\$ 525,800$ & $-\$ 6,449,163$ & $-\$ 2,257,207$ & $-\$ 3,666,156$ \\
\hline 2 & $-\$ 5,923,363$ & $\$ 525,800$ & $-\$ 6,449,163$ & $-\$ 2,257,207$ & $-\$ 3,666,156$ \\
\hline 3 & $-\$ 5,923,363$ & $\$ 525,800$ & $-\$ 6,449,163$ & $-\$ 2,257,207$ & $-\$ 3,666,156$ \\
\hline 4 & $-\$ 5,923,363$ & $\$ 525,800$ & $-\$ 6,449,163$ & $-\$ 2,257,207$ & $-\$ 3,666,156$ \\
\hline 5 & $-\$ 5,923,363$ & $\$ 525,800$ & $-\$ 6,449,163$ & $-\$ 2,257,207$ & $-\$ 3,666,156$ \\
\hline 6 & $-\$ 5,923,363$ & $\$ 525,800$ & $-\$ 6,449,163$ & $-\$ 2,257,207$ & $-\$ 3,666,156$ \\
\hline 7 & $-\$ 5,923,363$ & $\$ 525,800$ & $-\$ 6,449,163$ & $-\$ 2,257,207$ & $-\$ 3,666,156$ \\
\hline
\end{tabular}

\begin{tabular}{|lr|}
\hline PW(8\%) & $-\$ 22,767,963.63$ \\
AW(8\%) & $-\$ 4,373,097.45$ \\
BE Rev & $\$ 182,212$ \\
\hline PW(10\%) & $-\$ 21,528,981.63$ \\
AW(10\%) & $-\$ 4,422,171.23$ \\
BE Rev & $\$ 184,257$ \\
\hline PW(12\%) & $-\$ 20,412,042.18$ \\
AW(12\%) & $-\$ 4,472,640.47$ \\
BE Rev & $\$ 186,360$ \\
\hline
\end{tabular}

Experiment 5

\begin{tabular}{|r|r|r|r|r|r|}
\hline & & Depreciation & Taxable Income & Taxes $(35 \%)$ & ATCF \\
\hline 0 & $-\$ 3,680,599$ & & $\$ 0$ & & $-\$ 3,680,599$ \\
\hline 1 & $-\$ 5,215,171$ & $\$ 525,800$ & $-\$ 5,740,971$ & $-\$ 2,009,340$ & $-\$ 3,205,831$ \\
\hline 2 & $-\$ 5,215,171$ & $\$ 525,800$ & $-\$ 5,740,971$ & $-\$ 2,009,340$ & $-\$ 3,205,831$ \\
\hline 3 & $-\$ 5,215,171$ & $\$ 525,800$ & $-\$ 5,740,971$ & $-\$ 2,009,340$ & $-\$ 3,205,831$ \\
\hline 4 & $-\$ 5,215,171$ & $\$ 525,800$ & $-\$ 5,740,971$ & $-\$ 2,009,340$ & $-\$ 3,205,831$ \\
\hline 5 & $-\$ 5,215,171$ & $\$ 525,800$ & $-\$ 5,740,971$ & $-\$ 2,009,340$ & $-\$ 3,205,831$ \\
\hline 6 & $-\$ 5,215,171$ & $\$ 525,800$ & $-\$ 5,740,971$ & $-\$ 2,009,340$ & $-\$ 3,205,831$ \\
\hline 7 & $-\$ 5,215,171$ & $\$ 525,800$ & $-\$ 5,740,971$ & $-\$ 2,009,340$ & $-\$ 3,205,831$ \\
\hline
\end{tabular}

\begin{tabular}{|lr|}
\hline PW(8\%) & $-\$ 20,371,341.79$ \\
AW(8\%) & $-\$ 3,912,772.54$ \\
BE Rev & $\$ 163,032$ \\
\hline PW(10\%) & $-\$ 19,287,927.17$ \\
AW(10\%) & $-\$ 3,961,846.32$ \\
BE Rev & $\$ 165,077$ \\
\hline PW(12\%) & $-\$ 18,311,231.35$ \\
AW(12\%) & $-\$ 4,012,315.56$ \\
BE Rev & $\$ 167,180$ \\
\hline
\end{tabular}




\section{NUCLEAR ENERGY RESEARCH INITIATIVE (NERI) PROGRAM \\ GRANT NUMBER DE-FG07-00SF22168 \\ FINAL REPORT}

\section{Experiment 6}

\begin{tabular}{|r|r|r|r|r|r|}
\hline & & Depreciation & Taxable Income & Taxes $(35 \%)$ & ATCF \\
\hline 0 & $-\$ 3,680,599$ & & $\$ 0$ & & $-\$ 3,680,599$ \\
\hline 1 & $-\$ 5,197,164$ & $\$ 525,800$ & $-\$ 5,722,964$ & $-\$ 2,003,037$ & $-\$ 3,194,127$ \\
\hline 2 & $-\$ 5,197,164$ & $\$ 525,800$ & $-\$ 5,722,964$ & $-\$ 2,003,037$ & $-\$ 3,194,127$ \\
\hline 3 & $-\$ 5,197,164$ & $\$ 525,800$ & $-\$ 5,722,964$ & $-\$ 2,003,037$ & $-\$ 3,194,127$ \\
\hline 4 & $-\$ 5,197,164$ & $\$ 525,800$ & $-\$ 5,722,964$ & $-\$ 2,003,037$ & $-\$ 3,194,127$ \\
\hline 5 & $-\$ 5,197,164$ & $\$ 525,800$ & $-\$ 5,722,964$ & $-\$ 2,003,037$ & $-\$ 3,194,127$ \\
\hline 6 & $-\$ 5,197,164$ & $\$ 525,800$ & $-\$ 5,722,964$ & $-\$ 2,003,037$ & $-\$ 3,194,127$ \\
\hline 7 & $-\$ 5,197,164$ & $\$ 525,800$ & $-\$ 5,722,964$ & $-\$ 2,003,037$ & $-\$ 3,194,127$ \\
\hline
\end{tabular}

\begin{tabular}{|lr|}
\hline PW(8\%) & $-\$ 20,310,404.04$ \\
AW(8\%) & $-\$ 3,901,068.08$ \\
BE Rev & $\$ 162,545$ \\
\hline PW(10\%) & $-\$ 19,230,944.96$ \\
AW(10\%) & $-\$ 3,950,141.86$ \\
BE Rev & $\$ 164,589$ \\
\hline PW(12\%) & $-\$ 18,257,815.05$ \\
AW(12\%) & $-\$ 4,000,611.10$ \\
BE Rev & $\$ 166,692$ \\
\hline
\end{tabular}

\section{Experiment 7}

\begin{tabular}{|r|r|r|r|r|r|}
\hline & & Depreciation & Taxable Income & Taxes $(35 \%)$ & ATCF \\
\hline 0 & $-\$ 3,680,599$ & & $\$ 0$ & & $-\$ 3,680,599$ \\
\hline 1 & $-\$ 5,933,787$ & $\$ 525,800$ & $-\$ 6,459,587$ & $-\$ 2,260,855$ & $-\$ 3,672,932$ \\
\hline 2 & $-\$ 5,933,787$ & $\$ 525,800$ & $-\$ 6,459,587$ & $-\$ 2,260,855$ & $-\$ 3,672,932$ \\
\hline 3 & $-\$ 5,933,787$ & $\$ 525,800$ & $-\$ 6,459,587$ & $-\$ 2,260,855$ & $-\$ 3,672,932$ \\
\hline 4 & $-\$ 5,933,787$ & $\$ 525,800$ & $-\$ 6,459,587$ & $-\$ 2,260,855$ & $-\$ 3,672,932$ \\
\hline 5 & $-\$ 5,933,787$ & $\$ 525,800$ & $-\$ 6,459,587$ & $-\$ 2,260,855$ & $-\$ 3,672,932$ \\
\hline 6 & $-\$ 5,933,787$ & $\$ 525,800$ & $-\$ 6,459,587$ & $-\$ 2,260,855$ & $-\$ 3,672,932$ \\
\hline 7 & $-\$ 5,933,787$ & $\$ 525,800$ & $-\$ 6,459,587$ & $-\$ 2,260,855$ & $-\$ 3,672,932$ \\
\hline
\end{tabular}

\begin{tabular}{|lr|}
\hline PW(8\%) & $-\$ 22,803,240.62$ \\
AW(8\%) & $-\$ 4,379,873.19$ \\
BE Rev & $\$ 182,495$ \\
\hline PW(10\%) & $-\$ 21,561,968.76$ \\
AW(10\%) & $-\$ 4,428,946.97$ \\
BE Rev & $\$ 184,539$ \\
\hline PW(12\%) & $-\$ 20,442,964.99$ \\
AW(12\%) & $-\$ 4,479,416.20$ \\
BE Rev & $\$ 186,642$ \\
\hline
\end{tabular}

\section{Experiment 8}

\begin{tabular}{|r|r|r|r|r|r|}
\hline & & Depreciation & Taxable Income & Taxes $(35 \%)$ & ATCF \\
\hline 0 & $-\$ 3,680,599$ & & $\$ 0$ & & $-\$ 3,680,599$ \\
\hline 1 & $-\$ 5,934,108$ & $\$ 525,800$ & $-\$ 6,459,908$ & $-\$ 2,260,968$ & $-\$ 3,673,141$ \\
\hline 2 & $-\$ 5,934,108$ & $\$ 525,800$ & $-\$ 6,459,908$ & $-\$ 2,260,968$ & $-\$ 3,673,141$ \\
\hline 3 & $-\$ 5,934,108$ & $\$ 525,800$ & $-\$ 6,459,908$ & $-\$ 2,260,968$ & $-\$ 3,673,141$ \\
\hline 4 & $-\$ 5,934,108$ & $\$ 525,800$ & $-\$ 6,459,908$ & $-\$ 2,260,968$ & $-\$ 3,673,141$ \\
\hline 5 & $-\$ 5,934,108$ & $\$ 525,800$ & $-\$ 6,459,908$ & $-\$ 2,260,968$ & $-\$ 3,673,141$ \\
\hline 6 & $-\$ 5,934,108$ & $\$ 525,800$ & $-\$ 6,459,908$ & $-\$ 2,260,968$ & $-\$ 3,673,141$ \\
\hline 7 & $-\$ 5,934,108$ & $\$ 525,800$ & $-\$ 6,459,908$ & $-\$ 2,260,968$ & $-\$ 3,673,141$ \\
\hline
\end{tabular}

\begin{tabular}{|lr|}
\hline PW(8\%) & $-\$ 22,804,327.72$ \\
AW(8\%) & $-\$ 4,380,081.99$ \\
BE Rev & $\$ 182,503$ \\
\hline PW(10\%) & $-\$ 21,562,985.30$ \\
AW(10\%) & $-\$ 4,429,155.77$ \\
BE Rev & $\$ 184,548$ \\
\hline PW(12\%) & $-\$ 20,443,917.91$ \\
AW(12\%) & $-\$ 4,479,625.01$ \\
BE Rev & $\$ 186,651$ \\
\hline
\end{tabular}




\section{NUCLEAR ENERGY RESEARCH INITIATIVE (NERI) PROGRAM \\ GRANT NUMBER DE-FG07-00SF22168 \\ FINAL REPORT}

\section{Appendix E - 2 - Demand 48}

Below is an After Tax Cash Flow Analysis at MARRs of 8\%, 10\%, and 12\% respectively for each experiment described in the Analysis Section of this report. The annual demand for the experiments is 48 heat exchangers.

\section{Experiment 9}

\begin{tabular}{|r|r|r|r|r|r|}
\hline & & Depreciation & Taxable Income & Taxes $(35 \%)$ & ATCF \\
\hline 0 & $-\$ 3,680,599$ & & $\$ 0$ & & $-\$ 3,680,599$ \\
\hline 1 & $-\$ 9,580,134$ & $\$ 525,800$ & $-\$ 10,105,933$ & $-\$ 3,537,077$ & $-\$ 6,043,057$ \\
\hline 2 & $-\$ 9,580,134$ & $\$ 525,800$ & $-\$ 10,105,933$ & $-\$ 3,537,077$ & $-\$ 6,043,057$ \\
\hline 3 & $-\$ 9,580,134$ & $\$ 525,800$ & $-\$ 10,105,933$ & $-\$ 3,537,077$ & $-\$ 6,043,057$ \\
\hline 4 & $-\$ 9,580,134$ & $\$ 525,800$ & $-\$ 10,105,933$ & $-\$ 3,537,077$ & $-\$ 6,043,057$ \\
\hline 5 & $-\$ 9,580,134$ & $\$ 525,800$ & $-\$ 10,105,933$ & $-\$ 3,537,077$ & $-\$ 6,043,057$ \\
\hline 6 & $-\$ 9,580,134$ & $\$ 525,800$ & $-\$ 10,105,933$ & $-\$ 3,537,077$ & $-\$ 6,043,057$ \\
\hline 7 & $-\$ 9,580,134$ & $\$ 525,800$ & $-\$ 10,105,933$ & $-\$ 3,537,077$ & $-\$ 6,043,057$ \\
\hline
\end{tabular}

\begin{tabular}{|lr|}
\hline PW(8\%) & $-\$ 35,142,989.18$ \\
AW(8\%) & $-\$ 6,749,998.33$ \\
BE Rev & $\$ 140,625$ \\
\hline PW(10\%) & $-\$ 33,100,730.59$ \\
AW(10\%) & $-\$ 6,799,072.11$ \\
BE Rev & $\$ 141,647$ \\
\hline PW(12\%) & $-\$ 31,259,639.09$ \\
AW(12\%) & $-\$ 6,849,541.34$ \\
BE Rev & $\$ 142,699$ \\
\hline
\end{tabular}

Experiment 10

\begin{tabular}{|r|r|r|r|r|r|}
\hline & & Depreciation & Taxable Income & Taxes (35\%) & ATCF \\
\hline 0 & $-\$ 3,680,599$ & & $\$ 0$ & & $-\$ 3,680,599$ \\
\hline 1 & $-\$ 9,590,255$ & $\$ 525,800$ & $-\$ 10,116,055$ & $-\$ 3,540,619$ & $-\$ 6,049,636$ \\
\hline 2 & $-\$ 9,590,255$ & $\$ 525,800$ & $-\$ 10,116,055$ & $-\$ 3,540,619$ & $-\$ 6,049,636$ \\
\hline 3 & $-\$ 9,590,255$ & $\$ 525,800$ & $-\$ 10,116,055$ & $-\$ 3,540,619$ & $-\$ 6,049,636$ \\
\hline 4 & $-\$ 9,590,255$ & $\$ 525,800$ & $-\$ 10,116,055$ & $-\$ 3,540,619$ & $-\$ 6,049,636$ \\
\hline 5 & $-\$ 9,590,255$ & $\$ 525,800$ & $-\$ 10,116,055$ & $-\$ 3,540,619$ & $-\$ 6,049,636$ \\
\hline 6 & $-\$ 9,590,255$ & $\$ 525,800$ & $-\$ 10,116,055$ & $-\$ 3,540,619$ & $-\$ 6,049,636$ \\
\hline 7 & $-\$ 9,590,255$ & $\$ 525,800$ & $-\$ 10,116,055$ & $-\$ 3,540,619$ & $-\$ 6,049,636$ \\
\hline
\end{tabular}

\begin{tabular}{|lr|}
\hline PW(8\%) & $-\$ 35,177,242.27$ \\
AW(8\%) & $-\$ 6,756,577.40$ \\
BE Rev & $\$ 140,762$ \\
\hline PW(10\%) & $-\$ 33,132,760.27$ \\
AW(10\%) & $-\$ 6,805,651.18$ \\
BE Rev & $\$ 141,784$ \\
\hline PW(12\%) & $-\$ 31,289,664.38$ \\
AW(12\%) & $-\$ 6,856,120.42$ \\
BE Rev & $\$ 142,836$ \\
\hline
\end{tabular}

Experiment 11

\begin{tabular}{|r|r|r|r|r|r|}
\hline & & Depreciation & Taxable Income & Taxes $(35 \%)$ & ATCF \\
\hline 0 & $-\$ 3,680,599$ & & $\$ 0$ & & $-\$ 3,680,599$ \\
\hline 1 & $-\$ 11,107,911$ & $\$ 525,800$ & $-\$ 11,633,710$ & $-\$ 4,071,799$ & $-\$ 7,036,112$ \\
\hline 2 & $-\$ 11,107,911$ & $\$ 525,800$ & $-\$ 11,633,710$ & $-\$ 4,071,799$ & $-\$ 7,036,112$ \\
\hline 3 & $-\$ 11,107,911$ & $\$ 525,800$ & $-\$ 11,633,710$ & $-\$ 4,071,799$ & $-\$ 7,036,112$ \\
\hline 4 & $-\$ 11,107,911$ & $\$ 525,800$ & $-\$ 11,633,710$ & $-\$ 4,071,799$ & $-\$ 7,036,112$ \\
\hline 5 & $-\$ 11,107,911$ & $\$ 525,800$ & $-\$ 11,633,710$ & $-\$ 4,071,799$ & $-\$ 7,036,112$ \\
\hline 6 & $-\$ 11,107,911$ & $\$ 525,800$ & $-\$ 11,633,710$ & $-\$ 4,071,799$ & $-\$ 7,036,112$ \\
\hline 7 & $-\$ 11,107,911$ & $\$ 525,800$ & $-\$ 11,633,710$ & $-\$ 4,071,799$ & $-\$ 7,036,112$ \\
\hline
\end{tabular}

\begin{tabular}{|lr|}
\hline PW(8\%) & $-\$ 40,313,200.93$ \\
AW(8\%) & $-\$ 7,743,053.31$ \\
BE Rev & $\$ 161,314$ \\
\hline PW(10\%) & $-\$ 37,935,338.17$ \\
AW(10\%) & $-\$ 7,792,127.09$ \\
BE Rev & $\$ 162,336$ \\
\hline PW(12\%) & $-\$ 35,791,700.28$ \\
AW(12\%) & $-\$ 7,842,596.33$ \\
BE Rev & $\$ 163,387$ \\
\hline
\end{tabular}

\section{Experiment 12}

\begin{tabular}{|r|r|r|r|r|r|}
\hline & & Depreciation & Taxable Income & Taxes (35\%) & ATCF \\
\hline 0 & $-\$ 3,680,599$ & & $\$ 0$ & & $-\$ 3,680,599$ \\
\hline 1 & $-\$ 11,113,573$ & $\$ 525,800$ & $-\$ 11,639,372$ & $-\$ 4,073,780$ & $-\$ 7,039,792$ \\
\hline 2 & $-\$ 11,113,573$ & $\$ 525,800$ & $-\$ 11,639,372$ & $-\$ 4,073,780$ & $-\$ 7,039,792$ \\
\hline 3 & $-\$ 11,113,573$ & $\$ 525,800$ & $-\$ 11,639,372$ & $-\$ 4,073,780$ & $-\$ 7,039,792$ \\
\hline 4 & $-\$ 11,113,573$ & $\$ 525,800$ & $-\$ 11,639,372$ & $-\$ 4,073,780$ & $-\$ 7,039,792$ \\
\hline 5 & $-\$ 11,113,573$ & $\$ 525,800$ & $-\$ 11,639,372$ & $-\$ 4,073,780$ & $-\$ 7,039,792$ \\
\hline 6 & $-\$ 11,113,573$ & $\$ 525,800$ & $-\$ 11,639,372$ & $-\$ 4,073,780$ & $-\$ 7,039,792$ \\
\hline 7 & $-\$ 11,113,573$ & $\$ 525,800$ & $-\$ 11,639,372$ & $-\$ 4,073,780$ & $-\$ 7,039,792$ \\
\hline
\end{tabular}

\begin{tabular}{|lr|}
\hline PW(8\%) & $-\$ 40,332,362.07$ \\
AW(8\%) & $-\$ 7,746,733.64$ \\
BE Rev & $\$ 161,390$ \\
\hline PW(10\%) & $-\$ 37,953,255.54$ \\
AW(10\%) & $-\$ 7,795,807.42$ \\
BE Rev & $\$ 162,413$ \\
\hline PW(12\%) & $-\$ 35,808,496.39$ \\
AW(12\%) & $-\$ 7,846,276.66$ \\
BE Rev & $\$ 163,464$ \\
\hline
\end{tabular}




\section{NUCLEAR ENERGY RESEARCH INITIATIVE (NERI) PROGRAM \\ GRANT NUMBER DE-FG07-00SF22168 \\ FINAL REPORT}

\section{Experiment 13}

\begin{tabular}{|r|r|r|r|r|r|}
\hline & & Depreciation & Taxable Income & Taxes $(35 \%)$ & ATCF \\
\hline 0 & $-\$ 3,680,599$ & & $\$ 0$ & & $-\$ 3,680,599$ \\
\hline 1 & $-\$ 9,610,646$ & $\$ 525,800$ & $-\$ 10,136,446$ & $-\$ 3,547,756$ & $-\$ 6,062,890$ \\
\hline 2 & $-\$ 9,610,646$ & $\$ 525,800$ & $-\$ 10,136,446$ & $-\$ 3,547,756$ & $-\$ 6,062,890$ \\
\hline 3 & $-\$ 9,610,646$ & $\$ 525,800$ & $-\$ 10,136,446$ & $-\$ 3,547,756$ & $-\$ 6,062,890$ \\
\hline 4 & $-\$ 9,610,646$ & $\$ 525,800$ & $-\$ 10,136,446$ & $-\$ 3,547,756$ & $-\$ 6,062,890$ \\
\hline 5 & $-\$ 9,610,646$ & $\$ 525,800$ & $-\$ 10,136,446$ & $-\$ 3,547,756$ & $-\$ 6,062,890$ \\
\hline 6 & $-\$ 9,610,646$ & $\$ 525,800$ & $-\$ 10,136,446$ & $-\$ 3,547,756$ & $-\$ 6,062,890$ \\
\hline 7 & $-\$ 9,610,646$ & $\$ 525,800$ & $-\$ 10,136,446$ & $-\$ 3,547,756$ & $-\$ 6,062,890$ \\
\hline
\end{tabular}

\begin{tabular}{|lr|}
\hline PW(8\%) & $-\$ 35,246,247.14$ \\
AW(8\%) & $-\$ 6,769,831.33$ \\
BE Rev & $\$ 141,038$ \\
\hline PW(10\%) & $-\$ 33,197,285.96$ \\
AW(10\%) & $-\$ 6,818,905.11$ \\
BE Rev & $\$ 142,061$ \\
\hline PW(12\%) & $-\$ 31,350,152.10$ \\
AW(12\%) & $-\$ 6,869,374.35$ \\
BE Rev & $\$ 143,112$ \\
\hline
\end{tabular}

\section{Experiment 14}

\begin{tabular}{|r|r|r|r|r|r|}
\hline & & Depreciation & Taxable Income & Taxes (35\%) & ATCF \\
\hline 0 & $-\$ 3,680,599$ & & $\$ 0$ & & $-\$ 3,680,599$ \\
\hline 1 & $-\$ 9,589,241$ & $\$ 525,800$ & $-\$ 10,115,040$ & $-\$ 3,540,264$ & $-\$ 6,048,977$ \\
\hline 2 & $-\$ 9,589,241$ & $\$ 525,800$ & $-\$ 10,115,040$ & $-\$ 3,540,264$ & $-\$ 6,048,977$ \\
\hline 3 & $-\$ 9,589,241$ & $\$ 525,800$ & $-\$ 10,115,040$ & $-\$ 3,540,264$ & $-\$ 6,048,977$ \\
\hline 4 & $-\$ 9,589,241$ & $\$ 525,800$ & $-\$ 10,115,040$ & $-\$ 3,540,264$ & $-\$ 6,048,977$ \\
\hline 5 & $-\$ 9,589,241$ & $\$ 525,800$ & $-\$ 10,115,040$ & $-\$ 3,540,264$ & $-\$ 6,048,977$ \\
\hline 6 & $-\$ 9,589,241$ & $\$ 525,800$ & $-\$ 10,115,040$ & $-\$ 3,540,264$ & $-\$ 6,048,977$ \\
\hline 7 & $-\$ 9,589,241$ & $\$ 525,800$ & $-\$ 10,115,040$ & $-\$ 3,540,264$ & $-\$ 6,048,977$ \\
\hline
\end{tabular}

\begin{tabular}{|lr|}
\hline PW(8\%) & $-\$ 35,173,808.81$ \\
AW(8\%) & $-\$ 6,755,917.92$ \\
BE Rev & $\$ 140,748$ \\
\hline PW(10\%) & $-\$ 33,129,549.68$ \\
AW(10\%) & $-\$ 6,804,991.71$ \\
BE Rev & $\$ 141,771$ \\
\hline PW(12\%) & $-\$ 31,286,654.70$ \\
AW(12\%) & $-\$ 6,855,460.94$ \\
BE Rev & $\$ 142,822$ \\
\hline
\end{tabular}

\section{Experiment 15}

\begin{tabular}{|r|r|r|r|r|r|}
\hline & & Depreciation & Taxable Income & Taxes (35\%) & ATCF \\
\hline 0 & $-\$ 3,680,599$ & & $\$ 0$ & & $-\$ 3,680,599$ \\
\hline 1 & $-\$ 11,128,090$ & $\$ 525,800$ & $-\$ 11,653,889$ & $-\$ 4,078,861$ & $-\$ 7,049,228$ \\
\hline 2 & $-\$ 11,128,090$ & $\$ 525,800$ & $-\$ 11,653,889$ & $-\$ 4,078,861$ & $-\$ 7,049,228$ \\
\hline 3 & $-\$ 11,128,090$ & $\$ 525,800$ & $-\$ 11,653,889$ & $-\$ 4,078,861$ & $-\$ 7,049,228$ \\
\hline 4 & $-\$ 11,128,090$ & $\$ 525,800$ & $-\$ 11,653,889$ & $-\$ 4,078,861$ & $-\$ 7,049,228$ \\
\hline 5 & $-\$ 11,128,090$ & $\$ 525,800$ & $-\$ 11,653,889$ & $-\$ 4,078,861$ & $-\$ 7,049,228$ \\
\hline 6 & $-\$ 11,128,090$ & $\$ 525,800$ & $-\$ 11,653,889$ & $-\$ 4,078,861$ & $-\$ 7,049,228$ \\
\hline 7 & $-\$ 11,128,090$ & $\$ 525,800$ & $-\$ 11,653,889$ & $-\$ 4,078,861$ & $-\$ 7,049,228$ \\
\hline
\end{tabular}

\begin{tabular}{|lr|}
\hline PW(8\%) & $-\$ 40,381,490.12$ \\
AW(8\%) & $-\$ 7,756,169.78$ \\
BE Rev & $\$ 161,587$ \\
\hline PW(10\%) & $-\$ 37,999,194.64$ \\
AW(10\%) & $-\$ 7,805,243.56$ \\
BE Rev & $\$ 162,609$ \\
\hline PW(12\%) & $-\$ 35,851,560.65$ \\
AW(12\%) & $-\$ 7,855,712.80$ \\
BE Rev & $\$ 163,661$ \\
\hline
\end{tabular}

\section{Experiment 16}

\begin{tabular}{|r|r|r|r|r|r|}
\hline & & Depreciation & Taxable Income & Taxes $(35 \%)$ & ATCF \\
\hline 0 & $-\$ 3,680,599$ & & $\$ 0$ & & $-\$ 3,680,599$ \\
\hline 1 & $-\$ 11,127,912$ & $\$ 525,800$ & $-\$ 11,653,712$ & $-\$ 4,078,799$ & $-\$ 7,049,113$ \\
\hline 2 & $-\$ 11,127,912$ & $\$ 525,800$ & $-\$ 11,653,712$ & $-\$ 4,078,799$ & $-\$ 7,049,113$ \\
\hline 3 & $-\$ 11,127,912$ & $\$ 525,800$ & $-\$ 11,653,712$ & $-\$ 4,078,799$ & $-\$ 7,049,113$ \\
\hline 4 & $-\$ 11,127,912$ & $\$ 525,800$ & $-\$ 11,653,712$ & $-\$ 4,078,799$ & $-\$ 7,049,113$ \\
\hline 5 & $-\$ 11,127,912$ & $\$ 525,800$ & $-\$ 11,653,712$ & $-\$ 4,078,799$ & $-\$ 7.049,113$ \\
\hline 6 & $-\$ 11,127,912$ & $\$ 525,800$ & $-\$ 11,653,712$ & $-\$ 4,078,799$ & $-\$ 7,049,113$ \\
\hline 7 & $-\$ 11,127,912$ & $\$ 525,800$ & $-\$ 11,653,712$ & $-\$ 4,078,799$ & $-\$ 7,049,113$ \\
\hline
\end{tabular}

\begin{tabular}{|lr|}
\hline PW(8\%) & $-\$ 40,380,889.75$ \\
AW(8\%) & $-\$ 7,756,054.47$ \\
BE Rev & $\$ 161,584$ \\
\hline PW(10\%) & $-\$ 37,998,633.24$ \\
AW(10\%) & $-\$ 7,805,128.25$ \\
BE Rev & $\$ 162,607$ \\
\hline PW(12\%) & $-\$ 35,851,034.38$ \\
AW(12\%) & $-\$ 7,855,597.48$ \\
BE Rev & $\$ 163,658$ \\
\hline
\end{tabular}




\section{NUCLEAR ENERGY RESEARCH INITIATIVE (NERI) PROGRAM \\ GRANT NUMBER DE-FG07-00SF22168 \\ FINAL REPORT}

\section{Appendix E - 3 - Labor Costs}

Below is an experimental design matrix showing the results from the manufacturing simulations ran. The results show the amount of labors hours at each respective workstation in the model and total labor costs.

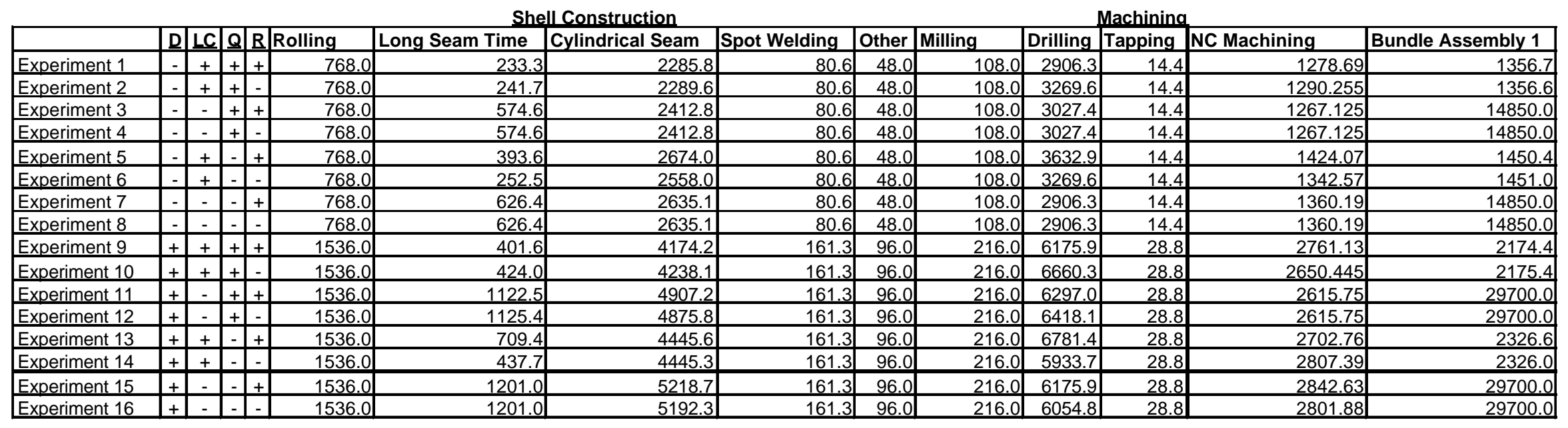

manhours per heat exchanger

$\$ 15.00$ per hour average rate

\section{\begin{tabular}{|c|}
\hline Manhours Cost per Heat Exchanger \\
\hline 0
\end{tabular}}

\section{Overhead}

Costs of business Functions and Engineering are assumed to be $\$ 500,000$ annually

because of lack of information. This assumes roughly 10 to 12 people in the front office 
NUCLEAR ENERGY RESEARCH INITIATIVE (NERI) PROGRAM

GRANT NUMBER DE-FG07-00SF22168

FINAL REPORT

Tube Bundle Construction

Other Operations

\begin{tabular}{|c|c|c|c|c|c|c|c|c|c|}
\hline Bundle Assembly 1 & Bundle Assembly 2 & Tube Loading & Tube Expansion & Grinding & Burning & NDE Inspection & Total Manhours & Annual Labor Expense & Annual Material \\
\hline 1356.7 & 1247.1 & 1033.3 & 26.9 & 463.3 & 96.0 & 960.0 & 12906.6 & $\$ 322,664$ & $\$ 4,103,075$ \\
\hline 1356.6 & 1249.4 & 1041.7 & 26.7 & 459.3 & 96.0 & 960.0 & 13299.9 & $\$ 332,499$ & $\$ 4,103,075$ \\
\hline 14850.0 & 14850.0 & 1041.7 & 2250.0 & 444.8 & 96.0 & 960.0 & 42793.4 & $\$ 1,069,835$ & $\$ 4,103,075$ \\
\hline 14850.0 & 14850.0 & 1041.7 & 2268.0 & 444.9 & 96.0 & 960.0 & 42811.5 & $\$ 1.070 .288$ & $\$ 4.103 .075$ \\
\hline 1450.4 & 1208.2 & 1150.0 & 27.5 & 448.0 & 96.0 & 960.0 & 14483.8 & $\$ 362,096$ & $\$ 4,103,075$ \\
\hline 1451.0 & 1232.3 & 1100.0 & 28.3 & 454.2 & 96.0 & 960.0 & 13763.5 & $\$ 344,089$ & $\$ 4,103,075$ \\
\hline 14850.0 & 14850.0 & 1066.7 & 2412.0 & 446.8 & 96.0 & 960.0 & 43228.5 & $\$ 1,080,712$ & $\$ 4,103,075$ \\
\hline 14850.0 & 14850.0 & 1125.0 & 2358.0 & 455.3 & 96.0 & 960.0 & 43241.3 & $\$ 1.081 .033$ & $\$ 4.103 .075$ \\
\hline 2174.4 & 1996.7 & 2175.0 & 46.7 & 903.6 & 192.0 & 1920.0 & 24959.3 & $\$ 623,983$ & $\$ 8,206,151$ \\
\hline 2175.4 & 1989.2 & 2108.2 & 45.8 & 922.7 & 192.0 & 1920.0 & 25364.2 & $\$ 634,105$ & $\$ 8,206,151$ \\
\hline 29700.0 & 29700.0 & 2108.3 & 4571.8 & 897.7 & 192.0 & 1920.0 & 86070.4 & $\$ 2,151,760$ & $\$ 8,206.151$ \\
\hline 29700.0 & 29700.0 & 2166.7 & 4662.0 & 883.1 & 192.0 & 1920.0 & 86296.9 & $\$ 2.157 .422$ & $\$ 8.206 .151$ \\
\hline 2326.6 & 1946.8 & 2175.0 & 47.3 & 894.7 & 192.0 & 1920.0 & 26179.8 & $\$ 654,495$ & $\$ 8,206,151$ \\
\hline 2326.0 & 1965.1 & 2300.0 & 47.9 & 910.4 & 192.0 & 1920.0 & 25323.6 & $\$ 633,090$ & $\$ 8,206,151$ \\
\hline 29700.0 & 29700.0 & 2250.0 & 4751.8 & 887.5 & 192.0 & 1920.0 & 86877.6 & $\$ 2,171,939$ & $\$ 8,206,151$ \\
\hline 29700.0 & 29700.0 & 2200.0 & 4950.0 & 920.4 & 192.0 & 1920.0 & 86870.5 & $\$ 2,171,762$ & $\$ 8,206,151$ \\
\hline
\end{tabular}




\section{NUCLEAR ENERGY RESEARCH INITIATIVE (NERI) PROGRAM \\ GRANT NUMBER DE-FG07-00SF22168 \\ FINAL REPORT}

\section{Appendix E - 4-Capital Costs}

Below is a listing of capital cost expenditures needed in order to create a heat exchanger manufacturing facility. The costs are then depreciated with a 7-year straight-line depreciation in Appendices E-1 and E-2.

\section{Primary Equipment Needs and Installation}

\section{Rolling Operation}

\begin{tabular}{|l|r|r|r|r|}
\cline { 3 - 5 } \multicolumn{2}{c}{} & Unit Cost & Quantity & Cost \\
\hline Bertsch Roller & Roll 10' length & $\$ 565,000$ & 2 & $\$ 565,000$ \\
\hline Installation Cost & & $\$ 80,000$ & 2 & $\$ 160,000$ \\
\cline { 4 - 5 } & & & $\$ 725,000$ \\
\hline
\end{tabular}

SMAW Spot Welding Long Seam

\begin{tabular}{|l|l|r|r|r|}
\cline { 3 - 5 } & \multicolumn{3}{|c|}{ Cost } \\
\hline MA 1212 HD & Manipulator & $\$ 24,950$ & 1 & $\$ 24,950$ \\
\hline TSP 56 & $20 \mathrm{ft}$ track & $\$ 4,100$ & 20 & $\$ 82,000$ \\
\hline Mouncoln Welder & Welding Held & $\$ 2,500$ & 1 & $\$ 2,500$ \\
\hline Installation Cost & & 2,500 & 1 & $\$ 2,500$ \\
\hline
\end{tabular}

SAW Welding long seam of cylinder

\begin{tabular}{|l|l|r|r|r|}
\cline { 4 - 5 } & \multicolumn{3}{|c|}{ Cost } \\
\hline MA 1212 HD & Manipulator & $\$ 24,950$ & 2 & $\$ 49,900$ \\
\hline Lincoln NA5/3 & $20 \mathrm{ft}$ track & $\$ 4,100$ & 14 & $\$ 57,400$ \\
\hline Mounting of Equipment & Welding Held & $\$ 5,000$ & 2 & $\$ 10,000$ \\
\hline Installation Cost & & 2.500 & 2 & $\$ 5.000$ \\
\hline
\end{tabular}

\section{SAW 2 Welding cylinders together}

\begin{tabular}{|c|c|c|c|c|}
\hline \multirow[t]{2}{*}{ Preston Eastin } & & \multirow[b]{2}{*}{ Unit Cost } & \multirow[b]{2}{*}{ Quantity } & \multirow[b]{2}{*}{ Cost } \\
\hline & & & & \\
\hline TDRA $200 \mathrm{HD}$ & Driver Turning Roll & $\$ 43,000$ & 2 & $\$ 86,000$ \\
\hline TIRA $30 \mathrm{HD}$ & Idler Turning Roll & $\$ 5,500$ & 14 & $\$ 77,000$ \\
\hline MA $1212 \mathrm{HD}$ & Manipulator & $\$ 24.950$ & 2 & $\$ 49.900$ \\
\hline Mounting of Equipment & & $\$ 2.500$ & 2 & $\$ 5.000$ \\
\hline Lincoln NA5/3 & Welding Held & $\$ 5,000$ & 2 & $\$ 10,000$ \\
\hline Installation Cost & & & All & \\
\hline & & & & $\$ 227,900$ \\
\hline
\end{tabular}

Tubesheet, Baffles, Nozzle Turning

\begin{tabular}{|l|l|r|r|r|}
\hline Toshiba Vertical Turning Lathe & & $\$ 750,000$ & 2 & $\$ 1,500,000$ \\
\hline Installation Cost & included & & & $\$ 0$ \\
\hline
\end{tabular}


Tubesheet Drilling, Reaming, Tapping, Pass Partitions, Tie Rods

\begin{tabular}{|l|l|r|r|r|}
\cline { 2 - 4 } & \multicolumn{1}{c|}{ Qost } \\
\hline Quickdrill & $120 " \times 120 "$ & $\$ 430,000$ & 2 & $\$ 860,000$ \\
\hline Installation Cost & included & & & $\$ 0$ \\
\hline Training & included & & & $\$ 10$ \\
\hline
\end{tabular}

Grinding

\begin{tabular}{|l|r|r|r|r|}
\cline { 3 - 5 } & Unit Cost & Quantity & Cost \\
\hline Pneumatic Grinder & & $\$ 299.50$ & 3 & $\$ 899$ \\
\hline
\end{tabular}

Burning

\begin{tabular}{|l|r|r|r|}
\cline { 2 - 3 } \multicolumn{1}{c|}{} & Unit Cost & Quantity & Cost \\
\hline Miller Spectrum Plasma Arc Cutter & $\$ 5,000.00$ & 2 & $\$ 10,000$ \\
\hline
\end{tabular}

Crane

\begin{tabular}{|c|c|c|c|}
\hline & Unit Cost & Quantity & Cost \\
\hline 100 Ton Crane (tall) & $\$ 105,000.00$ & 2 & $\$ 210,000$ \\
\hline 100 Ton Crane (short) & $\$ 65.000 .00$ & 2 & $\$ 130,000$ \\
\hline
\end{tabular}

Tube Expansions

\begin{tabular}{|c|c|c|c|}
\hline & Unit Cost & Quantity & Cost \\
\hline Torque Expansion Device & $\$ 75.00$ & 6 & $\$ 450$ \\
\hline
\end{tabular}

\begin{tabular}{|l|r|}
\hline Total Equipment Costs & $\$ 3,680,599$ \\
\hline
\end{tabular}

\section{Building Cost (Annual Leasing Costs)}

\begin{tabular}{|l|l|r|r|r|}
\hline Building (50000 square feet) & $\$ 4-\$ 5$ per sq ft & $\$ 200,000$ & $\$ 250,000$ & $\$ 225,000$ \\
\hline
\end{tabular}

\begin{tabular}{|l|l|l|}
\hline Low & High & Average \\
\hline
\end{tabular}




\section{NUCLEAR ENERGY RESEARCH INITIATIVE (NERI) PROGRAM \\ GRANT NUMBER DE-FG07-00SF22168}

FINAL REPORT

\section{Appendix E - 5 - Material Costs}

Below is a table showing the materials required for the creation of feedwater heat exchangers and the cost per unit.

\begin{tabular}{|c|c|c|c|c|c|c|}
\hline \multirow{2}{*}{ Unit Material Cost } & \multicolumn{6}{|l|}{ Shell Steel_ } \\
\hline & Length (ft) & Width (ft) & Depth (ft) & \multicolumn{2}{|c|}{ Volume of Stainless steel } & Density \\
\hline FW\#1 & 79.7 & 31 & 0.08 & \multicolumn{2}{|c|}{ 208. cubic } & 0.28 \\
\hline FW\#2 & 14.5 & 31 & 0.08 & \multicolumn{2}{|c|}{37.9 cubic } & 0.28 \\
\hline FW\#3 & 28.3 & 31 & 0.08 & \multicolumn{2}{|c|}{ 74.1cubic } & 0.28 \\
\hline $\mathrm{FW \# 4}$ & 69.6 & 31 & همص & \multicolumn{2}{|c|}{182 cubic } & 028 \\
\hline $\mathrm{FW \# 5}$ & 65.6 & 31 & 0.08 & \multicolumn{2}{|c|}{ 171. cubic } & 0.28 \\
\hline FW\#6 & 63.6 & 31 & 0.08 & \multicolumn{2}{|c|}{ 166. cubic } & 0.28 \\
\hline \multicolumn{7}{|c|}{ \# of Plates vary per HE Tubesheets and Baffles } \\
\hline Diameter & Depth & Volume of Stainless steel & & Density & & Steel per Exchanger \\
\hline 10 & \multicolumn{3}{|c|}{6.5416666 cubic } & \multicolumn{2}{|c|}{$0.28 \mathrm{lbs} / \mathrm{cu} . \mathrm{in}$} & 3232.944 \\
\hline & \multicolumn{2}{|l|}{ Tubes. } & Tube Cost & \multicolumn{2}{|c|}{ \# of Plates Plate Cost } & Total Material Cost/HE \\
\hline $\mathrm{E} / \mathrm{N} \# 1$ & 5000 & $\$ 2127$ & $\$ 10635965$ & 7 & $\$ 2670412$ & $\$ 24643665$ \\
\hline $\mathrm{FW \# 2}$ & 5000 & $\$ 3.87$ & $\$ 19.350 .25$ & 2 & $\$ 7.629 .75$ & $\$ 47.606 .18$ \\
\hline $\mathrm{F} / \mathrm{H} / 3$ & 5000 & $\$ 755$ & $\$ 37,76635$ & 4 & $\$ 1525950$ & $\$ 93,28246$ \\
\hline FW\#4 & 5000 & $\$ 18.58$ & $\$ 92.88120$ & 6 & $\$ 22.889 .24$ & $\$ 214.776 .12$ \\
\hline FW\#5 & 5000 & $\$ 17.51$ & $\$ 87,543.20$ & 6 & $\$ 22,889.24$ & $\$ 203,748.14$ \\
\hline$F W \# 6$ & 5000 & $\$ 16.97$ & $\$ 84.874 .20$ & 5 & $\$ 19.074 .37$ & $\$ 194.419 .27$ \\
\hline & & & & Averao & Cost & $\$ 1.025 .768 .83$ \\
\hline
\end{tabular}




\section{NUCLEAR ENERGY RESEARCH INITIATIVE (NERI) PROGRAM \\ GRANT NUMBER DE-FG07-00SF22168 \\ FINAL REPORT}

\section{Appendix E - 6 - Annual Costs}

This table summarized what costs will be incurred annually and separates them from initial capital expenditures.

\section{Equipment Cost Depreciation Seven-year Straight Line \\ $\$ 3,680,599 \quad \$ 525,800$}

\section{Fixed Costs}

$\$ 3,680,599$ Capital Costs

$\$ 225,000$ Leasing Costs

$\$ 3,905,599$

Variable Costs

\begin{tabular}{|l|l|r|r|}
\hline & & \multicolumn{1}{|c|}{ Units } & \multicolumn{1}{c|}{ Total } \\
\hline & Labor Costs per 6 & 4 & $\$ 322,664.17$ \\
\hline & Material Costs per 6 & 4 & $\$ 4,103,075.31$ \\
\hline
\end{tabular}

Annual Fixed Costs

$\$ 500,000$ Front Office (Engineering,etc.)

$\$ 225,000$ Annual Fixed Costs

500000

$\$ 225,000$

$\$ 5,150,739.48$ 


\section{NUCLEAR ENERGY RESEARCH INITIATIVE (NERI) PROGRAM \\ GRANT NUMBER DE-FG07-00SF22168 \\ FINAL REPORT}

\section{Appendix F - ARENA Simulation Results}

The following data is the raw results from the simulation models ran. They represent an example of ARENA 5.0 output information from Experiment 1.

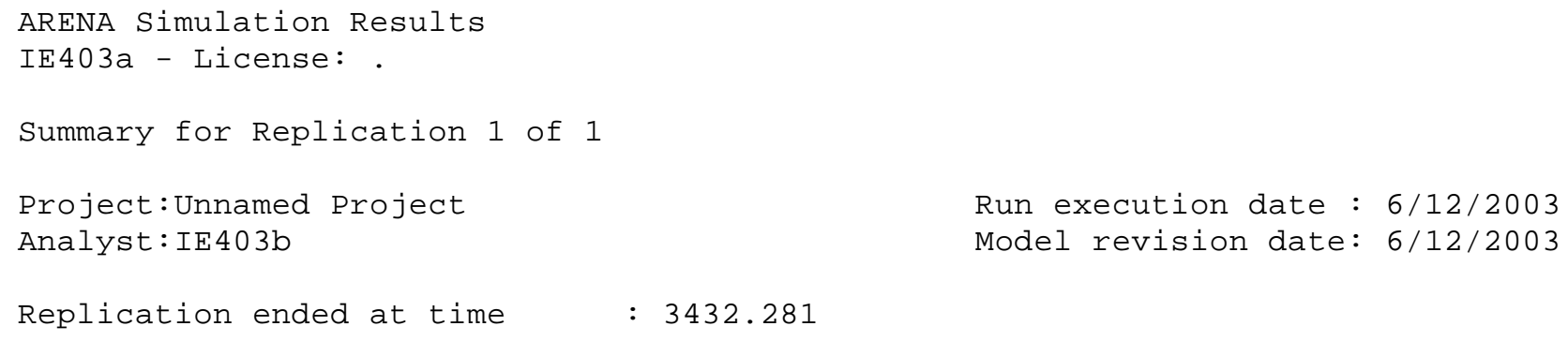

\section{(Insuf)}

(Insuf)

(Insuf)

(Insuf)

(Insuf)

(Insuf)

(Insuf)

(Insuf)

(Insuf)

(Insuf)

(Insuf)

(Insuf)

(Insuf)

(Insuf)

(Insuf)

(Insuf)

(Insuf)

(Insuf)

(Corr)

(Insuf)

(Insuf)

(Insuf)

(Insuf)

(Insuf)

(Corr)

\section{.00000}

.00000

.21551

.00000

54.680

.80000

11.800

1.6673

.00000

.00000

1.7947

.00000

.00000

73.548

.00000

.20000

160.27

14.500

586.16

157.17

160.27

125.21

1193.2

1495.1

16.866

157.17
48

24

192

24

48

240

240

250

226

65

41

240

185

209

24

126

23

240

240

6635

23

74

26

120

125

6000

DISCRETE-CHANGE VARIABLES

Identifier

\# in NDE Inspection_R_ .00000
Average Half Width Minimum

(Insuf)

.00000

.00000

.00000 


\section{NUCLEAR ENERGY RESEARCH INITIATIVE (NERI) PROGRAM GRANT NUMBER DE-FG07-00SF22168 \\ FINAL REPORT}

\begin{tabular}{|c|c|c|c|c|c|}
\hline bundlecrane 1 Idle & .92168 & (Insuf) & .00000 & 1.0000 & 1.0000 \\
\hline bundlecrane 1 Busy & .07832 & (Insuf) & .00000 & 1.0000 & .00000 \\
\hline \# in Face Milling_Larg & .44936 & (Insuf) & .00000 & 38.000 & .00000 \\
\hline bundlecrane 1 Inactive & .00000 & (Insuf) & .00000 & .00000 & .00000 \\
\hline Grinding_R Available & 1.0000 & (Insuf) & 1.0000 & 1.0000 & 1.0000 \\
\hline \# in Face Milling_R_Q & .08733 & (Insuf) & .00000 & 10.000 & .00000 \\
\hline \# in Inspection_R_Q & 20.714 & (Corr) & .00000 & 147.00 & .00000 \\
\hline Bundle Assembly_R Busy & .39570 & (Corr) & .00000 & 2.0000 & .00000 \\
\hline Drilling_Tap_sm_R Avai & 1.0000 & (Insuf) & 1.0000 & 1.0000 & 1.0000 \\
\hline \# in SAW 2_R_Q & .47320 & (Insuf) & .00000 & 5.0000 & .00000 \\
\hline Face Milling_R Availab & 1.0000 & (Insuf) & 1.0000 & 1.0000 & 1.0000 \\
\hline Finished Shells_R Avai & 1.0000 & (Insuf) & 1.0000 & 1.0000 & 1.0000 \\
\hline$\#$ in SMAW_R_Q & .00113 & (Insuf) & .00000 & 1.0000 & .00000 \\
\hline SAW 2_R Available & 2.0000 & (Insuf) & 2.0000 & 2.0000 & 2.0000 \\
\hline \# in Bundle Assembly_R & 94.555 & (Corr) & .00000 & 753.00 & .00000 \\
\hline Inspection_R Available & 1.0000 & (Insuf) & 1.0000 & 1.0000 & 1.0000 \\
\hline \# in Bundle Assembly_1 & 80.484 & $($ Corr $)$ & .00000 & 698.00 & .00000 \\
\hline \# in Grinding_R_Q & .00000 & (Insuf) & .00000 & .00000 & .00000 \\
\hline Bundle Assembly_1_R Av & 2.0000 & (Insuf) & 2.0000 & 2.0000 & 2.0000 \\
\hline Shell Rolling_R Busy & .21560 & (Corr) & .00000 & 2.0000 & .00000 \\
\hline Drilling_Tap_sm_R Busy & .00420 & (Corr) & .00000 & 1.0000 & .00000 \\
\hline \# in NC machining_R_Q & .54997 & (Insuf) & .00000 & 22.000 & .00000 \\
\hline Bundle Insertion Stati & .00350 & (Insuf) & .00000 & 1.0000 & .00000 \\
\hline Burn_Bevel Nozzle Hole & .04778 & (Insuf) & .00000 & 1.0000 & .00000 \\
\hline Tubeloading_R Availabl & 2.0000 & (Insuf) & 2.0000 & 2.0000 & 2.0000 \\
\hline \# in Deburring_R_Q & .18355 & (Insuf) & .00000 & 21.000 & .00000 \\
\hline \# in SAW_R_Q & $6.2790 \mathrm{E}-05$ & (Insuf) & .00000 & 1.0000 & .00000 \\
\hline Face Milling_Large_R $A$ & 1.0000 & (Insuf) & 1.0000 & 1.0000 & 1.0000 \\
\hline SAW_R Busy & .28128 & (Corr) & .00000 & 2.0000 & .00000 \\
\hline Finished Shells_R Busy & .00000 & (Insuf) & .00000 & 1.0000 & .00000 \\
\hline SMAW_R Available & 1.0000 & (Insuf) & 1.0000 & 1.0000 & 1.0000 \\
\hline NC machining_R Busy & .37255 & (Insuf) & .00000 & 2.0000 & .00000 \\
\hline \# in Drilling_Tap_sm_R & .00000 & (Insuf) & .00000 & .00000 & .00000 \\
\hline Tubeloading_R Busy & .30349 & (Insuf) & .00000 & 2.0000 & .00000 \\
\hline Inspection_R Busy & .27970 & (Insuf) & .00000 & 1.0000 & .00000 \\
\hline \# in Bundle Insertion & .00000 & (Insuf) & .00000 & .00000 & .00000 \\
\hline shellcrane Busy & .01398 & (Insuf) & .00000 & 1.0000 & .00000 \\
\hline Drilling_R Busy & .91732 & ( Insuf) & .00000 & 2.0000 & .00000 \\
\hline \# in Drill_Tap_large_R & .00000 & (Insuf) & .00000 & .00000 & .00000 \\
\hline Tube Expansions_R Avai & 2.0000 & (Insuf) & 2.0000 & 2.0000 & 2.0000 \\
\hline Face Milling_Large_R $B$ & .02014 & (Insuf) & .00000 & 1.0000 & .00000 \\
\hline SAW_R Available & 2.0000 & (Insuf) & 2.0000 & 2.0000 & 2.0000 \\
\hline NDE Inspection_R Busy & .02797 & (Insuf) & .00000 & 1.0000 & .00000 \\
\hline shellcrane Active & 1.0000 & (Insuf) & 1.0000 & 1.0000 & 1.0000 \\
\hline \# in Tubeloading_R_Q & .24147 & (Insuf) & .00000 & 3.0000 & .00000 \\
\hline \# in Finished Shells_R & .00000 & (Insuf) & .00000 & .00000 & .00000 \\
\hline bundlecrane Active & 1.0000 & (Insuf) & 1.0000 & 1.0000 & 1.0000 \\
\hline Bundle Assembly_1_R Bu & .36337 & (Corr) & .00000 & 2.0000 & .00000 \\
\hline Drill_Tap_large_R Avai & 1.0000 & (Insuf) & 1.0000 & 1.0000 & 1.0000 \\
\hline Bundle Insertion Stati & 1.0000 & (Insuf) & 1.0000 & 1.0000 & 1.0000 \\
\hline \# in tubequeue & 29.515 & (Insuf) & .00000 & 120.00 & .00000 \\
\hline Drilling_R Available & 2.0000 & (Insuf) & 2.0000 & 2.0000 & 2.0000 \\
\hline \# in Burn_Bevel Nozzle & $6.4241 \mathrm{E}-04$ & (Insuf) & .00000 & 1.0000 & .00000 \\
\hline NC machining_R Availab & 2.0000 & (Insuf) & 2.0000 & 2.0000 & 2.0000 \\
\hline \# in Welding_R_Q & .02647 & (Insuf) & .00000 & 4.0000 & .00000 \\
\hline
\end{tabular}




\section{NUCLEAR ENERGY RESEARCH INITIATIVE (NERI) PROGRAM GRANT NUMBER DE-FG07-00SF22168 \\ FINAL REPORT}

$\begin{array}{llllll}\text { Face Milling_R Busy } & .03147 & \text { (Insuf) } & .00000 & 1.0000 & .00000 \\ \text { Welding_R Available } & 1.0000 & \text { (Insuf) } & 1.0000 & 1.0000 & 1.0000 \\ \text { Tube Expansions_R Busy } & .00779 & \text { (Insuf) } & .00000 & 2.0000 & .00000 \\ \text { Welding_R Busy } & .01398 & \text { (Insuf) } & .00000 & 1.0000 & .00000 \\ \text { Bundle Assembly_R Avai } & 2.0000 & \text { (Insuf) } & 2.0000 & 2.0000 & 2.0000 \\ \text { \# in Shell Rolling_R_Q } & .00000 & \text { (Insuf) } & .00000 & .00000 & .00000 \\ \text { Burn_Bevel Nozzle Hole } & 1.0000 & \text { (Insuf) } & 1.0000 & 1.0000 & 1.0000 \\ \text { \# in Tube Expansions_R } & 1.7481 \mathrm{E}-04 & \text { (Insuf) } & .00000 & 1.0000 & .00000 \\ \text { Grinding_R Busy } & .00420 & \text { (Insuf) } & .00000 & 1.0000 & .00000 \\ \text { NDE Inspection_R Avail } & 1.0000 & \text { (Insuf) } & 1.0000 & 1.0000 & 1.0000 \\ \text { SAW2_R Busy } & 1.1443 & \text { (Corr) } & .00000 & 2.0000 & .00000 \\ \text { bundlecrane Busy } & .07832 & \text { (Insuf) } & .00000 & 1.0000 & .00000 \\ \text { \# in Drilling_R_Q } & 4.2760 & \text { (Insuf) } & .00000 & 20.000 & .00000 \\ \text { Shell Rolling_R Availa } & 3.0000 & \text { (Insuf) } & 3.0000 & 3.0000 & 3.0000 \\ \text { Drill_Tap_large_R Busy } & .00271 & \text { (Insuf) } & .00000 & 1.0000 & .00000 \\ \text { SMAW_R Busy } & .02007 & \text { (Insuf) } & .00000 & 1.0000 & .00000 \\ \text { \# in bundlecrane_Q } & .00000 & \text { (Insuf) } & .00000 & .00000 & .00000\end{array}$

COUNTERS

$\begin{array}{lrl}\text { Identifier } & \text { Count } & \text { Limit } \\ & & \\ \text { Bundle Assembly_C } & 6630 & \text { Infinite } \\ \text { channelcounter } & 17 & \text { Infinite } \\ \text { Channel Heads_C } & 18 & \text { Infinite } \\ \text { Finished Tubesheets } & 24 & \text { Infinite } \\ \text { Disposed Shells_C } & 24 & \text { Infinite } \\ \text { Tubes_C } & 120 & \text { Infinite } \\ \text { Bundle Assembly_1_C } & 60000 & \text { Infinite } \\ \text { SAW_BAD_C } & 7 & \text { Infinite } \\ \text { SAW_2_BAD_C } & 7 & \text { Infinite } \\ \text { Tube Expansions_C } & 126 & \text { Infinite } \\ \text { Finished Shell_Bundle_- } & 24 & \text { Infinite } \\ \text { Finished Shells_C } & 24 & \text { Infinite } \\ \text { shells } & 168 & \text { Infinite } \\ \text { Completed Nozzles } & 192 & \text { Infinite } \\ \text { Depart 13_C } & 24 & \text { Infinite } \\ \text { Tubeloading_C } & 125 & \text { Infinite } \\ \text { SMAW_C } & 2000 & \text { Infinite } \\ \text { Tube Bundle_C } & 24 & \text { Infinite } \\ \text { Nozzles Disposed_C } & 41 & \text { Infinite } \\ \text { Grinding_C } & 226 & \text { Infinite } \\ \text { FW1 Plates } & 24 & \text { Infinite } \\ \text { Deburring_C } & 240 & \text { Infinite } \\ \text { Channel Head_C } & 17 & \text { Infinite } \\ \text { Tubebundlescount } & 24 & \text { Infinite } \\ \text { Shell Flanges } & 48 & \text { Infinite } \\ \text { Raw Plates } & 192 & \text { Infinite } \\ \text { To Grinding } & 24 & \text { Infinite } \\ \text { Dispose Tube Group_C } & 24 & \text { Infinite } \\ \text { drillcount } & 26 & \text { Infinite } \\ \text { SAw 2_C } & 6270 & \text { Infinite } \\ \text { flangesdisposed_C } & 456 & \text { Infinite } \\ \text { SAw_C } & & \\ & & \end{array}$




\section{NUCLEAR ENERGY RESEARCH INITIATIVE (NERI) PROGRAM GRANT NUMBER DE-FG07-00SF22168 \\ FINAL REPORT}

$\begin{array}{lrl}\text { Depart 5_C } & 240 & \text { Infinite } \\ \text { Bundle_Bad_C } & 635 & \text { Infinite } \\ \text { Shells_81_Finished } & 24 & \text { Infinite }\end{array}$

OUTPUTS

Identifier Value

$\begin{array}{ll}\text { All Entities.VACost } & .00000 \\ \text { All Entities.NVACost } & .00000 \\ \text { All Entities.WaitCost } & .00000 \\ \text { All Entities.TranCost } & .00000 \\ \text { All Entities.OtherCost } & .00000 \\ \text { All Entities.TotalCost } & .00000 \\ \text { All Resources.BusyCost } & .00000 \\ \text { All Resources.IdleCost } & .00000 \\ \text { All Resources.UsageCost } & .00000 \\ \text { All Resources.TotalCost } & .00000 \\ \text { System.TotalCost } & .00000\end{array}$

FREQUENCIES

\begin{tabular}{|c|c|c|c|c|c|}
\hline $\begin{array}{l}\text {--Occurrences-- } \\
\text { Identifier }\end{array}$ & $\begin{array}{l}\text { idard } \mathrm{Re} \\
\text { Category }\end{array}$ & Number & AvgTime & Percent & Percent \\
\hline STATE (Face Milling_R) & BUSY & 47 & 2.2978 & 3.15 & 3.15 \\
\hline IDLE & 72.049 & 96.56 & 96.56 & & \\
\hline FAILED & 10.000 & 0.29 & 0.29 & & \\
\hline STATE(Bundle Insertion & BUSY & 24 & .50000 & 0.35 & 0.35 \\
\hline IDLE & 136.79 & 99.64 & 99.64 & & \\
\hline FAI LED & .10000 & 0.01 & 0.01 & & \\
\hline STATE (Bundle Assembly_ & BUSY & 39 & 17.472 & 19.85 & 19.85 \\
\hline IDLE $\quad 22$ & 108.79 & 69.73 & 69.73 & & \\
\hline FAILED & 19.855 & 10.41 & 10.41 & & \\
\hline STATE (NC machining_R) & BUSY & 14 & 48.649 & 19.84 & 19.84 \\
\hline IDLE & 210.16 & 79.60 & 79.60 & & \\
\hline FAI LED & 19.000 & 0.55 & 0.55 & & \\
\hline STATE (Bundle Assembly_ & BUSY & 27 & 23.153 & 18.21 & 18.21 \\
\hline IDLE 12 & 207.41 & 72.52 & 72.52 & & \\
\hline FAI LED & 19.882 & 9.27 & 9.27 & & \\
\hline STATE (Drill_Tap_large_ & BUSY & 48 & .19360 & 0.27 & 0.27 \\
\hline IDLE & 69.652 & 99.44 & 99.44 & & \\
\hline FAILED & 10.000 & 0.29 & 0.29 & & \\
\hline STATE(Tube Expansions_ & BUSY & 75 & .22633 & 0.49 & 0.49 \\
\hline IDLE & 46.754 & 99.44 & 99.44 & & \\
\hline FAI LED & .15714 & 0.06 & 0.06 & & \\
\hline
\end{tabular}




\section{NUCLEAR ENERGY RESEARCH INITIATIVE (NERI) PROGRAM GRANT NUMBER DE-FG07-00SF22168 \\ FINAL REPORT}

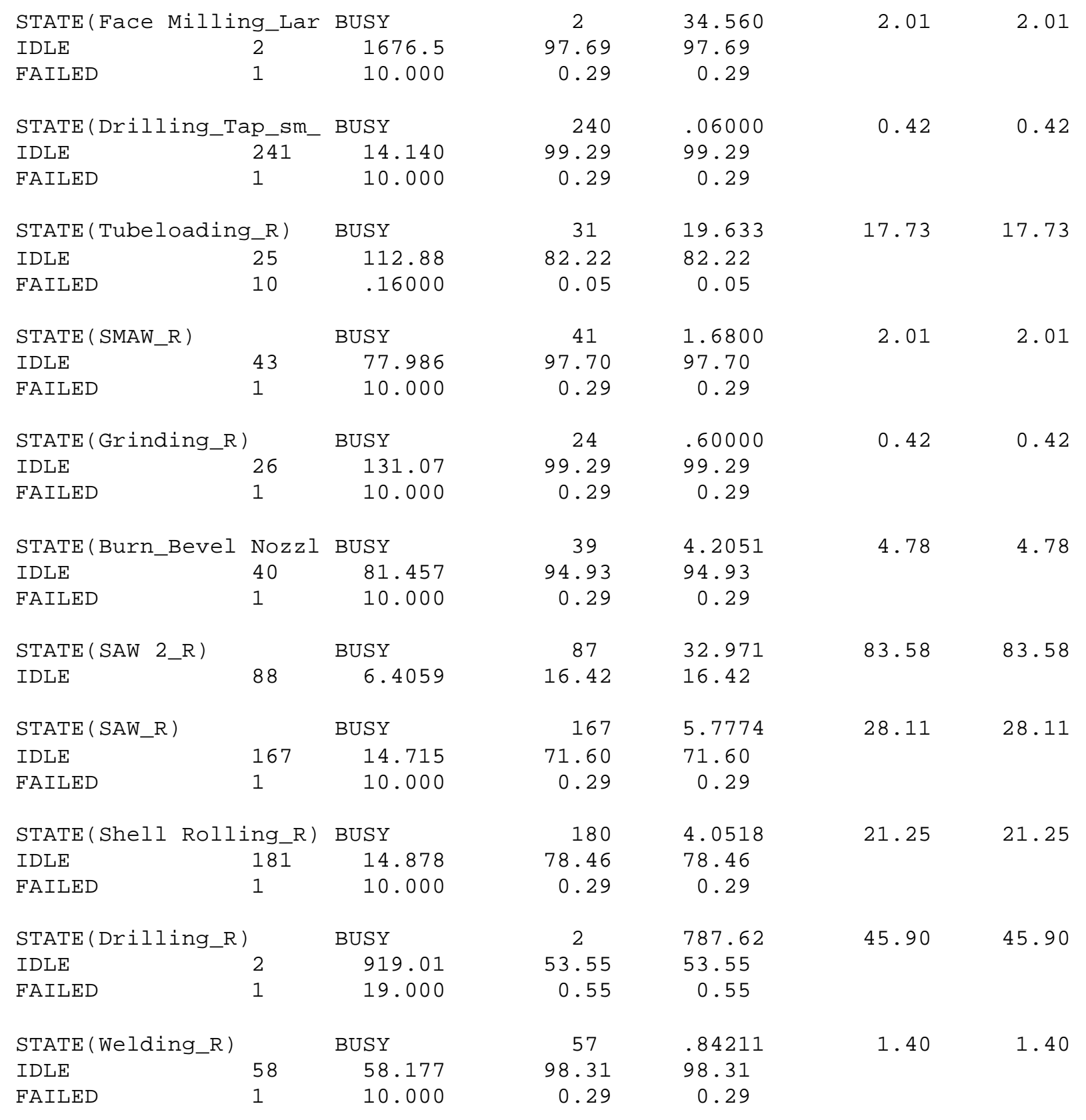

Simulation run time: 0.73 minutes.

Simulation run complete. 


\section{NUCLEAR ENERGY RESEARCH INITIATIVE (NERI) PROGRAM \\ GRANT NUMBER DE-FG07-00SF22168 \\ FINAL REPORT}

\section{Appendix G - Statistical Analysis}

The following results come from a statistical analysis of the simulation experiments ran. The results and analysis come from JMP 5.0.

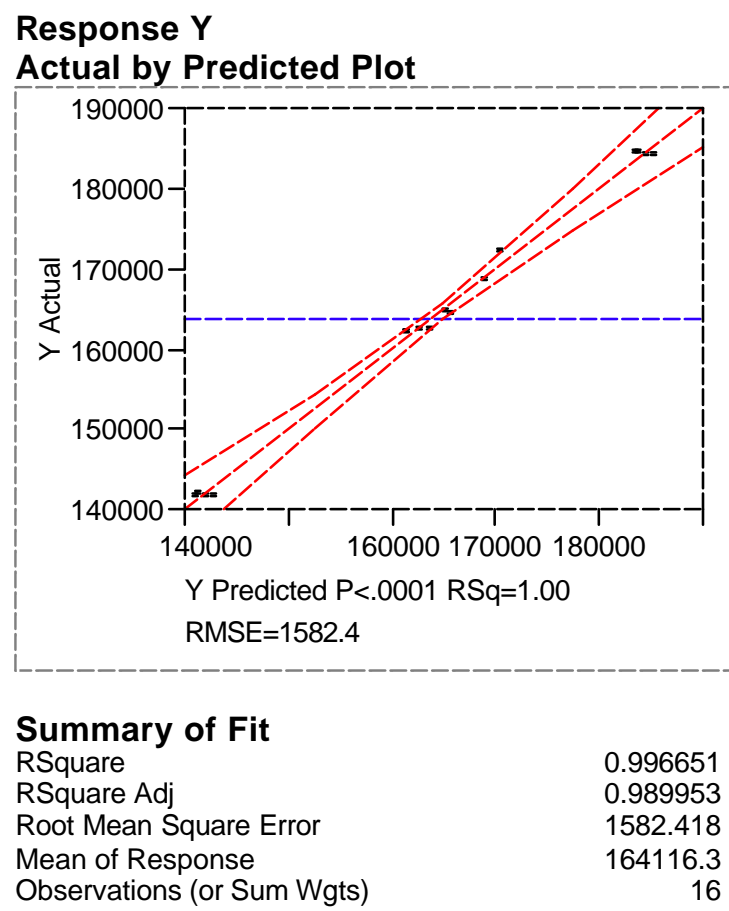

$\begin{array}{lrrr}\text { Analysis of Variance } & & \\ \text { Source } & \text { DF } & \text { Sum of Squares } & \text { Mean Square } \\ \text { Model } & 10 & 3726151210 & 372615121 \\ \text { Error } & 5 & 12520229.5 & 2504045.9 \\ \text { C. Total } & 15 & 3738671439 & \end{array}$

\section{Parameter Estimates}

Term

Intercept

Learning Curve[Hi]

Quality[90\%]

Reliability[90\%]

Demand[24]

Learning Curve[Hi] ${ }^{\star}$ Quality[90\%]

Learning Curve[Hi] ${ }^{\star}$ Reliability[90\%]

Quality[90\%]Reliability[90\%]

Learning Curve[Hi] ${ }^{*}$ Demand[24]

Quality[90\%]*Demand[24]

Reliability[90\%]Demand[24]

$\begin{array}{rrrr}\text { Estimate } & \text { Std Error } & \mathrm{t} \text { Ratio } & \text { Prob }>|\mathrm{t}| \\ 164116.25 & 395.6044 & 414.85 & <.0001 \\ -9327.5 & 395.6044 & -23.58 & <.0001 \\ -641.625 & 395.6044 & -1.62 & 0.1658 \\ 176.375 & 395.6044 & 0.45 & 0.6744 \\ 11963.375 & 395.6044 & 30.24 & <.0001 \\ -773.375 & 395.6044 & -1.95 & 0.1080 \\ 164.375 & 395.6044 & 0.42 & 0.6950 \\ -272.75 & 395.6044 & -0.69 & 0.5212 \\ 1010.125 & 395.6044 & 2.55 & 0.0511 \\ -750 & 395.6044 & -1.90 & 0.1165 \\ 186.25 & 395.6044 & 0.47 & 0.6576\end{array}$

\section{Effect Tests}

Source

Learning Curve

Quality

Reliability

Demand

Learning Curve*Quality

Learning Curve* Reliability

Quality*Reliability

Learning Curve*Demand

$\begin{array}{rr}\text { Nparm } & \text { DF } \\ 1 & 1 \\ 1 & 1 \\ 1 & 1 \\ 1 & 1 \\ 1 & 1 \\ 1 & 1 \\ 1 & 1 \\ 1 & 1\end{array}$

$\begin{array}{rrr}\text { Sum of Squares } & \text { F Ratio } & \text { Prob }>F \\ 1392036100 & 555.9148 & <.0001 \\ 6586922.25 & 2.6305 & 0.1658 \\ 497730.25 & 0.1988 & 0.6744 \\ 2289957462 & 914.5030 & <.0001 \\ 9569742.25 & 3.8217 & 0.1080 \\ 432306.25 & 0.1726 & 0.6950 \\ 1190281 & 0.4753 & 0.5212 \\ 16325640.3 & 6.5197 & 0.0511\end{array}$




\section{NUCLEAR ENERGY RESEARCH INITIATIVE (NERI) PROGRAM \\ GRANT NUMBER DE-FG07-00SF22168 \\ FINAL REPORT}

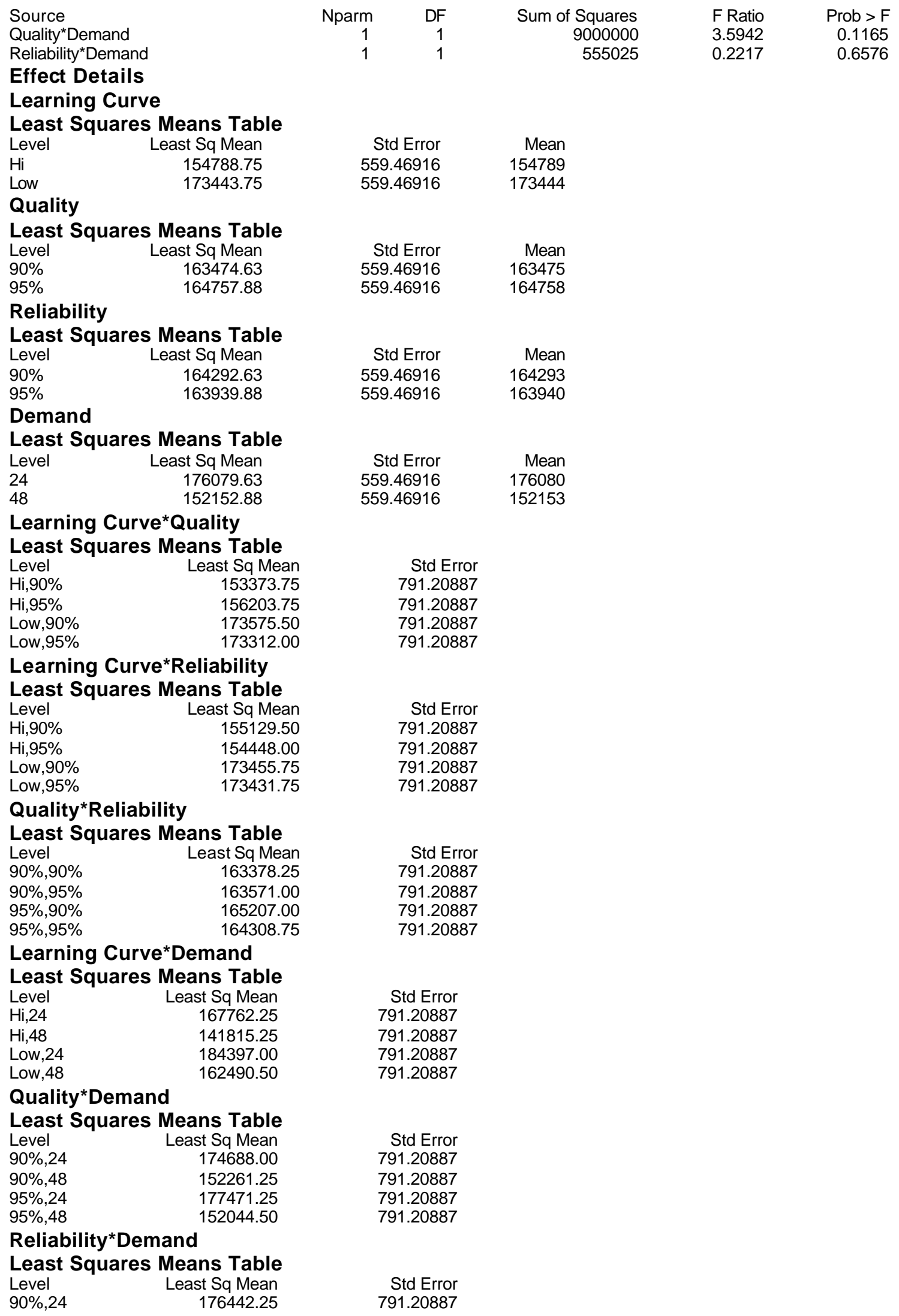




\section{NUCLEAR ENERGY RESEARCH INITIATIVE (NERI) PROGRAM \\ GRANT NUMBER DE-FG07-00SF22168 \\ FINAL REPORT}

$\begin{array}{lr}\text { Level } & \text { Least Sq Mean } \\ 90 \%, 48 & 152143.00 \\ 95 \%, 24 & 175717.00 \\ 95 \%, 48 & 152162.75\end{array}$

\section{Scaled Estimates}

Term

Intercept

Learning Curve[Hi]

Learning Curve[Low]

\section{Quality[90\%] \\ Quality[95\%] \\ Reliability[90\%] \\ Reliability[95\%] \\ Demand[24]}

Demand[48]

Learning Curve[Hi] ${ }^{*}$ Quality[90\%]

Learning Curve[Hi] ${ }^{\star}$ Quality[95\%]

Learning Curve[Low] ${ }^{\star}$ Quality[90\%]

Learning Curve[Low] ${ }^{\star}$ Quality[95\%]

Learning Curve[Hi] ${ }^{\star}$ Reliability[90\%]

Learning Curve[Hi] ${ }^{\star}$ Reliability[95\%]

Learning Curve[Low] ${ }^{*}$ Reliability[90\%]

Learning Curve[Low] ${ }^{\star}$ Reliability[95\%]

Quality[90\%]*Reliability[90\%]

Quality[90\%] ${ }^{\star}$ Reliability[95\%]

Quality[95\%] ${ }^{\star}$ Reliability[90\%]

Quality[95\%] Reliability[95\%]

Learning Curve[Hi]*Demand[24]

Learning Curve[Hi] ${ }^{*}$ Demand[48]

Learning Curve[Low] ${ }^{\star}$ Demand[24]

Learning Curve[Low] ${ }^{\star}$ Demand[48]

Quality[90\%]*Demand[24]

Quality[90\%]"Demand[48]

Quality[95\%]*Demand[24]

Quality[95\%]*Demand[48]

Reliability[90\%]*Demand[24]

Reliability[90\%] Demand[48]

Reliability[95\%] ${ }^{\star}$ Demand[24]

Reliability[95\%]Demand[48]
Std Error

791.20887

791.20887

791.20887

$\begin{array}{lr}\text { Std Error } & t \text { Ratio } \\ 395.6044 & 414.85 \\ & \\ 395.6044 & -23.58 \\ 395.6044 & 23.58 \\ & \\ 395.6044 & -1.62 \\ 395.6044 & 1.62 \\ 395.6044 & 0.45 \\ 395.6044 & -0.45 \\ 395.6044 & 30.24 \\ & \\ 395.6044 & -30.24 \\ 395.6044 & -1.95 \\ 395.6044 & 1.95 \\ 395.6044 & 1.95 \\ 395.6044 & -1.95 \\ 395.6044 & 0.42 \\ 395.6044 & -0.42 \\ 395.6044 & -0.42 \\ 395.6044 & 0.42 \\ 395.6044 & -0.69 \\ 395.6044 & 0.69 \\ 395.6044 & 0.69 \\ 395.6044 & -0.69 \\ 395.6044 & 2.55 \\ 395.6044 & -2.55 \\ 395.6044 & -2.55 \\ 395.6044 & 2.55 \\ 395.6044 & -1.90 \\ 395.6044 & 1.90 \\ 395.6044 & 1.90 \\ 395.6044 & -1.90 \\ 395.6044 & 0.47 \\ 395.6044 & -0.47 \\ 395.6044 & -0.47 \\ 395.6044 & 0.47\end{array}$

Prediction Profiler

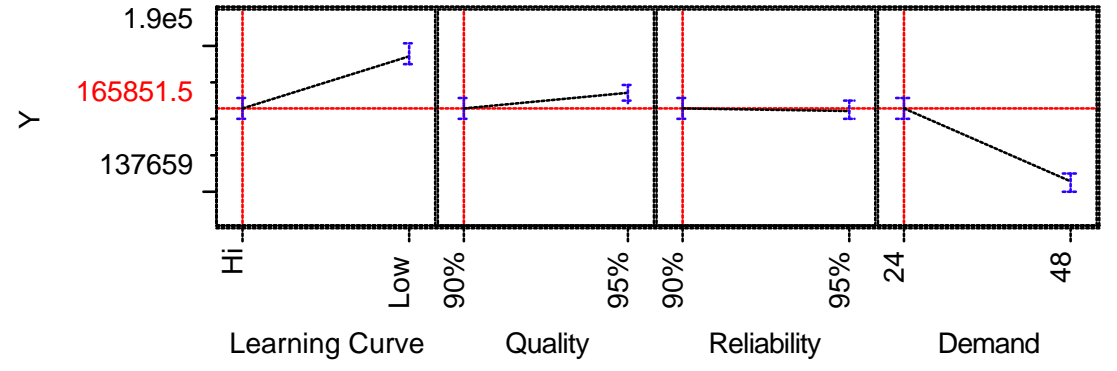

